\title{
Los procesos de formación estatal en Colombia vistos a través de la colonización y las prácticas políticas en el Quindío (1884 y 1930)
}

Wilder Andrés Carrero Delgado
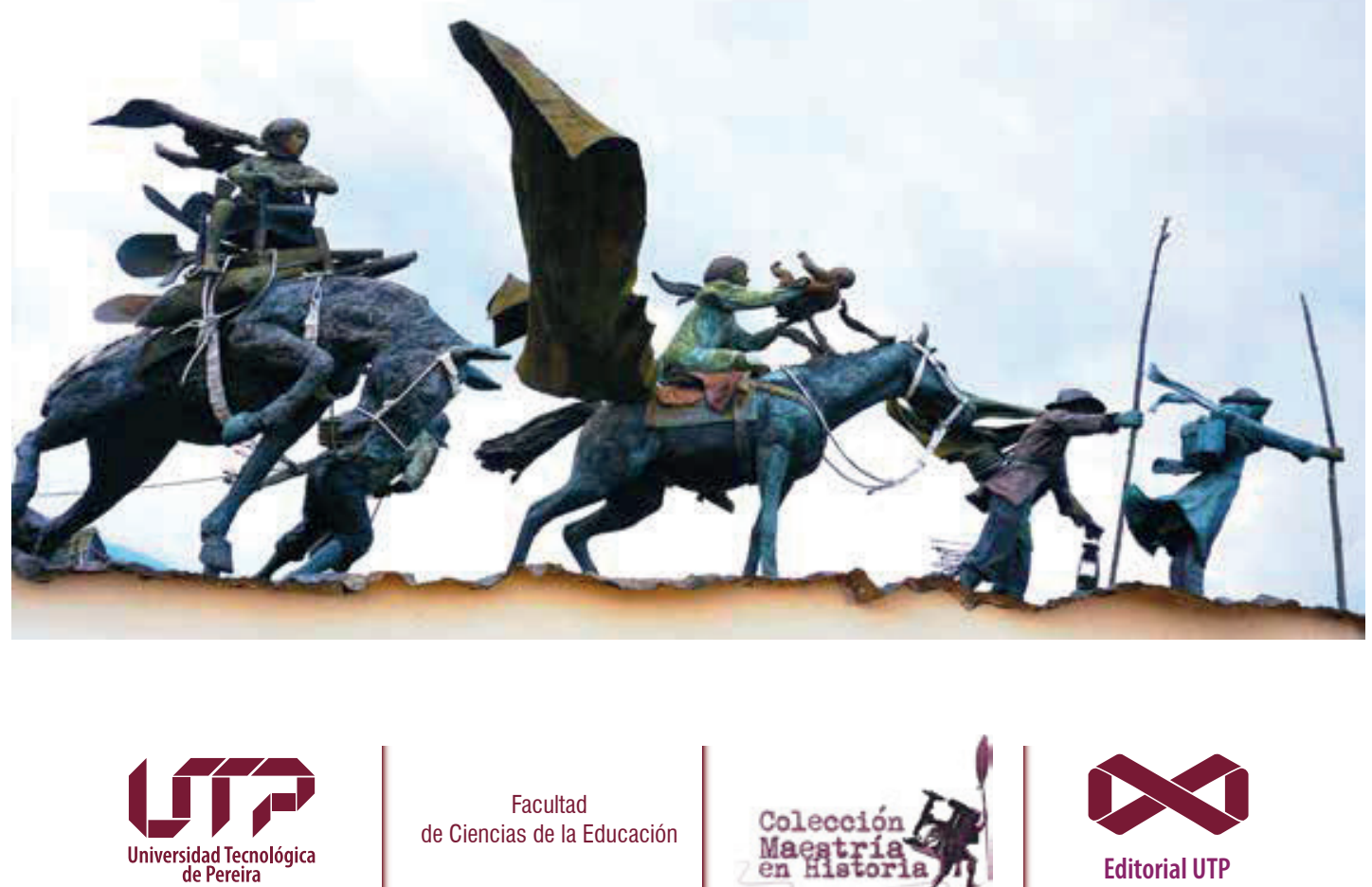

Facultad

de Ciencias de la Educación

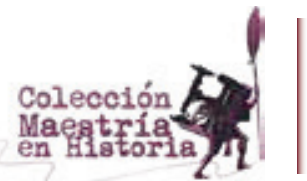

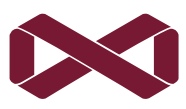

Editorial UTP 


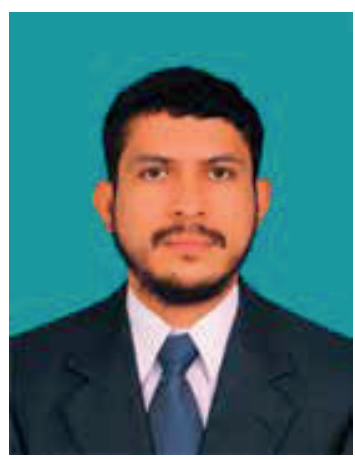

Wilder Andrés Carrero Delgado, (Palmira, Valle, Colombia ,1984).

Historiador y Magister en Sociología de la Universidad del Valle. Profesor invitado a la Maestría en Historia de la Facultad de Ciencias de la Educación de la Universidad Tecnológica de Pereira.

Autor de capítulos de libros y de artículos publicados en revistas nacionales especializadas en derecho e historia.

andrescarrerodelgado@gmail.com 


\section{Los procesos de formación estatal en Colombia vistos a través de la colonización y las prácticas políticas en el Quindío (1884 y 1930)}

Wilder Andrés Carrero Delgado

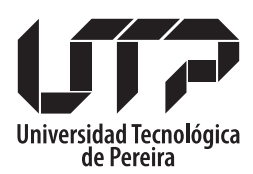

Facultad de Ciencias de la Educación

Colección Ensayos 2018 
Carrero Delgado, Wilder Andrés

Los procesos de formación estatal en Colombia vistos a través de la colonización y las prácticas políticas en el Quindío (1884 y 1930) / Wilder Andrés Carrero Delgado. - Pereira:

Universidad Tecnológica de Pereira, 2018.

300 páginas. - (Colección Textos ensayo).

ISBN: 978-958-722-310-1 eISBN: 978-958-722-541-9

1. Colonización 2. Conflictos sociales 3. Conflictos políticos 4. Calarcá (Quindío) - Colombia 5. Investigación cualitativa 6. Sociología

CDD 301.86134

(C) Wilder Andrés Carrero Delgado

(C) Universidad Tecnológica de Pereira

Primera edición

Universidad Tecnológica de Pereira

Vicerrectoría de Investigaciones, Innovación y Extensión

Editorial Universidad Tecnológica de Pereira

Pereira, Colombia

Coordinador editorial:

Luis Miguel Vargas Valencia

luismvargas@utp.edu.co

Teléfono 3137381

Edificio 9, Biblioteca Central "Jorge Roa Martínez"

Cra. 27 No. 10-02 Los Álamos, Pereira, Colombia

www.utp.edu.co

Montaje y producción:

Centro Recursos Informáticos y Educativos

Universidad Tecnológica de Pereira

Impresión y acabados:

Publiprint S.A.S.

Pereira

ISBN: 978-958-722-310-1

eISBN: 978-958-722-541-9

Reservados todos los derechos 


\section{Agradecimientos:}

Muchas veces me he preguntado para qué sirve el Estado, cómo se hace, cómo funciona, si todos los Estados son iguales, por qué en algunos hay una impresión de que la gente vive bien y en otros no. También me he formulado interrogantes sobre la corrupción, cómo deberíamos resolver los problemas políticos, por qué tenemos grupos armados con tanta capacidad de daño a las instituciones, etc.

Estas preguntas, el afán de querer hacer algo, las ganas de construir mí futuro y acompañar en la construcción de otros, el compromiso político que aprendí de mi padre a pesar de su conservadurismo y sus posturas innegociables, me llevaron a estudiar historia y seguir una carrera profesional como profesor de colegios y hoy, de universidad.

En vista de que mi carrera base daba respuestas pero no suficientes, decidí buscar otras disciplinas para comprender esa compleja relación entre el Estado, individuos

$y$ construcción de realidad. Fue por ello que inicié mi maestría en sociología y luego, atrapado entre la magia de Popayán comencé mi experiencia investigativa y profesional con la Universidad del Cauca. Inicialmente trabajé en el programa de Historia ofreciendo servicios de cátedra a ciencia política y antropología donde aproveché para explorar nuevas lecturas y enfoques que podían aportar a mi afán por respuestas y por el 'hacer'.

Fue durante estos años que conocí al profesor Luis Ervin Prado, a quien le agradezco las charlas que compartió conmigo. Él, enfocado en la guerra como unidad de análisis, comenzó a darme pistas para superar la lectura plana que solía hacer desde mi pregrado; es decir, cuando uno quiere estudiar un problema determinado tiene que separar la unidad de análisis del objeto de estudio y la población de estudio. No vale la pena preocuparme por un asunto si no tengo claro cómo lo puedo abordar.

Puesto que mi maestría en sociología estaba en su etapa de trabajo de grado, comencé a diseñar la técnica para levantar la información, al tiempo que pensaba un modelo de análisis que me permitiera pensar el Estado, los individuos y la construcción de la realidad.

Como estudiante de maestría, tuve la oportunidad de leer autores como Max Weber, Norber Elías, Pierre Bourdieu, Michael Mann, entre otros. Estos tenían la particularidad de estudiar el Estado, cómo funciona, cómo opera, quiénes lo administran, etc. En parte, lo que atiende al marco teórico estaba resuelto; era un asunto de comprensión de los autores en su tiempo y su espacio, de revisar sus diferencias y enfoques y así, con mucho cuidado, retomar aspectos interesantes, prácticos y ponerlos en juego para pensar mi problema de investigación. Entre charlas, lecturas, amigos y mucha presión surgió una pregunta general que fue puliéndose hasta convertirse en mi pregunta de investigación: ¿Cómo se puede estudiar el proceso formativo del Estado? Con este cuestionamiento resolví, en parte, la primera dificultad que tenía para hacer mi tesis de maestría: como historiador, pensar sociológicamente.

El historiador piensa los procesos, el cómo, va a las fuentes y estructura una multiplicidad de posibles explicativos; $y$ como profesional cuestiona, se pregunta por 
los reveces que muestran los documentos consultados: ¿Por qué así y no de otra manera? ¿Y si la decisión tomada fuera contraria? ¿Será que lo escrito es verdad?

El historiador profesional no pretende hacer apologías y mucho menos, abrazar las teleologías. En cuanto al sociólogo, el método, lo cuantificable, la rigurosidad, los límites, la simpática relación con la 'cientificidad', entre otras cosas lo lleva a estudiar aspectos precisos: el Estado, acciones colectivas, los movimientos sociales, la estructura, etc. Además de esto, el identificarse como "un sujeto activo de una manera de abordar el mundo" (Bauman, 2015, p. 9) fue la clave para comprender que aquí, entre la sociología y la historia comenzó a cristalizarse un proyecto de vida que me permitiría cerrar unas preguntas para abrir otras. Y así como cerraba preguntas y abría nuevas, también tuve que irme del Cauca $y$ pasé a trabajar en un programa de derecho. Y fue justamente mi arribo a esta disciplina lo que me permitió identificar la unidad de análisis y la población de estudio. Tenía claro que mi problema central era estudiar el Estado, pero debía encontrar cómo hacerlo, puesto que el solo decir Estado pesa, genera sensaciones encontradas y la literatura abruma.

Fue justamente durante este tránsito que apareció Catalina Naranjo, mi esposa.

Ella, desde su formación como Trabajadora Social me leyó, ajustó ideas, me dio pistas metodológicas, se sentó y organizó tablas para filtrar cientos de documentos y por fin, dejamos lista la estructura con la que se debía analizar toda la información recolectada.

¿Qué preguntarle a los documentos? ¿Qué documentación era pertinente? Era claro que necesitaba un cómo y ese lo encontré entre Bourdieu y sus estudios de los 'campos ' y la exploración del derecho, específicamente el derecho agrario. Así, ya estaba resuelta la segunda parte. Ahora la pregunta podría pensarse nuevamente. Estudiaría el proceso formativo del Estado a través de la transformación en la estructura del derecho agrario colombiano. Me faltaba fechas, lugar y algo más que me permitiera sentirme sociólogo. Fue aquí cuando apareció mi director de trabajo de grado, el Dr. Luis Carlos Castillo Gómez a quien le agradeceré eternamente su acompañamiento y sus fabulosas clases sobre acciones colectivas y movimientos sociales.

Fue justamente con él que pude articular un tercer asunto a mi problema de investigación; ¿Qué tal si a estos aspectos les agregamos la capacidad de agencia que tienen los individuos y cómo dicha agencia repercute en el diseño de la realidad social? Pues bien, eso fue lo que se hizo. Pensamos entonces que el proceso formativo del Estado se puede estudiar a través de uno de sus campos, para este caso el jurídico agrario, pero que es fundamental superar la visión unívoca de las disposiciones administrativas como productoras de realidad; más bien se trata de un ejercicio de ida y vuelta, de emisión y recepción. Por ello, la emisión de normativa agraria tiene una conexión directa en el uso que se haga de ella y la respuesta que tengan las poblaciones. A esto le llamamos: prácticas políticas.

Faltaba el lugar. Infinitos agradecimientos al profesor Miguel Camacho quien fue mi tutor de pregrado y con quien logré comprender la relevancia que tuvo el eje cafetero en la construcción del Estado a comienzos del siglo XX. Fue con él, con sus charlas, orientaciones, apreciaciones y regaños que decidí utilizar como población de estudio el eje cafetero entre los siglos XIX y XX. Así las cosas, esta investigación terminó por orientarse hacia el estudio del 
proceso formativo del Estado a través de las acciones colectivas llevadas a cabo en el actual Eje Cafetero, en el marco de la producción de legislación agraria entre el siglo XIX $y$ XX.

Después de graduarme de mi maestría decidí buscar al profesor Sebastián Martínez y compartirle mi experiencia. A él, otros agradecimientos por confiar en mí, apoyarme y abrirme espacio en su agenda. Finalmente este nuevo reto de publicar mi trabajo de maestría es producto de sus apreciaciones.

Agradezco a Jhon Jaime Correa, director de la Maestría en Historia, porque abrió las puertas de la misma para que este suscrito pudiera vinculase como profesor. Allí he seguido labrando ideas y nuevas preguntas. Ahora nuestro reto es seguir construyendo memorias de región, comprendiendo la relación entre los espacios y los tiempos. Agradezco a todo el equipo de la Maestría en Historia de la UTP por el esfuerzo que hacen para llevar a cabo estas publicaciones, por el acompañamiento que hacen en la revisión y corrección de estilo, y por la dedicación que tienen para que estos esfuerzos académicos no queden en vano. Finalmente agradezco a mi mejor amigo, hermano y escucha: Leonardo Ordoñez. Él es y será siempre con quien aprendo, cuestiono y mejoro como persona. 



\section{CONTENIDO}

CAPÍTULO PRIMERO: ASPECTOS GENERALES

1.1. El problema de investigación $\quad 11$

1.2. Estrategia metodológica 23

CAPÍTULO SEGUNDO: CONSIDERACIONES TEÓRICAS GENERALES 27

2.1. Estado, colonización y práctica política en la historiografía colombiana; aproximación teórica al problema de las categorías y el análisis del proceso formativo del Estado en Colombia.

2.1.1. De la lucha de clases a la racionalidad weberiana. Una interpretación institucional del proceso formativo del Estado. 28

2.1.2. Ideas generales para el marco interpretativo. $\quad 40$

2.1.3. Institucionalismo y teorías de clase en la historiografía colombiana. 43

2.1.4. Las perspectivas institucionalistas: análisis tentativos del proceso
formativo del Estado en Colombia.

2.1.5. Interpretaciones interdisciplinarias para el proceso formativo del Estado en Colombia.

2.1.6. Conciliando las tesis del proceso formativo del Estado: una propuesta interpretativa..

2.2. ¿Cómo se ha discutido teóricamente la categoría colonización?

2.2.1. Aproximaciones a los estudios sobre la Colonización. Rastreando sus definiciones en la historiografía colombiana.

2.2.2. Conciliando las interpretaciones de la colonización para identificar una guía analítica.

2.3. La práctica política como categoría de análisis: aproximaciones a su definición.

1.1. La dimensión histórica del Quindío: Estado, conflicto e instituciones en la colonización.

1.1.2. Migración en Colombia: el Quindío en la dinámica pobladora. 90

1.1.3. El Quindío: territorio de políticas públicas y políticas privadas 96

1.2. Las rendijas de la norma: tenencia de la tierra, frontera agrícola y legalización en la colonización. $\quad 105$

1.2.1. El control de los baldíos, ¿Por qué hablar de las rendijas de la norma? 114 centrales en el ramo de los baldíos. 
4.1.3. Interpretaciones y disposiciones administrativas de las burocracias centrales sobre los baldíos.

4.1.4. Consideraciones generales.

4.2. La construcción del poder local: la práctica política en la colonización.

4.2.1. De juntas pobladoras a concejos municipales: las disputas por la

instrumentalización de las instituciones entre colonos, empresarios y comerciantes.

4.2.2. El control de territorio: Burila, la Junta Pobladora de Colón (Pijao)

y el Concejo Municipal de Calarcá.

4.2.3. Ley 36 de 1907 y distribución de tierras en Calarcá. El concejo municipal y la disputa con los colonos.

4.3. Repertorios de protestas: las prácticas políticas de los colonos no vinculados al campo político de los concejos municipales.

4.3.1. Las transformaciones del conflicto: los casos Grisales, Jaramillo y Playa Rica.

Documentos de archivos históricos y notarías.

Periódicos.

Diario Oficial \# 5541, Edición Oficial, 1884.

Artículos de revistas en línea:

Blogs:

Libros en línea

Páginas institucionales:

Trabajos de grado:

Libros

Artículos de revistas: 


\section{CONTENIDO DE GRÁFICOS}

Gráfico 1: legislación sobre baldíos, 1820-1869 112

Gráfico 2: legislación sobre baldíos, 1870-1931 113

Gráfico 3: legislación sobre baldíos, 1820-1931 114

Gráfico 4: peticiones por usucapión, 1870-1931 120

Gráfico 5: número de transacciones y kilómetros cuadrados adjudicados
de baldíos, 1850-1930 (en períodos de 5 años)

Gráfico 6: adjudicaciones en Calarcá: 1897-1921 177

\section{CONTENIDO DE MAPAS}

Mapa 1: mapa de Salento y el Quindío $\quad 94$

Mapa 2: mapa de geográfico de Colombia y zona de estudio 98

Mapa 3: mapa de la Empresa Burila $\quad 101$

\section{CONTENIDO DE TABLAS}

Tabla 1: guía operacional de la categoría Estado 20

Tabla 2: guía operacional de la categoría colonización $\quad 21$

Tabla 3: guía operacional de la categoría práctica política 22

Tabla 4: distribución poblacional en el siglo XIX 92

Tabla 5: relación en distancias de Cartago a una población del Quindío 95

Tabla 6: legislación sobre baldíos, 1820-1869 111

Tabla 7: legislación sobre baldíos, 1870-1931 113

Tabla 8: peticiones por usucapión, 1870-1931 120

Tabla 9: nombre de los integrantes de la primera junta pobladora 161

Tabla 10: nombre de los integrantes de la junta pobladora del corregimiento Nueva Salento 161

Tabla 11: distribución de baldíos, concejo de Calarcá, 1908

\section{CONTENIDO DE ANEXOS}

Anexo 1: memorial enviado por los colonos de Calarcá al Gobierno central 224

Anexo 2: Decreto 326 de 1930 



\section{INTRODUCCIÓN}



Estudiar el proceso formativo del Estado nos exige desprendernos de los cuestionamientos tradiciones que sobre él tenemos. Si partimos de la consideración del Estado como una fuerza que se impone sobre los demás, como la máxima autoridad productora de la realidad, entonces nos tenemos que limitar a ver solo dos respuestas: o es exitoso o es fallido.

Pero más grave aún, estas dos respuestas tampoco son verídicas puesto que dependiendo lo que estudiemos, el Estado puede ser muy fuerte o débil. Además, ¿por qué los Estados tienen ciertos tipos de cristalización y no otros?, ¿por qué las poblaciones se comportan de una manera y no de otra?, ¿acaso lo que no está en el marco del deber ser quiere decir que hay ausencia de Estado?, ¿no será más bien que ese es también el Estado? Y si nos preguntamos, por ejemplo, ¿cómo ven, desde lo que llamamos periferia, al Estado, no estaríamos comprendiendo por qué hay poblaciones proclives a la evasión de los parámetros de Estado?

Esta investigación, en busca de respuestas a interrogantes como estos se orientará hacia las posibles alternativas interpretativas sobre el proceso formativo del Estado; para tal fin nos centramos en tres aspectos básicos: 1) prácticas políticas agenciadas por diferentes grupos y personas durante los procesos de colonización del eje cafetero, 2) en relación con la práctica política, la instrumentalización de la normativa agraria colombiana durante el tránsito del siglo XIX y XX y 3) la formación del Estado 
como un proceso de producción de discurso, emisión y recepción del mismo; lo que conlleva una reacción y posterior madurez de la estructura.

Para analizar estos asuntos, esta investigación se formuló la siguiente pregunta de investigación: ¿Cómo las prácticas políticas implementadas por colonos, empresarios, agentes del Estado y demás actores de la colonización en el Quindío, entre 1884 y 1930, permiten analizar el proceso formativo del Estado colombiano?

Como método de investigación histórico-sociológica se recurrió a la consulta de fuentes secundarias y primarias que conserva el Archivo General de la Nación, el Archivo Histórico de Cartago, el Archivo Central del Cauca, y el Archivo de la Biblioteca del Congreso de la República.

La investigación está dividida en cinco capítulos; el primero pretende relacionar al lector con lo que hemos llamado, aspectos generales, remitiéndonos a las categorías y subcategorías de análisis con los respectivos indicadores, y la pregunta y objetivos general y específicos. El segundo capítulo pretende acercarnos a una discusión teórica del Estado, la colonización y las prácticas políticas; principales categorías de análisis que sirvieron como norte de la investigación.

En el tercer capítulo se discute la relación entre los procesos de colonización y la formación del Estado, por lo que se optó por analizar la producción de normativa sobre la tenencia, ocupación y propiedad de la tierra y cómo la transformación de los conflictos alimentó la configuración de las políticas públicas sobre los baldíos.

Posteriormente, en el capítulo cuarto se analizan varios casos que sirvieron para relacionar la categoría de práctica política con la formación del Estado. En este capítulo se pretende justificar empíricamente el proceso formativo del Estado, a través la intervención de la administración central, la acción de las burocracias locales y la agencia de los actores en lo que Bourdieu (2000) denominó como campo político.

Finalmente presentamos las conclusiones para dar cuenta del desarrollo de cada objetivo, los principales logros y las limitaciones que fueron apareciendo durante el análisis. También se proponen otras líneas de investigación que surgen como producto de este trabajo y se deja por sentado que, al igual que el proceso formativo del Estado, este ejercicio seguirá en construcción. 


\section{CAPÍTULO PRIMERO: ASPECTOS GENERALES}





\subsection{El problema de investigación}

Tradicionalmente las discusiones sobre el Estado moderno han sido asociadas con el ámbito institucional y con preferencia por lo teleológico; por lo que la representación colectiva que se ha construido es la del Leviatán que controla la violencia y está obligado a garantizar no solo seguridad, sino empleo, justicia, verdad, progreso, paz (Rodríguez, 2009).

Sin embargo, gran parte de estas categorías, por no decir que todas, podríamos considerarlas como categorías vacías puesto que en el proceso histórico se han venido redefiniendo, y por lo mismo, cambiando. Ahora bien, en lo que respecta a las funciones del Estado y su interpretación, podría decirse que ha tenido la misma transformación conceptual.

Hoy somos herederos de dos corrientes de pensamiento sobre el Estado: la del interventor, a quien se le delegaron las funciones mencionadas, ${ }^{1}$ y la neoliberal, que

1 Cuando hablamos de Estado interventor nos referimos básicamente al modelo de Estado que se aplicó en el mundo occidental a partir de la crisis de 1929, y que popularmente es conocido como el Estado benefactor. Para el caso latinoamericano, los estados asumieron políticas intervencionistas amparadas en los principios teóricos de Keynes y la CEPAL. De todas formas, cada país fue autónomo en el uso e interpretación de dichas teorías, lo que conllevó a la cristalización de Estados más que fuertes económicamente, represivos y paquidermos. A mediados de los años de 1980, como producto de la corrupción institucional, la falta de garantías democráticas, el cierre parcial de los espacios público-políticos a favor de elites acantonadas en las instituciones gubernamentales, etc., el neoliberalismo se leyó como una alternativa para superar las dificultades políticas y económicas; por lo que el reciclaje interpretativo del liberalismo decimonónico se convirtió en la puerta de escape para las inconformidades políticas, así como también, de la libre empresa.

Es importante resaltar que las tesis neoliberales se han aplicado de acuerdo a las circunstancias internas en cada Estado, lo que ha permitido la sobrevivencia de algunos vestigios del Estado de Bienestar tanto en lo 
surgió como cuestionamiento a la intromisión del Leviatán en la vida de la persona (Bobbio, 2000; Offe, 1984; Habermas, 1998); pero ¿cristalizaron todos los Estados de occidente de la misma manera?, ¿debería estudiarse al Estado en el presente o en el pasado?, y de ser distinta la cristalización de los Estados latinoamericanos frente a los Europeos, africanos y norteamericanos, ¿podríamos considerar que todos los latinoamericanos fueron iguales?

Las discusiones sobre el Estado adquieren cada vez más vigencia, en especial al preguntarnos por su razón de ser, el sentido y los derechos que este conserva en relación con las personas, la propiedad, el pensamiento, la educación, etc.; más aún, cuando discute se la emergencia de nuevos movimientos sociales y acciones colectivas que reclaman derechos de autonomías, pero también, como en otros casos, exigen la intervención estatal (Carrero y Naranjo, 2014; Burbano, 2014; Hincapié, 2015).

Paradójicamente, estos movimientos yuxtapuestos en sus reclamaciones hacen mención al mismo problema, la debilidad del Estado: Los primeros cuestionan el orden del discurso, en el que se demuestra a través de preguntas y experiencias que el Estado no tienen razón de ser, que su intervencionismo no se justifica; luego es un mal no necesario (Bobbio, 2000, p. 12). Los otros grupos enfocan la discusión hacia una deuda histórica en relación con el deber ser del Estado y por lo tanto se le exige a esta institución, cuerpo, o discurso, que se materialice con acciones institucionales (Archila, 2005; Restrepo, 2006).

¿Quién tiene la razón? ¿Debe el Estado desaparecer o fortalecerse? ¿En qué tipo de Estado pensamos cuando se reclama en cualquiera de las dos vías mencionadas? En lo que respecta a Latinoamérica, podría decirse que la configuración de los Estados modernos estuvo cruzada por los discursos occidentales, aunque las condiciones materiales y las transformaciones históricas generaron una cristalización distinta a las europeas, africanas y norteamericanas (González, 2014).

Por este motivo, el estudio del Estado latinoamericano exige un acercamiento distinto 
al teleológico, pues como diría González (2014), "su cristalización se caracteriza por una presencia diferenciada de sus instituciones estatales en el espacio y el tiempo" (29). Por otra parte, aunque casi todo el continente hable un mismo idioma y tenga una religión y pasado común, las características internas nos obliga a pensar cada país bajo una lupa distinta y una disposición abierta a los procesos de formación institucional alejados de los principios teóricos tradicionales (Mann, 2006).

Es por ello que la discusión nos pone frente a dos situaciones: la primera tiene que ver con unas reclamaciones populares sobre el sentido del Estado: por un lado, disminución de su intervencionismo, y por el otro, exigencia de su presencia. La segunda discusión tiene que ver con un asunto teórico, y es que no todos los Estados occidentales cristalizaron de la misma manera y las teleologías impiden adentrarnos en las características intrínsecas de cada uno.

La otra pregunta inicial pretendía poner en discusión si el Estado debe estudiarse en el presente o en el pasado. Al respecto, consideraba Bourdieu (1997) que:

Proponerse pensar el Estado significa exponerse a retomar por cuenta propia un pensamiento de Estado, a aplicar al Estado unas categorías de pensamiento producidas y avaladas por el Estado, por lo tanto a no reconocer la verdad más fundamental de éste (91).

Desde esta perspectiva podría decirse que los estudios históricos son propicios al análisis del Estado, debido a que se alejan de las estructuras mentales e institucionales, permitiéndonos hacer un balance más objetivo y un acercamiento más coherente con el fin de la investigación.

Resuelto este punto, y teniendo presente la magnitud de formas interpretativas y problemas para abordar, se optó por considerar uno de los principales temas que hoy mueven las agendas gubernamentales y las discusiones en los ámbitos públicopolíticos: la cuestión agraria (Morales \& Eastman, 2014; González, 2014). En aras de vincularnos a estas discusiones nos formulamos las siguientes preguntas: ¿Cómo relacionar la cuestión agraria con el proceso formativo del Estado? ¿Cómo justificar una investigación socio-histórica del Estado, en el marco de una sociedad que reclama la acción de este, o que pretende enfrentarlo? ¿Cómo evitar que se leyera la investigación como una justificación del Estado dado su proceso histórico? 
Si bien la investigación apunta hacia los estudios institucionales, la pretensión no es juzgar o defender una actuación o una característica intrínseca de nuestro Estado; más bien se trata de construir hipótesis que contribuyan a las discusiones sobre su sentido, el uso histórico de sus instituciones, y que sirva de voz para aquellos y aquellas que, conscientes o no de sus acciones, contribuyeron con su proceso formativo a través de prácticas políticas.

Ahora bien, en el marco de una discusión vigente como lo agrario, analizar el proceso formativo del Estado permite adentrarnos en los fenómenos de violencia histórica, relaciones burocráticas, repertorios de protestas y cristalizaciones poliformas (Mann, 1997); por lo tanto, como plantea González (2014), esta perspectiva permite relacionar la configuración histórica del Estado con las regiones, su poblamiento y cohesión interna.

Evidentemente, para el caso colombiano las relaciones entre los hombres y mujeres, las instituciones y la tierra, fue y sigue siendo -aunque en menor escala-, el motor de los principales conflictos. Por esta razón el proceso formativo del Estado exige un acercamiento a la cristalización de este ámbito, pero con el interés de superar la lectura legislativa y más bien, pretendiendo relacionar su producción con las acciones y reacciones de las burocracias centrales y locales, los colonos, los cultivadores, empresarios, etc., que estuvieron vinculados a los conflictos por la propiedad, ocupación y tenencia de la tierra.

También exige, como plantea González (2014), el recurso de la multidisciplinariedad que permite analizar el proceso desde el centro hacia la periferia y viceversa, revisando la articulación entre instituciones centrales y locales, como también, la negociación del poder y la participación de quienes están en los márgenes del campo político $^{2}$ (Bourdieu, 2000).

2 Se entiende por campo, "una red o configuración de relaciones objetivas entre posiciones. Estas posiciones se definen objetivamente en su existencia y en las determinaciones que imponen sus ocupantes, ya sean agentes o instituciones, por su situación (situs) actual y potencial en la estructura de la distribución de las diferentes especies de poder (o de capital) -cuya posesión implica el acceso a las ganancias específicas que están en juego dentro del campo- y, de paso, por sus relaciones objetivas con las demás posiciones" (Bourdieu, 1995, p. 64).

Ahora bien, por política se entiende, la dirección o influencia que tienen los individuos de una sociedad sobre la trayectoria de una entidad política, que en sentido weberiano sería el Estado. Este punto se desarrollará con mayor precisión en el ítem 2.3 . 
De acuerdo con lo expuesto, podemos considerar que este trabajo es de tipo sociohistórico, dado que, al estudiar los conflictos relacionados con la tenencia, ocupación y propiedad de la tierra se pretende contribuir al análisis del proceso formativo del Estado usando la retrospectiva para estudiar la configuración del poder. Pero ¿Cómo relacionar la cuestión agraria con el proceso formativo del Estado?

Como podría deducirse de la obra de González (2014), la cuestión agraria está directamente relacionada con el proceso formativo del Estado, por lo que acercarnos a este asunto, exige reconocer dos cosas: 1) la capacidad institucional del Estado para regular las prácticas de adjudicación y explotación de los baldíos y 2) las dinámicas y cristalización en las zonas de colonización.

Considerando estos puntos se identificó un lugar y un tiempo que ofreciera la documentación necesaria; por tratarse de un ejercicio socio-histórico, se tuvo presente la discusión sobre los baldíos la cual no solo se referencia en los libros sobre el tema, sino en las memorias de los ministros y los pleitos abiertos entre los actores de las colonizaciones. Es importante recordar que el problema de los baldíos se exacerba a partir de 1870 con las reformas administrativas del ramo, por lo que la construcción de una política pública estuvo siempre envuelta en dilaciones e intentos infructuosos que aun hoy siguen vigentes.

En cuanto al tiempo, la propuesta de investigación se enmarca en la transición del siglo XIX al siglo XX (1884 - 1930) dado que es este periodo en el que se presenta la primera y segunda oleada pobladora más importante del Quindío, al tiempo que se funda la Empresa de Fomento y Colonización Burila y se establece jurídicamente una nueva relación entre el Estado y la sociedad con la Constitución de 1886.

La colonización del territorio del Quindío está directamente relacionada con la puesta en marcha de la Regeneración y su relación con la tierra, la ocupación del espacio y el establecimiento de programas empresariales en donde los principales políticos se vincularon al fomento colonizador. Esta relación conllevó a que se elevara la conflictividad en zonas de ocupación dado que en muchos casos, los empresarios usaron su poder político para dilatar procesos abiertos entre colonos y empresas, así como también, por la ambigüedad de los planos y límites de ocupación, las demandas y pleitos estuvieron sometidos a la vigilancia de los representantes del 
Estado donde los concejos municipales y los encargados de la veeduría territorial entraron en constante pugna por los resultados.

Después de 1930, año en que llega al poder el partido liberal e inicia con la modificación de la burocracia nacional y local, se creyó que la conflictividad se reduciría aprovechando la vigilancia y establecimiento de normativas a favor de los colonos y poblaciones que en la mayoría de los casos, llevaban procesos judiciales largos o se vincularon a repertorios de protesta alterando el orden público.

Pero ¿por qué el Quindío y las dinámicas de la colonización permiten acercarse al estudio de la formación del Estado colombiano a través de las prácticas políticas de colonos, empresarios y demás actores inmersos en los procesos de ocupación?

Es importante señalar que uno de los lugares de mayor relevancia en la historia de la colonización colombiana ha sido el territorio del Quindío, no solo por su ubicación como tapón entre el centro y el suroccidente del país durante el conflictivo siglo XIX -lo que había impedido además de una óptima y rápida comunicación una emergencia de autonomías políticas superiores a los intereses del grupo regenerador-, sino también porque la dinámica colonizadora en el territorio se prestó para que se manifestaran diversas facetas que van más allá del conflicto por la tierra, cruzando por el debate y funcionalidad de las autonomías municipales y las múltiples formas de reproducción de la riqueza y explotación laboral.

Desde el comienzo de la colonización se manifiesta un interés por parte de los políticos, colonos y empresarios vinculados a estos programas de llevar las instituciones del Estado colombiano como estrategia para la creación de soberanía, cohesión y legalidad; pero además de este aspecto, esta colonización, a diferencia de sus contemporáneas hacia otros territorios fue exitosa, pues en menos de un siglo el territorio pensado para colonizar estaba en su totalidad ocupado y de este proceso se destaca: 1) la capacidad de los empresarios territoriales y los gobiernos de turno para movilizar familias hacia la zona, 2) la rápida cristalización de las instituciones del Estado Central y 3) la inserción casi que inmediata en la economía nacional e internacional por medio del café. 
Para poner en marcha la investigación se ha optado por analizar el caso de Calarcá y esporádicamente se mencionará a Sevilla, dado que estas poblaciones desde los primeros años de poblamiento hasta 1930 tuvieron que enfrentar jurídica y físicamente a la empresa Burila y a diversos terratenientes de la zona que reclamaban dominios sobre los terrenos donde se habían asentado los colonos. Es aquí donde la experiencia del Quindío se manifiesta como una oportunidad para construir una nueva visión de los procesos migratorios en Colombia, dándole más peso a la capacidad de los actores inmersos en el conflicto para movilizarse a través de las vías de hecho, como también para instrumentalizar las instituciones del Estado, o en su defecto, contribuir hacia la formación y fortalecimiento del mismo.

En cuanto a la segunda variable, la configuración de las políticas públicas estuvo determinada por la transformación de los conflictos; conclusión que surgió después de analizar la evolución normativa en relación con las prácticas políticas de las burocracias locales y la presión social ejercida en las márgenes del campo político.

Dado que la colonización se fomentó hacia distintas zonas del país, fue necesario identificar una que nos permitiera no solo perseguir la discusión teórica, sino que diera luces sobre la transformación histórica dela legislación agraria; específicamente, la relacionada con la ocupación, propiedad y tenencia de la tierra. Por lo tanto, abordar estudios de caso como el del Quindío ofrecía no solo las características mencionadas, sino la posibilidad de confrontar interpretaciones tradicionales de la colonización antioqueña con una nueva perspectiva que pretende reconocer la participación de la mayoría de los actores de dicho proceso.

Después de identificados estos puntos se formuló la siguiente pregunta de investigación: ¿Cómo las prácticas políticas implementadas por colonos, empresarios, agentes del Estado y demás actores de la colonización en el Quindío, entre 1884 y 1930, permiten analizar el proceso formativo del Estado colombiano? Este interrogante nos llevó a desarrollar los siguientes objetivos:

Objetivo general: contribuir al estudio del proceso formativo del Estado colombiano a través del análisis de las prácticas políticas llevadas a cabo por colonos, empresarios y agentes del Estado, durante los conflictos en la colonización del Quindío: 1884 y 1930. 
Para darle desarrollo construimos tres objetivos específicos:

1. Desarrollar una guía interpretativa, a partir de las principales discusiones teóricas sobre el proceso formativo del Estado, para analizar la cristalización de las instituciones jurídicas y políticas de Colombia durante el proceso de colonización en el Quindío entre 1884 y 1930.

2. Analizar la dimensión histórica en la que se desarrolló la colonización del Quindío y cómo el Estado intervino regulando, a través de sus instituciones, los conflictos manifiestos entre los actores que se vincularon al proceso colonizador.

3. Analizar las estrategias (prácticas políticas) utilizadas por los actores de la colonización, para instrumentalizar las instituciones público-políticas, con el fin de equilibrar o desequilibrar la balanza del conflicto entre empresarios, terratenientes y campesinos colonizadores.

Con base en estos objetivos la tarea siguiente fue identificar las categorías de análisis propicias para el abordaje del trabajo; ejercicio complejo por el tipo de caso escogido y la hipótesis que se fue construyendo durante las discusiones de salón, y con algunos compañeros o colegas.

Finalmente se consideraron tres categorías de análisis: Estado, colonización y práctica política, y se identificaron subcategorías de análisis e indicadores por cada una, con el fin de fortalecer y diseñar unas guías interpretativas durante la discusión de los capítulos.

En cuanto a la categoría Estado, consideramos autores como Marx, Weber, Elías, Tilly y $\mathrm{Mann}^{3}$; siendo este último de gran utilidad, pues propone una teoría capaz de agrupar los principios de la sociología clásica, sin forzar las fuentes primarias para que se ajusten a dichos postulados.

3 En el segundo capítulo se profundiza en cada autor mencionando la literatura consultada para este ejercicio investigativo. 
Para facilitar la discusión, se identificaron las siguientes subcategorías:

1. Burocracia: En la que se incluyen los Agentes del Estado en el sentido weberiano; es decir, toda burocracia que sirve como administradora de las instituciones estatales y que están en el marco de un Estado de Derecho mediando entre las garantías consagradas por la ley y la sociedad civil.

2. Conflicto: este surge en la discrepancia de dos o más personas (naturales o jurídicas) que pretendiendo alcanzar un objetivo, recurren a estrategias de sometimiento hacia el contrincante. De acuerdo con la algidez del conflicto el Estado participa como mediador; sin embargo, su acción se transforma de acuerdo con las necesidades que vayan surgiendo.

3. Violencia: se relaciona directamente con la capacidad que tiene el Estado para ejercer un poder de sometimiento sobre los integrantes de la sociedad; aquí la definición estaría relacionada con las interpretaciones weberianas del tipo ideal de Estado; por lo que adquiere un matiz simbólico en las leyes al relacionar las acciones con la sanción o el castigo, y uno material, cuando la sanción o el castigo son susceptibles de medición, por ejemplo: la pérdida de la libertad, la propiedad o hasta la vida4.

4. Poder: se entiende como la capacidad de acción que tiene el Estado para intervenir en un conflicto; aunque es importante tener presente que la historiografía del Estado moderno considera con hechos que ese poder está mediado, tramitado o filtrado por los actores sociales que instrumentalizan la estructura. Así como ocurre con el conflicto, el poder es una categoría que permite ver la configuración histórica del Estado de acuerdo con las necesidades de las mismas sociedades; luego no podría pensarse únicamente desde la visión institucionalista.

4 P. Bourdieu es otro autor clave en esta interpretación pues su definición de Estado se basa en los principios weberianos, agregando a la discusión, el poder simbólico que se materializa en la educación, el derecho, etc. Para él, el Estado, “es una X (por determinar) que reivindica con éxito el monopolio legítimo de la violencia física y simbólica en un territorio determinado y sobre el conjunto de la población correspondiente. Si el Estado está en condiciones de ejercer una violencia simbólica es porque se encarna a la vez en la objetividad bajo forma de estructuras y de mecanismos específicos y en la $<$ subjetividad $>$ o, si se prefiere, en los cerebros, bajo forma de estructuras mentales, de percepción y de pensamiento. Debido a que es el resultado de un proceso que la instituye a la vez en las estructuras sociales y en las estructuras mentales adaptadas a esas estructuras, la institución instituida hace olvidar que es fruto de una larga serie de actos de institución y se presenta con todas las apariencias de lo natural” (Bourdieu, 1997, p. 98). 
Tabla 1: Guía operacional de la categoría Estado

\begin{tabular}{|c|c|c|}
\hline Categoría & Subcategoría & Indicadores \\
\hline \multirow{3}{*}{ Estado } & \multirow{2}{*}{$\begin{array}{l}\text { Burocracia } \\
\text { Conflicto }\end{array}$} & $\begin{array}{lr}\text { Agentes del } & \text { Estado: jueces, } \\
\text { procuradores, } & \text { agrimensores, } \\
\text { magistrados, } & \text { concejales, } \\
\text { alcaldes, } & \text { gobernadores, } \\
\text { secretarios, } & \text { senadores, } \\
\text { ministros, presidentes, etc. }\end{array}$ \\
\hline & & $\begin{array}{lr}\text { Enfrentamiento } & \text { jurídico, } \\
\text { enfrentamiento físico entre } & \text { forion } \\
\text { agentes del Estado y Civiles. } & \\
\text { Reacción } & \text { institucional, } \\
\text { mecanismos } & \text { represivos } \\
\text { materiales y simbólicos. }\end{array}$ \\
\hline & Poder & $\begin{array}{l}\text { Regulación del conflicto, } \\
\text { intervención estatal legal, } \\
\text { mediaciones y trámites, } \\
\text { repertorios de protesta. }\end{array}$ \\
\hline
\end{tabular}

En cuanto a la categoría colonización, se abordó desde la perspectiva de autores como Catherin LeGrand (1984, 1988), James Parsons (1961), Jaime Londoño (1996, 2008), Margarita Serje (2005), entre otros. Como subcategoría se consideró la frontera y se identificaron los siguientes indicadores: conflicto, institucionalización, ambigüedades de las leyes y prácticas.

En relación con la frontera se entiende en el sentido de Serje (2005), quien considera que no necesariamente se dan entre países, sino también en su interior. De igual forma las fronteras se pueden relacionar con los discursos y con aquellos espacios donde se está construyendo el Estado; es por ello que en estos lugares la institucionalidad es más fácil de filtrar; aunque la condición de periferia hace que las representaciones legales sean más venales que racionales. 
Estas condiciones determinan que la frontera sea propensa a conflictos de larga duración, donde las prácticas de las burocracias locales -sean venales o racionales-, como de la sociedad civil -sea legal o ilegal-, se naturalizan. Ahora bien, cuando las prácticas se institucionalizan adquieren un manto de legalidad a través de leyes $-s i$ se trata del Estado como centro-, o decretos y resoluciones -si se trata del Estado en las periferias $-^{5}$.

Debido a que las leyes, decretos y resoluciones, están compuestas por un sinnúmero de artículos, en la revisión de fuentes documentales no solo se detectó una prolija producción de normativa sino la ambigüedad de las leyes, prestándose para interpretaciones que exacerbaron los conflictos. Aquí reposa una subcategoría emergente: las ambigüedades de las normas.

De igual manera, los conflictos durante la colonización convirtieron las estrategias de los actores en prácticas que pueden ser consideradas como políticas. De todas formas, en la categoría frontera, las prácticas son usadas únicamente como indicador.

Tabla 2: Guía operacional de la categoría colonización

\begin{tabular}{|c|c|c|}
\hline Categoría & Subcategoría & Indicador \\
Colonización & Frontera & $\begin{array}{c}\text { Conflicto } \\
\text { Institucionalización } \\
\text { Ambigüedad de las leyes } \\
\text { Prácticas políticas }\end{array}$ \\
\hline
\end{tabular}

La última categoría central es práctica política, la cual permite el acercamiento a las prácticas de quienes estaban en el campo político, como en los márgenes de él. Esta discusión se amplía en los capítulos II y IV.

5 En la división administrativa de Colombia, después de 1886, el legislativo (Congreso de la República) es quien hace las leyes, sin embargo, los municipios pueden producir decretos y resoluciones. Es por ello que consideramos como centro, el Congreso de la República; por su parte, los concejos municipales son la periferia. 
Por otra parte, usar la categoría de práctica política permite el reconocimiento de las acciones legales e ilegales, pues la investigación logró identificar en las fuentes primarias cómo el uso de estrategias no consideradas por la ley (invasiones, huelgas, levantamientos, etc.), facilitaron la titulación de predios o el reconocimiento de la jornada laboral; asunto que finalmente es constitutivo del Estado.

Para definir las prácticas se tuvo presente a Weber y Bourdieu. En cuanto a lo político fue necesario recurrir a Hannah Arendt, quien logra trascender la definición institucional orientando la discusión hacia los orígenes del concepto.

Como la práctica política vincula la subcategoría de poder, a diferencia de la definición dada en la categoría Estado, aquí el poder está relacionado con la agencia de los individuos y grupos que vinculados o no al campo político, participan de la construcción del Estado por medio de la presión e injerencia en las disposición legales.

La otra subcategoría es conflicto, que para esta investigación debe leerse como producto de la reacción de los actores que no son agentes del Estado y se oponen a su intervención, específicamente cuando a nombre de la institucionalidad se trata de adjudicar tierras, entregar títulos e intervenir en el territorio.

Como es natural, la vinculación del Estado en la regulación de las normas genera violencia; para este caso esta se entiende como el enfrentamiento o disputa de derechos a través de la agresión entre los actores de la colonización. Finalmente la categoría repertorios de protesta congrega todas las estrategias de acción política legal como los derechos de petición, las reclamaciones, las denuncias, las demandas, y la violencia legítima en el sentido weberiano, dado que esta fue usada por agentes del Estado para controlar la alteración del orden público. 
Tabla 3: Guía operacional de la categoría práctica política

\begin{tabular}{|c|c|c|}
\hline Categorías & Subcategorías & Indicadores \\
& Poder & Movilización popular \\
& & Gerencia política \\
& & Liderazgo local y regional \\
& Enfrentamiento jurídico \\
Práctica & Conflicto & Enfrentamiento físico con \\
política & Violencia & agentes del Estado \\
& & Reacción a la regulación \\
& Ocupación de predios \\
& Repertorios de protesta & Bloqueos \\
& & Quema de propiedades \\
& & Violencia legítima \\
\hline
\end{tabular}

\subsection{Estrategia metodológica}

Metodológicamente este estudio es de tipo cualitativo, aunque en algunos apartes se hizo uso de variables cuantitativas facilitando la lectura de las adjudicaciones y producción de normativa. El recurso de lo cualitativo tiene que ver con el objetivo de la investigación y las bondades que esta metodología ofrece a la hora de acercarnos a un fenómeno social; lo que nos permitió hacer una lectura de las prácticas políticas como estrategias y de la configuración del Estado como producto de un entramado de acciones y relaciones sociales.

En este orden de ideas se consideró hacer un análisis documental, recurriendo a la consulta de los archivos conservados en el AGN (Archivo General de la Nación), el Archivo Central del Cauca, el Archivo Histórico de Cartago y el Archivo del Congreso. En términos operativos se diseñó una matriz de análisis compuesta por las categorías, subcategorías y fuentes documentales primarias que permitiera su justificación. De igual manera se extrajeron los datos cuantitativos ofrecidos por documentos públicos y se procesaron en Excel, recurriendo al uso de gráficas de lectura básica. 
La categorización y organización de los datos primarios se hizo pensando siempre en la relación histórica entre el proceso formativo del Estado, con la colonización y las prácticas políticas; por lo que fue necesario identificar los actores con sus nombres, cargos o participación en los hechos; como también, clasificar los sucesos en el marco de las subcategorías pretendiendo diferenciar las acciones gubernamentales del centro, con las disposiciones de las periferias y las reacciones populares.

Esta técnica permitió organizar la información primaria, al tiempo que se cruzaba con la bibliografía consultada y las preguntas que constantemente nos formulamos, sin embargo, una de las limitantes fue el volumen de la información obtenida que hizo del trabajo un ejercicio dispendioso tanto en tiempo, como en energías para mantener en pie el proyecto.

Otra limitante, paradójica en relación con la ya mencionada, fue no haber consultado el archivo del Incoder, antes Incora, dado que dicha institución se diseñó para atender los problemas agrarios de mitad de siglo y por ello se le entregó un significativo número de casos -algunos abordados en nuestra investigación-.

Por cuestiones políticas, al parecer, el proceso de restitución de tierras que vive hoy Colombia ha llevado a que el Incoder sea celoso con sus documentos, por lo que nuestra petición para acceder a esta información se respondió un año después de pedida (2013) y hoy, no hemos vuelto a tener noticia.

En cuanto al desarrollo de los objetivos, nuestra primera tarea fue el diseño de una guía interpretativa que a partir de las principales discusiones teóricas sobre el proceso formativo del Estado permitiera analizar la cristalización de las instituciones jurídicas y políticas durante la colonización en el Quindío.

Por ello se recurrió a diversos autores considerados como clásicos en la sociología del Estado: Marx (s.f.), Weber (1974), Elías (1972, 1989), Tilly (1990), Bourdieu (1997, 2000), Mann $(1997,2006)$, entre otros, y se propuso una discusión entre estos $\mathrm{y}$ las perspectivas institucionalistas hechas en Colombia. En este apartado fueron 
claves las interpretaciones de Bolívar (2003, 2004, 2006, 2010), González (1994, 1997, 2003, 2009, 2014), Múnera $(2009,2011)$, para comprender la relación entre teorías del Estado y análisis de su proceso formativo.

Finalmente, este objetivo nos permitió identificar la relación entre las burocracias, las reacciones populares, la acción del Estado y la producción de normativa. De igual forma nos alejó de las teleologías para comprender que el Estado se forma en un proceso histórico discontinuo y que las relaciones sociales son la base para su interpretación.

En esta línea se tuvo presente las consideraciones de González (2014), para quien el Estado colombiano en su proceso centralizador no destruyó los poderes locales, sino que los articuló; sin embargo, contribuyendo a la discusión y de acuerdo con los resultados e interpretaciones obtenidas de los casos de estudio consideramos que las burocracias, como dice Mann (2006), siempre fueron autónomas del Estado, por lo que lo la acción estatal sobre ellas fue débil dejando entrever en los casos de éxito una instrumentalización; asunto que nos pone frente a la institucionalidad como una hipérbole justificada por la historia política ${ }^{6}$.

Teniendo presente a estos teóricos, y que el Estado era producto más bien de un proceso histórico de interacciones sociales con levantamientos, asonadas, huelgas, represión, etc., pasamos al segundo objetivo: "analizar la dimensión histórica en la que se desarrolla la colonización en el Quindío y cómo el Estado intervino regulando a través de las instituciones, los conflictos entre los actores que se vinculan al proceso colonizador".

Para su desarrollo fue fundamental articular la literatura sobre el tema con las fuentes primarias encontradas en el AGN, el Archivo Central del Cauca y el Archivo Histórico de Cartago; como también las memorias de los ministros de Obras

6 A partir de 1886, la historiografía política colombiana pretendió justificar que la Regeneración fue el comienzo de una racionalización administrativa y la consolidación del Estado moderno; hipótesis que entra en crisis con los estudios locales y regionales al develar los intríngulis cotidianos del Estado y sus burocracias. Ver al respecto, Domínguez, 2015; González, 2014. 
Públicas y de Gobierno, el Código Fiscal y algunas disposiciones sobre la materia divulgadas en el Diario Oficial.

Como se trata de relacionar la colonización con el Estado, consideramos que la Constitución de 1886 pretendía sembrar las bases del Estado moderno, centralizando el poder y unificando las prácticas jurídicas. Fue por ello que, mediante la descripción y análisis de casos aleatorios se pudo contrastar la relación entre las normas y la cotidianidad de la colonización, poniendo de presente que habían grietas por la que los actores instrumentalizaran las instituciones, dejando a su paso, las pistas para que las futuras administraciones liberales consideraran que los principales conflictos por la tierra y el trabajo se debían a la incapacidad del Estado para definir y regular la propiedad privada y las relaciones sociales.

Dicho esto, el tercer objetivo profundizó en esas relaciones sociales con el fin de resolver la tercera categoría clave de nuestro estudio: la práctica política, entendida como las estrategias usadas por los actores de la colonización para alcanzar sus fines.

Vale la pena aclarar que esta investigación nos sirvió como un abrebocas para comprender un fenómeno dentro de los tantos que se materializaron en el periodo estudiado. De igual manera, movernos en el tiempo nos permitió identificar algunas raíces del problema agrario que permite evidenciar que no fueron únicamente las burocracias locales las culpables o inocentes, ni el Estado el débil o fuerte, sino la articulación entre acciones de estas burocracias, como también, reacciones de la población afectada ${ }^{7}$ las que contribuyeron a la configuración de un tipo de Estado.

Como se evidencia en Palacios (2011) y Bergquist (2007), el conservadurismo campesino y la capacidad de organización y agencia de los colonos inmersos en los conflictos sería la clave no solo para comprender la transformación de los conflictos, sino la configuración de un Estado en el que las burocracias centrales actuaron diseñando una política pública para la tierra, las locales transformaron esa política

7 Tales como envío de memoriales, demandas, quejas ante la personería municipal, invasiones a fincas, protestas, etc. 
en instrumento para sus intereses, y el colono, cultivador y demás actores que estaban en los márgenes del campo político, participaron cuestionando o acogiendo de acuerdo a su conveniencia, intereses o compromiso político. 



\section{CAPÍTULO SEGUNDO: CONSIDERACIONES TEÓRICAS GENERALES}





\subsection{Estado, colonización y práctica política en la historiografía colombiana; aproximación teórica al problema de las categorías y el análisis del proceso formativo del Estado en Colombia}

En términos generales, la historiografía del Estado moderno se ha fundamentado en análisis teleológicos y normativos (Bobbio, 2000), que según Mann (2006), pueden variar de acuerdo con la teoría desarrollada. Actualmente se consideran cinco grandes teorías del Estado:

1. Las teorías de las clases.

2. La teoría pluralista.

3. La teoría del elitismo auténtico.

4. La teoría del elitismo institucional.

5. La teoría del embrollo.

Con fines académicos, y pretendiendo justificar teóricamente nuestra investigación, a continuación presentamos las teorías institucionalistas y de clases debido a que ambas alimentaron el núcleo de los análisis hechos en relación con el proceso formativo del Estado en Colombia; posteriormente haremos referencia a la teoría del embrollo la cual nos sirve como guía interpretativa pues facilita la lectura y uso de las fuentes primarias sin encasillarlas en un marco teórico rígido. 
Al finalizar este primer apartado se pretende exponer, a través de la historiografía colombiana del Estado, no solo las principales tendencias analíticas sino las implicaciones académicas de forzar las fuentes primarias a marcos teóricos rígidos.

\subsubsection{De la lucha de clases a la racionalidad weberiana. Una interpretación institucional del proceso formativo del Estado}

Tanto Marx como Weber son autores fundamentales en el estudio del Estado porque sembraron las bases problémicas entorno a su operación, funciones y relación con los individuos. El eje central de sus debates giró sobre la condición de Estado actor-Estado lugar. Cuando se identificó al Estado como un lugar, -interpretación principalmente marxista de la teoría de las clases y pluralista-, se consideraba que era una estructura al servicio de la clase dominante con el objeto de alienar, dominar, reprimir y naturalizar los antagonismos de clase a través de la creación de una falsa conciencia, unas instituciones y una voluntad que era en sí la fuerza represora. De allí que Marx considerara que el Estado era el espacio de negocios para la burguesía.

De acuerdo con él:

El Estado no se basa en una voluntad dominadora, pero el Estado que surge del modo de vida material de los individuos, tiene la forma de una voluntad dominadora. Si esta voluntad pierde el dominio, quiere decirse no sólo que la voluntad ha cambiado, sino también que han cambiado la existencia y la vida material de los individuos, pese a su voluntad (Marx, s.f., p. 249).

Esta interpretación pone en evidencia varias cosas: primero, el Estado no es autónomo; segundo, el Estado es producto de la vida material, y tercero, las revoluciones ubican a una clase en el poder y por esta vía se impone su orden, verdad y justicia.

Al referirse a la administración gubernamental (burocracia en palabras weberianas, pero que Marx no alcanzó a definir como tal), Marx la consideró compuesta de sujetos serviles a la voluntad del Estado, que era en sí, la voluntad de la clase dominante materializada en la fuerza del derecho; por ello: 
Los individuos que gobiernan en estas condiciones, aparte de que su poder tenga que constituirse en el Estado, han de dar a su voluntad, determinada por estas circunstancias concretas, una expresión general en forma de voluntad del Estado, en forma de Derecho (p. 245).

En cuanto a la categoría de violencia, Marx consideró que esta nació con el Estado dado que es su expresión máxima para garantizar el poder de control sobre los demás. La violencia se puede sublimar en el derecho, siendo este la fuente de la racionalidad estatal. Desde su perspectiva, el derecho no era más que el reflejo escrito del pensamiento de las clases dominantes y por lo mismo su prédica de libertad era una falsa verdad que se justificaba en la positivización de las leyes. Al referirse a los marcos normativos, Marx decía:

Cuando se construye esa forma política [Estado], esta se materializa a través de la normativa jurídica -el derecho- que se asume como producto de la voluntad, pues es por voluntad que se supondría, se construyen las reglas jurídicas que rigen el mundo. Es por ello mismo que el derecho es ilusorio, pues se basa en una voluntad, y mejor todavía, en la voluntad separada de su base real: en la voluntad libre. Así, el derecho se reduce a las leyes existentes, y será el derecho privado complemento de la propiedad privada. Es por ello mismo que ni el derecho, ni la religión tienen una Historia independiente, sino más bien, una Historia atada a los procesos dependientes del capital (p. 248).

Max Weber compartía con Marx la idea que el Estado moderno había nacido con el capitalismo y que este era un actor que funcionaba con el impulso de la racionalidad representada en la burocracia; por ello lo definió como:

Una asociación de dominio de tipo institucional, que en el interior de un territorio ha tratado con éxito de monopolizar la coacción física legítima como instrumento de dominio, y reúne a dicho objeto los medios materiales de explotación en manos de sus directores pero habiendo expropiado para ello a todos los funcionarios de clase autónomos, que anteriormente disponían de aquellos por derecho propio, y colocándose a sí mismo, en lugar de ellos, en la cima suprema (Weber, 1974, p. 1060). 
Contraria a la interpretación marxista, aquí el Estado es capaz de ejecutar acciones sobre las supuestas élites de poder que gobiernan y que lo utilizan como estrategia para legitimarse. Al referirse a los administradores del Leviatán, es decir la burocracia, Weber la consideró como aquella organización de hombres racionales que dejarían a un lado sus intereses personales para servir a un interés superior, en este caso al Estado, y se legitimarían ante el resto de población que vivían en el territorio ${ }^{8}$.

Aunque Weber identificó tres tipos de dominación legítima (carismática, tradicional y legal burocrática), para nuestro interés investigativo nos interesa referirnos a la legal burocrática porque como él mismo lo expresa, esta es "específicamente moderna" (Weber, 1974: 173) ${ }^{9}$. El éxito de este tipo de dominación descansaba en la validez de las siguientes ideas entrelazadas entre sí:

- Que todo derecho "pactado" u "otorgado", puede ser estatuido de modo racional [...].

- Que todo derecho según su esencia es un cosmos de reglas abstractas, por lo general estatuidas intencionalmente [...].

- Que el soberano legal típico, la "persona puesta a la cabeza", en tanto que ordena y manda, obedece por su parte al orden impersonal por el que orienta sus disposiciones [...].

- Que -tal como se expresa habitualmente- el que obedece sólo lo hace en cuanto miembro de la asociación y sólo obedece "al derecho".

- Rige (en el caso racional) el principio de la separación plena entre el cuadro administrativo y los medios de administración y producción [...].

- En el caso más racional no existe apropiación de los cargos por quien los ejerce.

- Rige el principio administrativo de atenerse al expediente, aun allí donde las declaraciones orales sean de hecho la regla o estén hasta prescritas [...] (Weber, 1974, p. 175).

8 Para profundizar en la característica de este grupo de personas ver: Weber, 2006.

9 Ahora bien, podría pensarse que para el caso colombiano y especialmente el periodo de estudio, las burocracias no son plenamente racionales, sin embargo debemos tener presente que la emisión de la Constitución de 1886, pretendía racionalizar las relaciones entre el Estado, las burocracias y la población. Fue por ello que la constitución quiso centralizar las finanzas, los ejércitos, las elecciones, la educación, etc., con el fin de comenzar un proceso de transformación racional en la vida política del país. 
Para Weber la burocracia racional se caracterizaba por 10 elementos claves los cuales, de cumplirse, permitirían el buen funcionamiento del Estado. Este tipo ideal se consolidaba cuando los funcionarios individuales eran:

- Personalmente libres, se deben sólo a los deberes objetivos de su cargo.

- En jerarquía administrativa rigurosa.

- Con competencias rigurosamente fijadas.

- En virtud de un contrato, o sea (en principio) sobre la base de libre selección según:

- Calificación profesional que fundamenta su nombramiento -en el caso más racional: por medio de ciertas pruebas o del diploma que certifica su calificación-.

- Son retribuidos en dinero con sueldos fijos, derecho a pensión las más de las veces; son revocables siempre a instancia del propio funcionario y en ciertas circunstancias (particularmente en los establecimientos privados) pueden también ser revocados por parte del que manda; su retribución está graduada primeramente en relación con el rango jerárquico, luego según la responsabilidad del cargo y, en general, según el principio del "decoro estamental".

- Ejercen el cargo como su única o principal profesión.

- Tiene ante sí una "carrera" o "perspectiva" de ascensos y avances por años de ejercicio, o por servicios o por ambas cosas, según juicio de sus superiores.

- Trabajan con completa separación de los medios administrativos y sin apropiación del cargo.

- Y están sometidos a una rigurosa disciplina y vigilancia administrativa (Weber, 1974, p. 176).

Contrario a Marx, quien veía en la violencia la estrategia de las clases dominantes para legitimarse en el poder, Weber consideró la violencia como la expresión del Estado para legitimarse en el territorio; evidentemente se trata de una interpretación del Estado como actor y no como lugar. 
Su definición consideraba que el Estado podía verse por ello como:

Aquella comunidad humana que en el interior de un determinado territorio [...] reclama para sí (con éxito) el monopolio de la coacción física legítima. Porque lo específico de la actualidad es que a las demás asociaciones o personas individuales sólo se les concede el derecho de la coacción física en la medida en que el Estado lo permite. Este se considera, pues, como fuente única de "derecho" de coacción (Weber, 1974, p. 1056).

En esta definición es evidente que el Estado tiene el poder sobre el resto de las personas sean naturales o jurídicas; recuérdese que para Weber el poder significaba "la probabilidad de imponer la propia voluntad dentro de una relación social, aun contra toda resistencia y cualquiera que sea el fundamento de esa probabilidad" (p. 43). Ahora bien, aunque en esta relación se genera el conflicto, por tratarse de un análisis institucionalista, pareciera no ser considerado como intrínseco en la construcción del Estado y más bien un referente de disfuncionalidad.

Norber Elías es otro autor fundamental en el análisis del proceso formativo del Estado pues, aunque no desarrolla una teoría de las clases como lo hizo Marx o una teoría institucionalista como la de Weber, sí retoma aportes de ambos. En su obra, El proceso de la civilización (1989), dedica un capítulo al estudio del Estado considerando varios aspectos como la centralización, el poder para recaudar impuestos, el monopolio de la violencia física, la legalización y naturalización de ese poder entre los individuos que conforman el territorio, el pactismo entre élites, los favores políticos, etc.

Uno de los elementos más importantes de esta obra es resaltar la complejidad en la consolidación del Estado moderno, por lo que el autor, basado en la historia del Estado francés, planteó que su cristalización fue producto de un proceso largo y conflictivo en el que se evidencian distintas estrategias para distribuir el poder; asunto que no queda claro ni en Weber ni en Marx. 
Para Elías el Estado moderno es producto de la interdependencia entre la cohesión social y territorial a través de la centralización política, administrativa, económica y simbólica; por ello la Nación y el comportamiento distintivo de los grupos sociales se logra a través de estrategias que a largo plazo han permitido la continuidad de políticas y discursos en la que todos los estratos sociales están identificados.

Para estudiar la formación del Estado francés, Elías analizó la unificación territorial y militar llevado a cabo por los Capeto, haciendo referencia a las estrategias usadas contra los Monthléry, Rochefort, Ferté-Alais y Puiset, y cómo fueron incorporando sus posesiones y estableciendo un poder centralizado (Elías, 1989).

Para él, un factor clave fue la comunicación -en el sentido de la seguridad vial-y la posibilidad de movilizarse en el territorio, así como también la capacidad para controlar los recursos pues, mientras la casa de los Capeto se consolidaba sobre los territorios de los Monthléry, adquiría:

Al propio tiempo, un fortalecimiento militar y un enriquecimiento económico. El señorío de Montlhéry supuso ingresos por valor de 200 livres, una suma considerable para la época. Con el señorío vinieron 13 feudos directos y 20 indirectos, dependientes de los anteriores, o subfeudos cuyos beneficiarios pasaron a aumentar el poderío militar de los Capetos (Elías, 1989, p. 335).

En esta interpretación del Estado, la guerra (violencia) es el factor central que junto con otras estrategias normalizan las nuevas relaciones políticas; por ello Elías menciona que otra manera de acumular riqueza y control fueron las alianzas militares, económicas o en su defecto, los matrimonios, compras o conquistas que permitieron conseguir una posición superior frente a los vecinos; señores feudales que igualmente tenían poder militar, pero fueron sometidos durante la guerra. También menciona que fue fundamental la combinación de las cualidades personales de los representantes (burocracia), el apoyo de la Iglesia y el prestigio tradicional. 
Elías consideró que el Estado podía representarse en el monopolio de la fuerza pero también en el monopolio fiscal; por ello la constitución de los estados está determinada por el acceso efectivo a estos dos monopolios. Decía que:

Los medios financieros que afluyen así a este poder central, sostienen el monopolio de la violencia; y el monopolio de la violencia sostiene el monopolio fiscal. Ambos son simultáneos; el monopolio financiero no es previo al militar y el militar no es previo al financiero, sino que se trata de dos caras de la misma organización monopolista. Cuando desaparece el uno, desaparece automáticamente el otro, si bien es cierto que, a veces, uno de los lados del monopolio político puede ser más débil que el otro (Elías, 1989, p. 345-346).

Después de legitimados estos monopolios aparecen los siguientes que caracterizan un Estado moderno, por ejemplo: el monopolio del discurso que se imparte en las escuelas y que crea las identidades ${ }^{10}$.

El otro elemento interesante de esta tesis es que la consolidación del monopolio legítimo de la violencia y el discurso no se da precisamente en el marco del tipo ideal weberiano, sino que ese poder se filtra, se pacta, se acuerda. Es por ello que pareciera que el monopolio determina la existencia de un grupo pequeño de dominantes y uno grande de dominados, pero este monopolio tiene dos características principales: 1) de monopolio privado pasa a ser público (estatal) y 2) de dominio exclusivo pasa a ser dominio dependiente. Se construye entonces una relación entre dominante y dominado en la que el dominante tiene la garantía de su dominio, siempre y cuando los dominados acepten dicha condición que en sí, no es más que la aceptación de un orden que les está beneficiando por los eventos inscritos en la lucha por el poder; recuérdese que:

10 Al respecto puede consultarse a Bourdieu (1997) quien considera que la escuela es uno de los principales mecanismos represivos del Estado, pues allí se fragua su poder simbólico. 
Las sociedades incorporan las características de las naciones si la interdependencia funcional entre sus regiones y entre sus estratos sociales, así como sus niveles jerárquicos de autoridad y subordinación devienen lo suficientemente grandes y lo suficientemente recíprocos como para que ninguno de ellos sea capaz de subestimar por completo lo que los otros piensan, sienten o desean (Elías, 1970, p. 114-115).

Charles Tilly puede considerarse como otro pilar teórico para la interpretación del proceso formativo del Estado, especialmente porque su análisis es socio-histórico y retoma los principios teóricos ya mencionados para ofrecer una perspectiva general de la historia organizativa del Estado.

En su obra, Coerción, capital y los Estado europeos 990-1990 (1990), el análisis gira principalmente en torno a los gobernantes, las instituciones y la capacidad del Estado para consolidar el monopolio de la violencia y el recaudo. De igual manera se destaca que existen competidores dentro del territorio así como también fuera de él, por lo que es necesario establecer un monopolio legítimo al interior, construir ejércitos para la defensa contra otros estados y diseñar organizaciones que sirvan de alianza o defensa del orden. Siguiendo la visión weberiana, Tilly define al Estado como:

Una organización con poder coercitivo, diferente a los grupos de familia y parentesco y que en ciertas cuestiones ejercen una clara prioridad sobre cualquier otra organización dentro de un territorio de dimensiones considerables. El término incluye, pues, las ciudades-estados, los imperios, las teocracias y muchas otras formas de gobierno, pero excluye la tribu, las castas, las empresas e iglesias (Tilly, 1990, p. 20).

A diferencia de los Estados previos al siglo XIX, Tilly resalta que fue durante este período que se consolidó con mayor ahínco su poder expansivo gracias a la capacidad de movilidad y centralización de sus territorios, así como también, la transformación de sus administradores (burocracia). Dado que la actividad del Estado se amplió por 
el progreso de la navegación, la acción policial, el diseño de caminos férreos y de carreteras, la regulación de los capitales, la creación de escuelas, etc., se tuvo que, en ocasiones, incorporar especialistas al servicio, lo que llevó a multiplicar el número de funcionarios civiles ${ }^{11}$. Explica el autor que:

Simultáneamente, en el proceso de negociar directamente con la población subordinada, impuestos generalizados, servicios militares y cooperación con las disposiciones del Estado, la mayoría de los estados dieron dos pasos más de profunda importancia: un movimiento hacia el gobierno directo que redujera el papel de los patronos locales o regionales y llevara representantes del Estado a toda comunidad, y una expansión de las consultas populares en forma de elecciones, plebiscitos y legislaturas. Ambas cosas fomentaron el nacionalismo tanto en el sentido de la identificación popular con los objetivos del Estado (para la mayoría), como (para la minoría) en el sentido de oponerse a las demandas de uniformidad e integración, una oposición en nombre de grupos lingüísticos y culturales diferenciados (Tilly, 1990, p.104).

De esta manera el Estado se hacía omnipresente y racionalizaba las relaciones entre sus habitantes y el poder central; por ejemplo, después de un conflicto era común que hubiese un cambio en las burocracias, por ello el autor menciona cuatro hechos que comprometen la imagen de una planificación certera:

1. Después de una conquista, la primera estrategia es organizar una burocracia nueva con elementos de la antigua burocracia, así como también tener un ejército que esté compuesto con algunos de los viejos integrantes del ejército vencido.

2. Después de iniciar una guerra, es común que los agentes recaudadores terminen legitimándose como elementos constitutivos del Estado.

11 Al respecto, Philip Hoffman (2016) desarrolla una tesis muy interesante en la que amplía la discusión considerando que fue el aprendizaje por investigación el que le dio el poder a los europeos sobre el mundo. Para desarrollar su tesis utiliza distintos ejemplos demostrando que la especialización en el campo militar, mejorando cañones y usos de las armas, fue la clave sobre el tradicional aprendizaje por experiencia. 
3. Después de una guerra, lo que se manifiesta es que haya una distribución del espacio entre los estados partícipes de la pugna.

4. Después de iniciado un conflicto, es común el pacto y la alianza entre gremios y Estado. Así entonces podría construirse un nuevo mecanismo de administración del poder.

Según Tilly, el éxito del Estado estuvo en la capacidad de consolidar un poder que le permitió administrar la violencia a través de mecanismos represivos como los militares, y simbólicos como el derecho. De esta manera el Estado terminó por regular los conflictos considerados menores (de familia, entre vecinos, entre cuerpos administrativos del territorio, etc.) y se hizo legal en su intervención, desarmó a la población civil paulatinamente a través de la prohibición de duelos incautando armas o dispersando licencias para su uso; haciendo redadas policiales sometieron a otros señores que podrían disputar la legitimidad del mismo Estado y también lo hizo "construyendo temibles medios coercitivos propios y privando a la población civil de acceso a estos medios. En su mayoría, los estados recurrieron fuertemente al capital y los capitalistas cuando reorganizaron la coerción” (Tilly, 1990, p. 111).

Teniendo presente las definiciones hechas del Estado y las respectivas subcategorías consideradas en esta investigación (burocracia, poder, violencia, conflicto) surgen preguntas tales como: ¿Podría existir un caso donde se aplique una teoría pura del Estado? ¿Podríamos hacer un análisis formativo del Estado colombiano usando estas guías teóricas? ¿Acaso la configuración de nuestros estados responden a situaciones como las descritas por los clásicos?

La producción historiográfica sobre el Estado colombiano pareciera seguir al pie de la letra estas teorías; sin embargo, pensar el desarrollo histórico del país sin una correlación entre teorías institucionalistas y de clases no solo es displicente con los hechos, sino también una vía que podría generarnos problemas interpretativos pues finalmente el Estado no cristaliza de una manera universal, sino que está determinado por las características históricas de cada sociedad. 
Es por ello que, pretendiendo establecer una definición para las categorías mencionadas y que nos sirviera de guía interpretativa, se recurrió a la propuesta de Michael Mann (1997) quien consideró que la configuración histórica de los estados no necesariamente se regía por los principios puros de las teorías; más bien cada sociedad, de acuerdo con sus necesidades y estrategias de socialización, recurrió al fortalecimiento de algunas características mencionadas pero desechó o pospuso otras.

Su teoría considera que los Estados modernos cristalizaron de varias maneras atendiendo a las fuentes del poder social. Lo hicieron como "capitalistas, ideológico morales, militaristas y varias posiciones variables de un continuo representativo, que va desde la monarquía autocrática a la democracia de partidos, y de un continuo $<$ nacional> que va del Estado-Nación centralizado al sistema confederal" (Mann, 2006, p. 18).

Esta tesis permite desvirtuar la capacidad del Estado para regular el todo como un ser supremo y más bien expone los puntos ciegos que finalmente se convierten en las grietas usadas por los actores sociales para instrumentalizar su poder materializado en las instituciones. Mann justifica su idea cuando plantea que el Estado no siempre sabe lo que hacen sus miembros y su cristalización no ha sido precisamente una y de la misma forma, más bien ha sido variada ${ }^{12} \mathrm{y}$ está determinada por las necesidades de la misma sociedad. Ahora bien, a pesar de esta variabilidad de los Estados, según Mann (1997) hay cuatro cimas:

1) Una maduración de las relaciones económicas del capitalismo, 2) una representatividad mayor, 3) un proceso de centralización nacional y 4) un Estado militarista profesionalizado y burocratizado.

Mann considera que la Historia del Estado presenta dos tipos de Poder sobre el territorio donde se consolida; en el primer tipo de poder llamado despótico las élites

12 Él identifica 6 formas generales 1) Capitalista, 2) Ideológico-moral, 3) militarista, 4) MonarquistaAutocrático, 5) Democracia de partidos y 6) Estado-Nación centralizado o Estado-Nación confederado. 
gobiernan con autonomía; en este caso existe un "abanico de acciones que la élite tiene facultad de emprender sin negociación rutinaria, institucional, con grupos de la sociedad civil” (Mann, 2006, p. 6).

Fue durante esta cristalización que se popularizó la expresión de la reina: ¡open the head!, sin embargo el poder de estas élites era limitado en el territorio y su éxito estaba mediado, tramitado y hasta dilatado por élites menores, como puede verse en la expresión popular de América a fines de la Colonia: ¡se acata, pero no se cumple! $!^{13}$

El otro Poder es el usado en el Estado Moderno; hablamos entonces del Poder Infraestructural en el que es evidente "la capacidad del Estado para penetrar realmente la sociedad civil, y poner en ejecución logísticamente las decisiones políticas por todo el país" (Mann, 2006, p. 6), siendo un Estado despóticamente débil pero infraestructuralmente fuerte.

Entre las principales características cabe resaltar las que hicieron posible esta capacidad infraestructural:

1. Una división del trabajo entre las principales actividades del Estado que éste coordina centralmente.

2. La alfabetización, la capacidad de estabilización de transmisión de mensajes a través de los territorios estatales por sus agentes, y la capacidad de codificación y archivo de responsabilidades legales. Almacenaje de poder estatal.

3. Establecimiento de pesas, medidas y moneda, permitiendo el intercambio de mercancías bajo una garantía última de valor por el Estado.

4. Velocidad de comunicación de mensajes y de transporte de personas y recursos a través de mejoras en vías, barcos, telégrafo, etc., (Mann, 2006, p. 10-11).

13 Aún sigue siendo un problema colombiano la producción de las leyes y su cumplimiento. Todavía se mantiene el "se acata, pero no se cumple". Al respecto ver García Villegas (2014). 
El punto interesante y que nos servirá de guía para nuestro análisis es que finalmente para Mann (2006), como primero,

En toda la historia del desarrollo de la infraestructura del poder, no existe virtualmente técnica alguna que pertenezca por necesidad al Estado, o a la inversa, a la sociedad civil. Segundo, existe cierto tipo de oscilación entre el papel de las dos en el desarrollo social. [...] no se trata simplemente de oscilación, sino de una dialéctica (p. 10-11).

Ahora bien, en lo que respecta a la burocracia, esta se asigna racionalmente prioridades dentro de la administración; sin embargo, dependiendo el tipo de cristalización que tenga el Estado priman unas lealtades. De esta manera:

Los estados no establecen sus prioridades últimas entre funciones tales como la regulación de las clases, la centralización del gobierno o de la diplomacia. Los actores políticamente poderosos realizan la mayoría de las numerosas funciones estatales con el sentido pragmático, según la tradición y las precisiones del momento, y reaccionan con igual pragmatismo y precipitación a las crisis que los afectan a todos (Mann, 1997, p. 116).

Podríamos concluir que para Mann, así como en Elías y Tilly, el Estado es un actor y un lugar; ahora bien, el sentido más puro de las dos teorías mencionadas inicialmente (institucionalista y de clases) se difumina en la dialéctica histórica de los procesos formativos del Estado, esto sin mencionar que ambas parecieran negar la acción social o la capacidad que tienen los actores de negociar o participar en el diseño (conscientes o no) del Estado y sus formas de cristalización.

Por considerarse al Estado una arena, el despotismo está determinado por la voluntad popular que así lo dispone; pero también el Estado disminuye su capacidad despótica cuando al enfrentar el poder infraestructural es más fuerte sin recurrir a la violencia. En palabras de Mann (2006): 
El Estado, a diferencia de los principales actores de poder de la sociedad civil, está territorialmente limitado y centralizado. Las sociedades necesitaban que algunas de sus actividades sean reguladas sobre un territorio centralizado. Lo mismo sucede con las clases económicas dominantes, las Iglesias y otros movimientos de poder ideológico, y élites militares. Por tanto, ellos confían los recursos de poder a las élites estatales, recursos que no son capaces de recuperar completamente, precisamente porque sus propias bases socioespaciales de organización no están centralizadas ni territorializadas. Dichos recursos de poder estatal, y la autonomía a que llevan, pueden no ser muchos. Sin embargo, si el uso del Estado de los recursos conferidos genera ulteriores recursos de poder -como en realidad pretendían los mismos grupos de la sociedad civil- éstos normalmente fluirán a través del Estado, y llevarán así a un grado significativo de autonomía de poder. Por tanto, el poder autónomo del Estado es el producto de la utilidad de la centralización territorial incrementada para la vida social en general. Ésta ha variado de forma considerable a través de la historia de las sociedades, y consecuentemente lo ha hecho el poder de los estados (p, 36).

Como el concepto de Estado se hace confuso en la lectura de las teorías institucionales o funcionalistas, este puede ser definido por lo que parece o por lo que hace; por ello Mann retoma todas las perspectivas y construye su teoría del embrollo influenciado principalmente por Max Weber. Así para Mann (1997):

- El Estado es un conjunto diferenciado de instituciones y personal que

- Implica un centralidad, en el sentido de que las relaciones políticas irradian desde el centro y hacia el centro, para abarcar

- Una demarcación territorial sobre la que ese Estado ejerce

- En alguna medida, una capacidad de establecer normas autoritarias y vinculantes, respaldadas por algún tipo de fuerza física organizada (p. 85).

De esta tesis podemos destacar que los Estados tienen cuatro mecanismos para construir sus prioridades: el primero se relaciona con el establecimiento de 
Constituciones y código de leyes, el segundo, presupuestos, el tercero, mayorías políticas democráticas y el cuarto, la burocracia monocrática.

Por otra parte, la estrategia analítica de Mann permite identificar no solo la acción del Estado sobre los territorios, sino la participación de las burocracias y las reacciones de la población a dichas disposiciones que en muchos casos fueron jurídicas, militares o económicas. Esta teoría del proceso formativo del Estado tiene la ventaja de trascender las observaciones hechas por Marx, Weber, Elías y Tilly, reconociendo sus aportes, pero alejándose de las teleologías y ajustando las pretensiones teóricas al devenir histórico de cada sociedad.

\subsubsection{Ideas generales para el marco interpretativo}

¿Cómo contribuyen los cinco autores vistos al estudio del Estado y el diseño de una estrategia analítica para esta investigación? Desde Marx hasta Mann, las preguntas sobre el Estado siguen apuntando a un asunto clave: la relación que tiene este con las poblaciones.

Evidentemente, el joven Marx que citamos consideró que el Estado era un lugar al servicio de la clase dominante, por lo que el discurso jurídico, económico, militar, religioso, etc., pretendía legitimar el orden y normalizar las formas de explotación de unos sobre otros. Quizá, por el tiempo en el que vivió el autor, no alcanzó a analizar la funcionalidad de las burocracias y mucho menos profundizó en la participación de la sociedad civil como constructora de Estado ${ }^{14}$; sin embargo, considerar al Estado como productor de discurso materializado en el orden jurídico nos permite analizar en nuestro estudio de caso cómo se relacionaba la producción de normativa con la modernización estatal y el proyecto de sociedad pensado por las élites del centro.

Por su parte, Max Weber avanzó un poco más en la interpretación del proceso formativo del Estado identificando y alertando sobre los riegos que podría tener

14 De todas maneras el análisis propuesto en El 18 brumario de Luis Bonaparte, permite matizar esta hipótesis. Ver: Marx (2005). 
la sociedad con la aparición de las burocracias. De igual manera, sin entrar en los pormenores marxistas, vio en el Estado no solo un lugar sino un actor que se reservaba en su legitimidad el control del territorio, el discurso jurídico y el poder económico. No siendo suficiente, en el Estado moderno a diferencia de las otras formas de Estado de su tiempo, se elevó como máxima autoridad sobre las demás autoridades locales, monopolizó la violencia, los recursos, la verdad, la justicia y se hizo así mismo legítimo entre sus habitantes.

Para el caso colombiano podría pensarse que la teoría de la racionalidad weberiana no encaja, sin embargo, hay dos elementos claves que nos obligan a tener presente su interpretación: el primero tiene que ver con un asunto histórico, y es que el diseño de la Regeneración pretendió racionalizar administrativa y políticamente el Estado colombiano; la segunda razón tiene que ver con el sentido que debe tener el Estado. No se trata ahora de forzar los datos para que digan qué tan weberiano era el Estado colombiano, pero sí podemos identificar -desde la perspectiva de la racionalidad que vincula el accionar de las burocracias, el control de los recursos, el diseño de una normativa a nivel nacional, etc. -, cómo nuestro país fue ajustando paulatinamente su estructura jurídica y administrativa a las discusiones internacionales sobre el deber ser del Estado y cuál fue la participación de las burocracias centrales y locales en dichos ajustes.

En esta discusión sobre centralización y burocracias, los aportes de Norber Elías y Charles Tilly son relevantes. El primero contribuye con la identificación de las características procesuales de la formación del Estado mostrando que no se trata únicamente de centralizar el poder como lo veía Weber, sino de identificar las maneras para llegar a ello.

En la interpretación de Elías, el Estado es producto de una larga duración en la que el poder fue algunas veces filtrado y en otras, pactado; mientras tanto se hacían acuerdos matrimoniales, alianzas económicas y se recurría a estrategias para garantizar la legitimidad del centro beneficiando los aliados de las periferias. 
En el caso de Tilly, la relación entre capitalismo, fuerzas militares y coerción, permite adentrarse en las características de los procesos centralizadores haciendo énfasis en las estrategias de los gobiernos centrales y la participación de las burocracias locales.

Su análisis pone en evidencia la importancia de controlar la violencia y la recaudación de impuestos; de igual manera muestra cómo los Estados lograron regular el comportamiento cotidiano, diseñar cuerpos de policía capaces de reprimir y crear estructuras jurídicas que tuvieran eficacia simbólica en el territorio.

Para nuestro caso, si bien el Estado colombiano de finales del siglo XIX pretendía centralizar el poder y construir una estructura racional, como diría Bolívar (2006): ese proceso es parte de unos acuerdos, unas alianzas y unas estrategias de territorialización, desterritorialización y reterritorialización.

Este proceso es evidente en las relaciones que establecieron las burocracias centrales y locales mientras se construía una plataforma jurídica acorde a las necesidades cotidianas de la población. Al tiempo que esto sucedía, se materializaron luchas contra los opositores políticos a través de la guerra física y la disputa por la legitimidad entre los habitantes. De allí que muchos colonos dirigieran notificaciones al Gobierno deslegitimando las burocracias y cuerpos jurídicos locales, pero loando la tarea racional del centro; ¿acaso no es esta una pista para analizar el proceso de transformación racional del Estado?, ¿podríamos considerar estas prácticas como una vía de legitimación estatal en detrimento de las autoridades locales?

El último autor que referenciamos, es decir Michael Mann, nos permite acercarnos a una interpretación del Estado más flexible y coherente con el interés de nuestro análisis. Para Mann, el proceso formativo del Estado responde a una interrelación entre el poder absoluto que este se reserva y el poder infraestructural que alcanza.

Para desarrollar su tesis, Mann reconoce la importancia de los autores mencionados, de igual manera usa sus interpretaciones para revisar distintos procesos históricos y finalmente termina considerando que no todos los Estados cristalizaron de la misma manera y en el mismo tiempo; sin embargo, la constante fue la centralización del 
poder y la transformación de las burocracias a cuerpos administrativos racionales. Para nuestro caso de estudio, la propuesta interpretativa de este autor permite evitar las teleologías pero también reconocer las estrategias usadas en otras experiencias y revisar las nuestras.

En este sentido, la interpretación sobre la participación burocrática, el diseño de jurisprudencia, la capacidad de cohesión y la legitimidad en las periferias, son asuntos claves que deben tenerse presentes para estudiar el proceso formativo del Estado. Por otra parte, Mann nos permite encajar nuestro caso de estudio en el marco analítico del Estado, pues no solo ofrece una visión del centro hacia la periferia, sino que incentiva en el lector cuestionamientos sobre la reacción de los pobladores y grupos sociales al margen del campo político controlado principalmente por las burocracias.

Pasemos ahora a revisar algunos estudios sobre el proceso formativo del Estado en Colombia y su relación con los autores mencionados.

\subsubsection{Institucionalismo y teorías de clase en la historiografía colombiana}

La historiografía colombiana del Estado se agrupa a grandes rasgos en las dos esquinas de un análisis pendular. En la primera están las publicaciones que, usando los tipos ideales, describen detalladamente el funcionamiento de los órganos estatales y nombran con ahínco, quiénes fueron sus principales figuras públicas; también en este grupo están las publicaciones que partiendo del tipo ideal weberiano, mencionan las crisis para poner en tela de juicio no solo la institucionalidad, sino también el mismo Estado y su capacidad de acción. Algunas de estas tesis se apoyan en las interpretaciones de Norber Elías, Pierre Bourdieu, Charles Tilly y claro está, Max Weber.

La otra esquina del péndulo congrega las publicaciones no institucionalistas que influenciadas por el marxismo, pretendieron exponer las contradicciones del Estado 
moderno colombiano y cómo las élites habían gobernado históricamente; pero también hay ejemplos en los que se ajustan los hechos a la visión revolucionaria de la teoría, pretendiendo encontrar en momentos de crisis institucional unos supuestos de toma del poder popular llamado por los autores, del proletariado o del pueblo revolucionario.

Para Alexander Betancourt Mendieta (2007), el recurso teórico del marxismo se justificó en el cuestionamiento de la historia tradicional, es decir la institucionalista, que sucedió en Colombia y otros lugares de América Latina a partir de la transformación de la escritura como una labor de la historia social; al respecto dice:

Se entendía por tal, el ejercicio de narrar la historia de las clases pobres. Esta tendencia acrecentó la fuerte relación entre la escritura de la historia social y la narración de las protestas y los movimientos sociales. [...] Al respecto los miembros de los grupos de izquierda colombianos no fueron ajenos y se ve cómo temáticas propias de la cuestión política coyuntural como el tema de la tierra y la cuestión indígena, serán fundamentales para la determinación del accionar político de esos grupos (p. 146).

De esta manera ambas tendencias analíticas, es decir la marxista como la institucionalista, se caracterizaron por el seguimiento a un modelo interpretativo que bajo el paraguas reduccionista, terminó por forzar las fuentes a la prisión de la teoría y como diría Leopoldo Múnera (2009), "la génesis estatal [fue] juzgada, en términos generales, de acuerdo con un resultado final deseado, imaginado, o materializado en instituciones o aparatos que se ajustan en mayor o menor medida a un deber ser teórico o práctico" (p. 11).

¿Pero acaso la historia de los estados es teleológica? ¿Todos los estados cristalizan (Mann, 1997; 2006), de la misma manera y en los mismos tiempos? ¿Qué desempeño tiene la sociedad en la construcción de los estados? ¿Cuáles son los niveles de cohesión e integración social desarrollados en el territorio? 
Al parecer, los paradigmas más relevantes de la teoría sociológica tuvieron una interpretación teleológica del Estado, por ello mismo la crítica de Múnera (2009) y Bolívar (2010), dado que no solo la interpretación conllevó a forzar las fuentes, sino que también desestimó la acción social como constructora del Estado. Veamos algunos ejemplos, para posteriormente conciliar el problema interpretativo con el uso la colonización como unidad de análisis en el estudio del proceso formativo del Estado colombiano.

\subsubsection{Las perspectivas institucionalistas: análisis tentativos del proceso formativo del Estado en Colombia}

Desde el siglo XIX la producción bibliográfica sobre el Estado tuvo como eje central la institucionalidad; fue por ello que los actores principales eran héroes epónimos de la Independencia y los análisis se completaban con estudios sobre el Descubrimiento y las conquistas en el territorio nacional. José María Obando, Francisco Soto, José Hilario López, José Manuel Restrepo, Joaquín Acosta, José Antonio Plaza, José Manuel Groot, Joaquín Posada, y otros, son ejemplos fidedignos de una generación que pretendió construir una interpretación de la historia del Estado colombiano.

A grandes rasgos, sus obras son favorables a los españoles, especialmente cuando se refieren al pasado indígena y negro desestimando su aporte a la identidad y construcción del Estado. En cuanto a los conflictos durante el largo siglo XIX, se consideran como parte de la lucha entre progresistas y conservadores, y disfuncionales o negativos para el Estado ${ }^{15}$.

Después de la Regeneración (1878), la producción académica sobre el proceso formativo del Estado colombiano tuvo mayor énfasis en los asuntos institucionales; recuérdese que el positivismo era la fuente principal de interpretación y claro está, la historia que aún no estaba en el marco de una disciplina, se fabricada en los escritorios de abogados, militares, curas, comerciantes, entre otros prestigiosos señores de la república. De esta manera, la historia del Estado giraba en torno a

15 A propósito de esta literatura ver: Betancourt, A. (2007). 
las disposiciones constitucionales y el reconocimiento de la Regeneración, como el proyecto político que salvó a Colombia de la gran catástrofe federalista ${ }^{16}$.

Ya en el siglo XX, en todo el continente americano se habían fundado Academias de Historia con el fin de institucionalizar el pasado nacional, por ejemplo: El Instituto Histórico y Geográfico de Río de Janeiro (1838), el Instituto Histórico y Geográfico de Uruguay (1843), la Facultad de Humanidades de la Universidad de Chile (1843), la Academia Nacional de Historia en Venezuela (1888) y para Colombia, la Academia Colombiana de Historia (1902).

Por su naturaleza, la Academia fue creada para construir y ensalzar una historia patria, luego la característica de la historia institucional no era precisamente la crítica o la identificación de un enfoque teórico; más bien se trataba de una historia lineal que como diría Alexander Betancourt (2007), "convirtió a la historia en una apología de las capas dirigentes colombianas, con lo cual, el pasado se transformó en un proceso unilineal y perfectivo en donde no existían otros procesos, otros tiempos, otros sujetos y otras historias" (p. 52).

En los años treinta, la historia del Estado siguió girando en torno a los problemas legislativos; unas líneas institucionalistas encabezadas por el mismo presidente Eduardo Santos, promovieron la publicación de obras en las que se elevara el buen nombre de Francisco de Paula Santander adjudicándosele calificativos como: el hombre de las leyes, el fundador de la república, el forjador de la conciencia civil de la república, etc. Aunado a esto, se mandaron a erigir estatuas de Santander en varias ciudades del país y en 1948, se expidió la Ley 13 con el fin de escribir una historia de la república.

En la postura oficialista seguía rigiendo la perspectiva institucional; sin embargo puede identificarse un revisionismo con la llegada de los programas de historia, aunque no necesariamente se tratara de tesis marxistas. Germán Arciniegas y Luis Eduardo Nieto Arteta fueron ejemplos inspiradores para estas nuevas

16 Para leer una crítica al respecto, Rodríguez (2011). 
interpretaciones. Los grandes aportes de sus obras fueron la identificación de un nuevo actor en la construcción del Estado, ahora el pueblo (la plebe llamada por Arciniegas), hacía parte de la configuración de una sociedad que tradicionalmente fue vista como católica y legalista.

Otra obra de gran relevancia fue la de Antonio García, quien al elaborar la Geografía económica de Caldas (1978) describió el medio físico, la estructura social, la economía cafetera, la producción minera, los procesos de poblamiento y de urbanización, y dejó sembrada la semilla para los siguientes estudios regionales que podían adquirir un matiz de análisis nacional.

Desde la sociología, López de Mesa (1934) contribuyó con la interpretación de la configuración estatal desde los asuntos culturales, y fuertemente influenciado por las teleologías, logró penetrar en la esencia colectiva de la sociedad colombiana al tiempo que hablaba de un destino nacional a la mejor manera de Spencer. También fueron muy célebres las posturas de Laureano Gómez (1988), quien se refirió no solo en sus discursos, sino en casi toda su obra, a la realidad y el futuro del país.

Con la profesionalización de la academia y la llegada de las interpretaciones multidisciplinarias, el Estado fue analizado con nuevas ópticas teóricas; ya no se trataba únicamente de la visión expuesta, sino también de cuestionar la organización histórica, mirar la participación de nuevos actores sociales y movilizar estructuras interpretativas sobre hechos sociales. Marxistas, seguidores de la Escuela de los Annales, historiadores, sociólogos, antropólogos y politólogos inspirados en Weber, Tilly, Elías, etc., comenzaron a confeccionar un discurso sobre la construcción del Estado colombiano.

Hésper Pérez (2007), por ejemplo, comparó a Colombia, Argentina y México con el fin de mostrar cómo fue cristalizando el Estado moderno. Desde una perspectiva weberiana, Pérez consideró que el éxito del Estado estaba en la capacidad de cohesionar la población a través del monopolio legítimo de la violencia y la centralización del poder; asunto que según él, solo se logró en Colombia durante 
el gobierno de Rafael Núñez y la Regeneración, y se fortaleció finalmente, con la presidencia de Rafael Reyes (1904-1909).

Al referirse al periodo de la Independencia y posterior creación de los partidos políticos, el autor planteó que, "si bien las instituciones liberales funcionaron, estas lo hicieron en un circuito de un grupo reducido, las elites de los dos partidos, liberal y conservador, partido de honoratiores, que mantendrán su hegemonía a lo largo de la historia del país" (Pérez, 2007, p. 114). Cuando aborda la Regeneración, Pérez resalta a Núñez y Reyes, con el fin de explicar la transición política, desde una interpretación weberiana del Estado moderno, aunque como expone Múnera (2009):

Las relaciones políticas y militares durante las décadas ignoradas por Pérez le otorgaron la especificidad histórica al Estado colombiano, sin la cual las características teóricas terminan en un cascarón vacío que solo sirve para realizar adecuaciones normativas abstractas [...]. Los procesos políticos que vivió la comunidad que hoy es Colombia en el transcurso de estos años, construyeron trayectorias no lineales que ayudan a explicar la génesis del Estado, más allá de su adecuación al marco teórico utilizado (p. 15).

Con una perspectiva weberiana, Margarita Garrido (1983) plantea que la Regeneración pretendió construir un Estado centralizado y moderno, sin embargo, las dinámicas sociales y la dificultad para superar el caudillismo y gamonalismo, hicieron que dicho programa fuera lento y en algunos de los aspectos fracasara.

Garrido (1983) reconoce que la noción de cuestión estatal-nacional responde a tres elementos a saber y que son característicos de distintas sociedades latinoamericanas: "la unificación geopolítica; el logro de un proyecto económico que aparezca como vínculo de intereses nacionales; y la imposición de una cierta socio-nacionalidad" (p.1). Al referirse al primer elemento, considera la autora que la Regeneración fue la construcción de una unidad estatal nacional centralizada y por ello: 
Este aspecto busca la integración y centralización política administrativa de las regiones, sobre todo de las que están al interior de la frontera económica, con miras a fortalecer el Estado. También, busca reasumir los territorios, considerados como nacionales para confirmar en ellos la soberanía nacional de cara a otras Naciones. Este nuevo orden político implica la creación de un fuerte aparato estatal, burocrático y militar (p. 2).

En cuanto al proyecto de unidad nacional, en su aspecto político y territorial, significó:

El intento de centralizar y fortalecer el control del Estado por encima de las regiones. Externamente significa reivindicar la soberanía sobre territorios escasamente poblados y marginados de las fronteras económicas, sociales y culturales del país. Reglamentar las fronteras geográficas frente a las naciones limítrofes y la soberanía nacional frente a la intervención extranjera (Garrido, 1983, p. 6).

Por su parte, el revisionismo liberal tuvo también un aporte ideológico y de método. Como se planteaba anteriormente, Germán Arciniegas y Nieto Arteta fueron los primeros en reconocer la participación del pueblo, sin embargo, este último se propuso reinterpretar los hechos en la historia colombiana focalizándose en las relaciones económicas como factor determinante para la configuración política. En su obra Economía y cultura en la historia de Colombia (1941), resaltó la participación de Gaitán y cuestionó la configuración del Partido Liberal; hizo mención al intento de revolución burguesa en el siglo XX y su trabajo tuvo una gran influencia del marxismo.

Estas publicaciones se enfocaron en los asuntos económicos que vinculaban al movimiento obrero y al campesinado con las luchas sociales, o en su defecto, pretendieron develar cómo la estructura del Estado, había terminado en manos de las burguesías decimonónicas y por ello mismo, la violencia manifiesta entre quienes reclamaban participación en el poder y quienes no estaban dispuestos a dejarlo. 
Después de 1948, cuando el Bogotazo y el periodo conocido como La Violencia, la izquierda orientó su análisis al estudio del movimiento campesino, concentrándose en el acceso y tenencia de la tierra como factor determinante de las protestas y levantamientos armados. De todas maneras, el problema central estuvo orientado hacia la economía y no precisamente a cómo estas acciones contribuyeron a la formación del Estado.

El determinismo económico se fortaleció aún más cuando se quiso analizar si se podría hablar de campesinado en Colombia, y si en el país hubo o no feudalismo, lo que permitió robustecer la tesis de un capitalismo relativo; dado que se mantuvieron estructuras feudales en una dinámica de capitalismo comercial. Por otra parte, la atención de los principales investigadores se centró en Boyacá, Santander, la Costa Atlántica y el Sumapaz, y en menor medida Cauca y Tolima ${ }^{17}$.

Uno de los principales análisis que sirvieron de guía para esta interpretación fue el propuesto por Eric Wolf (1975), para quien en América Latina, las movilizaciones campesinas estaban determinadas por la evolución de la Hacienda en el contexto de una economía agro-exportadora.

Para Wolf existen tres fases claves en el estudio de las protestas campesinas: 1) la vinculada con el proceso de expansión de la hacienda, en la cual se identifica la estructura social, económica y política de las zonas rurales y la expansión de la hacienda sobre el territorio cercano, absorbe a cultivadores pioneros e indígenas, quienes inicialmente abrieron la frontera para terminar siendo convertidos en trabajadores sin alternativa alguna frente al mercado. Durante este proceso se dan las luchas entre campesinos que defienden sus propiedades de la voracidad de la hacienda, e indígenas que pelean por sus tierras comunales contra terratenientes amparados en el derecho usurpado. La dinámica del conflicto está determinada por lo que Tovar (1980) clasifica como Frontera Abierta o tierras baldías o de indios

17 En la sección dedicada al estado del arte sobre la categoría colonización, se amplía este punto dado que los estudios en mención fueron influenciados por la tesis de Eric Wolf (1975) y se concentraron en estudiar los procesos de colonización para analizar el Estado. 
salvajes y Frontera Cerrada o tierras de resguardo o campesinos parcelarios, que terminan incrustadas dentro de la hacienda.

En la segunda fase, llamada también de consolidación y estabilización,

La hacienda coexiste con otras formas de producción, con nuevas empresas agrícolas las y no agrícolas más intensivas en capital y con una mayor ocupación de mano de obra asalariada en vez de trabajo servil no remunerado, creándose sobre las haciendas una presión del mercado de trabajo recién constituido. En esta etapa, la reacción principal no proviene de los indígenas o campesinos desplazados sino de los jornaleros y peones agrícolas que tratan de mejorar las condiciones de venta de su fuerza de trabajo en los latifundios. Se destaca en esta fase la tendencia a establecer alianzas con otros trabajadores organizándose en sindicatos obreros y la proclividad a afiliarse a partidos políticos (Bejarano, 1985, p. 274).

En la tercera fase, se evidencia la decadencia de la hacienda porque modifica su modus operandi, o porque se rompen las formas de sujeción laboral por factores políticos, económicos, o apertura de oportunidades en otros lugares. La disolución de la hacienda genera según Wolf (1975) tres tipos de protesta a saber: 1) La invasión de los terrenos, el apoderamiento de los terrenos por arrendatarios y advenedizos, y movimientos para que se redacten nuevos contratos laborales y se estipulen las condiciones de trabajo y los salarios que van a regir para operaciones específicas.

Este modelo de análisis se aplicó principalmente en el estudio del Café (Machado (1977, 1981), Kalmanovitz (1978), Palacios (2002), Tovar (1975)), pero la conclusión es que no necesariamente, la primera faceta de la hacienda cafetera tiene la característica descrita por Wolf (1975), pues la expansión y sujeción de mano de obra no se orientó principalmente hacia zonas de resguardo o de parcelas campesinas, y si lo hizo, estos optaron por la apertura de nuevas colonias, antes de enfrentar la maquinaria jurídica y hostigadora emprendida por los hacendados ${ }^{18}$.

18 Este caso se puede rastrear en la colonización del Eje Cafetero. Allí, los conflictos entre empresarios y 
En cuanto a la segunda y tercera faceta, los estudios se concentraron en las zonas donde la hacienda cafetera se cruzó con la conformación de agremiaciones campesinas (Sánchez, 1976; Bergquist, 2007), es decir en el Sumapaz, Tequendama y Tolima, donde se reclamaban mejores condiciones laborales y derechos sobre la siembra y precio del café, sin excluir claro está, derechos sobre la tierra aunque este punto no sea precisamente el eje central de los problemas ${ }^{19}$.

El punto culmen de la línea interpretativa fue en la década de los ochenta (Bejarano, 1985; Medina, 1994) y comenzó su declive hacia la de los noventa, dada la ausencia de un debate entre los académicos y otras razones tales como:

1. El Estado no siguió financiando con el mismo interés que lo hizo cuando creó la Comisión de Estudios de la Violencia20 (que por cierto fue el momento de mayor producción académica sobre problemas agrarios).

2. Las fuentes de financiación privadas no necesariamente están interesadas en estos campos de investigación, como sí, en el de las ingenierías o la salud.

3. La desmovilización de los principales grupos armados de izquierda suponía cerrar el principal problema del siglo XX, La Violencia y la participación política.

4. La emergencia y consolidación de nuevas líneas de análisis histórico como la llamada historia cultural e Historia de las mentalidades 21 y el rápido crecimiento de las ciudades, que terminó por desplazar población al campo, trayendo consigo nuevos problemas de investigación, que por cierto, adoptaron en las escuelas de sociología las cuales fueron las más interesadas, en un comienzo, en el estudio de la tierra y la violencia.

colonos llevó a que los más pobres, que no tenían cómo pagar un abogado o en su defecto, no sabían de los medios jurídicos para su defensa, buscaran nuevas tierras. Esto determinó que la colonización en las partes planas se hiciera por empresarios y colonos con capital y en la parte montañosa, la colonización se hiciera por campesinos pobres. Para profundizar, ver Cadena (2008), Londoño (2008).

19 Al respecto Bejarano (1985) plantea que si bien,"el punto en discusión aquí, obviamente, no es el de si hubo o no conflictos esporádicos y locales por la tierra antes de 1930 sino por qué se generalizan a partir de allí, en qué términos se generalizan y cuáles son las circunstancias que producen el viraje desde las reivindicaciones por las condiciones de trabajo hacia un cuestionamiento de la propiedad" (p. 276).

20 Esta comisión fue reunida en 1987 por el entonces Ministro de Gobierno del Presidente Virgilio Barco, Fernando Cepeda Ulloa (Sánchez, 1987).

21 En una crítica muy fuerte a la emergencia de las modas académicas, Bejarano sale en defensa de la Historia Económica, así como también defiende la Historia Política y cuestiona las nuevas formas colombianas de Hacer Historia, (Bejarano, 1997). 
Pero la crítica no solo llegaba desde los revisionismos; también la perspectiva institucionalista hizo sus respectivos aportes entre los que se pueden resaltar dos; la lectura de Paul Oquist (2010) con su Derrumbe parcial del Estado y la de Pècaut (1985) con su Disolución progresiva del Estado. Para Oquist, ese derrumbe parcial fue producto de una desarticulación de las instituciones judicial, militar y legislativa, contrario a Pècaut, quien consideró que el Estado se debilitó cuando no fue capaz de servir como mediador y terminó por ser controlado por organismos gremiales como la Andi y Fedecafé2 2 .

En cuanto a Oquist, la tesis propuesta es susceptible de crítica, puesto que el autor confunde gobierno con Estado, reduce La Violencia al enfrentamiento de dos partidos políticos y desconoce, al parecer, a otros grupos como los movimientos obreros y campesinos; sin embargo, el aporte principal tiene que ver con el diseño y aplicación de una tipología para las manifestaciones regionales de La Violencia, en la que se resaltaron asuntos particulares como las vendetas.

Evidentemente el problema central de Oquist es la violencia, pues su mirada apunta hacia la relación del orden con la capacidad militar, de allí que vea al Estado como un ente regulador de los conflictos y deslegitime cualquier fenómeno que al parecer podría ser visto como la incapacidad del Estado para legitimar su fuerza. Este análisis le permitió al autor organizar las posibles causas de la violencia resaltando: causas políticas, socioeconómicas, instituciones, psicológicas, culturales y raciales. Sin embargo, contrario a esta tesis, Pècaut (1985) considera que,

La violencia es consustancial al ejercicio de una democracia que, lejos de referirse a una homogeneidad de los ciudadanos, reposa en la preservación de sus diferencias "naturales", en las adhesiones colectivas y en las redes privadas de dominio social y que, lejos de aspirar a institucionalizar las relaciones de fuerza que irrigan la sociedad, hace de ellas el resorte de su continuidad"

22 Por esta misma línea, ampliando el punto de Pècaut están los análisis de Eduardo Sáenz Rovner (1993, 2002). 
(p.17) [De allí que este autor termine por considerar que] "la violencia es pues, a la vez, la representación y modalidad concreta de las relaciones sociales y políticas" (25).

De todas maneras, la perspectiva de Oquist tiene elementos claves para sostener la discusión a nivel internacional; recuérdese que Colombia fue considerado un Estado fallido después de ocupar el puesto 14 del ranking internacional del 2005, dado que "State collapse sometimes happens suddenly, but often the demise of the state is a slow and steady deterioration of social and political institutions"23.

¿Sigue vigente esta discusión? De acuerdo con la lectura que se hizo por la comisión de académicos encargada de reconstruir las causas del conflicto social armado en Colombia (Pizarro et al., 2015), evidentemente Oquist es un autor de mucha importancia, pues algunas posiciones básicas son sugerentes, por ejemplo:

1. "La maduración de las contradicciones sociales, al convertirse en conflictos violentos, fue condicionada por la reducción progresiva del poder del Estado colombiano.

2. [...] Colombia, en el siglo XX, se ha caracterizado por tener un Estado cada vez más fuerte dentro de una debilitada estructura social, mientras que en el siglo XIX la relación era de una fuerte estructura social con un Estado débil.

3. El colapso del Estado no tiene que ver con debilidad o abandono, sino que es "parcial", en significados claves: la debilitada es la estructura social en sus relaciones con el Estado; los conflictos internos de la clase dirigente han desencadenado esta situación; las hegemonías exclusivistas de partido contribuyen al "colapso", y

4. Algunas manifestaciones concretas de este derrumbamiento son: la quiebra de las instituciones parlamentarias, policiales, judiciales y electorales; la pérdida de legitimidad del Estado entre grandes sectores de la población y la utilización concomitante de altos grados de represión; la resolución de

23 Recuperado de: http://foreignpolicy.com/2009/10/22/the-failed-states-index-2005. 
los conflictos partidistas de forma sectaria; las contradicciones profundas dentro del aparato armado del Estado; la ausencia física de la administración pública en grandes áreas rurales y geográficas" (Pizarro, 2015, p. 12).

De todas maneras, la comisión considera que si bien son tesis sugerentes, no se comparten como explicación del conflicto.

\subsubsection{Interpretaciones interdisciplinarias del proceso formativo del Estado en Colombia}

Después de la crisis de los paradigmas marxista y funcionalista (Gouldner, 1979), pareciera que la investigación sobre el proceso formativo del Estado, hubiese sido relegada y perdiera su atractivo como objeto de estudio; sin embargo, en la transición al siglo XXI vuelve a llamar la atención.

El uso en algunos casos de marcos teóricos más flexibles como los propuestos por Tilly o Mann, han permitido que nuevos investigadores se acerquen a la problemática del Estado colombiano; algunos con intereses en las guerras, otros en la institucionalidad, en las leyes o en las mismas élites, los nuevos ejercicios investigativos resaltan la necesidad de un marco teórico, seguido de ello mencionan las alternativas interpretativas y finalmente, optan por la interdisciplinariedad. Este último punto es clave en la investigación, pues se reduce la posibilidad de forzar las fuentes y las interpretaciones no están sujetas a las teleologías; asunto que pareciera liberar estos estudios de la jaula teórica marxista o institucionalista.

Se resaltarán puntualmente tres autores: Fernán González, Luis Ervin Prado e Ingrid Bolívar; pues si bien, en la transición de milenio se pueden reconocer muchos análisis sobre el Estado, por cuestiones prácticas, es más fácil remitir a los estados del arte o compilaciones como la de Luis Javier Orjuela (2010), Leopoldo Múnera, Edwin Cruz y Nathaly Rodríguez (2009; 2011) o Fernán González, Ingrid Bolívar y Teófilo Vázquez (2003) que construir uno, pues la presente propuesta no pretende tal objetivo. 
En cuanto a Fernán González (1987, 1994, 1997, 2003, 2014), su trabajo es abundante y cada vez más crítico en relación con la configuración histórica del Estado colombiano; en toda su obra se puede identificar un ejercicio de ajuste a los marcos teóricos, la revisión de algunas posturas y una sutil filigrana teórica comienza a emerger, convirtiéndolo en un autor que pareciera estar en el diseño de un modelo de análisis para el estudio del Estado.

De sus publicaciones, se resalta el tránsito por el modelo weberiano, pero principalmente una influencia de Norber Elías y en sus últimas disertaciones, de Charles Tilly, Barrington Moore, Ernest Gellner, Michael Mann, entre otros. Por su parte, González ha dedicado un importante número de páginas para pensar la política y el Estado, y cómo su configuración histórica se ve cruzada por la acción de las élites, las burocracias, la Iglesia y la guerra, siendo esta última categoría una de las más importantes.

Para González, la formación del Estado moderno en Occidente responde a un proceso histórico y gradual de construcción o adquisición de atributos: tales como la centralización del poder político, la unificación del territorio, la producción de regulaciones generales y la monopolización del uso de la fuerza, a fin de ejercer una dominación sobre la sociedad y una regulación de sus conflictos. Estos atributos generaron la capacidad del Estado para integrar regiones y poblaciones, pactar con las burocracias locales, y crear y reproducir determinados patrones de relación social.

Sin embargo, en el caso colombiano, como plantea Orjuela (2010), tanto Leal Buitrago como González, comparten la tesis de que la política partidista, por su formación temprana, impidió una separación entre política racional y política venal, dando origen a relaciones clientelistas ${ }^{24}$.

24 Orjuela (2010) considera que: "Para ambos, [González y Buitrago] el resultado es una situación de fragmentación social que inhibe la capacidad del Estado para integrar la sociedad, monopolizar el uso legítimo de la fuerza y centralizar su función reguladora. La fragmentación social y primacía de los jefes políticos locales impidió, el desarrollo de una burocracia racional y facilitó el control de las instituciones públicas locales por intereses particulares, lo cual conduce al desplazamiento de las políticas generales del Estado por intereses parciales de la sociedad (p. 24-25)". Por su parte, María Emma Wills (2002) considera que, "En 
Con el fin de ampliar la discusión sobre el Estado, González publicó en el 2014 el libro: Poder y violencia en Colombia, pretendiendo que sus lectores se ubicaran en un contexto nacional, pero también internacional. Para tal fin, el autor construye una compleja discusión teórica con autores como Tilly, Mann, Gupta, Geertz, Moore, Skocpol, entre otros, para finalmente matizar la "concepción ideal del Estado como una realidad homogénea y claramente diferenciada de la sociedad, con pleno dominio sobre el conjunto de esa sociedad" (González, 2014, p. 18).

Con este objetivo, la obra de González pretende relacionar la violencia del presente, y el tipo de cristalización estatal colombiana, con los procesos históricos que relacionan burocracias locales y regionales, clientelismo, centralización política, problemas agrarios, etc., e insta al lector a que construya una relación global del Estado.

Esta obra, compuesta de ocho capítulos, aborda en la primera parte, la discusión sobre la formación de los estados en Europa e Iberoamérica, profundizando en las discusiones sobre si Colombia es o no un Estado fallido, y cómo se ha relacionado la guerra con las estructuras burocráticas centrales y locales, cuál ha sido el desempeño de los partidos políticos y cómo se ha transformado la violencia desde el siglo XIX hasta nuestros días.

Durante la discusión, el autor menciona la importancia de analizar la formación del Estado desde las particularidades de los procesos de integración social, territorial y política; pues "normalmente la formación del Estado tiende a ser concebida desde el centro y pasa por alto el análisis de la interacción entre las burocracias centrales y los poderes de hecho que existen o van tomando cuerpo en regiones y localidades" (González, 2014, p. 21).

Colombia, luego de la Independencia, entre las esferas política y cultural se produjeron disonancias, algunas veces matizadas, y en otras muy agudas: si por un lado las prácticas políticas promovieron la construcción de redes multiclasistas de tipo clientelista que permitieron la inclusión de los sectores populares al mundo de las pasiones y las componendas partidistas, por el otro, las representaciones culturales sobre la autoridad y el prestigio social promovidas por las elites político-intelectuales legitimaron una distinción entre política profana y gran política que justificó la exclusión de los otrora incluidos (p. 45)”. 
Contrariando las tesis del Estado fallido, el autor opta por hablar del Estado en construcción o de:

Presencia diferenciada de las instituciones estatales en el espacio y el tiempo, sugiriendo que las instituciones estatales tienden a comportarse de distinta manera, según sean las particularidades de las regiones y localidades, especialmente en consonancia con el grado y el momento de su integración en el conjunto de la vida nacional (González, 2014, p. 29).

Otro factor relevante es que menciona constantemente la necesidad de crear una visión multiescalar de la configuración del Estado, donde se pueda ver la interacción entre las regiones, las localidades y el discurso nacional, para así evidenciar cuál ha sido la participación de las instituciones estatales, cuál ha sido el desempeño de los partidos políticos tradicionales y cómo las redes de poder local van adquiriendo dominio a través de las luchas electorales, las guerras civiles y los programas ideológicos articulados con el clientelismo.

También es importante resaltar que el autor dedica su atención a la manera como las poblaciones interpretan y se acomodan a las reformas estatales y sus particularidades. Es por ello que:

El análisis de la sociogénesis de los preconceptos sobre la Política y el Estado se convierte en parte integral del proceso de construcción simbólica del Estado y de la política para mostrar su carácter histórico. Este criterio nos lleva a superar las concepciones un tanto apocalípticas y catastrofistas, que buscaban aplicar a Colombia las caracterizaciones de Estado fallido o a punto de colapsar, pero también las visiones más recientes sobre la captura o reconfiguración mafiosas del Estado (González, 2014, p. 28).

En la segunda parte, González pretende analizar la trasformación de la violencia y con ella, del Estado. Para tal fin, se remonta hasta la Colonia, analizando las implicaciones de las reformas borbónicas y las tensiones regionales a comienzos de la República. Posteriormente, hace referencia a la conflictividad por la tenencia 
de la tierra y cómo la cuestión agraria se fue transformando hasta adquirir un tinte político-militar, acogido en el discurso de las guerrillas de mitad de siglo.

En este análisis, el autor estudia las transformaciones del conflicto con la modernización del país, y cómo esto se relacionó con el periodo de La Violencia, la emergencia del paramilitarismo, la expansión de la guerrilla y los acercamientos entre los gobiernos y los actores armados en un largo periodo que abarca las administraciones desde Betancourt hasta las del presidente Juan Manuel Santos.

En lo relacionado con la historia regional, las interpretaciones propuestas por Luis E. Prado $(2005,2007,2012,2013)$ pretenden ampliar la discusión sobre la relación entre la guerra y el Estado. Influenciado por Charles Tilly, Prado revisa la Guerra de los Supremos en la Provincia del Cauca, y finalmente centra su análisis en las redes de poder, las formas de reclutamiento y la relación entre el Estado central y las burocracias locales.

Para lograr tal fin, el autor hace un análisis pormenorizado que le permite al lector identificar cómo se configuraron las provincias en la Guerra de los Supremos, especialmente las provincias surorientales (provincias de Pasto, Popayán, Cauca y Buenaventura) y las nororientales (provincias de Pamplona, Socorro y Vélez) concluyendo que este fenómeno supera la interpretación tradicional de guerra civil por la evidencia de prácticas militares y bélicas más de corte patrimonialista que civil.

Por otra parte, el análisis de Prado permite una caracterización de las regiones mostrando cómo su configuración responde a un archipiélago político regional, gestado a partir de las redes de poder local, basadas en alianzas económicas, familiares, clientelistas, etc., que explican en buena medida la reacción de las provincias contra el gobierno central en la guerra (Prado, 2005).

Este análisis es de suma importancia porque permite evidenciar cómo se configuran las redes de poder local, que si bien, se trata de asuntos militares, no discrimina 
su estrategia de la que se pretende exponer en nuestro análisis cuando entremos a revisar los vínculos familiares y las maneras en que se desarrollaba la actividad política local.

En sus últimas publicaciones, Prado (2014) ahonda más en la idea mencionada, permitiéndole al lector acercarse a la vida de los actores influyentes en la Provincia del Cauca. Lo relevante de este artículo es que muestra la transformación de ciertos personajes en notables o principales en el Valle del Patía, y cómo este enclasamiento se mantiene hasta el siglo XX. Para tal fin el autor indaga "las características y valores presentes en ellos, los cuales les otorgó legitimidad en sus comunidades" (p. 243) y opta por llamarles "jefes naturales, metáfora con la cual pretende englobar el sentido de autoridad que encarnaron por fuera de las conceptualizaciones que sobre el poder local se han hecho, sin tener en cuenta su contexto sociocultural" (p. 243).

En nuestra conciliación teórica y de fuentes documentales desarrollada en las conclusiones, sostenemos que es fundamental para comprender la formación del Estado en las regiones, el reconocimiento del pacto entre el Estado central y los poderes locales y quizá por ello, la permisividad conservadora del siglo XX con los desmanes y la corrupción de las burocracias a nivel local. Por su parte Prado, y de allí la importancia teórica y metodológica de su lectura, sostiene que el Estado republicano "apeló a ellos [jefes naturales llamados en nuestra investigación, actores de la colonización que controlaron el campo político] para encargarlos de ejercer los cargos públicos y el control sobre las parroquias y sitios de donde eran originarios, desenvolviéndose como intermediarios culturales entre el gobierno y sus comarcas e institucionalizando su poder" (p. 243).

Podríamos entonces coincidir en que, tratándose de la guerra o la colonización, el Estado central para lograr la centralización pactó con los grupos locales un poder representativo del mismo; aunque este poder pudiera en muchos casos, salirse de las mismas manos del Estado. En este sentido y como se preguntaría Weber criticando las burocracias, su profesionalización y autonomía, “¿Cómo es posible en presencia de la prepotencia de esta tendencia hacia la burocratización, salvar todavía algún 
resto de libertad de movimiento individual en algún sentido?" (Weber, 1944, p. 1075). Consideramos que la presión social llamada en nuestro trabajo, práctica política es la respuesta a Weber y por allí mismo, las pistas para comprender la configuración histórica del Estado.

En cuanto a Ingrid Bolívar (2003, 2004, 2006, 2010), en su interpretación del proceso formativo del Estado sostiene que hay múltiples maneras de gestación, aunque como expone Mann (1997), no se podría negar que existe una paulatina centralización y monopolio de la violencia física. Es por ello que Bolívar (2003) considera necesario advertir y estudiar las formas diferenciadas en que se producen los esfuerzos centralizadores del Estado; pues estos son mediados, tramitados, y

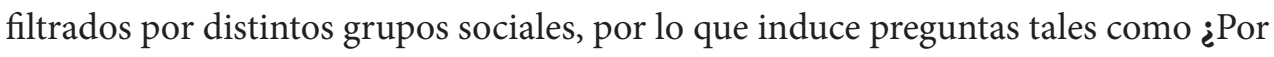
qué la sociedad colombiana es tan "exitosa” en su resistencia contra los esfuerzos centralizadores? ¿Cuáles serían las estrategias para enfrentar los procesos de centralización? ¿Es deseable el monopolio de la violencia?, etc.

Siguiendo de cerca esta propuesta interpretativa surgen dos elementos claves; 1) no se debe discutir si la concentración del poder o la constitución del monopolio de la violencia son deseables para todas las sociedades sino que se registra como regularidad, como pauta relacional en distintas experiencias; y 2) tales dinámicas de concentración y monopolio son definidas por condiciones particulares de la sociedad. En ese sentido, la exitosa resistencia de la sociedad colombiana a una dominación centralizada no corresponde a una esencia, ni es un atributo natural, sino más bien a la presencia de condiciones particulares que tienden a profundizar el rechazo (Bolívar, 2003).

Dado que la formación del Estado está inscrita la violencia, esta emerge como un fenómeno particular y por ello nos podemos preguntar por el orden político que se está configurando en las regiones donde la dominación no es formal e inmediata y donde el Estado central enfrenta la resistencia o competencia de otros grupos sociales y de otros actores armados. De esta manera, la violencia no se piensa como un fenómeno "exterior", o "posterior" al Estado, ni como su disfunción y límite, sino 
como un momento particular de ciertas relaciones sociales "interiores constitutivas" del ordenamiento social que el Estado tiende a representar.

Para Bolívar, Colombia es una sociedad desconectada en muchos sentidos. Esta desconexión se fortalece aún más cuando se estudia el territorio, el cual permite abrir grietas de escapatoria a los procesos de regulación social (colonizaciones, amiguismo, huidas, tierras salvajes, crisis económica, incapacidad militar, infraestructural, lingüística, de valores).

Es por ello que estudiar el proceso formativo del Estado exige relacionar los vínculos entre violencia política y construcción de la Nación. Para ello la autora propone identificar y discutir los hábitos de pensamiento predominantes que se han producido y mantienen vigencia al definir la Nación; asunto que obliga una identificación y lectura del nivel predicado por el actor social a través de preguntas por la identificación de ciertos grupos sociales a la Nación colombiana y el nivel más estructural, es decir sociogenético, "que tiene que ver con las condiciones de interdependencia social que hacen posible la emergencia de esa forma particular de comunidad que es la nación" (Bolívar, 2004, p. 73).

Siguiendo esta misma línea de análisis, la autora considera que hay categorías que dificultan la comprensión entre violencia política, formación de Estado y política regional, por lo que se hace necesario hacer una "biografía de los conceptos" (Bolívar, 2006); asunto que teóricamente nos ayudaría a dilucidar los ítems mencionados; por lo que es fundamental recordar que el conocimiento que tenemos del Estado,

No recoge la experiencia política regional, si no es entendiéndola como "en tránsito", como una política que va o debe ir hacia algo más moderno, más "integrado" al Estado nacional; [...] radicaliza la diferencia y se aproxima a la experiencia política de los colonos, los ribereños o de los pobladores urbanos pobres como un caso de diferencia cultural y La ansiedad por el camino de la "estatalización" -nos hace ver si la gente está "integrada" o no al Estado, si el Estado ha "logrado" o no penetrar la sociedad regional, si ahora los lazos 
políticos son "más modernos"-, [entonces], ni por el camino de la celebración folclórica o del realismo mágico - ese que nos hace creer que los ribereños son tan únicos o los costeños tan auténticos en la política- podemos comprender el sentido que la política tiene para varios de los grupos regionales y los actores sociales concretos (p. 94).

Estas propuestas interpretativas de Bolívar, nos permiten identificar elementos claves para nuestro trabajo: como primero, la importancia de reconocer los procesos de centralización del Estado, aunque resaltando que estos procesos son parte de un ejercicio pactado más que impositivo; el segundo factor tiene que ver con la necesidad de reconocer en las regiones, los autonomismos pero también, la aceptación de una estructura estatal y como último, la importancia de superar las rígidas definiciones teóricas con las cuales se estudia el Estado, aunque esto no quiere decir que no sean útiles.

Con estos planteamientos podría decirse que el Estado colombiano, a pesar de

Los esfuerzos centralizadores, tanto en términos del control de territorios como de poblaciones, ha encontrado serios obstáculos y resistencias de tipo geográfico, político, cultural y económico, los cuales generan, "espacios vacíos" donde "la posibilidad de consolidar el monopolio de la violencia se desperdiga, se desparrama en las manos de grupo sociales particulares. Por ello el Estado colombiano se ha caracterizado por su incapacidad histórica para integrar el territorio nacional y establecer el monopolio legítimo de la fuerza y de la producción de regulaciones. La capacidad estatal para mediar y canalizar los conflictos y las tensiones sociales es reducida. Éstos son resueltos al margen de las instituciones públicas, lo cual es la causa del surgimiento de diversas expresiones de "parainstitucionalidad", tales como los grupos privados de justicia y defensa, las mafias del narcotráfico, los movimientos guerrilleros y la economía informal, una de cuyas más recientes expresiones es el surgimiento de formas ilegales de captación de dineros del público, conocidas como "pirámides" en el lenguaje popular (Orjuela, 2010, p. 31). 


\subsubsection{Conciliando las tesis del proceso formativo del Estado: una propuesta interpretativa}

De acuerdo con lo revisado, ¿cómo podría construirse una interpretación del proceso formativo del Estado colombiano? Es evidente que todas las propuestas presentadas tienen una perspectiva susceptible de aceptación o crítica; algunas de las lecturas muestran una rigidez teórica que no permite ver los intríngulis naturales de los procesos históricos, otras, en especial las últimas, por recurrir a marcos teóricos flexibles, identifican nuevas variables o en su defecto, se dan el gusto de interpretar las fuentes con interpretaciones nuevas y reveladores.

Como vimos en este segundo capítulo, desde el siglo XIX se viene discutiendo la configuración del Estado pero los análisis han deambulado no solo en escuelas teóricas, sino en posturas políticas afines a la crítica o ensalzamiento del Estado, y no precisamente, con la búsqueda de una interpretación más amplia y conciliadora de su proceso formativo.

En el siglo XIX, por ejemplo, las interpretaciones centraron su atención en el diseño de una institucionalidad, resaltando la participación de los héroes de la Independencia y ocultando o desconociendo la participación de la sociedad civil. Por otra parte, estas interpretaciones giraron en torno a asuntos legislativos y militares, y los fenómenos relacionados con el conflicto fueron interpretados como disfuncionales. En el siglo XX, esta historiografía política pretendía construir un discurso que calara en toda la Nación; de allí que la historia del Estado colombiano girara en torno a las transformaciones institucionales.

Con la llegada de las academias de historia, la historiografía del Estado colombiano reconoció la participación de otros actores y 'el pueblo ‘ fue analizado posteriormente por la izquierda y el revisionismo para ensalzar movimientos y acciones colectivas mostrando la mezquindad de las élites políticas. En el siglo XX, las interpretaciones hechas por extranjeros abrieron un debate académico con relación a si el Estado era o no fallido, especialmente cuando se pretendió revisar su proceso formativo a la luz 
de la teoría weberiana, destacando el militarismo, pero desconociendo la capacidad de las poblaciones y sus burocracias para pactar y construir nuevas formas de relacionarse con el centro.

Finalmente hemos visto cómo la discusión sobre el Estado y su proceso formativo vuelve a las agendas académicas, pero en esta ocasión, los análisis son más generosos y propenden por una interdisciplinaridad y el uso de marcos teóricos relacionales que permitan reconocer la capacidad del centro para controlar las periferias, pero también, las estrategias de estas para mantener sus autonomías o pactar con ese control central.

De acuerdo con esto, y pretendiendo desarrollar un marco interpretativo acorde a nuestro interés, este trabajo recurre a la tesis de las cristalizaciones poliformas del Estado propuestas por M. Mann dado que no exige focalizarse en una variable, sino que considera la guerra, la economía, los movimientos sociales, las acciones colectivas, etc., como variables emergentes y de ello depende no una, sino muchas formas para estudiar el Estado ${ }^{25}$.

Como complemento a esta interpretación general del proceso formativo del Estado, recurrimos a la propuesta de González (2014) quien considera que para el caso colombiano, esa formación es multiescalar, puesto que responde a una interacción entre regiones, localidades, gentes y discurso nacional. Producto de este encuentro, podemos evidenciar la configuración que adquieren las instituciones estatales, el desempeño de los partidos y la importancia de las redes de poder local, tanto institucional-burocráticas, como de los grupos ubicados al margen del campo político.

25 Es importante mencionar que actualmente, no solo la sociología está interesada en los estudios sobre el Estado. La antropología, la historia, el derecho y la ciencia política, vienen diseñando interpretaciones amplias sobre las relaciones sociales y el Estado, las burocracias y el Estado, los movimientos sociales y el Estado. Para el caso colombiano, podemos mencionar los análisis de Serje (2005), Bolívar (2010), Múnera (2011), entre otros. 
¿Cómo articular la perspectiva de ambos autores? Como primera estrategia consideramos fundamental la identificación de un problema; en este caso, y siguiendo a González, la colonización en Colombia puede considerarse como un factor de suma importancia para entender la transformación histórica del Estado; puesto que durante los procesos de colonización a finales del siglo XIX, la ambigüedad jurídica y el débil poder central para regular la ocupación, tenencia y propiedad de la tierra propició el conflicto social.

De igual manera, González considera importante estudiar la interacción entre las burocracias centrales y los poderes de hecho que existen o van tomando cuerpo en regiones y localidades; este interés, junto con la interpretación de Mann del funcionamiento de las burocracias, nos permite fortalecer la propuesta de investigación dado que la colonización y sus conflictos, son un espejo que refleja la interpretación del deber ser del Estado y las prácticas en el sentido de Bourdieu, usadas por los agentes o instituciones con el fin de controlar un campo de poder, etc.

Pero como no solo se trata de interpretar las relaciones entre burocracias, sino profundizar en la acción de los individuos pertenezcan o no a los campos burocráticos; como segunda estrategia se recurrió al uso de la categoría práctica política, para reconocer la participación en el proceso formativo del Estado de los grupos ubicados en las márgenes del campo político.

Con el fin de alcanzar este objetivo, se propuso el análisis de la transformación del ámbito jurídico relacionado con la tierra, teniendo presente que esta transformación fue producto no solo de la acción de las burocracias centrales, sino también, de la presión social manifiesta en la creación de redes de apoyo para planificar acciones y repertorios de protesta contra otros colonos, o en su defecto, denunciar arbitrariedades de las burocracias locales.

A continuación se abriría la discusión de las dos siguientes categorías centrales, es decir colonización y práctica política, para finalmente proponer un modelo de análisis con el cual se pretende confrontar los capítulos III y IV, los cuales tienen 
un importante componente empírico con el cual se pretende justificar la respuesta al interrogante que guía la investigación. Esta conciliación entre teoría y datos empíricos se hará en el capítulo V llamado conclusiones.

\section{2.¿Cómo se ha discutido teóricamente la categoría colonización?}

Si el estudio del Estado ha sido abordado por corrientes institucionalistas y revisionistas, el análisis de los proceso de colonización también ha estado sujeto a marcos interpretativos e intereses de los investigadores. Gran parte de la producción académica ha pretendido ajustar los hechos sociales a modelos teóricos, o en su defecto, han construido hipótesis interpretativas, que basadas en el chovinismo regional, relacionan la precariedad o éxito de las colonizaciones con el tipo de población migrante, o las relaciones entre el centro y las periferias; en este sentido, ¿Cómo podríamos comprender la colonización?

Según el diccionario de la Real Academia de la Lengua, colonizar es "formar o establecer una colonia en un país" (RAE, 2014); sin embargo, como plantea Parsons (1961), este concepto puede ser confundido con el de poblamiento, que si bien, responden al mismo acto, su diferencia radica en que poblar es establecer una colonia sin dirección gubernamental; -como por ejemplo: aquellas primeras poblaciones hechas por negros cimarrones o personas consideradas delincuentes durante la colonia o los primeros años de la república-+-, y colonizar, es poblar y crear labranza como un acto dirigido por empresarios o medianos campesinos que tiene la característica de estar avalado por unas leyes que garantizan la ubicación en un espacio, sea este baldío o por Cédula Real obtenida desde la Colonia.

Para el caso colombiano se han planteado básicamente tres tipos o modelos de colonización:

- La colonización dirigida: Cuando el gobierno de un lugar o el Estado central, promueve la ocupación facilitando a través de normativas, la legalización de 
predios a los colonos o en su defecto, creado colonias como fue el caso de Boquía y Marmato.

- Colonización espontánea: Se entiende como aquella ocupación hecha en un sitio, comúnmente reconocido como baldío de la Nación por parte de campesinos, empresarios y especuladores, quienes se movilizan a la zona, mejoran el terreno para cultivarlo o venderlo a terceros y legalizan su ocupación por medio de notificaciones de un juez o funcionario público encargado de dichos procesos, $\mathrm{y}$

- Colonización empresarial: Relacionada con la especulación y promoción de ocupaciones en un territorio que se entiende como privado, por lo que deben fundarse pueblos, crearse vías y valorizarse las otras tierras cercanas a la gran propiedad de la empresa; este es el caso de la mayoría de las ocupaciones en el Quindío y Caldas, con empresas de fomento y colonización como Burila, González Salazar \& Cia., entre otras (Parsons, 1961; López, 1979; Vélez, 2002; Londoño, 2002).

Autores como Bert Helmsing (1981) consideraron que la colonización respondía a unos hechos históricos y unas temporalidades, por lo que propuso dividir el proceso en varias etapas: la colonización durante la Colonia; la colonización oficial; la colonización fomentada por empresas privadas; la colonización espontánea; la colonización de los años cincuenta durante La Violencia y la colonización hacia el suroriente del país en 1970 y 1980.

Para Helmsing la colonización espontánea se relaciona con las fundaciones hechas por colonos con el fin de erigir un nuevo poblado o traer una decisión judicial a su favor. En cuanto a la colonización dirigida, el objetivo es valorizar, comercializar y evitar posibles conflictos con personas que han penetrado la zona montañosa de una hacienda o se encuentran cerca, por lo que el propietario prefiere crear una nueva población antes de iniciar un litigio largo y costoso.

Ahora bien, aunque los estudios sobre la colonización tienden a confundir conceptos como poblamiento, colonización y frontera, es importante hacer referencia a la perspectiva de Jaime Londoño, quien utiliza el modelo de Richard Morse (patrón 
archipiélago) para explicar el poblamiento surcolombiano. Para Londoño (1996), en el caso de los espacios vacíos o despoblados al norte del Suroccidente colombiano, "la ocupación se efectuó desde las áreas pobladas durante la dominación española ubicadas en Antioquia, el valle del río Magdalena y el valle geográfico del río Cauca" (p. 138-139), y por lo tanto la colonización en Colombia, a diferencia del caso de los Estados Unidos, es una búsqueda de la centralización del poder, es la búsqueda del encuentro entre las regiones.

Estas dos definiciones de colonización permiten ajustar con facilidad el problema de investigación y las categorías propuestas pues durante el periodo de estudio, la colonización así fuese espontánea, dirigida o empresarial, tuvo la presencia manifiesta del Estado para regularla; de allí la emisión de normativa como se verá en el siguiente capítulo.

Veamos a continuación cómo se ha estudiado la colonización en la historiografía colombiana, para finalmente conciliar una propuesta interpretativa que se ajuste a la investigación.

\subsubsection{Aproximaciones a los estudios sobre la colonización. Rastreando sus definiciones en la historiografía colombiana}

Aunque existe un amplio número de investigaciones que abordaron los problemas de la colonización en Colombia, no necesariamente hubo una articulación entre los procesos colonizadores, las prácticas políticas y la construcción del Estado; quizá la principal razón se relaciona con el planteamiento de Alexander Betancourt (2007), para quien la historiografía colombiana, dependiendo del momento histórico, ha escogido unas líneas de investigación y unos objetos de estudio, mas no necesariamente ha logrado hacer un debate en torno a un problema ${ }^{26}$.

26 Con una visión más crítica, Bejarano decía que la investigación en Colombia responde a las modas interpretativas; después de agotada la moda se abandonan los problemas (Bejarano, 1997). 
Es por ello que al usar al campesinado como objeto de estudio, los análisis se hicieron principalmente desde tendencias revisionistas y por ello, aparece como un actor político perseguido ${ }^{27}$ de una clase dominante que impide su libre desarrollo y progreso material. Obviamente, no se tuvo presente que estas hipótesis son limitadas si se estudian casos como el del Quindío ${ }^{28}$ o en las fronteras del Amazonas, Caquetá, Putumayo, entre otros, (Ramírez, 2001). Al parecer, la relación entre colonización, prácticas políticas y formación de Estado no se ha establecido.

En cuanto a los marxistas, a pesar de preciarse de críticos, no analizaron la práctica política como creadora de Estado, sino que expusieron las relaciones de dominación y convirtieron a los campesinos y trabajadores en víctimas del sistema gubernamental. Entonces ¿Qué caracteriza la producción académica sobre la colonización? y ¿Cómo se relaciona esta con la formación del Estado y las prácticas políticas?

En términos generales, las publicaciones sobre la colonización tienden a ser historias-relato (Londoño, 1996, 2008; Betancourt, 2007), que remiten a la gesta de hombres aguerridos y no precisamente a sus problemas latentes o manifiestos. De todas maneras, hubo un grupo de académicos que alcanzaron a alejarse un poco de estos criterios y pusieron de manifiesto la conflictividad de dichos procesos. Entre las publicaciones más representativas están las de James Parsons (1961), Catherine LeGrand (1984, 1988), Christie Keith (1986) y Margarita Garrido (1983).

\footnotetext{
27 Betancourt (2007) plantea que hacia mediados de los años setenta, la producción historiográfica se caracterizó por: "el cuestionamiento de la Historia Tradicional [que] se hizo a partir de la transformación de la escritura de la historia como una labor de historia social. Se entendía por tal, el ejercicio de narrar la historia de las clases pobres. Esta tendencia acrecentó la fuerte relación entre la escritura de la historia social y la narración de las protestas y los movimientos sociales. [...] Al respecto los miembros de los grupos de izquierda colombianos no fueron ajenos y se ve cómo temáticas propias de la cuestión política coyuntural como el tema de la tierra y la cuestión indígena, serán fundamentales para la determinación del accionar político de esos grupos" (p. 146).

28 La crítica se puede rastrear en estudios como los de Keith Cristi (1986), quien al analizar la Violencia en el Quindío, puede ver cómo esta permite el ascenso al poder político y económico de un nuevo grupo social, conformado principalmente por antiguos apareceros, mayordomos, etc., y no precisamente los personajes políticos tradicionales. Igualmente el trabajo de investigación de Carlos Miguel Ortiz (2007) permite ver cómo en el caso del Quindío son los mayordomos y campesinos que se organizan en cuadrillas, quienes terminan por controlar el comercio del café, en detrimento de las clases dominantes tradicionales.
} 
En cuanto a Parsons (1961), su importancia para la historiografía de la colonización radica en ser pionero en estos estudios, así como también, introducir un modelo de análisis usado por un importante número de académicos de Antioquia, Caldas, Quindío, Risaralda y el Valle del Cauca. Como tesis planteó que la colonización antioqueña se debía considerar como el primer movimiento migratorio en Colombia que rompió la frontera agrícola. Al profundizar en la obra de Parsons, se pueden exponer dos aspectos centrales:

1. El autor logró resaltar la importancia de estudiar la colonización para comprender cómo se estructuró el Estado nacional durante el siglo XIX, exponiendo un proceso de poblamiento que fue organizado cronológicamente y planteando como objetivo central: analizar la ocupación de los espacios por parte de los antioqueños $y$,

2. Por ser un estudio geográfico, las minucias descriptivas y el uso de nuevas fuentes hizo que su obra fuera un texto de consulta obligatoria para iniciarse académicamente en el tema; sin embargo, la manera como fue recibida su obra, generó la publicación de nuevos ejercicios sin mayor crítica, claridad en los conceptos y con interpretaciones incorrectas de los procesos de poblamiento en Colombia.

De acuerdo con Londoño (2002), la crítica principal a la obra de Parsons es referirse a los procesos de colonización desde una perspectiva pasiva y mecánica ${ }^{29}$, esto sin contar con que su influencia llevó a que otros autores (Santa, 1993), no solo olvidaran a los colonos que no llegaron de Antioquia, sino que desconocieron completamente la importancia del conflicto para estudiar la formación del Estado.

29 Para Londoño: "La apropiación del modelo de colonización propuesto por James Parsons puede definirse de pasiva. Su aplicación puede catalogarse de mecánica. Este planteamiento se fundamenta en dos razones. La primera, producto del olvido o, mejor, de no tener en cuenta en el diseño de las investigaciones el concepto articulador (frontera) de la obra del geógrafo norteamericano. Esta noción no es explícita en el texto de Parsons; es implícita y está asociada con la propuesta esbozada por Frederick Jackson Turner para analizar el caso del desplazamiento hacia el Oeste en los Estados Unidos.

La segunda razón, es la forma como los historiadores colombianos han utilizado el modelo. En su uso han omitido las "particularidades" de los procesos estudiados. De esta manera, la historiografía colombiana contribuyó a validar la idea de un proceso de colonización hegemónico, donde la ocupación e incorporación de las tierras baldías de los departamentos de Risaralda, Quindío y de las estribaciones cordilleranas en el departamento del Valle del Cauca es parte de la colonización antioqueña” (Londoño, 2002, p. 213). 
En cuanto a Catherine LeGrand $(1984,1988)$ y Keith Christie (1986) la colonización tuvo un sinnúmero de matices que la hicieron violenta y no rosa como lo había expuesto Parsons. Para Christie la colonización en Colombia tuvo varios procesos, pero en el caso antioqueño hacia el Viejo Caldas, puede decirse que fue el más famoso, el mejor documentado y tal vez el más importante en Colombia.

Su estudio acepta la ruta colonizadora propuesta por Parsons alejándose de la visión romántica de los campesinos que derrotaron a los latifundistas en su búsqueda de tierra y seguridad en la frontera semi-tropical y escarpada. También es importante resaltar que su trabajo está dividido en dos partes; en la primera analiza el proceso de ocupación del Viejo Caldas y en la segunda hace un estudio de La Violencia, resaltando la movilidad social y el cambio en las élites gobernantes en el territorio ${ }^{30}$.

Para LeGrand (1984, 1988), en la colonización de los territorios colombianos siempre estuvieron presentes los colonos, empresarios, terratenientes y en menor medida, el Estado, quien lo hizo con la publicación de leyes de tierras. Otro aspecto que debe ser resaltado de sus artículos y obras, es que desvirtúa tanto la leyenda rosa de la colonización, como la creencia que solo los antioqueños iniciaron la ampliación de la frontera agrícola después de la independencia; para ello, trae debates tan complejos como el proceso de construcción del Estado moderno colombiano.

En cuanto a la metodología usada, se resalta el buen uso de las fuentes documentales, principalmente los litigios que se adelantaron en las diversas regiones del país donde había procesos de colonización. Igualmente hace balances estadísticos sobre la concentración de tierras y los expone en mapas que acompañan su investigación, aunque no puntualiza en aquellos casos en los que la colonización se legitimó por los representantes del Estado y falló a favor de los colonos. Un aspecto importante es que LeGrand hace una ruptura con la tesis planteada por Parsons y que legitimaron autores como Santa.

30 Esta tesis sobre movilidad social y política de las élites durante la Violencia está bien desarrollada por Carlos Miguel Ortiz (2007). 
Para Garrido (1983), la importancia de colonizar las zonas de frontera tiene que ver con que

Las instituciones estatales están dirigidas en primera instancia a ser los mecanismos de acción política y control de ese poder en el espacio restringido marcado por las fronteras económicas y de mayor densidad demográfica. Pero en segunda instancia, el poder debe tratar de reasumir todo el territorio jurídicamente reconocido como nacional para poder darle a este reconocimiento un respaldo real. Esta reasunción se hace con tres movimientos principalmente: a) la conquista y colonización que vayan ensanchando la frontera agrícola y demográfica de una parte, b) la adecuación de los medios de control del Estado para establecer su presencia en todo el territorio y c) los tratados y convenios internacionales sobre límites, comercio, aduanas, manejos de recursos naturales, etc., que deben atender a defender la soberanía nacional (p. 11).

Un elemento a resaltar es la referencia al conflicto, pues los autores mencionados no hacen un seguimiento a los procesos como tales, y si bien es cierto, mencionan algunos casos en los que se manifiestan movilizaciones sociales, no profundizaron en las mismas. Será para las investigaciones de finales de los años 1980 y comienzos de 1990, cuando el nudo comienza a desenvolverse abriendo camino a los estudios regionales.

De esta línea se resaltan los trabajos de Olga Cadena (1988), Hermes Tovar (1995) y Juan Carlos Vélez (2002). En cuanto a Cadena, se enfocó en la Historia Empresarial, específicamente en la colonización del Quindío y actual norte del Valle del Cauca planteando que no se trató únicamente de un proceso de poblamiento espontáneo, sino que fue un poblamiento dirigido por empresarios experimentados.

Cadena resalta varios aspectos tales como: la ineficiencia de algunos representantes del Estado para velar por los derechos de los campesinos de la región que afrontaron la avanzada empresarial y la ilegalidad de sus acciones. Igualmente el trabajo logra desvirtuar la idea sobre los antioqueños como únicos empresarios, pues si 
bien la empresa era dirigida por ellos, quienes habían iniciado el proyecto eran principalmente caucanos y el hecho de tener antioqueños en su dirección radicaba principalmente en el interés de Lisandro Caicedo, principal accionista y fundador, de no tener que enfrentar pleitos relacionados con tierras.

Otro aspecto importante es que la autora se refiera a las relaciones entre colonos que tienen poder adquisitivo y político con quienes no lo tienen, y cómo después de solucionado el problema con la empresa Burila, se inicia otro entre los mismos habitantes del pueblo por el control de las tierras. Hay que resaltar que Cadena propone este último problema como propuesta de investigación para alguien interesado en profundizar sobre los conflictos de la colonización.

En el caso de Tovar (1995), la colonización está vinculada a la tenencia de la tierra, dado que parte de esta se convirtió en un recurso fiscal para el naciente Estado Republicano con el fin de pagar a quienes estuvieron participando en las batallas de la Independencia. Además de esto, algunos baldíos fueron destinados como instrumento para fomentar la inmigración extranjera al país; para ello se crearon normas que regulaban el número de plazas que podría tener una persona, esto con el objetivo de evitar la acumulación, así como también programas de fomento como la entrega de caminos y peajes a quienes quisieran construirlos.

Plantea el autor que a mediados del siglo XIX el afán de modernización llevó a que el Estado usara los baldíos ya no únicamente como un medio de pago sino también como un enganche para la ampliación de la red vial (nuevos caminos y vías férreas); por tal motivo se hizo la Ley 7 , de mayo de 1845, que estipulaba que cuando algún individuo o compañía:

Quisiere construir a su costa algún camino, canal, puente o calzada, el poder ejecutivo se hallaba autorizado para conceder un cobro de un peaje durante 50 años, hasta 8.000 fanegadas de tierras baldías por cada legua de camino o canal que se construyera y, para cada familia que se asentara en las partes despobladas de los caminos nacionales, hasta 60 fanegadas de tierras baldías, 
a orillas o en las proximidades de esos caminos, para que las cultivaran y residieran en ellas (Tovar, 1995, p. 54).

Al comienzo y hasta mediados del siglo XIX, el Estado se dedicó a entregar baldíos para ocupar el interior; posteriormente su preocupación se centró más en regular los procesos de apropiación y dirimir los conflictos que comenzaron a presentarse por razones de la titulación de estas tierras. En vista de las corrientes migratorias, el Estado promulgó la Ley 70 de Julio 4 de 1866 que ordenaba formar un Catastro de baldíos con sus recursos. El interés de la Nación era ubicar los bosques que contuvieran quinas, goma elástica, bálsamos, palos de tinte y demás maderas de exportación y otros productos vegetales. Sería con la ley 61 de junio 24 de 1874 con la que marcaría un hito en la legislación agraria colombiana ${ }^{31}$.

Otro elemento interesante es que para Tovar (1995) no necesariamente las leyes se crearon para favorecer a un grupo determinado de pobladores, sino más bien que "el conflicto entre los portadores del capital y de recursos y aquellos que no disponían sino de su fuerza de trabajo caracterizó los desbalances y las concentraciones en la apropiación de los baldíos" (p. 148); en este sentido, según la zona se podrán encontrar casos de mayor democratización o en su defecto, de concentración de la tierra.

De acuerdo con Tovar (1995), la colonización implica conflicto y por ello mismo, las acciones tomadas por los colonos pueden ser vistas como prácticas políticas; es por ello que:

\footnotetext{
31 La principal característica de esta ley es que regulaba los procesos de apropiación de tierras acentuando la defensa de los derechos de los trabajadores u ocupantes previos a los intentos de acaparamiento o de petición de concesión y legalización. Se pretendía dar protección a los ocupantes previos a cualquier programa empresarial; hecho que se manifestó constantemente en la Cordillera Central y en zonas de colonización empresarial. En el año de 1882 se legisló una nueva norma (Ley 48 de agosto 28 de 1882) que pretendía regular con mayor ahínco el funcionamiento de la propiedad rural, sin embargo esta norma no fue de mucho bien para los colonos pobres que no tuvieran con qué pagar una asesoría. En el capítulo tercero se ampliará este asunto.
} 
En un universo con tantos actores, era hasta cierto punto lógico que se presentaran estas desavenencias. Cultivadores, comisiones agrarias, agrimensores, cabildos municipales, gobernaciones y empresarios actuaban para regular y, en esencia, precisar límites. Deslindar y adjudicar era el fundamento de la vida de esta sociedad que no cesaba de debatir y reclamar sus derechos. Se desarrollaba una lucha por fijar un lindero, por colocar unos mojones, por precisar hasta dónde iban los derechos y las posesiones de unos y otros. Éste era el eje de la cuestión agraria en el siglo XIX en estas fronteras (p. 180).

En el caso de Juan Carlos Vélez (2002), su estudio, Los pueblos allende el río Cauca, establece una relación entre la construcción de caminos y el poblamiento de los sitios por donde se tenía que pasar; para lograr su análisis se vale de preguntas tales como ¿Qué trayectos se privilegiaron? ¿Cómo se inició la articulación e integración del espacio antioqueño con la construcción de estos caminos? ¿Qué sectores sociales intervinieron? ¿De qué manera la construcción de caminos generó procesos de colonización?

El estudio menciona la construcción de vías de comunicación, el flujo demográfico, la creación de redes mercantiles, la instauración de autoridades administrativas, la difusión expansiva de discursos y la aplicación de dispositivos de control social; igualmente se estudian fenómenos como la guerra, delimitación espacial y procesos de delimitación hacia el río Atrato ${ }^{32}$.

En su trabajo aborda la noción de control, entendido como el conjunto de actividades que despliega el Estado para lograr un orden determinado a través del registro, conteo, ubicación, expropiación y regulación de las gentes y los recursos. También menciona la frontera, entendida como el área de transición entre lo conocido y lo desconocido, como muro que se erige para la defensa, como puente que facilita los

32 Con esto se trata de afirmar que Antioquia logró cohesión espacial y cultural a partir de la toma de conciencia de la importancia estratégica del suroeste, ubicado, precisamente, en un punto intermedio entre Medellín y el Atrato, entre Medellín y el vecino Estado de Cauca (Vélez, 2002, p XXIV). 
intercambios, como un espacio que es discontinuo, movedizo y no permanente que invita a penetrar y a no detenerse, que está vacío y puede ser ocupado ${ }^{33}$.

De acuerdo con lo planteado surgen los siguientes interrogantes: ¿Cuál es la importancia de estas investigaciones en relación con el problema de trabajo que nos compete? ¿Qué cabos sueltos dejan estas investigaciones para que sean abordadas posteriormente?

Como primero, estos trabajos son ejercicios académicos que cumplen con un modelo de investigación, proponen una hipótesis y se valen de una metodología que da credibilidad a sus conclusiones. Ahora bien, del trabajo de los pioneros se puede resaltar que la ausencia de una crítica a los sucesos acaecidos durante las migraciones, permitió formular nuevas tesis en las que se expuso cómo dichas colonizaciones estuvieron inmersas en el conflicto; por otra parte, al exacerbase las confrontaciones, se optó por plantear la tesis del terrateniente vs el campesino desposeído, aspecto que no necesariamente tuvo ese criterio.

Producto de esto emergieron los estudios regionales que mostraron que las dinámicas de poblamiento variaron de acuerdo a la región que se estudiara; sin embargo, dejaron abiertas nuevas problemáticas como por ejemplo: la relación entre el conflicto, la acción política social y la formación del Estado. Otro elemento que se resalta es que no se profundizó en la historia económica que podría dar respuesta sobre la supuesta democratización en la entrega de lotes y ejidos a los colonos y ciudades nuevas, así como también, se dejó a un lado el seguimiento a la repartición de las tierras tras varias generaciones de haberse adjudicado un terreno ${ }^{34}$.

\footnotetext{
33 Vélez (2002) plantea que: "en la primera mitad del siglo XIX, el espacio ubicado en la parte meridional de la provincia de Antioquia, entre el río Cauca y la Cordillera Occidental, era un territorio periférico, marginal y desintegrado. Esta condición hacía del espacio un obstáculo para la integración espacial y demográfica de Antioquia, y para la proyección económica y política de la élite comercial de Medellín. Esta zona, no obstante, tenía una cohesión geográfica interna, determinada por la existencia de accidentes como el río Cauca y la Cordillera Occidental que lo circunscribían y delimitaban...Por su carácter de inhóspito y desconocido se constituyó en una frontera cultural, de la que los habitantes de Antioquia tenían una imagen negativa, asociada a la de los lugares donde el hombre no había puesto su impronta "civilizadora"” (p. 16). 34 Un ejercicio interesante al respecto lo hizo Álvaro López Toro (1979), Lenis Ballesteros (2009) y Gärtner (2005).
} 
Hacer un seguimiento a estos problemas podría introducir una variable que relacione entre el número integrantes de una familia a quien se le adjudica un determinado territorio y la medición de este terreno adjudicado. Este elemento se usaría con el propósito de analizar las posibilidades de herencia sobre la tierra que garanticen no solo la propiedad de la misma para los hijos de los colonos, sino también la permanencia o migración buscando una propiedad privada. Ahora bien, si se mantiene en el territorio ¿quiénes atienden esa oferta de mano de obra?, probablemente la aparición de los arrendatarios y aparceros o nuevos migrantes colonos.

La caracterización de cada una de las modalidades de la colonización (espontánea, empresarial y estatal) es otra variable de importancia pues permite ver si hay imbricaciones o superposiciones entre ellas. Esto permitiría explicar la ocupación, rutas y comportamiento demográfico; por ejemplo, Jaime Londoño propone que se analicen las políticas de colonización impulsadas por el Estado y cómo variaron entre el siglo XIX y el XX.

Los resultados de estas políticas pueden estudiarse para evaluar las adjudicaciones individuales de terrenos baldíos y hacer un análisis pormenorizado de las concesiones a las colonias pobladoras. Con estas líneas de trabajo es factible preguntarnos ¿qué porcentaje de los terrenos concedidos a las colonias se entregó a los colonizadores? Allí tendríamos aspectos para revisar como por ejemplo, la evolución de la propiedad privada en un espacio donde abundaron los especuladores y acaparadores de tierra, invasiones a baldíos, etc.

Lo clave de estas propuestas analíticas es que nos permiten reconocer y discutir las prácticas e instituciones que traían los colonizadores. Por ello podemos preguntarnos ¿cuáles eran las instituciones sociales que habían construido los actores participantes del proceso de ocupación en esta región de frontera?, ¿quiénes controlan las estructuras de poder (económico, político, religioso, cultural, social) en la región y cómo lo ejercen?, ¿cómo se forman las estructuras de dominación y cómo se ejerce? 


\subsubsection{Conciliando las interpretaciones de la colonización para identificar una guía analítica}

Después de revisar las perspectivas generales sobre los estudios de la colonización, podemos organizar esta producción académica en dos grandes bloques y estos a su vez, en sub grupos que abarcan desde historias locales hechas por personas públicas, hasta estudiantes y profesores universitarios. De igual manera, estos estudios han tenido enfoques apologéticos como también teóricos, que van desde visiones geográficas hasta sociológicas; en este sentido ¿Qué perspectiva, es la más acertada para definir la categoría y las respectivas subcategorías de esta investigación?

Como primero, considerar la colonización desde la perspectiva de Garrido (1983) nos permite identificar el interés del Estado por regular el territorio, de allí su interpretación de la Regeneración y de las políticas públicas desarrolladas para ocupar los baldíos. En esta misma línea está la interpretación que hace Londoño (1996), al describir el territorio como un archipiélago, pero también reconociendo que la ocupación de estos espacios intermedios fue una estrategia gubernamental.

Ahora bien, que la ocupación fuera conflictiva como lo presenta LeGrand (1984) no quiere decir que el Estado fuera débil o fuerte, más bien podría interpretarse como algo intrínseco a la configuración del Estado colombiano (González, 1987, 1994, 1997, 2003; Bolívar, 2004, 2006, 2010 y Leal Buitrago, 2010). Esta perspectiva de la colonización, como lo presenta Tovar (1995), pone en evidencia a un Estado interesado en institucionalizar el proceso, sin embargo, por la ambigüedad de las leyes y tratarse de zonas de frontera, el conflicto tendía a exacerbarse, en ese sentido, ¿Cómo se entiende la frontera en esta investigación?

La frontera puede comprenderse desde dos perspectivas: 1) la antropológica y económica, y 2) la histórica y sociológica. En cuanto a la primera, se entiende por frontera, aquellos lugares "opuestos a la civilización, [que representaban] la anarquía y el caos frente al orden de racionalidad [y que por su naturaleza eran hostiles en ciertos paisajes] como las selvas, la alta montaña, las ciénagas o los manglares" (Serje, 2005, p. 116); pero que después de 1850 "pasaron a ser tierras baldías o públicas 
pertenecientes al gobierno local o nacional [que], con el aumento de la demanda por productos de zonas templadas o tropicales en el mercado mundial [...] y con la extensión de redes de transporte, [...] comenzaron a adquirir valor económico [pero también se convirtieron] en válvula de escape que permitía aminorar tenciones entre terratenientes y campesinos" (LeGrand, 1984, p. 14).

En cuanto a la segunda, se entiende por frontera "una zona de interpenetración entre dos sociedades previamente definidas, [en la cual son] las características geográficas del área [las que] determinan los límites de la actividad humana" (Raush, 1999, p 17); igualmente, la frontera puede ser comprendida básicamente "como um desdobramento da teoria da expansão territorial do capital" (Martins, 1996, p. 48), en la cual, esta expansión territorial del capital es conflictiva, pone en juego el tema de la propiedad de la tierra, y atenta a la sobrevivencia de diferentes sectores sociales.

En este sentido, y tratando de hacer una paralelo entre las dos definiciones, podríamos decir que: la frontera es un espacio vivo de interacción entre grupos humanos y naturaleza, donde se difumina lo legal (escrituras públicas, Policía, Ejército, proyectos económicos) y lo ilegal (delincuencia, poblaciones anteriores a los edictos de colonización, persecución y desplazamientos), en la cual se cruza lo que López Toro (1979) llamó la lucha entre el hacha y el papel sellado y se abre paso el lugar de la alteridad con el proceso civilizatorio. La frontera también muestra cómo el Estado pretende legitimarse, posicionándose como el único garante de seguridad y orden, pero que en su mismo camino, arrastra consigo el conflicto, haciendo de ella un caldo de cultivo para el choque entre diferentes actores.

De acuerdo con esta interpretación, volvamos al párrafo previo a la definición de frontera, para retomar las consideraciones de Tovar y LeGrand.

Podríamos decir que ambas posturas son interesantes; sin embargo, una relectura del proceso ajustada a la tesis de la cristalización poliforma del Estado (Mann, 2006) nos permite considerar dos asuntos; el primero, es que evidentemente hay un interés 
de intervención estatal ${ }^{35}$ para regular el conflicto, pero la pretensión de soberanía característica de los Estados de derecho (Zagrevelsky, 2011), pone en evidencia una desarticulación de las lógicas sociales de construcción de realidad, con las supuestas lógicas verdaderas amparadas en el derecho, es decir, mientras se emitía normativa para aclarar ¿De quién es la tierra?, la cotidianidad del campesino era hacerse propietario de un terreno a través de la palabra. Entonces no es únicamente en la frontera donde se inicia el problema, es más bien en la cultura de propietario donde quizá comienza a gestarse la evolución del conflicto ${ }^{36}$.

Por otra parte, no se trata de un Estado débil como lo presenta LeGrand, más bien que el Estado no es una institución despótica como diría Mann (1997), sino que su cuerpo está históricamente filtrado, pactado, acomodado a las necesidades de los grupos vencedores y transformados en nuevas élites; como también está ajustado a las disposiciones de aquellos que se ven afectados directa o indirectamente con la normativa emitida, es decir: el Estado no necesariamente es producto de su autonomía, y la reacción de los afectados por las disposiciones legales genera conflicto; por ello su capacidad gerencial (de los afectados y del Estado), determina la forma como cristalice (González, 2014).

A continuación, demos paso a la discusión de la categoría: práctica política.

\subsection{La práctica política como categoría de análisis: aproximaciones a su definición}

Tratándose de una investigación que pretende contribuir con los análisis del proceso formativo del Estado, consideramos fundamental reconocer que su cristalización histórica no es única y uniforme sino variada; en términos de Michael Mann, el Estado es un embrollo, de allí nuestro interés por usar su teoría.

35 Este punto queda en evidencia en el segundo capítulo dedicado a la emisión de normativa sobre la tierra.

36 Esta hipótesis aventurada surge de la lectura de Palacios (2011). 
Por otra parte, pretendiendo fortalecer la interpretación sobre ese proceso formativo a la luz de un caso específico, recurrir a las interpretaciones propuestas por Fernán González nos permitió identificar que esa formación debe ser vista a la luz de las relaciones políticas entre actores y que dichas relaciones se materializan en contextos como las colonizaciones; lo que permite apreciar las tensiones históricas entre burocracias locales y nacionales durante los procesos de centralización estatal.

Ahora bien, autores como LeGrand, Londoño, Tovar, entre otros mencionados en el apartado anterior, nos facilitaron la identificación de los caminos para el análisis de la colonización, reconociendo que no es suficiente con revisar estas tensiones entre burocracias, sino que también es importante vincular en el análisis a los demás actores que están en las márgenes del campo político y que su acción contribuye también a ese proceso formativo del Estado.

Podríamos decir entonces que tenemos dos categorías de análisis abordadas: Estado y colonización, las cuales están entrelazadas y nos permiten hacer un contexto histórico-sociológico con el fin de poner en la mesa de discusión no solo las tensiones emergentes, sino también, la acción interventora de las instituciones.

Pero como no se trata únicamente de estudiar las tensiones burocráticas entre lo local y lo nacional, sino también reconocer la participación de otros actores en el proceso formativo del Estado, fue necesario recurrir a la categoría de práctica política, dado que esta nos permite abordar las estrategias de acción iniciadas por las burocracias nacionales o locales, así como también, las estrategias de los demás actores que estaban en los márgenes del campo.

Para tal fin se recurrió a los aportes de P. Bourdieu (2000), específicamente en lo relacionado con las prácticas y la teoría de los campos, que para esta investigación sería el campo político. En este sentido, ¿qué entender por campo político y cómo se relaciona con las prácticas políticas?

Bourdieu (2000) consideró que los asuntos políticos podían ser analizados desde la perspectiva del campo en el cual unos grupos de agentes, personas o instituciones, 
se reservan su dirección ${ }^{37}$. De acuerdo con él, este espacio o campo político también contribuye a la gesta del Estado, que finalmente es entendido como el gran campo de campos; pero debido a que el control del campo es producto de la disputa entre sus integrantes, quienes lo monopolizan también diseñan estrategias para legitimarse y deslegitimar a sus competidores, relegándolos a la marginalidad por no contar con los capitales (simbólico, económico, cultural, etc.) que garanticen una igualdad y reconocimiento. De todas formas, "se reconoce la presencia o la existencia de un agente dentro de un campo por el hecho de que transforma el estado del campo (o que cambian muchas cosas si lo retiramos)" (Bourdieu, 2000, p.15), asunto que se puede evidenciar a partir del capítulo IV cuando se analicen los efectos de la presión social en la transformación jurídica de la tierra.

Los conflictos relacionados con la tierra entre burocracias locales y nacionales; así como también, entre burocracias y colonos, o en su defecto entre los mismos colonos, es un reflejo de cómo se formaba el Estado en uno de sus ámbitos; especialmente cuando estos conflictos contribuyeron a la creación de normativa, es decir, a la regulación legal a través del derecho.

El otro factor clave en este análisis tiene que ver con la instrumentalización de las instituciones por parte de cualquier actor, individuo u organización que ubicado en el campo político, sea burocracia o esté en las márgenes del campo, movilizó a su favor el poder estatal; pues finalmente, como diría Bourdieu (2000),

Las luchas políticas son luchas entre responsables políticos, pero en esas luchas, los adversarios, que están en competencia por el monopolio de la manipulación legítima de los bienes políticos, tienen un juego común que es el poder sobre el Estado (que pone fin, en cierta medida, a la lucha política puesto que las verdades de Estado son verdades transpolíticas, al menos oficialmente $\left.^{38}\right)$ (p. 15-16).

37 La definición de campo se hizo en el primer capítulo a pie de página, por lo que se remite al lector a dicho capítulo.

38 Cuando el Estado pone fin a una disputa en nuestro caso, sea a favor o en contra del demandante, este fallo responde a la capacidad argumentativa de los actores del pleito; así como también a la instrumentalización 
¿Pero cómo llamar a estas estrategias usadas por los actores del campo? Nuevamente Bourdieu aporta al análisis la categoría de práctica, por lo que consideraremos, de acuerdo con los análisis hechos en las fuentes documentales, que tanto las burocracias como los demás actores de la colonización tenían unos saberes, pero especialmente, un saber sobre el saber-hacer en la política.

Este saber hacer, llamado aquí práctica no debe ser leído desde el sentido de la lógica sino del habitus, es decir, como un conjunto de esquemas construidos socialmente, a partir de los cuales los sujetos perciben el mundo y actúan en él; de allí que los colonos recurrieran a prácticas o estrategias aprendidas en experiencias previas a su llegada al Quindío

Es por ello que a través del análisis y caracterización de los conflictos durante la colonización, se identificaron dos grupos de actores que podían ser analizados a la luz de esta teoría interpretativa:

1. Los pertenecientes al campo político, agrupados para su comprensión en burocracias, empresarios y representantes de la población ante los agentes del Estado central, y

2. Las organizaciones sociales de los márgenes del campo, que representaban a los excluidos de las burocracias o del mismo campo por ser considerados contrincantes políticos o competidores por el acceso a un bien, sea este mueble o inmueble. También se tuvieron presentes los casos aleatorios en los cuales se evidenciaron movilizaciones individuales las cuales, a pesar de no obtener inicialmente el resultado esperado, después de 1930 comenzaron a reconocerse por el Gobierno entre los miles de casos similares ${ }^{39}$.

de los contextos regionales, nacionales e internacionales. En nuestro caso de estudio, como veremos a partir del capítulo tercero, el éxito en los pleitos estuvo determinado por la argumentación presentada por los actores y la capacidad de moverse en el campo político. Respecto a la instrumentalización de los contextos internacionales, ver: Tarrow (1994).

39 Al respecto revisar el subcapítulo 4.1.2. del cuarto capítulo, en el cual se pretende exponer la posición asumida por las burocracias centrales frente a hechos como estos. 
Con el fin de mantener la idea central de nuestro análisis nos formulamos la siguiente pregunta: ¿Qué influencia tiene en el proceso formativo del Estado las tensiones entre los grupos que están en el campo político y sus márgenes?

Como se mencionaba anteriormente, hubo un importante número de pobladores que fueron marginados del poder y convertidos en opositores o en su defecto, categorizados por las burocracias locales y contendores como invasores, delincuentes, ilegales, etc.; lo que deja en evidencia no solo una estrategia de instrumentalización jurídica en contra del opositor, práctica muchas veces efectiva; sino también una marginación del poder que de acuerdo con Offe (1984), generan la movilización popular.

Es por ello que una lectura en profundidad, desinstitucionalizada y libre de juicios de valor, nos permite ver en la reacción de los excluidos, la búsqueda de satisfacción a sus necesidades por las vías extra- institucionales, que en muchos casos, cruzan la frontera de la legalidad y con el paso del tiempo y las recurrencias, obligan al Estado a rediseñarse y adoptar sus peticiones en la política pública. Interpretando los efectos generados por la exclusión política y la reacción social, Estrada (2003) se pregunta:

¿No es esa misma marginación una decisión eminentemente política con efectos también en este orden? [Evidentemente], una concepción restrictiva y restringida de la política, obstaculiza la comprensión de los actores colectivos como actores políticos. El reto teórico y empírico consiste en dar cuenta de la existencia de lo político más allá de los límites formales e institucionales del sistema (p. 193).

Estas estrategias, tanto las usadas por empresarios, políticos y colonos reconocidos legítimos dueños de los bienes y las desarrolladas por las agrupaciones de colonos o acciones individuales se pueden enmarcar en lo que Max Weber (1979) llamó acción social, especialmente porque esta surge como producto de la relación social entendida como una conducta, por lo que se considera la probabilidad de que los 
individuos actuarán en una forma, con sentido identificable y por ello presentaran unas regularidades.

Este último factor llama la atención, pues para Weber, la regularidad de la acción, es decir, el desarrollo de una acción repetida por los mismos agentes o extendida a muchos, tiene la característica que su sentido es planificado y típicamente homogéneo; pensemos entonces en estrategias usadas por los colonos del Quindío para dirimir los conflictos durante la colonización: envío de derechos de petición, búsqueda de apoyo en personas públicas del pueblo (curas, concejales, viejos políticos retirados, militares), asociación de campesinos para elevar rápidamente su caserío a municipio y adquirir autonomía administrativa, etc.

Ahora bien, es importante resaltar que la identificación de estas características de la acción tiene dos vías: el sentido del tipo o detalle descriptivo de la acción y la conexión singular, susceptible de ser imputada y cargada con un destino; es decir, ganar el pleito y permitir a las burocracias y agentes del Estado establecer los intersticios de las normas que deberían ser revisadas y por lo mismo, ajustadas a los contextos.

Estas prácticas tiene otros elementos agregados que permiten dar pistas al problema, entre estos, el hecho de estar en el marco de la legitimidad, que en términos del Estado moderno es la legalidad u obediencia a preceptos jurídicos positivos; sin embargo, como es de suponerse, la acción social a la cual nos referimos tiene el tinte de 'lucha' en el sentido positivo, porque finalmente esta acción está orientada por el propósito de imponer una voluntad propia sobre otras y esto genera una resistencia de la contraparte la cual se materializó en distintos espacios de lo público-político: en lo legal, cuando el conflicto estaba en el marco de lo jurídicamente permitido, y lo ilegal, cuando el conflicto se desarrollaba con la violencia no considerada por la normativa: quemas, asesinatos, desplazamientos forzados, etc.

De acuerdo con lo expuesto, ¿por qué no se han reconocido las estrategias de los colonizadores como prácticas políticas no solo para ganar los pleitos, sino también como formadoras de Estado? La respuesta podría encontrarse en la misma génesis 
interpretativa del proceso formativo del Estado y de la categoría política, pues si se trata de un Estado liberal, la acción social se orienta a la construcción de asociaciones privadas que satisfacen las necesidades personales, y si se trata de un Estado benefactor e intervencionista, la ética de la solidaridad como uno de los fines del Estado, permite la identificación de esas necesidades sociales y actúa con el fin de resolverlas, incluso contra intereses de algunas minorías poderosas o de élite.

Esta consideración trae por efecto un desconocimiento de la capacidad gerencial de la acción social en la construcción del Estado, pues lo considera como un cuerpo autónomo y racional, asunto que en la primera parte se discutió y podría decirse, es susceptible de discrepancia. Por otra parte, creer que la historia institucional latinoamericana siguió al pie de la letra las tesis del liberalismo sería un engaño, pues se estaría desconociendo el mismo proceso histórico de cristalización estatal y los matices adquiridos en unas lógicas que Diego Eduardo López (2004) explica ampliamente en su libro, la Teoría impura del derecho.

El asunto clave es que la sociología clásica hizo una diferenciación entre lo que es el Estado o lo Institucional y lo considerado como social, reservando la categoría de lo político al Estado como lo había establecido la filosofía clásica, es decir, como un axioma que los equiparaba. De esta manera, cualquier acción política se relaciona inmediatamente con el ejercicio del poder institucional, enmarcado en las lógicas jurídicas y del quehacer cotidiano desde el escritorio gubernamental; sin embargo, Hannah Arendt (1997) fue más allá ampliando su uso y permitiéndose que la categoría política fuera parte explicativa de la acción. Esta consideración nos abre la puerta para exponer qué se considerará como política en el marco de las prácticas.

Pero volvamos a Weber para seguir ampliando la justificación teórica. Él reconoce que la política es un concepto amplio que abarca cualquier actividad directiva autónoma, pero finalmente es enfático en considerar que "por política entenderemos solamente la dirección o la influencia sobre la trayectoria de una entidad política, aplicable en nuestro tiempo al Estado" (Weber, 1979, p. 82). 
Evidentemente, la definición weberiana considera que la categoría política "se relaciona únicamente con el ejercicio de participación en el poder o posibilidad de influir en la distribución de éste, entre los distintos estados o el mismo Estado y hombres que lo componen" (Weber, 1944, p. 83).

Cuando se dice que una cuestión es política, o que son políticos un ministro o un funcionario, o bien que una decisión ha sido políticamente condicionada, lo que se quiere siempre decir es que la respuesta a esa cuestión, o la determinación de la esfera de actividad de aquel funcionario, o las condiciones de esta decisión, dependen directamente de los intereses existentes sobre la distribución, la conservación o la transferencia del poder. Quien hace política aspira al poder; al poder como medio para la consecución de otros fines (idealistas o egoístas) o al poder por el poder, para gozar del sentimiento de prestigio que él confiere dejando las puertas abiertas para que más adelante las teorías de la acción agregaran a ésta la condición de creadora de colectivos y servidumbre de herramientas para movimientos sociales. Aun así, la acción social no se transforma en acción política (Weber, 1944, p. 84).

¿Por qué considerar entonces que la acción es también política, y que la acción social puede ser vista como política? El principal problema se centra en la consideración de la acción más allá del hacer, como la realización de un algo para satisfacer necesidades; en este sentido la idea weberiana es interesante porque le adjudica una racionalidad, una planificación, una coherencia al hacer. Sin embargo, Weber desconoce lo político de la acción, siempre y cuando no esté en el marco del campo político $^{40}$.

Esta perspectiva entra en crisis con la interpretación de Arendt (1997) quien sublima la categoría de lo político. Para ella, y allí la importancia de la categoría, lo político

40 Recuérdese que el reconocimiento de los márgenes del campo politico y sus actores es producto de la interpretación amplia y ambiciosa de Bourdieu, junto con las nuevas tendencias analíticas del proceso formativo del Estado; puesto que en los análisis tradicionales del Estado, como se pudo evidenciar en la revisión historiográfica sobre la formación del Estado colombiano, los grupos de presión social fueron invisibilizados o en su defecto, victimizados, restándole importancia a su acción como constructora de orden social 
no está únicamente en el marco de lo institucional, más bien podría pensarse que lo considerado por la sociología, la filosofía y la ciencia política, es una degradación paulatina del concepto, pues, en la génesis del mismo, la política se relaciona con un mecanismo racional que solo se da entre hombres libres, pertenecientes a la polis y que a través de las vías racionales del diálogo, logran construir consensos para organizar la sociedad (Oro, 2008).

La sublimación del concepto le permite a Arendt considerar que la política no es precisamente exclusividad de lo institucional (de hecho, esta es antípoda en lo prístino de la categoría), sino que se trata más bien de un asunto de la capacidad humana para planificar racionalmente la búsqueda de un interés. En palabras de Arendt (1997):

Los prejuicios que en la crisis actual se oponen a la comprensión teórica de lo que sea propiamente la política conciernen a casi todas las categorías políticas en que estamos acostumbrados a pensar, sobre todo a las categorías entre medios-fines, que entienden lo político según un fin último extrínseco a lo político mismo; también a la presunción de que el contenido de lo político es la violencia y, finalmente, al convencimiento de que la dominación es el concepto central de la teoría política (p, 98).

El recurso interpretativo de Arendt facilita el uso de la categoría como auxiliar para comprender que la presión ejercida por los grupos de colonos del Quindío, tuvo un criterio político, así no estuvieran inscritos dentro de organizaciones consideradas como parte del campo político, es decir que se puede reconocer la importancia de las márgenes. Ahora bien, hay que resaltar que las estrategias durante el proceso de colonización fueron diversas, como se verá en los siguientes capítulos, combinando las interpretaciones clásicas con la arendtiana de la acción política; pues así como se pueden evidenciar las movilizaciones sociales en el marco de las lógicas institucionales (concejos municipales por ejemplo) también hubo presión violenta, que adquirieron su condición de políticas e hicieron parte de lo que consideraríamos, el proceso formativo del Estado. 
De acuerdo con esta breve presentación, en esta investigación se entenderán las prácticas políticas como las estrategias de acción que desarrollaron los actores de la colonización en el Quindío y que por la configuración y forma que adquirieron los conflictos, se convirtieron no solo en estrategias para alcanzar un fin premeditado, sino también en la justificación para que, a partir de 1930, los gobiernos liberales pusieran en la agenda de debate la necesidad de resolver los problemas generados por la ambigüedad jurídica de la tenencia, ocupación y propiedad de la tierra.

De todas formas, aunque esta argumentación esbozada pretende justificar el recurso de la categoría práctica política, podríamos preguntarnos, ¿por qué no hablar de acciones colectivas?, ¿acaso los repertorios mencionados, no pueden leerse con base en la discusión teórica de la acción colectiva?

Un elemento clave para responder esta pregunta tiene que ver con la importancia de evitar los anacronismos y errores interpretativos; pues si bien, se trata de acciones, la interpretación teórica exige ubicarnos en unas categorías y lógicas que muy probablemente, no se pueden identificar en el caso estudiado. Por otra parte, las acciones colectivas suelen presentarse en contextos de choque entre actores sociales y el Estado (Olson, 1965; Tilly, 1978; Tarrow, 1994; Touraine, 1997; García, 2013; Torres, 2007); asunto que riñe inmediatamente con nuestra propuesta, dado que el enfrentamiento no es precisamente contra el Estado, sino contra unas élites locales $\mathrm{u}$ otros actores similares; siendo la constante, una denuncia ante los organismos de control central, donde los querellantes se identifican con derechos adquiridos en el marco jurídico y argumentan que se les está vulnerando dichos privilegios ${ }^{41}$, por parte de unas burocracias que a nombre del Estado, menoscaban el interés público general.

Pero si abrimos el abanico interpretativo de las acciones colectivas, podríamos decir que no necesariamente van en contra del Estado (Garretón, 2002; Escobar, Alvarez y Danigno, 2001; Carrero y Naranjo, 2014; Burbano, 2014), por lo que esta categoría

41 Recuérdese que para Marx, los derechos del Estado moderno no son más que los privilegios del ancien régime (Marx, s.f.). 
es proclive a nuestro análisis. De todas maneras, ¿Cómo justificar teóricamente el enfrentamiento entre actores, que sin pertenecer al campo político, con sus acciones construyen también Estado? Esta inquietud es el motor para optar por otra categoría, que si bien podría ser repertorios de protesta, en su definición no alcanza a dar pistas para el reconocimiento de los hechos y estrategias como constitutivas del proceso formativo del Estado; por lo que el recurso de la categoría prácticas políticos, nos permite no solo resolver el problema teórico de la acción, sino también justificar por qué dichas acciones, sean o no pensadas como constructoras de Estado, finalmente cristalizan en normativa para legitimar o regular; asunto que puede leerse como construcción de Estado.

\subsection{Consideraciones generales del segundo capítulo}

El presente capítulo se dividió en tres bloques que pretendían abordar las categorías centrales y las respectivas subcategorías de esta investigación. Inicialmente se hizo referencia al Estado, trayendo a discusión cinco interpretaciones teóricas de la sociología con el fin de identificar las principales características de su proceso formativo.

Posteriormente se hizo mención a las obras de la historiografía colombiana sobre el Estado, identificando en ellas unas tendencias interpretativas que se relacionan con momentos de producción académica mundial e intereses políticos. También pudimos analizar las corrientes institucionalistas y las corrientes revisionistas que aportaron elementos claves tales como: el fortalecimiento institucional, la producción de legislación, la participación de las poblaciones y la relación entre los conflictos, la sociedad y el Estado.

Al finalizar el apartado se propuso conciliar las definiciones de Estado y construir una interpretación más propicia al interés de esta investigación, por lo cual, retomando la propuesta de Mann (2006) y la discusión de González (2014), 
consideramos que para estudiar el proceso formativo del Estado, es necesario tener presente la interacción entre el centro de poder y las periferias, incluyendo en esto, la participación tanto de las burocracias locales, como de la población o actores al margen del campo político.

Desde esta perspectiva se pretende analizar el Estado no solo como una institución autónoma y capaz de ejercer violencia y control en todo el territorio, sino como la sumatoria de instituciones materiales, culturales y simbólicas que con el paso del tiempo, se han ido cristalizando de acuerdo a las necesidades y la presión que ejerce, tanto la sociedad civil como las burocracias y con los contextos en los que tiene lugar.

Después de presentar la categoría Estado, y justificar una ruta interpretativa para el caso colombiano, abordamos la noción de colonización con el fin de discutir a la luz de varios autores cómo se había estudiado el poblamiento colombiano y qué relación podría tener con la configuración institucional y social del país. Durante la discusión se hizo mención a varios problemas susceptibles de ser investigados y que seguramente, aportarían al análisis del proceso formativo del Estado.

Al cierre de la categoría, se pretendió justificar cómo el estudio de la colonización permite adentrarse en el análisis del proceso formativo del Estado, identificando los conflictos y las transformaciones que este tuvo en el ámbito administrativo y jurídico. De todas maneras, es importante resaltar que la transformación de los conflictos fue producto de la relación entre las disposiciones gubernamentales y la respuesta de la población, por lo que se hizo necesario abordar una tercera categoría que diera pistas para analizar la interacción entre centro y periferia, y campo de poder y sociedad.

Esta tercera categoría es la práctica política, la cual se fundamenta en dos elementos claves: el primero tiene que ver con el reconocimiento de la acción política como prácticas ejecutadas por los actores de la colonización, que lograron controlar las instituciones del Estado a través de la participación como funcionarios y servidores públicos; el segundo elemento clave tiene que ver con la re-significación de lo 
político, relacionando la categoría no solo en el ámbito institucional, sino también, en la planificación de estrategias que persiguen un objetivo específico.

Esta última consideración nos pone frente al tercer elemento relevante de la categoría, y es que las prácticas políticas, hechas en el marco de la institucionalidad o por fuera de ella, contribuyeron al proceso formativo del Estado, al presionar sobre el diseño de una política pública por medio de las vías legales o ilegales de los actores inmersos en los conflictos.

A continuación se pretende presentar el capítulo III y IV, en el cual se hará mayor énfasis en los hechos que en la teoría, sin embargo se pretende que su lectura se haga teniendo presente las discusiones propuestas a la luz de las tres categorías centrales: Estado, colonización y práctica política.

De igual manera, es importante que se tenga presente que los conflictos durante el proceso de colonización vincularon varios actores al campo político; aunque algunos quedaran al margen de dicho campo y al parecer sus acciones no tuvieran parte en la configuración histórica del Estado colombiano. Al respecto cabe decir que fue más bien, producto de la acción y reacción social frente a la legislación y estructura jurídica sobre la tierra, lo que evidencia un tipo de cristalización estatal en Colombia, por lo menos, en lo que al ámbito jurídico en el uso de la tierra compete. 



\section{CAPÍTULO TERCERO: CONTEXTO}





\subsection{La dimensión histórica del Quindío ${ }^{42}$ : Estado, conflicto e instituciones en la colonización}

Para confrontar la propuesta teórica con los datos empíricos, este capítulo pretende abordar la relación entre los procesos de colonización en el Quindío entre 1880 y 1930 y la construcción del Estado. De acuerdo con esto, la distribución analítica gira en torno a dos bloques problemáticos: en el primero se hace una breve descripción del espacio territorial, las características que rodearon la dinámica colonizadora del Quindío y la relación con la política pública de tierras y poblamiento. En el segundo, se analiza cómo las limitaciones y ambigüedades normativas, determinaron la transformación de los conflictos por la tenencia, ocupación y propiedad de la tierra. Al finalizar, se hará una breve conclusión en la que se espera resaltar los principales elementos de la discusión, al tiempo que se presentarán los estudios de caso con los que justificamos nuestro planteamiento inicial sobre el proceso formativo del Estado y su relación con las prácticas políticas.

\footnotetext{
42 Hoya del Quindío o Quindío para nuestra investigación, comprende los actuales municipios de Alcalá, Armenia, Caicedonia, Calarcá, Circasia, Filandia, Montenegro, Pijao, Génova, Quimbaya, Salento, Sevilla y Ulloa. Este territorio forma una superficie [aproximada] de 3.170 kilómetros" que se reparten entre los actuales Departamentos del Quindío y Valle del Cauca. La ubicación espacial se establece en la parte occidental de la Cordillera Central que se prolonga en forma de media luna y de ella se desprende un lugar llamado "Páramo de Yerba-Buena", la empinada cuchilla de las Coloradas que se extiende hacia el Norte formando un semicírculo que va a morir frente a Cartago donde termina también la nombrada colina. Siguiendo el río La Vieja coge los límites de Sevilla para salir al río San Marcos y luego ir a buscar el Páramo de Barragán para finalmente coger la Cordillera Central en los límites con el departamento del Tolima (Valencia, s.f., p. 15).
} 


\subsubsection{El espacio territorial}

Entre 1880 y 1930, la geografía del Quindío se transformó a través de la migración y fundación de nuevas poblaciones; al respecto, como se vio en el capítulo anterior, hay una abundante producción académica que relata estos procesos de colonización desde diferentes perspectivas; sin embargo, el desarrollo de los conflictos no se ha relacionado con la formación del Estado, como tampoco, se ha pretendido estudiar la participación y desempeño que tuvieron cada uno de los actores inmersos en la colonización.

Por tal motivo, este capítulo pretende discutir la problemática partiendo de las siguientes preguntas: ¿Qué desempeño tuvo el Estado durante los conflictos de la colonización en el Quindío? ¿Las funciones y actuación de las burocracias locales y regionales estaban justificadas en prácticas venales, o eran funcionarios racionales en el sentido weberiano?, ¿Podría hablarse de prácticas políticas como guía interpretativa para analizar la organización de los colonos durante el conflicto? De igual manera se consideró necesario formular una premisa que sirviera de guía analítica, por lo que se planteó la siguiente:

No se trata de juzgar al Estado por su intervención durante los conflictos; tampoco se trata de comprobar que la burocracia estatal era venal o racional. Sin interés y mucho menos de defensa del Estado, se considera que este estaba -y aún está-, en un proceso formativo, por ello no contaba con una legislación agraria sólida que resolviera las disputas entre propietarios y colonos, especialmente cuando los primeros argumentaban un derecho real manifiesto en una escritura (¿falsa?, ¿verdadera?) y los segundos, sustentaban su derecho en la buena $\mathrm{fe}^{43}$, o en su defecto, en el incentivo gubernamental de ocupar baldíos.

43 A propósito de este asunto, Marco Palacios (2011) propone una posible respuesta en la disputa que puede haber entre la tradición cultural del concepto de propiedad y apropiación heredada del sistema jurídico español y la implementación del sistema de Código Civil Napoleónico. 
En cuanto a la venalidad de la burocracia, puede decirse que las prácticas gubernamentales cumplían más bien los parámetros descritos por Mann $(1997)^{44} \mathrm{y}$ presentados por Guillén Martínez (1996) quien consideró que en el caso colombiano era claro que el poder se había heredado desde la Colonia y durante la República se usaron estrategias como las alianzas, el compadrazgo, los matrimonios, etc., para conservarlo; este caso no es ajeno a nuestra zona de estudio ${ }^{45}$.

En vista de que estos procesos se desarrollaron en un contexto jurídico limitado y ambiguo, los actores de la colonización recurrieron a varias prácticas políticas que iban desde el recurso legal (demandas, denuncias públicas, litigios) hasta el ilegal (organizaciones armadas, quemas de bienes, cohecho, constreñimiento, extralimitación de funciones) con el fin de alcanzar sus objetivos.

\subsubsection{Migración en Colombia: el Quindío en la dinámica pobladora}

Comenzando el siglo XIX, el poblamiento en Colombia se caracterizaba por lo que Jaime Londoño (2008) denominó 'patrón archipiélago', pues la herencia de la Colonia había dejado un sinnúmero de poblaciones pequeñas y distantes, concentrando los principales núcleos poblacionales en cuatro áreas:

\footnotetext{
44 Mann (1997), considera que la burocracia se desarrolla racionalmente de acuerdo a sus prioridades dentro de la administración, sin embargo dependiendo el tipo de cristalización que tenga el Estado priman unas lealtades. De esta manera:

Los estados no establecen sus prioridades últimas entre funciones tales como la regulación de las clases, la centralización del gobierno o de la diplomacia. Los actores políticamente poderosos realizan la mayoría de las numerosas funciones estatales con el sentido pragmático, según la tradición y las precisiones del momento, y reaccionan con igual pragmatismo y precipitación a las crisis que los afectan a todos (p. 116).

45 Antes de la Violencia, el Quindío, Risaralda, Norte del Valle del Cauca y el mismo Caldas se caracterizaron por que sus élites gubernamentales no solo habían heredado el poder como lo describe Max Weber en sus formas de dominación, sino que utilizaron diversas estrategias para mantenerse con este. Puede verse su evolución como élites políticas y empresariales, así como también estrategias tales como el matrimonio, las alianzas, los amiguismos, los compadrazgos, etc. Siguiendo a Londoño (2003) se puede comprobar este tipo de fenómenos en el caso de la familia Caicedo y la Familia Arango de Caldas. Para los Caicedo es necesario mantener el control de la empresa Burila, por eso no solo se aseguraron de tener el mayor número de acciones dentro de la empresa, sino que la hija de Lisandro Caicedo termina como esposa de Marcelino Arango Palacio, primer gerente de la Compañía. Luego veremos a Arango Palacio encabezando la lista de gobernadores del posterior Departamento de Caldas (junio 24 de 1909 - agosto 22 de 1909).
} 
La altiplanicie cundi-boyacense y la hoya alta del Suárez, que conformaban la región oriental del país; en las áreas circundantes Pasto, Túquerres, Popayán y Cali, en el suroccidente colombiano; en el centro Antioquia; y en las regiones costeñas vecinas Cartagena, Mompox y Santa Marta (Melo, 1987, p. 127).

Durante mucho tiempo esta situación no varió significativamente ${ }^{46}$; más bien, como resultado de las guerras civiles y las crisis económicas se amplió la dispersión poblacional en detrimento de la urbanización y ocupación de las áreas vacías; por lo que podríamos decir que en medio de estos islotes habían grandes y espesas selvas con insignificante población dispersa, cruzadas por caminos muy difíciles de transitar que facilitaban la anomia política y la configuración de un Estado en el cual los poderes locales eran más fuertes que el mismo centro ${ }^{47}$.

Esta situación comenzó a cambiar finalizando el siglo XIX cuando el país inició una transformación reflejada en el crecimiento de la prole ${ }^{48}$, que junto con el agotamiento militar y económico de las élites regionales, demandó el diseño de un Estado capaz de apaciguar el caos político y poner en marcha un proyecto económico que resolviera la fragmentación interna y la crisis social ${ }^{49}$.

46 De acuerdo con Safford y Palacios (2002), el crecimiento poblacional en Colombia fue importante en el último cuarto de siglo, siendo el Cauca y Antioquia donde la cifra se elevó al 300\%, mientras el conjunto nacional crecía al $166 \%$.

47 Se podría decir que gran parte de la configuración política colombiana del siglo XIX y el XX, con todas sus estructuras formativas que permitieron la legitimación del caudillismo y el gamonalismo, responden a los procesos de poblamiento con que se inició la república. Al respecto ver Franco (s.f.), González (2006, 2014). Otra lectura relevante sobre las guerras y sus consecuencias en la población y la política en Jorge Villegas y José Yunis (1979).

48 En relación con el Cauca y Antioquia, Carmen Elisa Flórez y Olga Lucía Romero (2010) plantean que: "Este mayor crecimiento poblacional de la región [hizo] que, entre 1835 y 1898, solo Cauca y Antioquia ganen población en detrimento de los demás estados. Cauca pasa de tener el 13\% a albergar el 19\% de la población del país. Por su parte, Antioquia pasa de tener un 10\% al 15\% de la población. Por el contrario, las demás regiones, y especialmente Bolívar, Magdalena y Santander pierden importancia. Es evidente que la dinámica demográfica de la región Antioquia-Cauca determina el crecimiento demográfico del país durante la segunda mitad del siglo XIX" (p. 406).

49 Este objetivo, impulsado por la Regeneración, implicó reformas de tipo administrativo, económico, poblacional, entre otras; de allí el cambio de la Constitución en 1886, la centralización del poder político, la remoción de las burocracias tradicionales por otras afines al proyecto. 
Tabla 4: Distribución poblacional en el siglo XIX

\begin{tabular}{|c|c|c|c|c|c|c|c|c|}
\hline & & & & & & & & Población \\
Estado & $\mathbf{1 8 3 5}$ & $\mathbf{1 8 4 3}$ & $\mathbf{1 8 5 1}$ & $\mathbf{1 8 6 4}$ & $\mathbf{1 8 7 0}$ & $\mathbf{1 8 8 7}$ & $\mathbf{1 8 9 8}$ & $\mathbf{1 8 9 8} /$ \\
& & & & & & & & $\mathbf{1 8 3 5}$ \\
Antioquia & $10,10 \%$ & $10,50 \%$ & $11,60 \%$ & $12,40 \%$ & $13,50 \%$ & $14,20 \%$ & $14,80 \%$ & $47,35 \%$ \\
Bolívar & $11,30 \%$ & $9,60 \%$ & $8,70 \%$ & $8,90 \%$ & $9,10 \%$ & $9,20 \%$ & $9,00 \%$ & $-20,83 \%$ \\
Boyacá & $18,40 \%$ & $17,90 \%$ & $18,20 \%$ & $18,70 \%$ & $18,40 \%$ & $16,80 \%$ & $16,40 \%$ & $-10,95 \%$ \\
Cauca & $13,40 \%$ & $14,80 \%$ & $14,90 \%$ & $15,80 \%$ & $16,00 \%$ & $17,30 \%$ & $19,10 \%$ & $42,82 \%$ \\
Cundinamarca & $16,30 \%$ & $15,40 \%$ & $15,20 \%$ & $16,10 \%$ & $15,30 \%$ & $15,00 \%$ & $15,10 \%$ & $-7,43 \%$ \\
Magdalena & $3,90 \%$ & $3,40 \%$ & $3,20 \%$ & $3,60 \%$ & $3,30 \%$ & $3,10 \%$ & $3,20 \%$ & $-19,25 \%$ \\
Santander & $16,70 \%$ & $18,10 \%$ & $18,20 \%$ & $15,50 \%$ & $16,00 \%$ & $15,40 \%$ & $13,10 \%$ & $-21,05 \%$ \\
Tolima & $10,00 \%$ & $10,10 \%$ & $9,90 \%$ & $9,00 \%$ & $8,50 \%$ & $9,00 \%$ & $9,10 \%$ & $-9,21 \%$ \\
\hline Total (miles) & $\mathbf{1 . 5 7 1}$ & $\mathbf{1 . 8 1 4}$ & $\mathbf{2 . 0 9 4}$ & $\mathbf{2 . 4 4 1}$ & $\mathbf{2 . 7 1 3}$ & $\mathbf{3 . 6 6 6}$ & $\mathbf{4 . 1 8 3}$ & $\mathbf{1 , 7}$ \\
\hline Fuente: Flórez y & & & & & & & & \\
Romero, 2010, & & & & & & & & \\
\hline p. 404. & & & & & & & \\
\hline
\end{tabular}

Pero junto con el crecimiento poblacional se incrementó la presión sobre las tierras productivas, obligando a las nuevas generaciones a trasladarse hacia otros sitios $\mathrm{y}$ probar la suerte del colonizador. ¿Cuáles serían las zonas propicias? De acuerdo con varios autores (Parsons, 1996; Raush, 1999; Vélez, 2002; LeGrand, 2007; Lenis, 2009; González, 2014), las migraciones más importantes fueron hacia el occidente del antiguo Estado Soberano de Antioquia y el Estado Soberano del Cauca que comprendía el actual Chocó, y los actuales Caldas, Quindío, Risaralda y Norte del Valle; pero también hubo migraciones hacia el Oriente colombiano, en los actuales departamentos del Meta y Putumayo que eran administrados como Territorios Nacionales y la Costa Caribe; región de disputa significativa entre colonos y empresas nacionales o extranjeras como la United Fruit Company.

Ahora bien, con relación al Quindío, la colonización vista como parte del proceso formativo del Estado propone dos líneas de análisis relevantes: la primera se relaciona 
con la categoría de frontera desde la perspectiva de Serje (2005), LeGrand (1984) y Martins (1996), la segunda línea se relaciona con el conflicto por la ocupación, tenencia y propiedad de la tierra, dado que la ocupación inicial del Quindío sirvió como válvula de escape a la presión poblacional de Antioquia, Cauca, Cundinamarca y Boyacá (Londoño, 2008; Tobasuña, 2007) aunque trajera consigo las dinámicas de la colonización y posteriormente, con el incremento del número de familias en la región se manifestaran las mismas denuncias y enfrentamientos entre colonos, empresarios y políticos.

Podría decirse que el Quindío tuvo una transformación simbólica relevante durante la Regeneración, pues las tierras adquirieron un precio y valor ${ }^{50}$ comercial, político y militar que re-significó su existencia; a pesar de que gran parte del siglo XIX estuviera cruzado por el interés gubernamental de dominar la selva para resolver asuntos de movilidad interna y orden público.

Desde el gobierno de Bolívar, el Quindío representaba una ruta rápida entre el centro y el occidente, por lo que se propuso la construcción del Camino del Quindío o Camino nacional que iniciaba en la actual Cartago -población del norte del departamento del Valle-, subía hasta Salento (actual población del departamento del Quindío) y terminaba en Ibagué- Tolima, para posteriormente aprovechar el río Magdalena con el fin de ir hacia Bogotá o la Costa Atlántica (Cartagena o Santa Marta), aunque la dificultad para mantener en funcionamiento la ruta llevó a que constantemente el camino se malograra.

Fue por ello que el gobierno de Pedro Alcántara Herrán (1841-1845) promovió la fundación de Barcinales (1841), una población hecha con presos encargados de abrir la selva y mantener el camino. Posteriormente, durante la administración de Tomás Cipriano de Mosquera (1845-1849) se siguieron haciendo reformas administrativas con el fin de sostener la vía, hasta 1860, cuando estalló la guerra y Barcinales prácticamente quedó deshabitada.

50 Para una discusión sobre el precio y el valor, revisar el análisis de Eric Roll (2009), específicamente los capítulos del III - VIII. 
Mapa 1: Mapa de Salento y el Quindío

\section{MAPA 2. Camino del Quindio}
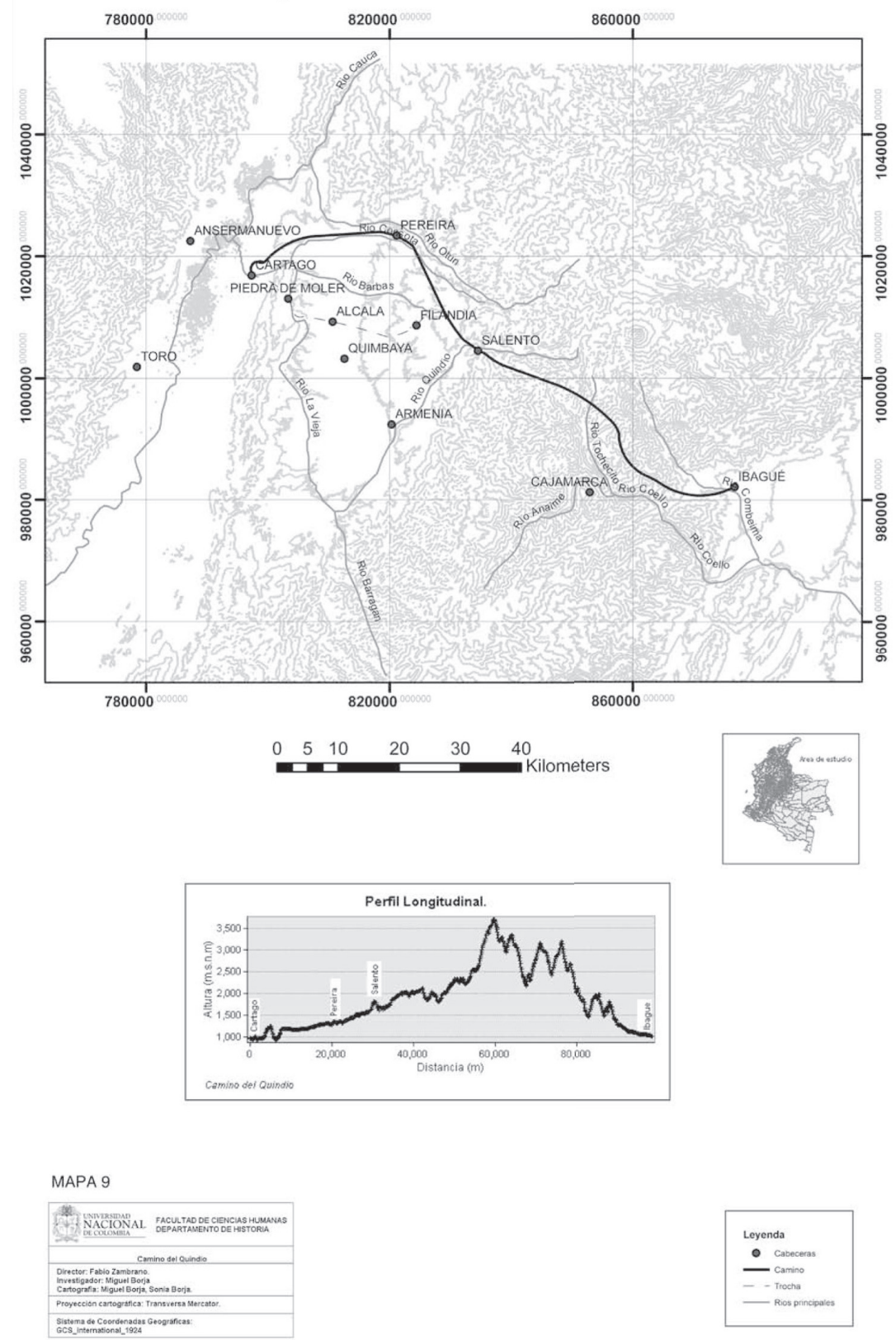
Hacia 1878, la Provincia del Quindío contaba únicamente con 6 distritos y 8 caseríos, manteniendo una baja densidad poblacional, entre otras cosas por la dificultad para acceder a las escarpadas y pantanosas tierras selváticas; aun así, las descripciones de algunos funcionarios del gobierno, consideraban que habría "altas posibilidades de crecimiento dado el empuje empresarial que presentaban sus gentes" ${ }^{\text {"51. }}$.

Tabla 5: Relación en distancias de Cartago a una población del Quindío

\begin{tabular}{|c|c|c|}
\hline Capital del Municipio o punto de partida & $\begin{array}{l}\text { Nombre de las secciones, cabeceras } \\
\text { o Distritos }\end{array}$ & $\begin{array}{l}\text { Distancia } \\
\text { en leguas }\end{array}$ \\
\hline \multirow{15}{*}{ Cartago } & Obando & 4 \\
\hline & Victoria (a) & 6 \\
\hline & Pereira & 6 \\
\hline & Sta Rosa & 8 \\
\hline & Salento & 111 \\
\hline & María (presunta actual villamaría) & 14 \\
\hline & \multicolumn{2}{|l|}{ Caseríos } \\
\hline & Zaragoza & 1 \\
\hline & Sta Ana (Filadelfia) & 2 \\
\hline & $\mathrm{Paz}$ & 2 \\
\hline & Gutiérrez & 3 \\
\hline & Condina (hoy desaparecida) & 7 \\
\hline & $\begin{array}{l}\text { San Francisco (presunta } \\
\text { chinchiná?) }\end{array}$ & 11 \\
\hline & Palestina & 12 \\
\hline & Segovia & 14 \\
\hline \multicolumn{3}{|c|}{$\begin{array}{l}\text { Fuente: Elaboración propia de acuerdo con: ACC, Archivo muerto, sección República, caja } \\
\qquad 145,1878, \text { ff. } 65-68 .\end{array}$} \\
\hline
\end{tabular}

¿Cómo y por qué termina convirtiéndose el Quindío en un receptáculo poblacional tan importante? Si bien, la condición de frontera en el sentido de Serje (2005),

51 ACC, Sección República, Informe sobre la visita del Delegado de Instrucción Pública a los pueblos del norte, 1878 , caja 145 , ff. $65-68$. 
articulado a una baja densidad poblacional de comienzos de siglo, había sido la piedra en el zapato para el mantenimiento del Camino del Quindío y el poblamiento en la región; a finales del siglo XIX, la ubicación y la presión poblacional en el sur de Antioquia, norte del Cauca, Cundinamarca y Boyacá, llevaron a que esta frontera se transformara en lo que LeGrand (1984) denominó como "válvula de escape que permitía aminorar tensiones entre terratenientes y campesinos" (p. 14).

\subsubsection{El Quindío: territorio de políticas públicas y políticas privadas}

El poblamiento del Quindío responde a dos momentos u olas migratorias; las previas a 1880 y las que siguieron hasta pasados los años de $1920 .{ }^{52}$ En la primera se resalta la presencia de colonos del Cauca, Antioquia, Tolima y Boyacá; aunque la literatura sobre el tema haya priorizado la migración antioqueña ${ }^{53}$. La segunda ola migratoria fue en el siglo XX y se caracterizó por la producción cafetera, la especulación con los precios de la tierra y la intervención del gobierno liberal en 1930 para legalizar poblaciones y propiedades.

Podríamos decir que varios factores incidieron en la migración, entre los que se cuenta: la comercialización de cerdos, la búsqueda de guacas y la apertura de nuevas fronteras agrícolas a través de empresas dedicadas a la colonización como la empresa Burila. Sin embargo, no todo el territorio fue producto de la intervención de dicha empresa, pues también hubo casos de poblados fundados fuera de la zona del grupo empresarial que pertenecía a terratenientes o eran baldíos de la Nación ${ }^{54}$.

52 Jaime Londoño (2008) plantea que el poblamiento del territorio estuvo jerarquizado en tiempo y
espacio y motivado por: "1) la existencia de terrenos baldíos, 2) los imaginarios en torno a la frontera,
asociados a la invención y difusión de leyendas que aluden a la existencia de lugares míticos con grandes
tesoros; 3) la economía de exportación ligada a la consolidación del café en calidad de producto que vincula
a la economía colombiana al mercado mundial; y 4) la construcción del Ferrocarril del Pacífico en el
departamento del Valle del Cauca y sus ramales a Armenia, Pereira y Manizales (p. 196-197).
$53 \quad$ Al respecto de la colonización antioqueña apologética ver Londoño (2002). Para indagar sobre las tesis
en contra de la leyenda rosa de la colonización consultar a Christie, (1986; 1978; 1984), LeGrand (1988)
López, Cano y Mora (2007), Quiceno (2007) Tobasuña (2007) y Cadena (1988).
$54 \quad$ Los casos de Calarcá y Sevilla son ejemplos muy interesantes. El primero se trata de una población
que tuvo varios pleitos con la empresa y moviliza firmas, abogados y hasta se organizar con campesinos que
tuvieron que enfrentar a la empresa por no reconocer la legalidad de sus poblaciones y el segundo caso se 
Inicialmente los caseríos recién fundados se mantenían con los pocos recursos que enviaba Cartago, ciudad encargada de administrar la Provincia; sin embargo, después de la Regeneración se proyectó en la zona un ambicioso plan que consistía en incrementar la producción cafetera promovida desde 1879 por el Gobierno, y valorizar las tierras de propietarios y empresarios a través del mejoramiento y creación de vías, explotación de salinas y fundación de poblaciones (Garrido, 1983; Flórez, 1997; Valencia, 1990; Valencia, 1993).

Pero si bien, este proyecto incrementó el número de poblaciones y contribuyó a la creación de nuevas vías para interconectar el centro del país con el occidente, también se convirtió en foco de conflictos entre campesinos, colonos, empresarios y especuladores que durante todo el proceso de poblamiento, se enfrentaron asegurando la legitimidad de la ocupación y fundación de las poblaciones; pues dada la ambigüedad de las leyes, el aseguramiento de la propiedad de un lote estuvo determinado por la capacidad de instrumentalizar las instituciones del Estado y movilizar a su favor los fallos de jueces y representantes del Gobierno.

Este tipo de problemas en los procesos colonización no son necesariamente únicos en Colombia, el continente o por qué no decirlo, el mundo entero. Es sabido que todo proceso que vincule relaciones económicas y políticas se presta para la conflictividad entre quienes tienen acceso al capital y el Gobierno, y quienes están por fuera de dichas esferas; más cuando la colonización supera la idea básica de ocupar un lugar y se identifica con los distintos tipos que pueden manifestarse en un periodo, lugar o momento (LeGrand, 1988; Christie, 1984; Martins, 1996). 
Mapa 2: Mapa de geográfico de Colombia y zona de estudio

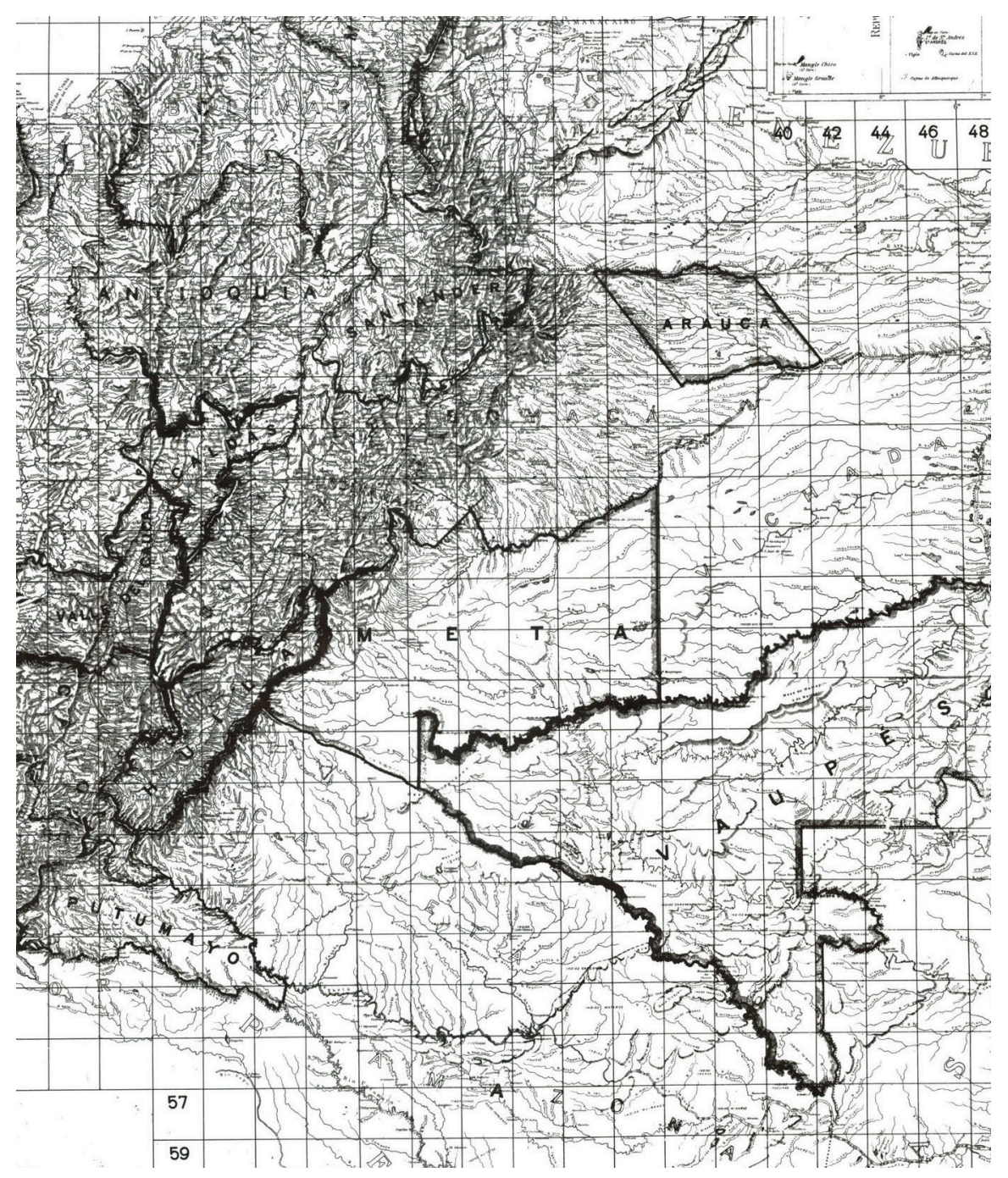

En cuanto al Quindío, la alianza entre regeneradores y la Empresa de Fomento y Colonización La Burila (Corrales, 1988) fundada en 1884 y disuelta en 1930, permitió la ocupación del territorio a través de la ejecución de un programa empresarial de valorización, venta de tierras e intervención en las fundaciones, apertura de caminos 
y distribución del espacio. Pero dado que dicha intervención se hizo en un vasto territorio que jurídicamente no les competía y que había sido creado por medio de un mal deslinde, los conflictos con colonos y otros pequeños empresarios hizo de la existencia de la empresa un lío judicial.

¿Cómo surgió la empresa de fomento y colonización La Burila? ¿Qué programas proponía? ¿Cómo actuaron los agentes del Estado? Al saber del proceso colonizador del Quindío, en 1884 Lisandro Caicedo ${ }^{55}$ hace un juicio de deslinde de la hacienda La Paila, diligencia que le permitió hábilmente jugar con los linderos de este predio y correr el límite oriental que correspondía a la zona montañosa o de Burila conocida con el nombre de la Sierra de los Pijaos hasta la Cordillera Central, así como también, mover los linderos norte y sur. Estas maniobras le facilitaron la apropiación de los territorios de la Hoya del Quindío y norte del Valle.

Mientras se practicaba la demarcación surgieron dos propuestas muy importantes para los gobiernos regional y nacional. Dichas propuestas estaban relacionadas con la construcción de una vía que comunicara al Tolima con el Cauca por Anime y el diseño de una empresa de colonización dirigida que se conocería como La Burila. Consciente de sus ambiciones empresariales y de la importancia que podría tener la empresa que estaba promoviendo, Lisandro Caicedo ingenió una compañía que fuese lo suficientemente atractiva como para asociarse con las élites manizalitas conocedoras y experimentadas en la dinámica colonizadora-, las élites caucanas -quienes fueron los políticos más importantes durante el siglo XIX- y capitalistas extranjeros que vieran en el negocio de la colonización una buena oportunidad para aumentar sus riquezas.

La empresa Burila, registrada según escritura pública en la Notaría Primera de Manizales el 25 de noviembre de 1884, se propuso de acuerdo a los estatutos

55 Lisandro Caicedo Delgado, hijo mayor de José María Caicedo y Zorrilla y la señora María Ignacia Delgado, fue un empresario caucano dedicado a la venta y fomento de la colonización en las tierras de la hacienda La Paila, entre las que se cuenta el latifundio de Burila; posterior zona de litigio con colonos. Para profundizar sobre Caicedo ver: Arroyo, J. (2006); Carrero, A. (2010); Londoño, J. (2003, 2008). 
iniciales una duración de 25 años ${ }^{56}$. Después de fundada, puso en valorización y venta los terrenos que pertenecían a la familia Caicedo (principalmente a los señores Lisandro y Belisario Caicedo), y terminó convertida en una sociedad de 63 personas, entre los que se contaban presidentes, políticos de la región y figuras públicas de reconocimiento nacional.

La empresa Burila inició con un capital de $\$ 100.000$ dividido en mil acciones. El objeto de la compañía, era "la explotación de los terrenos de Burila, [...] las minas, salinas y carboneros existentes en dichos terrenos" ${ }^{57}$, pero también era fundamental para la empresa, poblar el vasto territorio que comprendían sus linderos garantizando de esta manera el desembotellamiento del Cauca; por ello el capítulo 7 de la escritura mencionaba el sentido de la colonización y el fomento, considerando que sería:

El logro más adecuado de las tierras i [sic] allá donde se sea que pueda empatarse las tres más [cordilleras], la del Tolima por Anaime, la del Valle del Cauca por la Paila i de Antioquia por Circacia, lo más cerca posible de la confluencia de los ríos Barragán y Quindío que juntos forman el caudal de la Vieja, conllevando las mejores condiciones de salubridad, clima i fotografía, cederá la compañía un gran lote de cuatro mil fanegadas de forma rectangular... [y] ...En el centro de ese globo de tierra se demarcará el área para una ciudad con una extensión de cuatrocientas fanegadas conforme a las indicaciones y planos que oportunamente se le pasarán a un agente que allí tratará de tener la compañía ${ }^{58}$.

Por disposiciones de los accionistas, la compañía comenzó a ser administrada por élites antioqueñas que posteriormente se convirtieron en los empresarios y políticos del departamento de Caldas; de esta manera, los Caicedo garantizaban el éxito de la empresa en lo que tenía que ver con el poblamiento, al tiempo que ponían en su bolsillo un proyecto ambicioso de colonización ${ }^{59}$.

\footnotetext{
56 Escritura Pública, Empresa Burila, Manizales, Notaría Primera, 1884

57 Escritura Pública, Empresa Burila, Manizales, Notaría Primera, 1884, art. 1 y 4.

58 Escritura Pública, Empresa Burila, Manizales, Notaría Primera, 1884, art. 40 y 41.

59 Considero importante resaltar este punto dado que los autores que han trabajado la colonización
} 
antioqueña (Parsons, Valencia, Santa) han dejado claro cuáles eran las capacidades administrativas y empresariales de los antioqueños, dejando de lado u obviando las capacidades de los caucanos. Es de resaltar que en el libro de Albeiro Valencia (2000) Colonización, fundaciones y conflictos agrarios, se hace un acercamiento a la Compañía Burila muy desde la herencia comercializadora de los antioqueños a las élites manizalitas y no se profundiza en el papel preponderante de Lisandro Caicedo. En la página 243, cuando hace relación a la constitución de la empresa Burila, Albeiro Valencia hace referencia de la siguiente manera: "Llama la atención el hecho de constituirse la Sociedad en Manizales, donde los socios de dicha ciudad solo poseen 18 acciones frente al resto de accionistas; ello se explica porque su gerente es don Marcelino Arango P., prestante figura de Manizales, y son elegidos miembros del consejo los señores Víctor Cordovés y Manuel María Grisales, ampliamente conocidos por su actividad económica y como orientadores de la colonización empresarial desde Manizales hacia otros puntos del futuro departamento de Caldas. Las razones habría que buscarlas en este último aspecto ya que para esta época la clase empresarial, que se había formado en la región, estaba dirigiendo la colonización del Quindío, de Pereira y del Valle de Risaralda" (p. 243).

Aunque en un principio estoy de acuerdo con el autor al plantear que son los manizalitas quienes coordinan la empresa por su experiencia, también debo aclarar que no se tiene en cuenta el papel de los empresarios caucanos y para el caso de Burila, el papel y la inteligencia como negociante de Lisandro Caicedo.

Si se revisa la historia empresarial de Lisandro Caicedo, podemos ver que desde 1845, año en que muere su padre y él asume los negocios de la familia, la intención primaria es ganar dinero. ¿Cómo lo logra? A diferencia de algunos representantes de las élites caucanas que se quedaron con tierras y se arruinaron junto a ellas, Lisandro Caicedo se dedicó al mundo del comercio, fundó una empresa de Fomento y colonización y cuando se da cuenta que la dinámica colonizadora del Quindío se acerca a sus predios, decide crear una compañía tan atractiva tanto para los caucanos como para los manizalitas.

En este punto, creo importante resaltar que antes de la creación la Compañía Burila, Lisandro Caicedo ya contaba con la experiencia de haber fundado dos compañías de fomento y colonización, la primera con el señor David R. Smith y la segunda con el señor Tomás Uribe Toro. En ambos casos, es interesante notar que Lisandro Caicedo nunca se encargó directamente de la gerencia de las compañías, sin embargo siempre estuvo presente supervisando minuciosamente cada movimiento o transacción (Londoño, 2008).

Dado este antecedente, considero que Lisandro Caicedo no dirigió Burila, no por falta de experiencia, sino que era una práctica común en él asociarse con personas que consideraba idóneas para el manejo de sus negocios, a quienes delegaba la gerencia, no sin antes aclarar que él estaría siempre al tanto de los diversos sucesos que pudieran acaecer.

Esta fue una forma de no involucrarse en cualquier conflicto que pudiera tener con colonos, pero siempre fue claro el control sobre sus empresas. En el caso de Burila, es su hija quien seguirá su legado empresarial, pero para esto habría que hacer futuras investigaciones sobre el papel de las élites caucanas en la colonización. 
Mapa 3: Mapa de la Empresa Burila

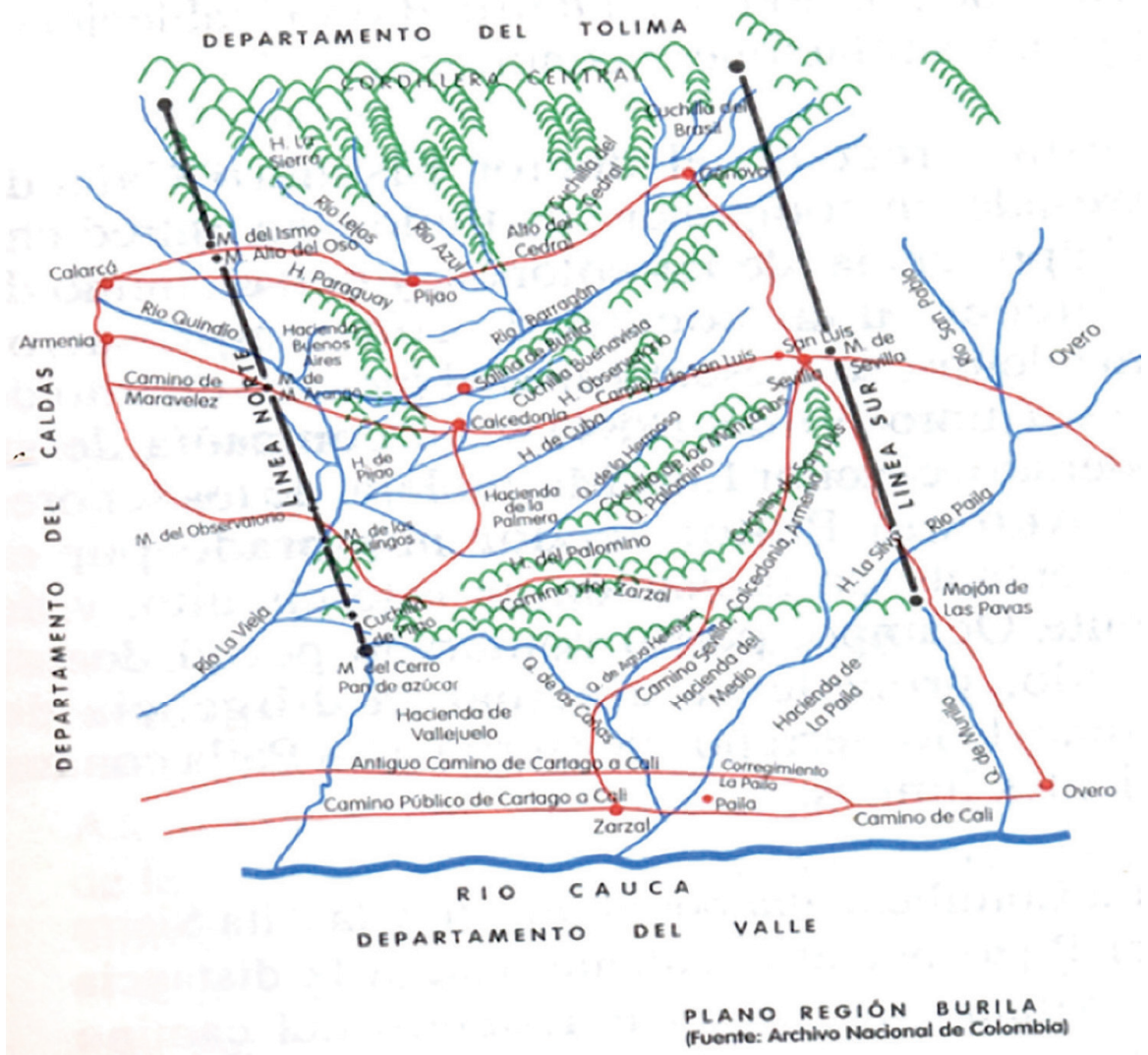

Como toda sociedad anónima, la compañía Burila tenía un capital real -la tierra- y un capital ficticio -las acciones-; estas se podían vender en el mercado y crecer más rápidamente que el capital real porque se podían dividir, aumentar de precio o depreciar, sin que variara el capital efectivo (Cadena, 1988). Ahora bien, en cuanto a la colonización la política empresarial sobre los terrenos incultos se orientó a la explotación y dirección de poblamientos, esto justifica que las escrituras mencionen la importancia de tener un centro poblado para establecer las oficinas de la empresa (Londoño, 2003, p. 424). 732-81 
Hacia 1884 el control caucano guardaba para sí el 90,04\% de las acciones y dejaba a los demás inversionistas con el 9,96\% de la empresa; por su parte, Lisandro y su hermano Belisario Caicedo controlaban el 56,21\% del total de la empresa (457 acciones de 812), garantizando que los objetivos de ambos se hicieran realidad.

Tabla 6: Número y porcentaje de acciones vendidas de la empresa Burila a 1884

\begin{tabular}{|c|c|c|}
\hline Origen de los Accionistas & Acciones & Porcentaje \% \\
\hline Caucanos & 731 & 90,04 \\
\hline Otros $^{*}$ & 81 & 9,96 \\
\hline Total & 812 & 100 \\
\hline${ }^{*}$ Bogotá, Circacia, Manizales, Aranzazu, Santa Rosa, Salento. \\
\hline Fuente: tabla construida por el autor con base en: Cadena, 1988, Anexos 2; \\
lista de socios. \\
\hline
\end{tabular}

Burila también se valió de la prensa local para publicitar el poblamiento; por lo que fue común encontrar en periódicos como El Aviso -que circulaba en el Quindío, Caldas, Tolima y Antioquia-, y El Ferrocarril que circulaba en Cali, mensajes dirigidos a "los hombres emprendedores del Gran Cauca y a aquellas personas que buscan mejorar su suerte por medio del trabajo" ${ }^{60}$, para que fueran a colonizar las tierras de Burila.

En 1886, cuatro años después de la fundación de la empresa, Marcelino Arango, primer gerente de la empresa y segundo gobernador del Departamento de Caldas (junio 24 de 1909 - agosto 22 de 1909) expuso ante la asamblea de accionistas cómo los terrenos se habían convertido en el punto de llegada para muchas familias colonizadoras.

$60 \quad$ Periódico El Ferrocarril (1884), Cali, № 263, Octubre 3 p. 1049. 
Dado que el conocimiento sobre dichas tierras era popular, los agentes y el gerente de la compañía siempre estuvieron al tanto del desarrollo de la colonización y los hallazgos de minas dentro de Burila; por tal motivo, aprovechando la valorización y que sus principales accionistas eran representantes del proyecto regenerador, el gerente de la compañía empezó a ver con buenos ojos la idea de fomentar la venta de acciones a empresarios nacionales y extranjeros. En el informe comentado, el gerente recalcaba que:

Con ocasión del descubrimiento de ricos sepulcros en el dilatado valle de $\mathrm{La}$ Vieja hoy está llamando la atención de los empresarios mineros del país ese privilegiado suelo; la riqueza de los sepulcros denuncia la existencia de minas. Sensible es que especulaciones de este género -las únicas que se pueden poner en armonía perfecta y fecundada pequeños y opuestos intereses en la síntesis de un fin común grandioso- no sean estudiadas ni comprendidas por nuestros hombres de negocios; refractario generalmente a todo adelanto que puede con sus inveterados hábitos de rutina ó con una sindéresis formada en nuestro alejamiento de todo comercio civilizado que nos hace pesimistas, sino intolerantes con cuanto diga relación con cosas nuevas ó no vistas dentro de la esfera de las vulgares ó comunes apreciaciones. Más los que tanto por patriotismo como por cálculo pretendemos llevar adelante una empresa como esta tenemos confianza en que su desarrollo y resultados serán norma de una especulación industrial desconocida y estímulo eficaz para los que en pos de nosotros se propongan avanzar por los mismos caminos

Es factible que el Gobierno Nacional cuando se penetre de espíritu y de tendencias de esta empresa de colonización, explotación y fomento quiera patrocinarla y ampararla como especulación de interés general de grande trascendencia por cuanto su esfera de acción no se concreta a las tierras de Burila solamente sino que en su desarrollo natural y lógico irá dilatándose mediante adquisiciones sucesivas de tierras de particulares o baldías al sur de nuestros desconocidos Andes Centrales ricos en todos los dones de una 
naturaleza pródiga y fecunda; cuando especulaciones de menos interés público han obtenido el favor y la liberalidad oficiales [sic] (AHC, fondo: Judicial, serie: Demandas, f. 92, p. 72).

La vinculación de personajes de la vida pública nacional como accionistas de la empresa, había permitido solidificar las bases legales de la misma. Dicho respaldo durante el proyecto regenerador facilitaba el rol social de la empresa, pues las colonizaciones se dirigían siempre hacia el bien de la Nación y del programa de Gobierno.

En el informe ya mencionado, Marcelino Arango decía que:

Juzgo de oportunidad indicaros que sería prudente y provechoso reservar un número considerable de acciones no menor de 300 para brindarlas en el extranjero. Esta indicación tiene su fundamento en el conocimiento de referencias dignas de crédito, relacionadas con esta especulación dadas a conocer por un accionista amigo nuestro en un viaje reciente y tal asenso doy a dichas referencias y tanta importancia al incidente que me permito suplicaros que autorise [sic.] al Gerente para hacer las gestiones que crea conducentes al objeto; alentándome al pediros esta autorización la probabilidad de buen suceso así como el común anhelo de atraer a nuestro país, aunque en pequeña escala, por ahora, el elemento extranjero industrioso y de trabajo en condiciones preparadas y propicias para una formal colonización y para exportaciones de índole complexa apreciables sin dificultad por el criterio especulativo (AHC, fondo: Judicial, serie: Demandas, f. 92, p. 72).

Por lo que la asamblea votó diciendo:

Queda el Gerente autorizado para celebrar todo convenio, arreglo, negocio o transacción que juzgue conveniente a los intereses de la empresa concorde con las indicaciones del informe y de la aprobación que les ha impartido la asamblea. Entre las autorizaciones que les confiere figura en primer término la de gestionar y entrar en arreglo para lograr la colocación de acciones 
en el extranjero de conformidad con su solicitud. Del uso que hiciere de esta autorización y el resultado de las gestiones dará cuenta el concejo administrativo (AHC, fondo: Judicial, serie: Demandas, f. 92, p. 73).

Después de concesión de poderes al gerente, solo se había obtenido una propuesta de compra-venta de parte del señor Dr. Santiago M. Eder, por la cantidad de $\$ 64.000$; sin embargo, durante la vigencia de la empresa se presentaros varios proyectos de compra de terrenos a gran escala como fue el caso con el Conde de Goussencourt, empresario francés vinculado a empresas de ferrocarriles y de poblamiento en el continente americano (Carrero, 2010).

Además de la publicidad y gestión que hacía Arango, Lisandro Caicedo consideraba que el Gobierno Nacional estaría dispuesto a destinar hectáreas que se abrirían paso con la colonización y en correspondencias con el Conde, por ejemplo: insistía que la zona propuesta para colonizar tenía:

Riquezas de todo género, hoy, en parte, disputadas sin provecho y daño para los intereses nacionales por unos pocos pobladores, de precedentes dudosos entre quienes no faltarán algunos requeridos por la función de la ley ó escapados de la justicia penal; habiendo podido observar en ellos una mal disimulada tendencia a alejar ó repeler el elemento sano e industrioso de los pueblos más cercanos del Cauca, Antioquia y Tolima que se sienten atraídos por la riqueza de esta rica región y parecen llamados a estrechar vínculos sociales - de tiempo atrás flojos o relajados, y a confundir allí mediante la confraternidad del trabajo honrado sus destinos y su suerte [sic] (AHC, fondo: Judicial, serie: Demandas, f. 92, p. 72).

De esta manera la empresa logró consolidarse en la zona; sin embargo, como se presentará a continuación, la dificultad de regular el proceso de colonización y la ambigüedad jurídica generaron diversas problemáticas que nos servirán para analizar el proceso formativo del Estado, visto desde la interacción de sus agentes y la población civil. 


\subsection{Las rendijas de la norma: tenencia de la tierra, frontera agrícola y legalización en la colonización}

\section{“Cómo se prueba el dominio con respecto al Estado, con respecto al colono, con respecto al poseedor y a otro aspirante con respecto a ese dominio?"61}

En términos generales, el interés tanto del Estado como de los empresarios y colonos era ocupar tierras que se presumían como baldías; pues debido a las condiciones ambientales de del país, la selva, pantanos y demás ecosistemas, impedían una comunicación eficaz, económica y rentable entre los puertos y el interior, así como también, entre los llamados centros y periferias.

Podría decirse que los actores implicados en los procesos colonizadores consideraban positivo para el país y sus economías familiares, abrir selva o secar pantanos y poblar, aunque no necesariamente, las formas para concretar dicho proyecto fueran iguales; por lo que se manifiesta una ausencia entre la verdad y la realidad, es decir, la verdad es la enunciación previa donde encontramos una idea general, un poco romántica, donde todos los actores proponen un mismo país, un mismo programa, una idea generalizada de desarrollo, un proyecto popularizado y conservador de propietario y de legitimación de las leyes y el Estado; la realidad está en las relaciones sociales que imbrican a los actores, pues fue allí donde la práctica del proyecto entró en crisis y enfrentó intereses personales con intereses generales.

¿Por qué ocurre este fenómeno? ¿Cuál es la posición del Estado? ¿Cómo se comportan los empresarios y los colonos? ¿Los agentes del Estado asumen una posición racional en el sentido weberiano?

Para comenzar a respondernos debemos comprender la evolución cultural y política de la administración de la tierra por parte del Estado y cómo la transición al

61 Intervención del Magistrado Zuleta Ángel ante la Cámara de Representantes; esta argumentación es la guía para la comprensión del res nullius, en: Anales de la Cámara de Representantes, 20 de diciembre de 1935; p. 1841, (como se cita en Palacios, 2011, p. 28). 
capitalismo liberal, confrontó tradiciones de explotación de este bien, con prácticas económicas que propendían por un uso y re-conceptualización de la propiedad. Esto puede ser explicado al revisarse la historia de la administración pública y su evolución, así como también, la emisión de leyes y decretos oficiales que pretendían regular las relaciones sociales y abrir paso a las nuevas tesis de explotación, uso y disfrute de los bienes.

Un ejemplo de ello lo vemos en la codificación nacional, que como expone Suescún (2008), dejó a Colombia en un vórtice jurídico el cual comenzó a resolverse después de implementado el proyecto de La Regeneración; de allí la frase célebre de Rafael Núñez: "Regeneración Administrativa o catástrofe".

Durante el sigloXIX Colombia administró el territorio nacional entre Constituciones, guerras civiles, Confederación, Centralismo, Federación y nuevamente Centralismo; constantemente se emitían decretos, leyes, sentencias y demás actos administrativos que llevaban a un constante choque de poderes los cuales se resolvían en la guerra militar o jurídica. Como ejemplo está la definición y unificación del Código Civil, con el cual se regularía jurídicamente todo el territorio colombiano. Al respecto dice Suescún (2008) que:

En la Nueva Granada, desde el comienzo de la República, rigieron simultáneamente las leyes granadinas y las españolas; en los Estados Unidos de Colombia, la Ley 42, de 16 de mayo de 1865, y la Ley 57 bis, de 7 de junio de 1872, ratificaron ese régimen. Sin embargo, algunos Estados Federales, en ejercicio de su autonomía legislativa, adoptaron sus propias normativas; así, la Asamblea Legislativa del Estado de Cundinamarca, por Ley de 8 de enero de 1859, adoptó para dicho Estado el Código Civil de Chile. El Estado del Cauca lo adoptó también en el mismo año, el de Panamá en 1860 y los de Boyacá y Antioquia en 1864. Posteriormente, el Congreso de los Estados Unidos de Colombia, por Ley 84 de 26 de mayo de 1873, lo adoptó como Código Civil de la Unión colombiana, aclarando que debía aplicarse "en los asuntos de la competencia del Gobierno general con arreglo a la Constitución 
y en los civiles comunes de los habitantes de los Territorios que él administra", posteriormente la Ley 57 de 1887, reiteró su adopción (p. 237).

Esta situación nos muestra un país que pasó casi todo un siglo pretendiendo unificar sus leyes y por lo mismo, si partimos del principio que las leyes responden a la necesidad de regular una sociedad, ¿Cuáles son las exigencias de nuestro fragmentado país? ¿Todas las regiones vivían las mismas situaciones? ¿Las necesidades de controlar la propiedad, ocupación y tenencia de la tierra, son similares en el territorio colombiano?

Es claro que no son las mismas necesidades, no se viven las mismas situaciones y el control en la ocupación, tenencia y propiedad de la propiedad de la tierra estuvo caracterizado por la emisión de normativa, mas no por la apropiación de la problemática como un asunto de interés público.

Para el Estado del siglo XIX, con sus representantes políticos influidos por un discurso capitalista liberal y considerando la riqueza como producto de la explotación y reproducción del capital en el mercado, quizá la tierra no fue el centro de atención ${ }^{62}$. El Gobierno diseñaba códigos para regular la explotación de minas, bosques, ríos (de allí el Código Fiscal) también diseñaban reglas de mercado (Código Mercantil) y hasta se construyeron códigos para reglamentar las mismas relaciones sociales (Código Civil); sin embargo, como exponía el ingeniero Ruperto Ferreira, encargado de la revisión de las adjudicaciones hasta 1886: pareciera que al Gobierno no le interesara el control de sus baldíos y viera en ellos solo un medio para saldar sus deudas adquiridas desde la Independencia a través de bonos territoriales ${ }^{63}$.

62 Exceptuando lecturas como las de Smith, para quien la tierra al igual que para los fisiócratas, representaba el mecanismo para el enriquecimiento sin explicación de dónde llegaba en sí la riqueza; para los siguientes representantes de la Escuela de la Economía Política la riqueza surge de la explotación de los bienes y la tierra pasa a un segundo plano para darle la importancia a la industria. Marx fue un poco más allá de estas interpretaciones, viendo el excedente no como el motor de la riqueza únicamente, sino como el robo producto de la explotación del burgués al proletariado. Él lo llamó Plusvalía. Ver: Roll (2009); Smith (1997); Mill (1943); Marx (2004).

63 AGN, baldíos, tomo 7, Bogotá septiembre 6 de 1886, ff. 97. 
Para Ferreira, a diferencia de otras fuentes de riqueza, la tierra no tenía la atención que debía merecer, prestándose a la especulación y el aprovechamiento por parte de empresarios y políticos protervos. Múltiples casos se presentaban en el país con situaciones como las descritas a continuación:

Apenas se proyecta cualquier obra que sea efectuada como de utilidad a la república y ya se exigen concesiones de miles de hectáreas como pudiera exigirse cualquier cosa inútil sin que sea como el caso de que la concesión se verifique sin que la nación ponga todas las condiciones que aconsejará la prudencia para que con facilidad pudiera rescatarse cuando la obra no se lleva a cabo y teniendo en cuenta que una vez dadas a la circulación los títulos vienen estos a poder de terceros a quienes no puede exigirse responsabilidad de ninguna clase... Además como las adjudicaciones de extensiones considerables constituyen fincas rurales que no es posible a sus dueños manejar convenientemente en atención a los recursos del país, ha resultado que estas propiedades improductivas se interponen para alejar a los cultivadores en pequeña escala que tienen que buscar detrás de ellas donde establecerse en terrenos de la nación (AGN, Baldíos, tomo 7, Bogotá septiembre 6 de 1886, f. 97).

La tierra pareciera ser vista solo en el sentido de dominar y ocupar, asunto que para los gobiernos nacionales y locales, exigía una asignación presupuestal con el fin de crear carteras dentro de los ministerios y un control efectivo que solo se podría alcanzar con un personal idóneo. Lo que podríamos leer entre líneas, es que la tierra debía ser explotada, mas no se le dio la relevancia como a otros bienes. La literatura general sobre economía posiciona a la tierra como un referente de atraso, por lo que las sociedades avanzadas se caracterizaban por la urbanización mas no la ruralidad; asunto que reñía en un país donde los censos presentaban un población porcentualmente mayoritaria en la zona rural.

En los programas implementados por los gobiernos decimonónicos, es evidente que no hay un interés significativo por intervenir en lo rural; más bien el Estado abandona este ámbito para dejarlo en manos de la mano invisible del mercado. Los 
costos de este supuesto no solo generaron conflictos, sino que conllevaron a una desarticulación entre el discurso estatal y la práctica de la vida cotidiana, incremento de la violencia y la corrupción y emergencia de estrategias políticas de defensa por parte de los grupos vinculados a las problemáticas durante la colonización.

$\mathrm{Al}$ hacer una retrospectiva sobre lo agrario, encontramos que durante todo el siglo XIX la herencia colonial se mantuvo en relación con la propiedad de las tierras productivas, por ello este bien se concentraba en manos de una minoría vinculada al Gobierno o a un pasado nobiliario; además de esto, durante la Independencia con el fin de solucionar las deudas adquiridas con militares, el Gobierno recurrió a la forma romana del ager publicus populi Romani que consideraba como autónomo al Estado para administrar y traspasar tierras a ciudadanos, es decir al ager privatus vectigalisque.

Por otra parte, el Estado también heredó la ficción jurídica del res nullius o que el bien no tiene dueño, luego este puede tomarse por conquista u ocupación; en conclusión, en vista de que el Estado no controlaba sus baldíos, porque no los había medido ni localizado con precisión, el ager publicus se convierte en res nullius, es decir, propiedad indefinida (López, 2004), lo que facilitó la apropiación de muchos baldíos e impidió jurídicamente al Estado, establecer los derechos de propiedad sobre los bienes baldíos.

Con la universalización de la racionalidad civilista napoleónica, se adoptó el Código Civil que conservaba vestigios de res publicus hispano; en 1873 se unificó el Código Civil para todo el país y como dice Palacios (2011), medio siglo después era claro el desorden en los modos de apropiación de la tierra ${ }^{64}$.

64 De acuerdo con Palacios (2011): "La incipiente urbanización, cierta mejoría de los niveles de vida y el aumento de la población ampliaban el mercado agropecuario y, a la par, los conflictos por la propiedad de la tierra, objeto de renovada competencia en muchos planos cruzados: entre terratenientes, nuevos y viejos; entre terratenientes y pobladores de nuevos asentamientos; entre terratenientes y pobladores en zonas de viejos asentamientos; entre diferentes estratos de campesinos; entre blancos, mestizos e indígenas. Los mapas regionales de estas situaciones son abigarrados y hasta incomprensibles porque la antorcha del Código Civil y del Código Fiscal dejaban en la penumbra o en total oscuridad miles de colombianos en situaciones de facto" (p. 27). 
¿Cómo explicar entonces un fenómeno de esta magnitud?, ¿no se esperaría pues que la regulación estatal fuera antes bien acogida y ayudara a reducir la conflictividad?, si las leyes y códigos eran emitidos desde la razón capitalista, ¿No llevaban insertos elementos positivos en el sentido de la creación de propietarios y de Estado moderno?

El problema de la propiedad y su uso era transversal a las relaciones no solo de tipo material sino simbólicas (religiosas por ejemplo) y por ello podemos resaltar algunos elementos tales como el sentido o concepción de propiedad y su uso, y la forma como se regularía frente a la tradición de la adquisición; recuérdese que inicialmente el modelo independentista coqueteó con los principios del Código Civil Napoleónico, posteriormente terminó por asumir de nuevo los principios del Código de Indias (López, 2004).

En cuanto al uso, se evidencia una transformación al revisar las constantes movilizaciones populares y repertorios de protesta que durante el siglo XIX, enfrentaron el agotamiento de la frontera agrícola con un crecimiento poblacional que terminó en incursiones a las tierras públicas (ejidos) como también privadas. Hay ejemplos como el de las haciendas caucanas, de Cundinamarca y Antioquia en los que se evidencia el fenómeno en diversos procesos judiciales abiertos por colonos pobres, invasores, agregados, rentistas y supuestos dueños.

El problema radicaba en la concepción o tradición de la idea de riqueza que cristalizó en Colombia. Mientras el uso de un bien para hacer riqueza es un elemento distintivo del capitalismo decimonónico; el bien en el modelo tradicional español es asociado a la ostentosidad y el poder. En este caso, las minas y la tierra tenían ese sentido (Martínez, 1996).

Esta problemática comenzó a exacerbarse a partir de las reformas liberales de Mosquera y su Ministro de Hacienda, Florentino González, y después, con la radicalización durante el gobierno de José Hilario López y el posterior Olimpo Radical (Palacios y Safford, 2002; Pinzón, 2009). En el siglo XX el asunto continuó a 
razón de la lectura y discusión de las tesis de León Duguit, quien introdujo la idea de la Función Social de la Propiedad; esta lectura justificó la movilización y ocupación de tierras sin explotación.

El segundo punto del debate tiene que ver con la regulación hecha por el Estado como institución legal que garantiza el control de la propiedad, es decir, que determina quién es el dueño del bien; sin embargo, la relación entre propiedad y tierra se refiere a ella como un bien social, que en el caso de los colonos, como diría Palacios (2011), "primero se legitima en el tejido de los vecindarios y solo después, y eventualmente, en las instituciones del Estado" (p. 71).

Este fenómeno obligaba al Estado a regular los conflictos entre los actores de la colonización quienes, alegando desde distintas posturas jurídicas, exponían en los estrados judiciales las ambigüedades normativas pues "a medida que había más presión humana sobre los baldíos, aumentaban las querellas judiciales y, con estas, las fricciones conceptuales y legales entre los dos órdenes jurídicos emanados respectivamente del Código Fiscal y Civil" (Palacios, 2011, p. 86).

De todas maneras, la racionalidad liberal decimonónica pretendió constantemente hacer propietarios y por ello, la emisión prolija de leyes sobre la propiedad de la tierra durante los siglos XIX y XX; por ejemplo, entre 1820 y 1869 se emitieron 95 leyes, 168 decretos administrativos, 6 resoluciones, 2 circulares, 1 acto legislativo y se hizo una concesión. Por la importancia de regular esta producción de normativa el Decreto del 20 de agosto de 1856 pretendió unificar los códigos que habían hasta el momento, sin embargo este se derogó por el del 9 de enero de $1870^{65}$.

65 En 1930, por mandato presidencial, se le pidió al Ministerio de Industrias que hiciera una compilación de las Leyes, Decretos y Resoluciones que se hubiesen emitido después de 1820 con el fin de hacer un balance al respecto y consolidar una política pública efectiva en relación con los baldíos. Esta información está en un informe de más de 1.500 páginas, dividas en cuatro tomos y que para el fin de esta investigación, el autor consultó el tomo III y organizó en cuadros estadísticos (Memorias del Ministerio de Industrias al Congreso de 1931. Bogotá, Imprenta Nacional, p. 10-583). Las respectivas memorias de los ministros pueden ser consultadas en la biblioteca del archivo del Congreso. 
Tabla 7: Legislación sobre baldíos, 1820-1869

\begin{tabular}{|c|c|c|c|c|c|c|}
\hline Fechas & Leyes & Decretos & Resoluciones & Circulares & Concesiones & $\begin{array}{c}\text { Actos } \\
\text { legislativos }\end{array}$ \\
\hline $1820-1829$ & 16 & 23 & 1 & 1 & & \\
\hline 1830-1839 & 9 & 58 & & 1 & 1 & \\
\hline 1840-1849 & 14 & 44 & & & & \\
\hline $1850-1859$ & 30 & 26 & 2 & & & 1 \\
\hline $1860-1869$ & 26 & 17 & 3 & & & \\
\hline TOTAL & 95 & 168 & 6 & 2 & 1 & 1 \\
\hline Fuente & Elaboraci & $\begin{array}{l}\text { ropia, con b } \\
\text { de } 1931 \text {, to }\end{array}$ & $\begin{array}{l}\text { se en: Memoria } \\
\text { no III. Bogotá, }\end{array}$ & $\begin{array}{l}\text { s del Ministe } \\
\text { mprenta Na }\end{array}$ & $\begin{array}{l}\text { io de Industria } \\
\text { onal, p. 1-73. }\end{array}$ & al Congreso \\
\hline
\end{tabular}

Gráfico 1: Legislación sobre baldíos, 1820-1869

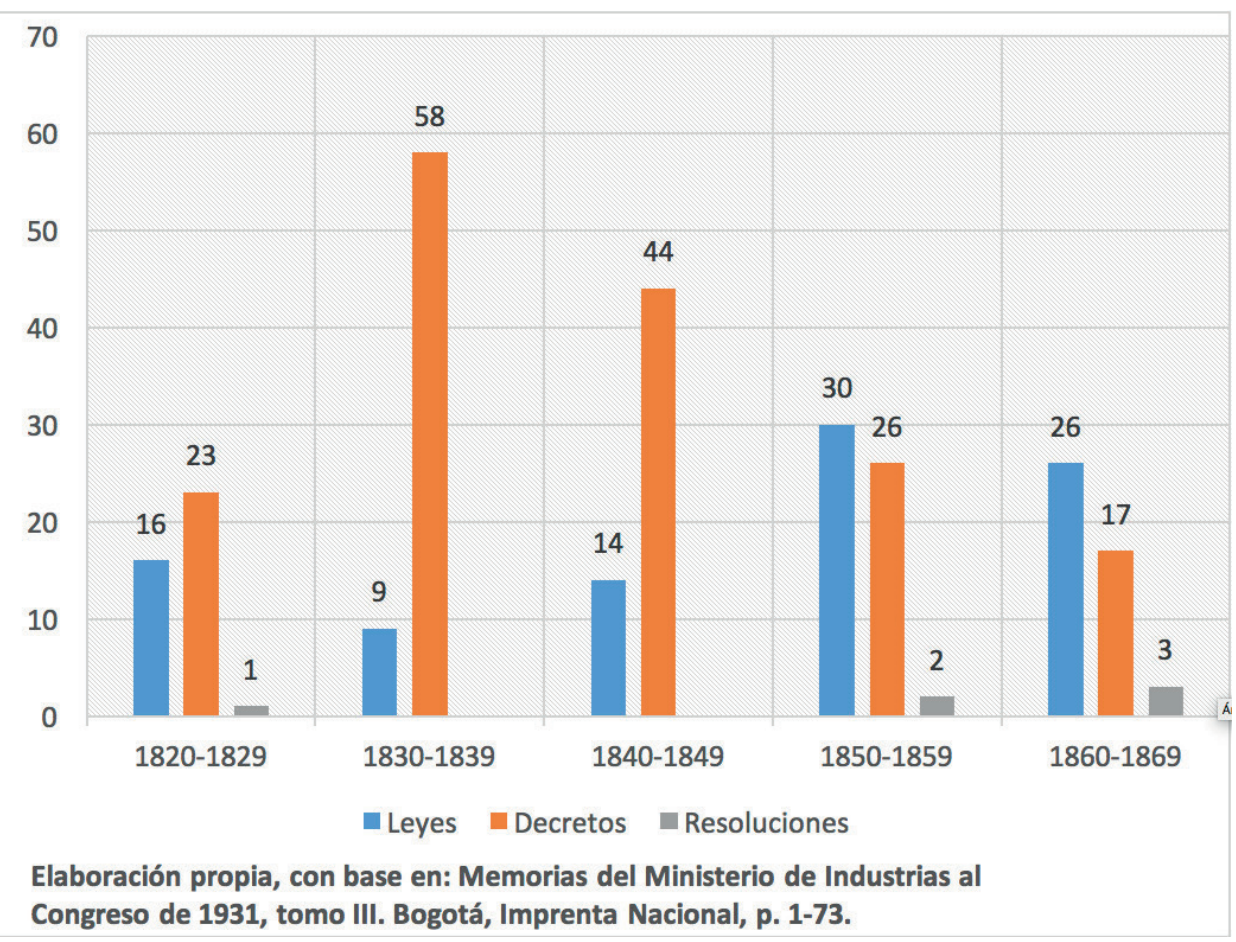


Llama la atención de este gráfico la evidente desarticulación jurídica entre el legislador y la realidad del ciudadano, pues la necesidad de controlar la propiedad de la tierra puso en una constante producción jurídica a los parlamentarios, generando no solo un desgaste de los mismos, sino un caos al no saberse sobre qué o cuál ley actuar. Ahora bien, antes de 1870 el problema es más de precisión sobre lo que regula la ley, que el diseño mismo de las leyes; por esto la abundancia de los decretos. Después de esta fecha y entrando al siglo XX, el problema es a la inversa; recuérdese que a partir de 1870, la legislación sobre baldíos adquirió un nuevo enfoque. Los bosques, minas y baldíos dejaron de usarse únicamente para el pago de deudas adquiridas por la Nación con militares o empresas, abriendo la discusión sobre cuál debería ser el mejor uso a estos bienes. Como producto de ello se pretendió regular con mayor atención las adjudicaciones, así como también, se propuso entregar el ramo a nuevas carteras, preferiblemente que no fueran las de los ministerios de Industria y Comercio, Fomento, Guerra y Marina, etc.

Tabla 8: Legislación sobre baldíos, 1870-1931

\begin{tabular}{|c|c|c|c|c|}
\hline Fechas & Leyes & Decretos & Resoluciones & Circulares \\
\hline $1870-1879$ & 72 & 22 & 10 & \\
$1880-1889$ & 48 & 14 & 4 & 3 \\
$1890-1899$ & 27 & 11 & 23 & 24 \\
$1900-1909$ & 17 & 31 & 72 & 2 \\
$1910-1919$ & 41 & 40 & 22 & 1 \\
$1920-1931$ & 38 & 174 & 155 & 8 \\
\hline Total & 243 & 56 & 24 & 2 \\
\hline & Elaboración propia, con base en: Memorias del Ministerio de Industrias \\
Fuente & al Congreso de 1931, tomo III. Bogotá, Imprenta Nacional, p. 73-583. \\
\hline
\end{tabular}


Gráfico 2: Legislación sobre Baldíos, 1870-1931

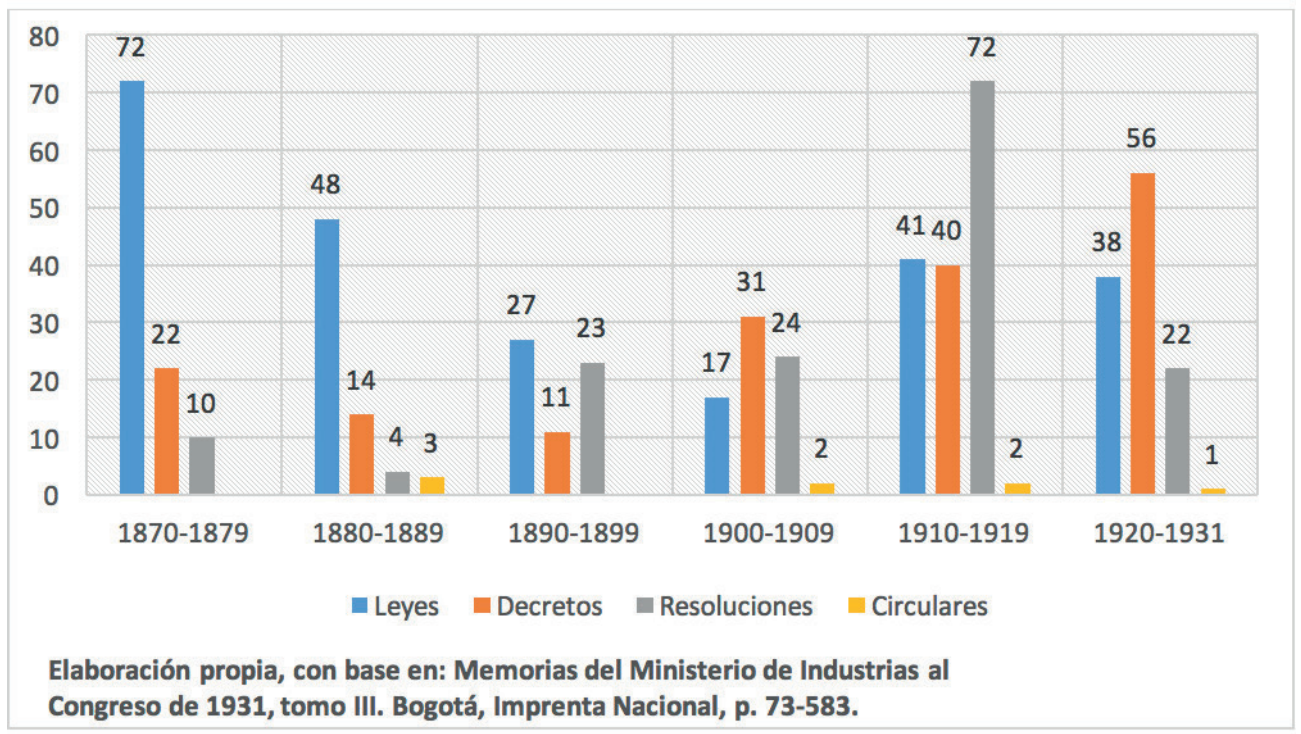

Después de 1870, la producción de normativa tuvo modificaciones internas, lo que se relaciona directamente con las disposiciones del Gobierno Nacional, por ejemplo: aunque hubo más leyes que decretos, de 1900 en adelante se evidencia un repunte de los decretos o especificaciones sobre asuntos que no son claros en las leyes. De igual manera, es claro el incremento de las resoluciones que giran en torno a la materia, como se puede corroborar en el siguiente gráfico, que muestra la década de los 1870 como la de mayor producción de leyes, la primera década del siglo XX como la de mayor número de resoluciones y las dos restantes, es decir 1910 y 1920, como la de mayor emisión de decretos. 
Gráfico 3: Legislación sobre Baldíos, 1820-1931

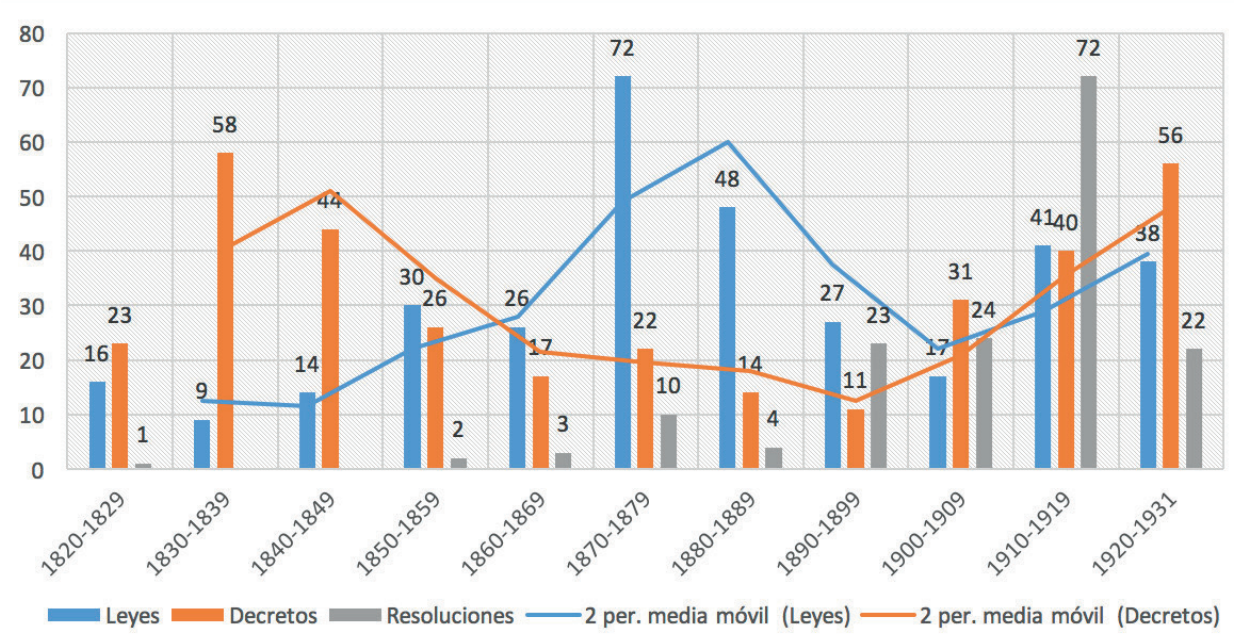

Elaboración propia, con base en: Memorias del Ministerio de Industrias al Congreso de 1931, tomo III. Bogotá, Imprenta Nacional, p. 73-583.

\subsubsection{El control de los baldíos, ¿Por qué hablar de las rendijas de la norma?}

En la descripción weberiana del Estado moderno, se parte de la idea de que las burocracias hacen un tránsito de la venalidad a la racionalidad, el funcionario público es un individuo que se desprende de su interés egoísta para darle paso a un interés general y por ello no trabaja para sí, sino para el Estado (Weber, 1919; Weber, 1974). De todas maneras se debe recordar que la formación del Estado, es producto de un ejercicio paulatino de centralización del poder (Elías, 1989), luego el control y cumplimiento de las normas, pasa por unos intersticios que solo son cerrados bajo tres estrategias: la primera tiene que ver con una capacidad material del Estado central por regular las periferias, en este sentido hablaríamos de una estructura jurídica y militar capaz de someter a quienes se desvían del proyecto estatal. Se trata de someter a los representantes de la administración pública por medio de una vigilancia y control constante que debe garantizar el cumplimiento o fin último del estatuto con el cual funciona el Estado en cuestión. 
La otra vía se relaciona con una burocracia racional en el sentido weberiano; el político moderno trabaja para el bienestar general y no para el suyo, aunque esto depende no solo de un programa estatal que ha venido madurando, sino también de la capacidad económica para sostener una burocracia que permita el funcionamiento de las instituciones, mientras logra garantizar la vigilancia y control de quienes se desvían del camino racional del Estado.

La tercera estrategia tiene que ver con la práctica política como formadora de Estado, es decir, la capacidad de los actores que conviven dentro del territorio nacional, para frenar los intereses de las burocracias representativas del Estado. Esta práctica política puede ir por varias vías, entre las que se destacan las opositoras al discurso hegemónico (contraestatales), incluyendo aquí los grupos de oposición, los grupos indígenas llamados salvajes por la jurisprudencia nacional y aquellas agrupaciones que manifiestan una resistencia al proceso de centralización y homogenización promovida por el Estado. Es importante aclarar, que no necesariamente los fines manifiestos son de tipo político en el sentido de Bourdieu (2000), pues muchas veces la resistencia se hace solo por sentir amenaza sobre una autoridad tradicional, mas no trasciende esta resistencia para construir poderes alternativos ${ }^{66}$. Ahora bien, como se presentaba en el capítulo segundo, esto no quiere decir que no se pueda considerar estas estrategias como prácticas políticas.

Otra forma de ver la práctica política es cuando algunas agremiaciones de ciudadanos se movilizan reclamando la presencia del Estado con el fin de garantizar la plenitud de unos derechos adquiridos. Esta práctica puede denunciar, reclamar, hacer público un exceso de fuerza del mismo Estado central o local, cuestionar la ambigüedad natural del derecho, etc. La práctica política se convierte en un mecanismo con el cual la sociedad presiona y el Estado logra cristalizar congeniando intereses puntuales con intereses generales.

66 Al respecto, Martins (1996) hace un estudio relevante sobre el enfrentamiento en las fronteras del Amazonas brasileño entre indígenas, hacendados y el Estado. 
Al revisar el caso del Quindío a través de las denuncias, fallos judiciales, sentencias de la corte y pronunciamientos del ejecutivo o el legislativo, es evidente que en el siglo XIX no se había logrado articular el discurso central con la dinámica cotidiana de las periferias, lo que obligaba a los grupos del margen del campo político, a luchar contra las burocracias locales y demás contendores por medio de reportorios de protesta legales (memoriales, denuncias, pleitos) o ilegales (invasiones, quemas, atentados contra la vida de agentes de las empresas territoriales, etc.).

En algunas discusiones halladas en el AGN, sección baldíos, se puede ver cómo los funcionarios encargados de atender denuncias se referían al proceso de poblamiento con miradas distintas a los legisladores, por ejemplo: el alegato iniciado por el ya mencionado Ruperto Ferreira, contra los legisladores de 1888 después de promover una reforma a la administración de baldíos.

Al parecer, las constantes denuncias por ocupación de terrenos privados, modificación ilegal de linderos, apropiación de baldíos por empresas de colonización y claro está, la ambigüedad de las leyes llevaron a la creación de una comisión para verificar la asignación y regulación de dichas entregas. ¿Cómo se hacía una adjudicación? Se esperaba que una persona natural o jurídica pudiera reclamar como bono territorial ${ }^{67}$ las tierras que, pertenecientes a la Nación en forma de baldío, estaban dispuestas para el poblamiento, la explotación y el enriquecimiento. Así, la empresa o el empresario denunciaba ante el gobernador de la provincia y este a su vez ante presidente del Estado Soberano que en un lugar determinado habían terrenos baldíos y posterior a una revisión hecha por un agrimensor, pagado por el denunciante, se certificaba la autenticidad para adjudicar el predio.

Sin embargo, el resultado común era que después de la adjudicación llegaran denuncias insinuando agrimensuras inexactas, desconocimiento de pobladores

67 A partir de los años ochenta del siglo XIX la especulación con los precios de la tierra se convirtió en una estrategia económica no solo de moda en el mundo, debido a la aparición de las economías financieras, sino también una manera para redimir bonos territoriales e incrementar los precios de tierras de haciendas que no eran productivas. Es común encontrar en las registradurías la denuncia de empresas de colonización que, a manera de Sociedades Anónimas reunían bonos territoriales y reclamaban el derecho sobre los baldíos de $\mathrm{X}$ o Y territorio donde se pudiera comenzar un proyecto colonizador. 
asentados antes de la misma o peor aún, la asociación entre gobiernos locales y empresarios para apropiarse de extensiones superiores a las denunciadas violentando derechos sobre otros tenedores de la tierra. Es por ello que el Ingeniero Ferreira denunció en su informe cómo se apropiaban ilegalmente de los baldíos con el consentimiento de las autoridades locales y, aprovechando la ambigüedad de la normativa, engañaban a los jueces y autoridades centrales. Decía al respecto que:

Se encuentran allí unas pocas leyes que unidas a varias expedidas desde 1800 hasta 1873 sirvieron de base al título X del Código Fiscal que hoy rige y en el cual está condensado lo de baldíos en 86 artículos. Pero después de promulgado este código se han dado las leyes 61 de 1874, 52 de 1877 y 48 de 1882, y 24 decretos ejecutivos en desarrollo de lo precipitado por ellas, de manera que al presente hay que consultar para los casos que ocurren, además del código y de las leyes citadas, no pocos decretos, circulares y resoluciones de diferentes fechas, y fue por haber tenido el propósito de evitar esta laboriosa consulta por lo que vi preferible encerrar en un solo cuerpo lo que debía servir de norma en el asunto. Además que como cada una de las disposiciones dadas en un largo lapso de tiempo han tenido por objeto atender á alguna necesidad, resolver alguna dificultad o llenar algún vacío, puede asegurarse que de lo que de todas ha quedado de todas vigente representa lo que la experiencia ha demostrado ser más conveniente y considere por lo tanto que podrá muy bien darse á todo esto el carácter de ley sin la inestabilidad de que suele adolecer los decretos [sic] (AGN; Baldíos, Tomo 9, Despacho de Hacienda, Bogotá, julio 16,1888 , f. 13).

Los resultados de este fenómeno, aunados al desconocimiento de las leyes por parte de algunos colonos, contribuyó al abandono de las tierras y la búsqueda de nuevas zonas de cultivo o en su defecto, asunto más evidente en el siglo XX que del XIX, asumir una postura contenciosa que solía articularse con acciones violentas. Cuando estos casos llegaban a oídos de la administración central generaba preocupaciones; esto es más que evidente en las justificaciones a la prolija producción de leyes y decretos para regular los procesos de colonización. 
¿Cómo participaba el Estado Central en la regulación de este fenómeno? Aunque durante el siglo XIX, el Estado central se encargaba de fiscalizar las adjudicaciones, después de 1870 estas pasaron a manos de los gobernadores departamentales y prefectos municipales y en el siglo XX a los concejos municipales. Al parecer, este tránsito del poder pareciera ser positivo, pues finalmente el concejo municipal es el espacio de poder popular más importante en el siglo XX; la pregunta que podemos formularnos es si: ¿Estaban los concejos municipales inmersos en el arrebato de tierras? En el siguiente capítulo, abordaremos algunos casos en los que la participación de esta corporación varió de acuerdo a los intereses de sus integrantes.

Ahora bien, aunque se produjera una significativa legislación no quiere decir que esta fuera acertada o peor aún, pareciera que el Estado fuera tímido a la hora de intervenir y regular las relaciones entre poseedores de facto y de título. Muchas hipótesis se han construido al respecto, desde las que sostienen un Estado gobernado por élites que se vieron beneficiadas de las dilaciones, hasta las que presentan un Estado que desconoce los problemas, pasando por las que presentan un interés del modelo capitalista por apoyar las migraciones de campesinos pobres a las ciudades, con el fin de abaratar la mano de obra que se vincularía a la producción industrial, tesis que es discutible en un país más rural que urbano.

Lo cierto es que los costos de esta ambigüedad jurídica, y la incapacidad del Estado central para regular los procesos de ocupación, tenencia y propiedad de la tierra pueden ser vistos como uno de los principales causantes del atraso económico y rezago en la participación del mercado internacional ${ }^{68}$. Ahora bien, lo llamativo de la colonización en zonas de frontera (Serje, 2005) fue generar un incremento en los precios de la tierra, determinado principalmente por la fluctuación del mercado cafetero y de otros productos de exportación y comercialización internacional, aunque no necesariamente hubiese sido aprovechado para incrementar la producción y beneficiarse de las bonanzas ${ }^{69}$. Dicen Torres, Fazio y López-Uribe (2010) que,

68 Esta tesis es desarrollada ampliamente por Torres, Fazio y López-Uribe (2010) quienes consideran que esa incapacidad racional-administrativa del Estado generó que el conflicto por las tierras no permitiera un amplio desarrollo productivo y una verdadera inserción provechosa en el mercado internacional.

69 Esta hipótesis es inversamente proporcional para el caso de mediados de siglo XX durante el periodo conocido como La Violencia; al respecto ver Ortiz (2007). 
Para el caso colombiano, por ejemplo, los datos notariales de las tierras en Cundinamarca muestran que el precio por fanegada aumentó más del 200\% entre la década de 1850 y el final de siglo. A medida que la tierra se volvía escasa, los derechos de propiedad informales no eran suficientes. La titulación de las tierras baldías se volvió una necesidad para los productores agrícolas si querían sacar provecho de las oportunidades que ofrecían los mercados mundiales $^{70}$ (p. 252).

¿Por qué esta ambigüedad y difícil control del territorio? En la Colombia decimonónica existían cuatro elementos claves para distinguir la propiedad territorial: había propiedades coloniales llamadas haciendas, tierras de la Iglesia, propiedades indígenas o resguardos, pequeñas propiedades campesinas concentradas principalmente en las provincias de Antioquia después de las reformas de Mon y Velarde, Pasto y Socorro, y tierras de dominio público o baldías que pueden ser de los municipios para la explotación o de la Nación ${ }^{71}$.

Según LeGrand (1988), la relación del Estado con la tierra respondía a dos fases, la primera se mantuvo desde la Independencia hasta 1870 y tenía que ver con la resolución de problemas fiscales, aunque también se fomentara la colonización con inmigrantes y se beneficiara con baldíos a los pueblos recién fundados. La segunda se dio después de 1870, cuando se incrementó el interés de explotar los recursos agrícolas, especialmente en áreas de frontera, fomentando la colonización; asunto que Cadena (2008) analiza como estrategia no solo económica sino política para comunicar internamente al país. Para LeGrand (1988):

Las leyes especificaban que aunque no hubieran solicitado título legal, por el hecho de su ocupación, los colonos adquirían derechos de tierra. Se prohibía expresamente a los tenedores de bonos la adquisición de territorios

$70 \quad$ Para ampliar la discusión ver: Demsetz, Harold (1967).

71 De acuerdo con Vélez (2012),

Entre 1827 y 1931, el 97,8\% de las concesiones de tierras baldías se entregaron a particulares; el 1,5\% a empresas de diversa índoles y $0,7 \%$ a entidades territoriales. Los particulares recibieron el 78,3\% de la tierra, las empresas 6,7\% y los municipios y departamentos 10,6\%. Para la fundación de nuevos poblados se otorgaron 18 concesiones con un total de 141.819 hectáreas equivalente a 4,4\% de la tierra entregada en ese período. 
ya abiertos por los colonos, y en los pleitos sobre derechos a la tierra la ley favorecía sobre los demás aspirantes a quienes la hubieran labrado durante cinco o más años. Así, en los años posteriores a 1870 el congreso colombiano reconoció explícitamente un conflicto potencial entre colonos y grandes empresarios, y al hacerlo tomó partido por los colonos. Los cultivadores de baldíos fueron el único grupo campesino de Colombia cuyos derechos obtuvieron una definición legal explícita a fines del siglo XIX y comienzos del XX. Al mismo tiempo, el gobierno incitaba a los colonos independientes a solicitar por vías legales la adjudicación de la tierra que cultivaban, pues sin títulos de propiedad no podían vender ni hipotecar sus parcelas. Al fortalecer así los derechos legales de los cultivadores y al facilitar la obtención de sus títulos de propiedad, el gobierno colombiano buscaba estimular la colonización y utilización económica de los baldíos por ambos, grandes y pequeños productores (p. 38).

Tabla 9: Peticiones por usucapión ${ }^{72}, 1870-1931$

\begin{tabular}{|c|c|c|c|}
\hline Años & Colonos & Otros & Totales \\
\cline { 1 - 1 } $1870-89$ & 2 & 3 & 5 \\
\cline { 1 - 1 } $1880-89$ & 23 & 18 & 41 \\
\cline { 1 - 1 } $1890-99$ & 37 & 43 & 80 \\
\cline { 1 - 1 } $1900-09$ & 64 & 95 & 159 \\
\cline { 1 - 1 } $1910-19$ & 94 & 98 & 192 \\
\cline { 1 - 1 } $1920-29$ & 210 & 160 & 370 \\
\cline { 1 - 1 } $1930-31$ & 24 & 39 & 63 \\
\cline { 1 - 1 } TOTAL & 454 & 456 & 910 \\
\hline \multicolumn{2}{|c|}{ Otros: Municipios, terratenientes, particulares } \\
\hline \multicolumn{4}{|c|}{ Fuente: LeGrand (1988). } \\
\hline
\end{tabular}

72 La usucapión es una categoría mencionada constantemente en códigos, leyes, decretos, memoriales, etc., revisados en esta investigación. Se entiende como usucapión, la hoy conocida prescripción aquisitiva o positiva; es un modo de adquirir la propiedad sobre una cosa. Para el análisis amplio, ver Palacios (2011) 
Gráfico 4: Peticiones por usucapión, 1870-1931

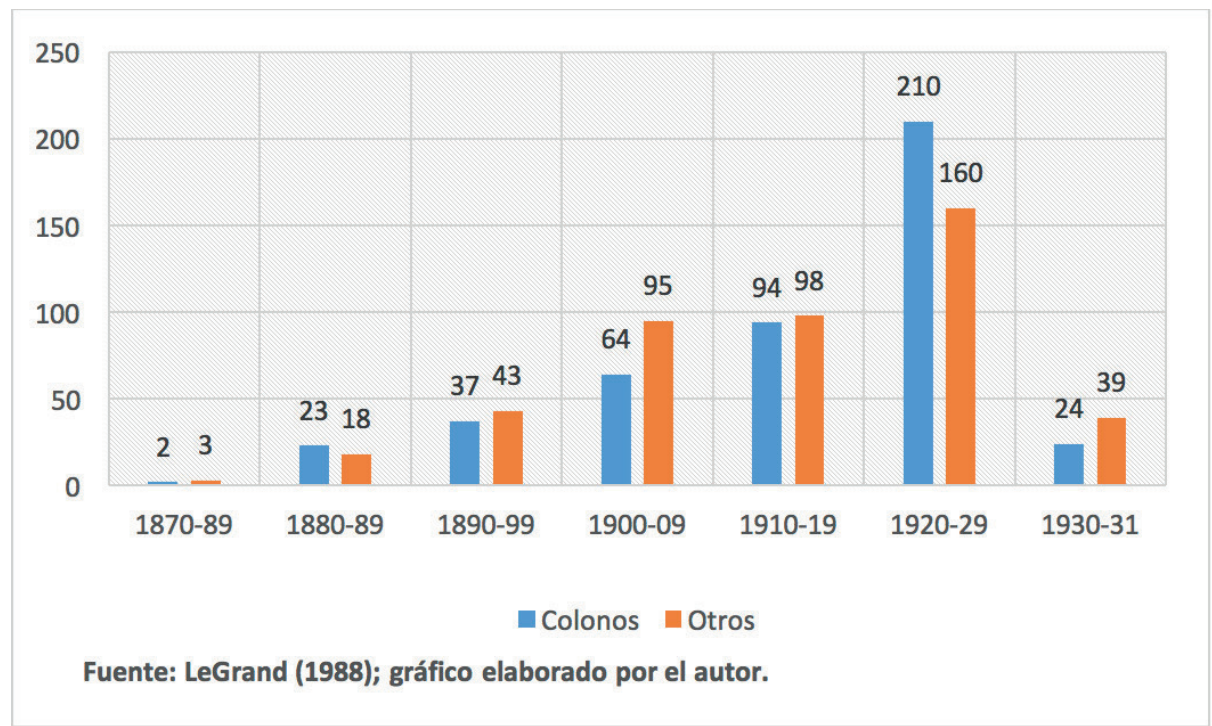

Las principales leyes emitidas durante el siglo XIX en relación con la tenencia, ocupación y propiedad de la tierra fueron: la 61 de 1874, 52 de 1877 y 48 de 1882, junto con varios decretos ejecutivos en desarrollo de lo precipitado por ellas, esto sin contar con las guías dispuestas para que el público interesado supiera cómo se debía pedir una adjudicación. En el siglo XX como dice Vélez (2012) la legislatura gira en torno a cuatro etapas...

Asociadas a otras tantasleyes fundamentales en las que se plasma la orientación de la política. La ley 200 de 1936 define la primera, orientada principalmente a la legitimación de los títulos y subsidiariamente a la redistribución. En 1944, con la ley 100 de ese año, se entra en una especie de interregno: regularizar las formas de trabajo en el campo era su objetivo. Con la ley 135 de 1961 se retoma con fuerza el problema de las redistribución. Sin renunciar expresamente a la intervención estatal directa en la distribución de la propiedad rural, las leyes 4 y 5 de 1973 y 6 de 1975 reorientan la política hacia el fomento de la producción y bajan el énfasis a las cuestiones la tenencia. Con la ley 160 de 
1994 se busca dejar en el mercado la cuestión de la tenencia apoyando el acceso del campesinado pobre a la tierra con el crédito subsidiado ${ }^{73}$.

Ahora bien, la producción de leyes para este periodo es ubérrima y la constante es querer regular las adjudicaciones, entonces ¿Cómo se adjudica?, ¿Cuál dependencia debe encargarse de hacer las gestiones? De acuerdo con el Decreto de 7 de enero de 1870, la Nación se reservaba el derecho de usar los baldíos en deuda pública a menos que se reclamara por un empresario extranjero, un colegio o nuevos pobladores. Con el fin de llevar los trámites del proceso, se destinó la a Secretaría del Interior y Relaciones exteriores; sin embargo cuando se trataba de militares que requerían baldíos, se encargaba a la Secretaría de Guerra y Marina ${ }^{74}$.

El mencionado Decreto también especificaba el proceso adecuado para denunciar un terreno baldío, sin embargo por su ambigüedad se tuvo que ajustar. Para el ejecutivo era claro que "la concesión de licencias para explotar bosques nacionales, en grandes extensiones, [podía] producir el monopolio de este ramo de riqueza nacional, en favor de pocas personas"75.

El Gobierno sabía que los fenómenos denunciados por los cultivadores o algunos propietarios eran ciertos y que realmente el gran perdedor era la Nación, pues al final no tenía cómo controlar la adjudicación y fluctuación real de la propiedad; por ello, otros parágrafos del Decreto establecían como extensión máxima 2 leguas cuadradas de tierra. De allí en adelante, se emitieron más decretos aclarando parágrafos de otros decretos sobre el ramo, hasta la Ley 70 de mayo 14 que limitó la adjudicación de baldíos de la Nación.

En 1873, la Ley 106 de junio 13 instó en su capítulo segundo, artículo 875, a las administraciones regionales de la Unión, para que obtuvieran un conocimiento exacto de los bienes que tenía la Nación en forma de baldíos, a su vez establecía una

73 Recuperado de: http://luisguillermovelezalvarez.blogspot.com/2012/03/politca-y-legislacion-detierras-en.html.

74 Memorias del Ministro de Industrias al Congreso de 1931, Bogotá, Imprenta Nacional, p. 74-84.

75 Memorias del Ministro de Industrias al Congreso de 1931, Bogotá, Imprenta Nacional, p. 85. 
Oficina de Estadística Nacional con empleados y sueldos expresados en el artículo 1197 del mismo código.

En el artículo 871 de dicha Ley se reputaban como baldíos y por consecuencia de propiedad nacional:

1) Las tierras incultas en los territorios que administra la nación.

2) Las márgenes de los ríos navegables no apropiados a particulares con título legítimo.

3) Las costas desiertas de la República.

4) Las islas de uno u otro mar, dentro de la jurisdicción de esta, que no estén ocupadas por poblaciones organizadas o por poblaciones con justo título.

5) Las tierras incultas de las Cordilleras y Valles ${ }^{76}$.

Como se esperaban protestas por dicha Ley, el siguiente artículo establecía que:

Los que se consideren dueños de partes de la tierra expresada en el artículo anterior, o que pretendan tener algún derecho a ellas, deberán comprobarlo ante la Oficina de la Estadística Nacional, con título legítimo, o con la justificación legal de haberlas poseído durante veinticinco años, con posesión real, continua y efectiva del terreno cultivado ${ }^{77}$.

De igual manera, se estableció que los gobiernos de los 9 estados deberían buscar las estrategias más adecuadas para deslindar los terrenos particulares de los nacionales.

Después de 1870, los problemas con la tierra se agudizaron debido a las migraciones y el interés por poblar, por ello la primera ley que termina por ser parte del Código Fiscal (sesión X) fue la 61 de 1874, en la que por primera vez el colono estaba protegido y se reconocía su dominio sobre las tierras cultivadas y cultivables. Recuérdese que en los códigos anteriores, este entraba en competencia con el posible comprador

76 Memorias del Ministro de Industrias al Congreso de 1931, Bogotá, Imprenta Nacional, p. 99.
77 Memorias del Ministro de Industrias al Congreso de 1931, Bogotá, Imprenta Nacional, p. 85. 
y los baldíos no se orientaban principalmente al fomento de una colonización de pequeños propietarios ${ }^{78}$, aunque se privilegiara al colono si tenía con qué adquirir la propiedad denunciada ${ }^{79}$.

Dada la presión social sobre los baldíos, se tuvo que afinar la ley mencionada, por lo que el 1 de julio de 1873 se emitió desde el ejecutivo, una resolución comunicando a través del Diario Oficial número 2910 que:

Tanto en las adjudicaciones hechas ya, como en las que adelante se haga, se entenderán decretadas sin perjuicio de los derechos adquiridos por los pobladores o cultivadores con anterioridad a dichas adjudicaciones, por tener establecida casa y labranza, en los terrenos que se trate al tiempo que se decrete la adjudicación, conforme a la Ley del 9 de marzo de 1863. En consecuencia, siempre que hayan individuos establecidos con casa y labranza dentro los linderos de la extensión que se adjudica, dichos individuos no podrán ser perturbados en la posesión y propiedad del terreno a que tengan derecho; y la adjudicación será nula en la extensión correspondiente al número de cultivadores que tengan derechos adquiridos, en la proporción de 6 hectáreas, 4000 metros cuadrados por cada una ${ }^{80}$.

Aclarar la adjudicación y explotación es interesante por dos cosas a saber: la primera, es que efectivamente se reconoce al colono como propietario y se privilegia si este está previo al deslinde; el problema central se verá en las siguientes leyes porque finalmente le tocaría al colono justificar con testigos que allí tenía casa y

78 Este caso se puede ver también en países como Costa Rica donde la distribución de los baldíos se pensó principalmente para pagar deuda pública aunque finalmente en el auge exportador los pequeños propietarios fueran protegidos por la Ley. El asunto interesante es que, como en el caso colombiano, el éxito de dichas leyes estaba determinado por la capacidad de movilización social que tuvieran los actores inmersos en el conflicto. LeGrand (1988).

79 Podría mencionarse como ejemplo el caso de la Ley 106 de 1873 que rigió hasta el 1 de abril de 1913 donde, en su artículo 895 decía que: "Los que se hayen [sic] en posesión de tierras baldías al tiempo que se vendan, con casa y labranza en ellas, pero sin título de propiedad, y los que las hayan denunciado y hecho los gastos de medición y avalúo, tienen derecho a ser preferidos en la venta en igualdad de posturas; pero si lo intentaren tanto el poseedor como el denunciante, será preferido el poseedor" (Memorias del Ministro de Industrias al Congreso de 1931, Bogotá, Imprenta Nacional)".

80 Memorias del Ministro de Industrias al Congreso de 1931, Bogotá, Imprenta Nacional, p. 121 
labranza, así como también, que llevaba un número de años para acceder al derecho de usucapión. El otro factor clave en esta ley es que hace relación al número de hectáreas para cultivo; ¿Cuánta tierra necesita un campesino?

El número de hectáreas adjudicadas es un elemento importante no solo para evitar la concentración de la propiedad, sino para darle un uso racional a los bienes. El Estado que describimos en estas páginas se vio inmerso en el debate de cuánta tierra debería adjudicar, cómo debería adjudicarse, qué tipo de producto privilegiar; o si se entregaban más hectáreas, cuántas si era para una población, un empresario territorial o un empresario agrícola. De igual manera, este asunto se convierte en un factor de movilización popular para reclamar derechos de propiedad, pues durante las discusiones sobre el número de hectáreas que deberían asignarse era común que se suspendieran las adjudicaciones con el fin de no afectar los intereses personales de aquellos interesados en incrementarlas o en su defecto, en no perderlas.

La publicación de la Ley 61 de 1874 fue el primer reconocimiento público al colono aunque también puede decirse, exacerbó la disputa entre los actores de la colonización. Al revisar la estructura de la ley, es claro que el colono adquiere para el Estado la figura de propietario de buena fe y solo podría ser privado de su propiedad en un juicio civil u ordinario. En el artículo primero, por ejemplo, se reconoce que:

Todo individuo que ocupe terrenos incultos de la Nación, a los cuales no se les haya dado aplicación especial por la Ley, y establezca en ellos habitación y labranza, adquiere derechos de propiedad sobre el terreno que cultive, cualquiera que sea su extensión ${ }^{81}$.

En los siguientes artículos, la ley privilegia al colono sobre cualquier otro interesado en adquirir títulos sobre un baldío; el artículo segundo expresa que al haber cultivos se adjudicará el doble de su terreno y si hace cercas, entonces este colono adquiere propiedad dentro de sus cercas. Más adelante, en el artículo cuarto, se reconoce no solo la propiedad del colono sino que se premia con 30 hectáreas más, siempre y

81 Memorias del Ministro de Industrias al Congreso de 1931, Bogotá, Imprenta Nacional, p. 122. 
cuando, tenga sus respectivos cultivos, casa y lleve más de cinco años habitándola. No siendo suficiente, la ley estableció dos artículos que llaman la atención: el artículo quinto, que reconocía el posible conflicto de intereses, por lo que la Ley expresa que:

Cuando en una misma localidad se establezcan varios pobladores y en la prosecución de sus trabajos se ocasionaren disputas, la autoridad política encargada de la administración del Distrito o Corregimiento a que corresponda la localidad, a solicitud verbal o escrita de cualquiera de los pobladores, hará comparecer ante ella a los individuos entre quienes se haya suscitado la disputa, y si no pudiere lograr que estos avengan amigablemente, procederá, previa inspección ocular del terreno, a demarcar provisionalmente los límites dentro de los cuales cada uno de los colonos puede continuar sus trabajos. El funcionario encargado de hacer la demarcación dejará constancia, de todos los incidentes de ella en un expediente, que remitirá al Presidente o Gobernador del Estado o Prefecto del Territorio para su apropiación ${ }^{82}$.

Por su parte, el artículo 13 dejó la responsabilidad en los servidores públicos de publicitar la ley, así como también, guardar a los colonos a través de la vigilancia sobre el cumplimiento de la normativa.

Otra ley mencionada por los colonos fue la 52 de 1877 que derogó el artículo 12 de la ley 61 de 1874, donde se establecía que los lotes superiores a 200 hectáreas, deberían ser trazados como cuadrados y la ley 48 de 1882, la cual se diseñó con el fin de poner fin a los alegatos entre colonos y supuestos propietarios. Esta ley se conoció como 'la prueba maldita', dado que exigía, en su artículo cuarto que:

En el juicio plenario de propiedad del terreno único admisible contra cultivadores de terrenos baldíos, establecidos en ellos con casa y labranza, el actor deberá exhibir los títulos legales de la propiedad de la tierra que reclama, que tengan una antigüedad de diez años, por lo menos, y en los cuales se expresen, con toda claridad, los linderos del terreno que reclama como suyo ${ }^{83}$.

82 Memorias del Ministro de Industrias al Congreso de 1931, Bogotá, Imprenta Nacional, p. 121.

83 Memorias del Ministro de Industrias al Congreso de 1931, Bogotá, Imprenta Nacional, p. 149. 
Evidentemente, este requerimiento ponía en desventaja a los colonos aunque la misma ley estableciera en su artículo primero que los principios de propiedad se adquirían con cultivos y que el ministerio ampararía a los cultivadores como lo establecía la ley 61. Como veremos más adelante, las estrategias de los reclamantes con títulos eran de diversa índole, pues el problema del poblamiento y la legalización del mismo estaban comúnmente imbricados por distintas variables. En muchos casos, los cultivadores no conocían de las leyes que les protegía, en otros, los conflictos se dieron entre los mismos cultivadores y también es evidente que las cercanías políticas y familiares entre los actores del proceso, crearon una especie de grieta entre la norma y la realidad, donde se filtraban los efectos esperados de la ley.

De todas formas, no está demás pensar que en el siglo XIX colombiano se producía tanto derecho que no se cumplía, porque "su función no era ser cumplido, sino legitimar a los gobernantes. En otras palabras, porque el derecho una y otra vez legitima a los gobernantes con su eficacia simbólica" (García, 2014, p. 19) 84 $^{84}$

Finalizando el siglo XIX, dos fenómenos nuevos, además del crecimiento poblacional, fueron relevantes para la colonización en las regiones colombianas: la crisis cafetera y la Guerra de los Mil Días (Villegas y Yunis, 1978; Jaramillo, 2007). De acuerdo con Sánchez, Fazio y López-Uribe (2010), cuando se hace una revisión de las notarías en relación a la fluctuación de baldíos, la evidencia muestra que:

A comienzos de la década de los ochenta se presentó una reducción en la titulación que estuvo seguida por una recuperación que comenzó en 1886, cuando un nuevo ciclo de crecimiento exportador comenzó, llegando a alcanzar un pico de 3.000 kilómetros cuadrados entre 1891 y 1895. Las concesiones de tierras tuvieron su nivel más bajo entre 1901 y 1905, justo después de la Guerra de los Mil Días. Una vez la guerra terminó, la titulación de tierras aumentó alcanzando su nivel máximo entre 1920 y 1925 (Sánchez, Fazio, López-Uribe, 2010, 255).

84 A propósito de la sociología jurídica, el análisis del profesor Mauricio García Villegas da muchas pistas respecto a la prolija normatividad colombiana pero su incapaz aplicación en la vida cotidiana. Para un debate de mayor envergadura ver: Boaventura de Sousa Santos (2009). 
Gráfico 5: Número de transacciones y kilómetros cuadrados adjudicados de baldíos, 1850-1930 (en períodos de 5 años)

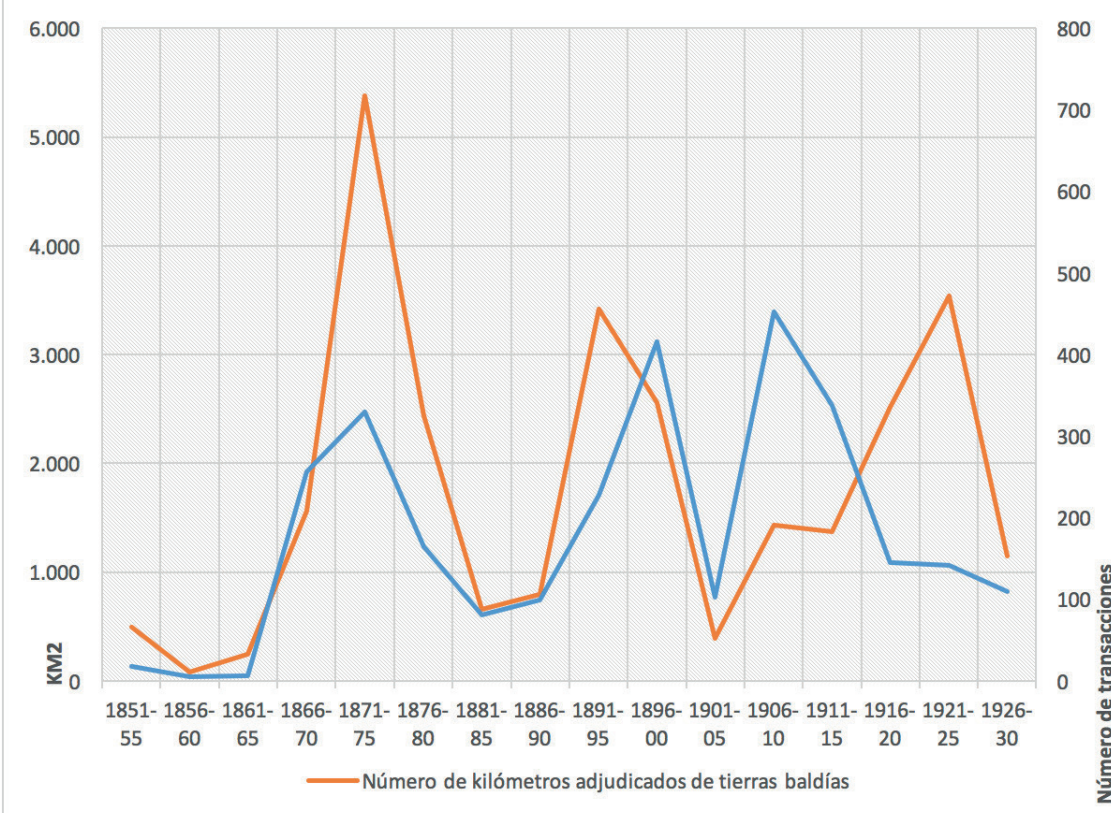

Fuente: Sánchez, Fazio y López-Uribe (2010, p. 255).

De acuerdo con LeGrand (1977) y Palacios (2002), se puede resaltar que las características de los conflictos y la fluctuación de las propiedades, estuvieron determinados por dos factores después de 1870; en el primero:

La mayor demanda de titulación de tierras que coincide con la oferta de titulación por parte de los colonos, cuyo fin era adquirir derechos de propiedad formales sobre sus tierras; y el segundo, la usurpación por parte de los terratenientes de los mismos terrenos; impulsados éstos por las mayores expectativas de ganancia sobre los retornos de la tierra (Sánchez, Fazio y López-Uribe, 2010, p. 257).

A estos dos factores, hay que sumar la argumentación de los colonos en sus peticiones: la transformación en el paradigma de la propiedad. 
En el siglo XX, la riña entre la realidad y la teoría jurídica ya no es latente sino manifiesta; hay mucha gente viviendo y explotando baldíos y tierras privadas a manera de colonato, arrendamiento y otras figuras no consideradas en el marco jurídico del trabajo, pero asumidas como consuetudinarias; por otra parte, el Estado quiere regular el proceso de colonización pero no sabe cómo porque las leyes, decretos y pronunciamientos son muchos y no hay orden al respecto.

P. Gilhodes (1989) plantea que en la transición del XIX al XX son tres las cuestiones que determinaron la característica de los conflictos agrarios y claro está, la orientación política de las tierras: por un lado estaba la resistencia indígena a la disolución de sus resguardos, caso álgido en el Cauca, los conflictos en la colonización de tierras nuevas y los conflictos entre arrendatarios y hacendados, asunto que se pretendió resolver con nuevos códigos y finalmente con la Ley 200 de 1936, aunque antes de la mencionada Ley 200 se emitieron leyes como la 56 de 1905 que tuvo vigencia hasta 1911 (Arango, 1977).

Si se pretende concluir este punto, puede decirse que hay tres aspectos que emergen como posibles obstáculos para consolidar los proyectos políticos de la colonización y un Estado fuerte y garante de las reglamentaciones jurídicas; el primero tiene que ver con la ya mencionada ambigüedad normativa que ponía de presente no solo la falta de unificación de los códigos sino la incapacidad del Estado por regular con sus agentes, los procesos de adjudicación y titulación de los bienes; el segundo tiene que ver con la participación de los empresarios y colonos interesados en la adjudicación y titulación de tierras, quienes se valieron de sus contactos familiares o de amiguismos para utilizar las leyes a su favor y aprovecharse de sus conocimientos al respecto, y el tercero, tiene que ver con la actitud asumida por muchos colonos, que por diversos motivos tales como desconocimiento de las leyes, tradiciones sobre la idea de propiedad, o los costos y dificultades para titular, optaron por una acción violenta con el fin defender sus propiedades de los ataques perpetrados por los supuestos dueños, o en su defecto, terminaron huyendo hacia otras zonas despobladas. 
En el siguiente capítulo, se pretende profundizar sobre los problemas mencionados, por tal motivo, emergen categorías como práctica política y las subcategorías mencionadas previamente: protestas, levantamientos, quemas, estrategias para controlar los concejos municipales, etc. Teniendo presente esto, se mostrará cómo el Estado es producto de la interacción entre agentes (burocracia) y la presión social; cómo las estrategias sociales pueden ser consideradas en el marco de la categoría política al recurrir a la perspectiva arendtiana y cómo el proceso de colonización del Quindío, es un caso de estudio viable para analizar las relaciones sociales en el marco del proceso formativo del Estado. 


\section{CAPÍTULO CUARTO: LOS ESTUDIOS DE CASO}



"Siempre fue la repartición de las tierras un problema vital para las sociedades, cuya paz y consecuencial engrandecimiento se basa en la armonía de todos los derechos y en la posibilidad de mejora para todos los asociados" (Memorias del Ministro de Agricultura y Comercio, 1917, p. LXXVIII).

\subsection{Las prácticas políticas o la instrumentalización de lo institucional; el Quindío entre 1880 y 1930}

En este capítulo se pretende ampliar el análisis de los conflictos surgidos durante la colonización del Quindío, por ello se usaron algunos casos hallados en el AGN, que por su característica, no solo fueron relevantes en la región sino que facilitan la discusión de las categorías Estado, colonización y práctica política.

La importancia de estos conflictos radica en el seguimiento a su transformación, pues pone en evidencia las prácticas de las burocracias locales como también, las estrategias de los colonos, cultivadores, abogados, agrimensores y demás actores de la colonización quienes a través de repertorios de protesta, se movilizaron para 
alcanzar fines. Como resultado de esta interacción entre burocracias y actores sociales, tenemos la construcción de unas prácticas políticas que contribuyeron al diseño de la estructura jurídica para regular la tenencia, ocupación y propiedad de la tierra.

El capítulo se divide en tres ítems: en el primero se pretende analizar la perspectiva que tenía el gobierno central sobre los procesos de colonización y los conflictos por los baldíos. Para el desarrollo de este punto se usaron las memorias de los ministerios de Gobierno, Industrias, Agricultura y Comercio, Hacienda y el Procurador Departamental.

Lastimosamente no se pudo acceder a todas las memorias de los ministros, pues el Archivo del Congreso se encuentra en un proceso de organización documental y gran parte de la información estaba extraviada; aun así se pudo consultar un importante volumen de información que nos permitió identificar dos posturas sobre la materia: la conservadora y la liberal de los años treinta (30) del siglo XX. El segundo ítem aborda la construcción del poder político en lo local; para ello se recurre al uso de la categoría práctica política, como guía de análisis de las estrategias usadas por los colonos con el fin de controlar los campos de poder, y de esta manera, enfrentar a empresarios y algunos representantes del Estado que estaban en su contra.

Este aparte se construyó con base en la documentación del Archivo General de la Nación (AGN) -en especial el fondo baldíos-, el Archivo Municipal de Cartago y el Archivo Central del Cauca, que se relacionaba con las disputas entre los colonos de Calarcá y la empresa Burila.

Como la categoría reconoce a quienes están dentro del campo político y en sus márgenes, fue necesario identificar casos que expusieran movilizaciones representativas para la investigación. Por ello se tomó el pleito entre cultivadores y colonos contra el concejo de Calarcá, poniendo de presente que los repertorios de protestas son una fuente para justificar la categoría de práctica política y Estado, 
pues este se va formando como producto del interés de las burocracias sobre algún ámbito y de la presión social.

El tercer ítem presenta varios casos en los que algunos colonos ganaron los pleitos; sin embargo, consideramos importante mencionar la suerte de quienes los perdieron y quedaron involucrados en disposiciones judiciales. Lo relevante es ver cómo la instrumentalización de las instituciones se convirtió en el arco del triunfo para muchos.

La transformación de los conflictos estudiados nos permitió identificar la reacción de las autoridades locales y nacionales para resolver los problemas de orden público generados por las protestas. Posteriormente, se analizó el tipo de representación que construyó el receptor de las normas; pues así como muchos acogían el debido proceso, la algidez de los conflictos, combinada con la dilación y presión social sobre las tierras, creó un coctel de desmanes y violencia que impulsó a muchos cultivadores hacia las vías de hecho, desestimando la legalidad y forzando al gobierno a emitir fallos al respecto.

Durantela administración conservadora, los fallos administrativos y judiciales fueron principalmente represivos; durante los gobiernos liberales hubo una permisividad y al parecer, un interés por reconocer las razones de dichas movilizaciones.

Veamos a continuación el desarrollo de esta propuesta.

\subsubsection{Conflictos y formación del Estado, una perspectiva institucional de la colonización}

"El país ha vivido formal y superficialmente una vida democrática; es el momento de que empiece a vivirla real y profundamente". Darío Echandía. (Memorias del Ministro de Agricultura, 1935, p. III). 
En su disertación sobre la eficacia simbólica del Derecho, Mauricio García (2014) planteaba que:

Buena parte del derecho radica en que funciona como un utensilio que puede ser usado para distintos oficios, uno de los cuales es el propiamente jurídico. Su eficacia no solo se debe medir por su capacidad para alcanzar los objetivos jurídicos que se proponen en sus normas, sino también, y a veces de manera preferente, por la capacidad para alcanzar otros objetivos, de tipo político, a través de la representación que el lenguaje normativo produce entre los receptores de esas normas (p. 46).

En este sentido, ¿qué relación había entre el derecho y la propiedad sobre la tierra?, ¿cómo las burocracias leían las necesidades de la sociedad en el ámbito agrario?, ¿servía la estructura jurídica para alcanzar objetivos ajenos a las normas?, ¿qué representación podrían haberse hecho los receptores de las normas?, ¿las reacciones de dichos receptores contribuían al diseño de nuevas estructuras institucionales?, ¿podríamos pensar que las reacciones de los receptores, son parte en la construcción del Estado?

Para adentrarnos en las disposiciones normativas del ramo de los baldíos, es necesario tener presente no solo la emisión de leyes sino también, contextualizar las burocracias y el tipo de Estado que se estaba construyendo; con sus tiempos y sus sistemas administrativos.

Tengamos presente que para finales del siglo XIX, el país venía de un desmoronamiento institucional generado no solo por las guerras civiles, sino también por la incapacidad para controlar los distintos ámbitos que componen las estructuras estatales, por ejemplo: no se contaba con un ejército nacional, tampoco había un control centralizado sobre las finanzas públicas y la emisión de moneda; la recaudación de impuestos era casi que precaria y riesgosa, y cada gobernador de los 9 estados autónomos, podía disponer a su favor del fisco público y por el lado de las burocracias, estas eran más venales que racionales, por lo que la centralización del 
poder político fue el primer paso para levantar de la crisis a Colombia (Palacios y Safford, 2002; Bushnell, 2002; Flórez, 1985).

Como vimos en el capítulo anterior, en lo que respecta a los baldíos, la legislación era abundante, pero ambigua, especialmente después de 1870 cuando se combinó el crecimiento poblacional con la demanda sobre tierras productivas, generando una movilización de brazos hacia nuevas zonas consideradas como fronteras de colonización; por lo que se esperaría que los conflictos fueran el común denominador, especialmente si se trataba de contextos donde los intereses económicos de algunas personas, contaban con el favoritismo y respaldo de las administraciones locales.

Además de esto, el problema de la tierra traía consigo más que la misma demanda sobre los baldíos, pues la transición del siglo XIX al XX implicó la transformación del paradigma de riqueza ${ }^{85}$, como también de orden social. Las revoluciones obreras del mundo europeo, junto con la presión poblacional, exigían una restructuración de los Estados, asunto que para América Latina y Colombia no era ajeno (Halperin, 1981).

Fue por ello que la república de 1886 pretendió legitimarse a través de la racionalidad política y administrativa; sin embargo sostenía sus pilares jurídicos en principios conservadores (Jaramillo, 1964) y por más que la legislación quiso proteger a los pequeños cultivadores, la falta de herramientas legales y el peso de un pasado colonial, ponían no solo al Estado a disposición de unas elites tradicionales, sino que cultivaban la disidencia y deslegitimación de la institucionalidad.

En la transición del siglo XIX al XX, las tierras productivas y las nuevas fronteras eran abundantes, quizá por ello inicialmente la conflictividad no fue significativa, pues el colono pobre abandonaba los predios movilizándose a nuevas zonas de frontera, mientras los ricos con injerencia en el campo político, peleaban por sus derechos en los estrados judiciales ${ }^{86}$; pero a partir de 1915, el agotamiento de las

85 Entendida esta como los bienes materiales.

86 Este caso se puede evidenciar en Calarcá, Sevilla, Armenia, Pereira y demás poblaciones del Eje Cafetero que se enfrentaron a empresas o políticos de la región, y ganaron los pleitos como se verá más 
nuevas tierras disponibles incrementó la presión social generando un choque entre cultivadores, empresarios, concejos municipales y otros colonos.

Como los pleitos duraban mucho tiempo, con el fin de presionar sobre las decisiones judiciales o administrativas, los implicados combinaron estrategias políticas enmarcadas en la legalidad, tales como los memoriales, las demandas, las querellas, etc., aunque también recurrieron a las que James Scott denominó como weapons of the weak. El recurso a la invasión, la quema de propiedades, el robo el abigeato y el asesinato, podría decirse que fue producto de la frustración de aquellos y aquellas que veían perder el esfuerzo de varios años, o en su defecto, que buscando suerte en las colonizaciones, perdían los pleitos por tierras o nunca volvían a saber sobre los mismos.

Esta crisis institucional, aunada a la transición social del siglo XX, obligó a que las administraciones gubernamentales se pronunciaran deslegitimando las movilizaciones de obreros y trabajadores de la tierra, al tiempo que igualaban las demandas con el socialismo; asunto aprovechado astutamente por las élites locales para justificar la represión.

A modo de ejemplo, está la circular emitida desde la Secretaría de Gobierno en 1919 que establecía las siguientes medidas en caso de presentarse una movilización social no avalada por las autoridades gubernamentales:

Que cuando una reunión pública degenere en sedición, en montón o tumulto, o en asonada, se proceda como lo disponen los artículos 216 y 223 del Código Penal;

Que en dicho caso se instruya el sumario contra los responsables, especialmente contra los promotores, y se les reduzca a prisión, de acuerdo con las leyes sobre procedimiento criminal;

Que se tengan presentes las disposiciones penales sobre sedición, montón o tumulto y asonada, y especialmente las de los artículos siguientes del Código 
Penal, y que se procure su estricto cumplimiento (Memorias del Ministro de Gobierno, 1919, p. XVII-XVIII).

Preguntemos nuevamente: ¿Qué representación podrían haberse hecho los receptores de las normas?, y si entráramos en detalle sobre cada disposición administrativa de los baldíos, ¿cómo leerían jurídicamente los cultivadores y colonos la transformación normativa?, ¿acaso se comprendian las necesidades agrarias de un país en crecimiento con un Estado pobre económicamente y débil en lo jurídico?

Durante los primeros años del siglo XX, se presenció un incremento de los conflictos; en algunas partes más que en otras, la presión sobre la tierra y la propiedad movilizó la atención del campo político que en ocasiones legislaba, en otras reprimía o en su defecto, hacía un alto para pensar sobre la suerte de las poblaciones y los inversionistas (Memorias del Ministro de Agricultura y Comercio, 1918, p. 19).

Con los liberales en el poder (1930), se pensó que se abriría la válvula de escape a la presión social. En las memorias y documentos públicos sobre materia administrativa, es común encontrar referencia a los beneficios que traería la intervención del ogro filantrópico (Paz, 1978) en los porvenires de la sociedad; es quizá por ello que el Ministro de Agricultura y Comercio, Darío Echandía, defendiendo la intervención del Estado en los puntos críticos del ramo: trabajadores y labriegos, se dirigía al Congreso de 1935 para explicar que:

El orden público es una resultante de la acción de determinado estatuto jurídico en determinado medio social. Cuando juricidad y realidad se acoplen naturalmente, habrá orden, y éste se verá perturbado cuandoquiera que se sobrevenga un desequilibrio o disparidad entre tales factores.

Suelen imputarse entre nosotros muchos tropiezos y deficiencias de la vida política a defectos de las instituciones: tíldase de reaccionaria la constitución; las leyes civiles de anacrónicas; arbitrario y bárbaro parece el código represivo; rudimentaria la legislación social.

Los hombres de Ley se inclinan a resolver con el mero expediente de las fórmulas legales, los complejos problemas de la política y la administración. 
No es de ahora, sin embargo, que contra esta panacea arguyó el clásico que de nada aprovechan las vanas leyes escritas si no están secundadas por vivas costumbres. Estas mismas, sin embargo, cuando operan al margen de la ley, demuestran una insuficiencia en ella. Por eso la costumbre codificada ha sido, en gran parte, la primera manifestación del derecho escrito; el legislador realista la consagra en textos positivos, precisándola y organizándola. El dato social, la necesidad sugerida por la experiencia, confirmada por el hábito, da cimiento a la construcción jurídica. Sobre ese dato la técnica del derecho obra para ir transformando los actuales de la realidad ambiente (Memorias del Ministro de Agricultura y Comercio, 1935, p. IV-V).

Sin embargo, si se sigue la discusión del ministro, nos surgen varias inquietudes: ¿podría considerarse la experiencia, el motor de una legislación agraria?, ahora bien, usando la perspectiva de Echandía, ¿las prácticas políticas a las que nos hemos referido, contribuían en la construcción del Estado? A continuación veremos cómo, desde la perspectiva de las burocracias centrales, se opinó sobre la materia agraria, los conflictos y la suerte de los actores de la colonización.

\subsubsection{Colonización, conflictos y Estado; consideraciones de las burocracias centrales en el ramo de los baldíos}

Revisar las consideraciones administrativas sobre la colonización, los conflictos y la raison d'être del Estado, permite analizar las posturas durante la transición del siglo XIX al XX, especialmente las relacionadas con las disposiciones y acciones legales de las burocracias locales, burocracias centrales y los cuerpos de control y vigilancia como las procuradurías y personerías municipales.

Como se discutía a lo largo del segundo capítulo, la presión demográfica sobre las tierras productivas y la inserción del país a los mercados internacionales, obligó a poner en disposición nuevas fronteras de colonización; pero como la regulación en las asignaciones era dificultosa, y la transparencia en los trámites estaba determinada por la buena fe, la conflictividad se hizo proporcional a la demanda sobre predios. 
Fue por ello que entre 1870 y 1930 se fraguaron las condiciones para lo que después llamaríamos "la cuestión agraria" (Gilhodes, 1989), haciendo referencia al conflicto político, económico y de orden público que azotó varios departamentos del país y transformó las relaciones sociales en conflictos armados; ¿pero por qué considerar estas fechas?

Si bien, se presentaron un importante número de demandas por tierras $\mathrm{y}$ adjudicaciones viciadas antes de 1870, esta fecha es clave porque el Estado comenzó una transformación jurídica en relación con conceptos y disposiciones como propiedad privada, número de hectáreas que pueden adjudicarse, uso de los baldíos, identificación y estadística de los mismos, límites de la propiedad privada, conceptualización y caracterización de los bienes, apropiación estatal sobre la riqueza, etc.

En cuanto a 1930, tanto en lo nacional como lo internacional, su importancia radica en la aceptación y consolidación del intervencionismo estatal, por lo que las burocracias centrales radicalizaron sus acciones a favor de la institucionalidad y en detrimento de las autonomías locales justificando públicamente la importancia de fortalecer los tentáculos del Estado hasta intervenir los campos de la vida cotidiana en lo público y lo privado.

Para el caso colombiano, los gobiernos liberales se aliaron con los movimientos populares y de partidos disidentes pretendiendo no solo llegar al poder y finalizar con más de 30 años de conservadurismo, sino también solucionar los problemas más urgentes del orden social, por ejemplo: lo laboral, lo agrario, lo comercial, la devaluación de la moneda, las exportaciones, la institucionalidad, etc.

Por otra parte, las movilizaciones campesinas, indígenas, estudiantiles, obreras y de mujeres, llenaron los periódicos locales y nacionales con noticias que traían incertidumbre o vientos de cambio; pero ¿Tiene relación la cuestión agraria con las disposiciones administrativas previas a esta fecha? ¿Podría decirse que la transformación normativa fomentada por el gobierno liberal, se fundamentó en los 
antecedentes de su administración? Aventurando una respuesta, de acuerdo con los resultados de esta investigación, podríamos decir que sí. Veamos a continuación las consideraciones de las burocracias centrales sobre las colonizaciones, los baldíos y el conflicto.

\subsubsection{Interpretaciones y disposiciones administrativas de las burocracias centrales sobre los baldíos}

Los conflictos por tierras y adjudicaciones se centraron básicamente en regiones donde había un importante crecimiento poblacional y procesos de colonización; sin embargo, varios factores determinaron la transformación de estos conflictos, entre los que se pueden mencionar, la concepción jurídica dada a este bien, junto con la capacidad del Estado para regular las respectivas entregas, explotación y uso de los baldíos.

Como podemos evidenciar en documentos oficiales, a partir de 1878 el Gobierno asumió el asunto como prioritario, proponiendo la creación de instituciones de vigilancia que hicieran deslindes y visitas a los respectivos municipios donde las autoridades locales eran incapaces de garantizar transparencia y cuidado en las adjudicaciones. Para tal fin, se emitió el Decreto 505 de 1881, que suspendía las entregas de tierras hasta que el Congreso legislara al respecto, exceptuando aquellos casos donde ya habían iniciado trámites legales.

De igual manera, el Gobierno hacía énfasis en la necesidad de legitimar el reciente y unificado Código Fiscal, porque en su artículo 940 se consideraba que:

En cualquier tiempo que se denuncie y se pruebe que un terreno adjudicado como baldío se comprende una estencion mayor de la que espresa la adjudicación, el escedente volverá al dominio de la nación, teniendo derecho el que haga y pruebe el denuncio, a que se le adjudique, de preferencia a cualquiera otro peticionario, el terreno que halla escedente [sic.] (AGN; Baldíos, tomo 2, Despacho de Hacienda y Baldíos, Bogotá, 15 de enero de 1878; ff. 378-380). 
Estas acciones permiten considerar que había interés para llevar a buen término las adjudicaciones, sin embargo, el vacío se presentaba al momento de entregar los predios, es decir, cuando las burocracias locales tenían que actuar en representación del Estado. ¿Qué pasos debían seguirse para la adjudicación de un terreno? ¿Qué disposiciones jurídicas establecían estos procesos? En 1878 era requisito que los interesados tuvieran un certificado del alcalde de la población donde se haría el requerimiento; de igual manera era obligatorio que los interesados fueran pobladores, cultivadores o colonos de los terrenos donde estaba la solicitud (art. 907 y 922 del código fiscal); posteriormente se enviaba la petición al Presidente del Estado Soberano y se procedía a la demarcación de los linderos y la mensura, lo que estaba considerado en el Decreto ejecutivo número 518 de 1874, que establecía demarcar de manera precisa y mencionar los predios colindantes para así respetar el poblamiento previo por derecho ${ }^{87}$.

¿Cómo se hacia la medición, verificación y entrega de las tierras que se estaban reclamando? Según el artículo 3, de la Ley 25 de abril de 1870, se encargaba a una Comisión Agraria para tal labor, y era:

La Corporación Municipal de la Aldea, si la hubiere, y en su defecto a la primera autoridad política a la que le corresponde hacer el nombramiento de [la dicha] Comisión Agraria. En cuanto a la comisión de los miembros de esta, llegado al caso, se estará a lo que los códigos políticos y municipal estatuyan sobre el particular [...] o que el poder Ejecutivo del mismo Estado resolviese en ejercicio de sus funciones. La Comisión Agraria tendrá un Secretario nombrado por la corporación municipal o la primera autoridad política de la aldea cuyas principales funciones serán las de autorizar todos los actos de la comisión y las copias de las diligencias de la entrega de cada lote de terreno que distribuya a los pobladores (AGN, Baldíos, tomo 2, agosto 19 de 1879, f. 468).

87 AGN, Baldíos, tomo 2, Oficina de Estadística Nacional, Mayo 12 de 1879, ff. 244-246. 
Pero no todos los procesos eran regulados fácilmente por las autoridades locales y nacionales, por lo que se dispuso a la Oficina de Estadística Nacional, apéndice del Despacho de Hacienda y Fomento, la resolución de asuntos relacionados con las invasiones a predios, los cuales serían posteriormente remitidos a los presidentes de los Estados $^{88}$.

A partir de 1878, la discusión sobre los baldíos se amplió significativamente en el Gobierno; la presión sobre tierras baldías, las constantes denuncias de abusos de autoridad, apropiación indebida y la necesidad de resolver el uso que se estaba dando a estos bienes, llevó a que la Cámara de Representantes se pronunciara, instando al poder ejecutivo para que suspendiera "en cuanto lo permitan las leyes nacionales, la adjudicación definitiva a particulares, de tierras baldías, mientras se hacen a los estados las adjudicaciones del número de hectáreas a que ellos tienen derechos por leyes nacionales preexistentes"89.

¿Quién era dueño de qué? ¿Cuántas tierras disponibles tenían los Estados Soberanos? ¿prescribían los bienes baldíos? Al año siguiente, nuevamente la Cámara de Representantes se pronunció pidiendo que no se hicieran adjudicaciones hasta que el Congreso legislara de acuerdo con las necesidades del contexto ${ }^{90}$. Como respuesta a los constantes llamamientos de esta instancia gubernamental, el Congreso respondió diciendo que:

La legislación sobre tierras baldías exige indudablemente reformas urgentes, tanto para evitar que esta propiedad mal -por lo menos en su parte mas valiosa y mejor situada - se adjudique a unas pocas manos i paralice el desarrollo industrial como para poner remedio siquiera a esa parte, a la destrucción de las riquezas vegetales que dichas tierras tienen, i que hoy se esplotan [sic] no solo sin precisión sino de una manera salvaje. [...] i que según es patente para todos, empieza a producir conflictos ${ }^{91}$.

\footnotetext{
88 AGN, baldíos, tomo 2, enero 30 de 1880, f. 257.

89 AGN, Baldíos, tomo 3, Secretaría de la Cámara de Representantes, agosto 20 de 1880, f. 79-80.

90 AGN; Baldíos, tomo 3, Secretaría de la Cámara de Representantes, mayo 31 de 188, f. 81.

91 AGN, Baldíos, tomo 3, Despacho de Hacienda, Bogotá, junio 2 de 1881, f. 97.
} 
La formación de la legislación agraria evidencia un interés por parte de las administraciones centrales para definir sobre quién descansaba la titularidad del bien, por ello podemos preguntarnos: ¿Eran los Estados Soberanos autónomos para disponer de los bienes baldíos? ¿Cómo podían hacer uso de ellos, o era el Estado central quien debía regular estas adjudicaciones, estableciendo un procedimiento riguroso y pormenorizado para garantizar el buen uso y la legalidad de las titulaciones?

Mientras se resolvían preguntas como estas, el Despacho de Hacienda pidió un informe de todas las tierras entregadas en adjudicación hasta $1881^{92}$, y el Senado en reunión plena pidió al ejecutivo que se abstuviera de:

Hacer adjudicaciones de tierras baldías hasta que el Congreso legisle sobre la materia, y nombre por presidencia una comisión para que redacte, lo más pronto posible un proyecto de ley en el sentido de que lo ha insinuado la Cámara de representantes y el poder ejecutivo nacional, y de acuerdo con las observaciones hechas en la discusión ${ }^{93}$.

¿Qué tan efectivo era este llamado del poder central para discutir las necesidades del ramo? Como puede evidenciarse en diversas comunicaciones, el Gobierno sabia que era necesario resolver jurídicamente los asuntos conceptuales y materiales vinculados a la colonización, pues como argumentaba el Ministerio de Hacienda:

Si nuestras riquezas han de ser destruidas fatalmente, vale más que sus despojos sean para todos en lugar de servir para unas pocas compañías que por contar con mayores recursos y mayores influencias, tratan de apoderarse de las tierras, escluyendo al pobre y al desvalido del beneficio que ellas les ofrecen para mejorar su condición [sic. ${ }^{94}$.

92 AGN, Baldíos, tomo 3, Poder Legislativo, Secretaría del Senado, Bogotá, marzo 28 de 1881, f. 436.

93 AGN; Baldíos, tomo 3, Poder Legislativo, Secretaría del Senado, Bogotá, junio 27 de 1881, ff. 447448.

94 AGN, Baldíos, tomo 3, Despacho de Hacienda, Bogotá, junio 1881, f. 98. 
Para resolver estos asuntos, se propuso una comisión que se dedicara al estudio pormenorizado de la situación y propusiera soluciones administrativas y coherentes con las necesidades del contexto histórico ${ }^{95}$, pero la discusión y viabilidad de los proyectos presentados se amplió hasta 1888, sin resolverse los problemas jurídicos de la materia; mientras tanto, en los sitios de concentración poblacional se seguían presentando las distintas formas de apropiación legal e ilegal que generaron los repertorios de protesta.

Como la comisión encargada al Ingeniero Ruperto Ferreira seguía insistiendo en la importancia y viabilidad de su informe, el 30 de abril de 1888 el Despacho de Hacienda consideró que era necesario volver a realizar una investigación que fuera coherente con las necesidades del año 88 y no como argumentaba Ferreira, quien pretendía avalar un informe presentado en 1886 , por lo que las características internas del proyecto excedían la viabilidad del mismo.

Decía el informe del Despacho de Hacienda, que el documento:

A la luz de quien lo discriminó, tiene 400 artículos que lo hacen excesivo, complica más los costos de las adjudicaciones, pone en riesgo el concepto de propiedad y por ello altera a los propietarios y por último, genera mayores dificultades para la adjudicación de tierras. De igual forma hay un desconocimiento de las disposiciones administrativas, pues asuntos que son del Ejecutivo terminan en manos del legislativo ${ }^{96}$.

¿Qué era poner en riesgo el concepto de propiedad? ¿Qué era alterar a los propietarios? ¿Por qué dificultaba más los procedimientos propuestos por Ferreira? El informe de la comisión pretendía que el Estado regulara todos los procesos, que asignara personal capacitado para hacer las respectivas adjudicaciones y que evaluara nuevamente los terrenos entregados con anterioridad al proyecto y de

95 En el tercer capítulo, ítem 3.2.1. o "El control de los baldíos, ¿Por qué hablar de las rendijas de la norma?" se hace una presentación más amplia del informe entregado por la comisión encargada al Ingeniero Ruperto Ferreira, para evaluar la pertinencia y estado de las adjudicaciones a 1886.

96 AGN, Baldíos, tomo 9, Despacho de Hacienda, Bogotá, abril 30 de 1888, ff. 58-70. 
ser el caso, reclamara la titularidad de los excedentes de tierras absorbidos por los terratenientes. De igual manera el proyecto quería dar mayores beneficios al pequeño cultivador en detrimento de las concentraciones de tierras, pero para el Gobierno conservador de finales del siglo fue más fácil desentenderse de la responsabilidad en las adjudicaciones, por lo que dejó a la discrecionalidad de los gobernadores el manejo de los baldíos.

En el siglo XX la situación no había cambiado y la cartera de los baldíos deambulaba entre ministerios y disposiciones jurídicas, dificultando los procesos de adjudicaciones. Al respecto, el Ministerio de Hacienda consideraba que si bien, los baldíos eran asunto del Ministerio de Obras Públicas, era necesario hacerle algunas observaciones para optimizar su uso, pues por su abundancia, el Gobierno y los ministerios a cargo no habían prestado la atención adecuada.

En el informe presentado al Congreso de 1914, decía el ministro que:

Escaso el país de población, y por ende de brazos para el cultivo de sus tierras ubérrimas, las leyes que se han expedido sobre baldíos han tenido siempre por fin principal atraer hacia éstos la acción civilizadora del trabajo; más desgraciadamente la liberalidad de nuestras leyes en la materia han dado ocasión a serios peligros para la Nación por parte de elementos extraños, y ello ha hecho pensar de que no es patriótico ni prudente entregar nuestras tierras incultas, asiento mañana de ciudades y pueblos, campo fecundo de industrias, quizá gigantescas, de modo desconsiderado o a tontas y locas [...]. Cierto que, dada la extensión y naturaleza de nuestras tierras baldías, su mensura y clasificación serían por extremo dispendiosas, pero esto no obstantes la necesidad y conveniencia en hacerlas se impone, y podría disponerse en la ley que aquellas se practicaran de preferencia en las regiones más importantes por su posición geográfica y otras condiciones ${ }^{97}$.

97 Memorias del Ministro de Hacienda, 1914, p. XXX-XXXI. 
Como se puede evidenciar, habían pasado más de 40 años y todavía no se resolvían las preguntas que hicimos al comienzo: ¿De quién son los baldíos? ¿Cómo deben adjudicarse? ¿Cuál es el uso y adecuado para explotar estos bienes? De igual manera se denunciaba que los baldíos eran importantes, pero el Estado no había podido administrar sus bienes adecuadamente, ni siquiera diseñando una estadística que diera cuenta de cuántas tierras tenía y cuántas había entregado.

En 1916, la Procuraduría General de la Nación hizo una inspección al Ministerio de Hacienda, nueva instancia encargada de la cartera de los baldíos, con el fin de verificar el estado de los procesos que se estaban llevando. El informe presentado al Congreso habla por sí mismo: decía el procurador que:

Por desgracia, en las diferentes reorganizaciones de los ministerios, el ramo de Baldíos andubo transhumante, y sólo ahora se ha venido a quedar adscrito al Ministerio de Hacienda, pero con notorias deficiencias de empleados y asignaciones e instalado en pésimo local que no ha permitido el arreglo de los archivos, ni independizar los valores del contacto público.

En aquella oficina se han consumado, según se deprende de la diligencia de la visita citada, hechos delictuosos, ya mediante la falsificación de bonos territoriales, por cantidad no despreciable de hectáreas [...] ora por la sustracción de bonos territoriales que respaldaban las corrientes solicitudes de adjudicación en forma de depósitos $[\text { sic. }]^{98}$.

Debido a la gravedad de la denuncia, el Gobierno pasó el ramo al recién creado Ministerio de Agricultura, quien en el informe al Congreso de 1917 presentó su preocupación por la situación de los baldíos, pues la negligencia de las administraciones locales, junto con la incapacidad del Estado para administrar adecuadamente, seguía prestándose para situaciones de corrupción y violencia en las regiones. Denunciaba el ministro varios asuntos entre los que se resaltan los siguientes: 
1. El amparo al pequeño cultivador de terrenos baldíos contra los adjudicatarios que adquieren grandes extensiones de tierra, a cambio de títulos de deuda o de concesión, no pueden descuidarse y pasar inadvertidos por más tiempo, sin riesgo de que, como por la comisión de toda injusticia, se formen y acumulen sedimentos de odio y de revuelta.

2. Conviene de modo urgente proveer también a la defensa de los derechos de la Nación sobre los terrenos baldíos contra ocupaciones fraudulentas, que a más de privar al Estado de bienes apreciables, dan margen a abusos que no están en su mano impedir ni contener.

3. Deseoso de obtener y recopilar el Ministerio, por Departamentos e Intendencias, datos acerca de la existencia y condiciones de tierras baldías en el territorio nacional, dirigió a todos los Municipios de la República una circular bastante detallada, que a pesar de lo fácil de contestar, sólo mereció la respuesta de ciento ochenta y dos entre las ochocientas municipalidades del país.

4. La apatía con que se corresponde a llamamientos y esfuerzos como el de que hablo, y cuyo objetivo en interés de los mismos municipios no puede ser más evidente, es supremamente desalentadora para quienes en el desempeño de su cargo y en el deseo de acertar, se ven en el caso de pedir informes y hacer investigaciones encaminadas a la solución de determinados problemas ${ }^{99}$.

Los tres elementos que resaltamos del informe traen a colación asuntos que fueron la bandera del gobierno liberal: el primero tiene que ver con la resolución de los problemas de las adjudicaciones, favoreciendo de esta manera a los presuntos verdaderos dueños de los predios y al pequeño cultivador. El segundo aspecto se relaciona directamente con el intervencionismo del Estado, pues aunque las administraciones conservadoras llegaron al poder con la Constitución de 1886, la herencia del liberalismo decimonónico mantenía vigente la discusión sobre las autonomías; asunto que se corrobora en el último punto mencionado en el cual las administraciones locales, por dilación o desacato al centralismo, no informaban de los pormenores de los litigios y las adjudicaciones.

99 Informe del Procurador de Hacienda, 1916, p. 79-81. 
Debido a que la discusión sobre la suerte de los baldíos se hacía más recurrente, el Gobierno emitió la Ley 71 de 1919, aunque no resolvió la titularidad de la Nación sobre los mismos; pero ¿por qué debía la ley referirse al respecto?, ¿acaso no se daba por sentado que el Estado era dueño del todo? Si bien, en la cultura popular podría considerarse que el Estado es el dueño de los bienes, en el ámbito jurídico, es la doctrina la que orienta la disposición judicial.

$\mathrm{Al}$ no haber una norma escrita que diera la titularidad de estos bienes al Estado, fue común la usurpación con el aval de los jueces que se reservaban la discrecionalidad interpretativa de las leyes. Por otra parte, la mencionada Ley 71 no daba solución a las adjudicaciones al considerar los baldíos como un todo igualitario sin discriminar la viabilidad en el uso de los suelos, ubicación y facilidades para el acceso.

Otro de los asuntos considerados en la ley era la creación de la Oficina de Longitudes con el fin, entre otras cosas, de diseñar varios planos que dieran cuenta de los terrenos baldíos que tenía la Nación; sin embargo, como informaba el Ministro de Agricultura al Congreso de 1818:

La Oficina de Longitudes [...] mal ha podido ejecutar esa labor. Compuesta de ingenieros, sin el concurso de abogados ni de información especial, y constantemente ocupada en importantísimos trabajos que se absorben todo su tiempo y atención, no se la puede culpar, por no haber ni siquiera iniciado el levantamiento de aquellos planos. El defecto ha radicado, en gran parte, en la misma ley, que no apreció suficientemente la índole especial de la Oficina que se creaba; pero, más que todo, proviene de la apatía e indolencia con que en el país se miran los asuntos de interés general ${ }^{100}$.

Y a renglón seguido, seguía expresando el ministro que:

A riesgo de parecer redundante, creo de mi deber insistir en que se adopte alguna medida en relación con este asunto, pues siendo negativo el título de la Nación a las tierras baldías, las cuales son del Estado por no tener otro dueño,

100 Memorias del Ministro de Agricultura y Comercio, 1918, p. 101 
se facilita extraordinariamente su apropiación, sin sujeción a las leyes, por los particulares. Requeridos que ellos sean para hacer la devolución al Estado, les basta para defenderse exigir que éste, como demandante y de conformidad con las disposiciones civiles y judiciales, suministre y presente la prueba de su propiedad, prueba que como negativa que es, no puede practicarse ${ }^{101}$.

Como se verá en los siguientes apartados, mientras más avanzaba el siglo más se exacerbaban los conflictos, poniendo de manifiesto la urgencia de una disposición administrativa en el ramo. Ahora bien, hubo pronunciamientos que favorecieron la represión, sin embargo los resultados eran desfavorables para la popularidad de muchos gobernantes quienes terminaban envueltos en denuncias por corrupción.

Después de 1920, el Ministerio de Agricultura optó por diseñar una política pública que lograra resolver el asunto de la propiedad real de los baldíos, por lo que era fundamental saber qué era privado y qué era del Estado. Para ello propuso dos vías; la primera consistía en el pago a un funcionario para que averiguara en las zonas de litigios, qué pertenecía realmente a la Nación y qué había sido entregado legalmente. El experimento se llevó a cabo en el Magdalena y como resultado de la investigación se:

Dictó la Resolución ejecutiva número 434, por medio de la cual se autorizó al Fiscal del Tribunal Superior del Distrito Judicial de Santa Marta para que iniciara las acciones y adelantara los juicios que fueran necesario o a que hubiere lugar, con el objeto de asegurar los derechos de la Nación en los terrenos baldíos existente en el Departamento del Magdalena y que se hallaran en poder de particulares sin título legítimo ${ }^{102}$.

La otra alternativa, más cercana a los intereses del Gobierno, consistía en titular a los particulares las tierras adquiridas legal o ilegalmente, siempre y cuando, estos colaboraran creando mapas y estadísticas sobre los predios. ¿Por qué en la Costa se

101 Memorias del Ministro de Agricultura y Comercio, 1918, p. 103.

102 Memorias del Ministro de Agricultura y Comercio, 1923, p. XVII. 
aplicaba una estrategia y en el resto del país otra? ¿Acaso las denuncias por desmanes y corrupción no eran suficiente para que el gobierno aplicara la misma estrategia de la Costa en todo el país?

Como primero, la situación de la Costa Atlántica era grave, pues no solo habían denuncias contra empresas extranjeras como la "United Fruit Company", la “Tropical Oil" o la "Colombian Railways \& Navigation Company", sino que también se denunciaban asuntos laborales y de corrupción en la administración local (Gaitán, J. (SF), LeGrand, 1989; 2007). Quizá por la presión social ejercida desde distintas instancias públicas y privadas, el Gobierno optó por medidas más acordes con las peticiones de la región. Sin embargo, para el caso del Quindío, podría decirse que la gravedad de los conflictos no alcanzaba la misma importancia; por otra parte, el Gobierno conservador no podía ser desacreditado entre sus aliados, por lo que era más fácil pactar que someter a quienes controlaban los predios con pleitos por ilegalidad.

Después de 1930 con la llegada al poder del Partido Liberal, las demandas hechas por cultivadores, trabajadores, indígenas y demás actores sociales afectados por los procesos de modernización, tuvieron un mayor reconocimiento. Contrario a los conservadores, las reformas liberales se orientaron hacia dos asuntos: 1) la importancia y legitimidad del intervencionismo estatal y 2) el reconocimiento de una legislación ambigua e inconsecuente con situaciones materiales insostenibles, por ejemplo: el abandono institucional del campo y la necesidad de legislar sobre la materia de los baldíos y las relaciones laborales ${ }^{103}$ (Pècaut, 1985).

Según el Ministro de Agricultura, Darío Echandía, la legislación en materia agraria era insuficiente para resolver el problema que tenía el país, por lo que consideraba necesario ajustar la estructura jurídica aunque no necesariamente se cambiara la Constitución.

103 Entre 1930 y 1938, los informes consultados de los ministros de hacienda, agricultura y gobierno tienen la particularidad de mencionar el intervencionismo estatal como fuente de orden social; de igual manera referencian países como Estados Unidos y hacen mención de su éxito económico y social como producto de la acción estatal en la vida pública y privada. 
En el informe que entregó al Congreso de 1935, Echandía se refería a las necesidades de su tiempo considerando que:

Los hombres que llevan la dirección del Estado están constreñidos a orientarse sobre el terreno de la realidad. Una política que se despegue del hecho real para seguir tras la exigencia lógica de un sistema rígido, estará destinada al choque desilusionante con las verdades concretas. Por eso antes de planear una reforma legislativa, es necesario otear bien el terreno donde la máquina ha de obrar, precaverse contra la explicación, demasiado fácil, de las deficiencias políticas y administrativas por la falta de acomodamiento de la constitución y las leyes del país a una teoría concebida a priori o recibida sin beneficio de inventario ${ }^{104}$.

Evidentemente se trata de una propuesta de intervencionismo estatal, pero a diferencia de los conservadores, Echandía instaba a que las consideraciones jurídicas estuvieran en concordancia con las realidades políticas. En su cartera, por ejemplo, se tenían que resolver dos asuntos claves: el laboral y el agrario; por tal motivo ¿cómo afrontar el momento que vivía el país?

Al respecto decía que:

El momento colombiano que vivimos es manifiestamente de adaptación de hechos nuevos a instituciones viejas. Las circunstancias ambientes han cambiado, conservándose en sus líneas generales el sistema jurídico, y de aquí resulta una situación de desequilibrio y desajuste. Siendo este hecho evidente, la labor de discriminación que debe anteceder a la reforma del estatuto legal del país, consiste en distinguir en éste las partes vivas de las caducas. Un criterio ligero sugiera, acaso, la renovación súbita y total; pero la experiencia secular enseña que el progreso legislativo se hace lenta y rítmicamente a medida que la observación demuestra la necesidad de sustituir las porciones muertas de las leyes ${ }^{105}$. 
Cuando se refirió al asunto agrario, el ministro no escatimó en detalles mencionando los desmanes que se venían presentando; de todas maneras, lo interesante de su descripción fue reconocer que los repertorios de protestas no eran algo únicamente de su tiempo, sino producto de procesos históricos en los que la acción estatal había sido indiferente ante los hechos cotidianos de los trabajadores y cultivadores. Igualmente, consideraba que el Estado tenía una deuda histórica que podría saldarse modificando la estructura jurídica agraria para hacerla consecuente con su tiempo y diseñando una estructura legal que resolviera los problemas del ámbito laboral.

En el marco de esta discusión, nuevamente se retomaron las categorías susceptibles de debate: la propiedad privada y el derecho del Estado sobre las cosas. En cuanto al primer asunto, mencionaba Echandía que:

La propiedad territorial no está suficientemente definida, porque no aparece claramente separada de la pública, porque la noción de posesión del suelo es vaga y poco inspirada en una tendencia al aprovechamiento económico de la tierra, y porque los procesos no están racionalmente organizados para asegurar soluciones rápidas, equitativas e ilustradas. El problema ofrece dos fases: el terrateniente no recibe de la ley títulos netos que le sirvan para mantener contra el Estado su propiedad; y el colono está expuesto a ser expulsado de la tierra reputada de otros, sin compensación por el trabajo que incorporó al suelo inculto, de buena fe, creyéndolo baldío ${ }^{106}$.

Al referirse al derecho que tenía el Estado sobre cualquier propiedad, el Partido Liberal siempre le fue favorable; sin embargo, la presión externa era contraria, tanto que se acusaba de inconstitucional sus propuestas. Un ejemplo, es la misiva enviada por la SAC (Sociedad Colombiana de Agricultores) en la que le increpaban diciendo que:

Dicho proyecto, al ser traducido en ley, sería peligroso para el derecho de propiedad que consagra la Carta Fundamental de la Nación, para el orden

Memorias del Ministro de Agricultura y Comercio, 1935, p. VIII. 
social, para la marcha normal de los negocios y para el desarrollo agrícola, porque sus vagas disposiciones fomentarían una serie interminables de pleitos hasta entre los mismos cultivadores a quienes se trata de favorecer con un nuevo concepto de propiedad, lo cual es abiertamente contrario a la Constitución que hoy nos rige y que establece que "los derechos adquiridos con justo título con arreglo a las leyes civiles por personas naturales o jurídicas, no pueden ser desconocidos ni vulnerados por leyes posteriores ${ }^{107}$.

\subsubsection{Consideraciones generales}

Durante la discusión, hemos pretendido analizar el proceso histórico de la legislación sobre baldíos; evidentemente existen dos momentos claves para referirse a los conceptos fundamentales del ramo: propiedad privada y control del Estado.

De un lado, los gobiernos conservadores consideraban importante la intervención, pero la presión de las elites locales impedía estas acciones. Por otra parte, podría pensarse que las administraciones conservadoras fueron permisivas con la corrupción, aunque también hay que reconocer la debilidad del Estado para intervenir, más cuando se trataba de un Estado disminuido por las guerras decimonónicas, inaugurando constitución (1886) y con una legitimidad en entredicho, especialmente después de la guerra de los Mil Días.

Con la transformación del ámbito laboral y agrario, se agudizaron los conflictos, tanto en las empresas como en el campo. Este asunto obligó a pensar con mayor urgencia las categorías susceptibles del ramo; pero fue con la llegada de los liberales cuando comenzó a discutirse con mayor interés el tema. Quizá las condiciones externas, como los compromisos adquiridos durante las elecciones, hicieron que el Gobierno no dudara en presentar proyectos reformistas; sin embargo, la condición del campo y de los obreros siguió siendo conflictiva y los intentos de reestructuración jurídica quedaron en el papel, pues finalmente la disposición de las elites locales y la capacidad de movilización popular, determinaron el éxito o fracaso de las políticas públicas.

107 AGN, Baldíos, tomo 5, sin fecha, f. 151. 
A continuación, analizaremos a través de varios casos la transformación de los conflictos como producto de la presión social y la reacción de las burocracias locales; esto con el fin de justificar que las prácticas políticas o estrategias de los actores, terminaron contribuyendo al proceso formativo del Estado.

\subsection{La construcción del poder local: la práctica política en la colonización}

Como hemos visto, las colonizaciones durante los siglos XIX y XX dejaron manifiesto que la centralización del poder estatal estaba determinado por la disposición de las burocracias locales y los actores sociales de las periferias, y no precisamente por el peso de las leyes y los aparatos de coerción. De igual manera, esta centralización no solo dependía de la voluntad de dichos actores, sino de su capacidad de agenciar e instrumentalizar el discurso político-legal y traer a los pleitos una parte del Estado, es decir, leyes y decretos que sirvieran a su favor; dinámica que permite considerar que todo lo que se ha cristalizado como político tiene un origen social y viceversa.

Otro elemento interesante es que finalmente los conflictos permitieron que el Estado se reformara constantemente y tuviera que ajustar las leyes sobre tenencia, ocupación y propiedad de la tierra a las necesidades que surgían en el transcurrir de los litigios.

También es necesario reconocer que la acción de los actores fue determinante para dichos ajustes, pues al revisar procesos judiciales de colonos, los memoriales enviados a los ministerios y Presidencia, y los informes entregados por agrimensores e ingenieros encargados de informar sobre la materia, se dilucidan varios elementos:

1. Si se trata de procesos judiciales: la constante es que los colonos invaden lotes que consideran baldíos porque, o no saben sobre su dueño, o en su defecto, al momento de la invasión, están en litigio por la ambigüedad con la que fueron adjudicados. 
2. Si se trata de memoriales: se considera necesario que el Gobierno tome cartas en el asunto legislando adecuadamente y teniendo presentes las necesidades materiales de los colonos, en relación con las posibilidades de acceder a una propiedad por las vías legales, y,

3. Si se trata de informes: los ingenieros y agrimensores se quejan de la incapacidad del Estado para consolidar su poder sobre los baldíos, pues no ha definido con claridad y estadística, cuáles son las tierras públicas y privadas, y tampoco ha logrado diseñar una política que facilite los procesos de adjudicación y control de dichos predios.

Otro elemento relevante tiene que ver con las autonomías locales, pues, aunque la experiencia regeneradora pretendió centralizar el poder político y administrativo a través del nombramiento desde el ejecutivo de personal para las gobernaciones departamentales, intendencias y comisarías; el autonomismo siguió vigente en la figura del Concejo Municipal, convirtiéndolo en un espacio político capaz de enfrentar directa o indirectamente las disposiciones del centro.

Fue así como surgieron dentro de este espacio de poder grupos de presión que se movilizaron, en algunos casos, a favor de colonos y en otros en contra de ellos; también fueron capaces de enfrentar con el uso de las leyes (instrumentalización) y repertorios de acciones tales como la invasión a predios, financiación de abogados y desarticulación de otras juntas pobladoras, a grandes empresarios que tenían vínculos directos con el poder central.

Pero si los concejos municipales sirvieron para garantizar las autonomías del poder local, también fueron administrados venalmente, y por ello los conflictos tuvieron varios procesos en los que el éxito consistió en la capacidad de agencia de los actores. Veamos entonces algunos ejemplos que nos sirvan como ejemplo para este análisis. El primer caso tiene que ver con la Empresa de Fomento y Colonización La Burila ${ }^{108}$ -de la cual ya se hizo mención en el tercer capítulo-, y el conflicto con los primeros colonos, la Junta Pobladora y finalmente el Concejo Municipal de Calarcá. Este pleito

108 Notaría Primera de Manizales, 25 de noviembre de 1884. 
tuvo una duración de casi treinta años y su transformación estuvo determinada por la capacidad de movilización política de los actores.

Inicialmente la empresa tuvo que enfrentar al Concejo de Salento, del que dependía administrativamente el primer asentamiento de colonos, después al formase la Junta Pobladora de Nueva Salento (hoy Calarcá), la empresa pretendió interferir argumentando que las tierras hacían parte de su territorio y cuando se creó el Municipio de Calarcá, las disputas se caracterizaron no solo por llegar a estrados judiciales, sino por la constante intervención de Burila fomentando la colonización de tierras en litigio, y por parte del Concejo de Calarcá y la Personería Municipal incentivando la ocupación de tierras que Burila consideraba como suyas y las justificaba en la primera escritura de fundación.

El segundo caso tiene que ver con el mismo Concejo Municipal de Calarcá, pero esta vez la práctica política no puede leerse como la defensa de los colonos, sino más bien como la defensa de los intereses municipales, los cuales a su vez tienen un matiz de venalidad al percibirse en las denuncias interpuestas por curas, el Procurador Municipal y los afectados directos del favoritismo por algunas personas del pueblo, como también la dilación en las adjudicaciones y el prevaricato. ¿Por qué tal comportamiento de los Concejales?

Evidentemente, se trata de un Estado en el que la herencia colonial e independentista, en relación con las autonomías regionales seguía vigente, y por lo tanto la centralización estaba filtrada, mediada y con una alta corruptela.

Como lo plantea Michael Mann (2006), el Estado no siempre sabe lo que hacen sus miembros y su cristalización no ha sido precisamente una y de la misma forma, más bien ha sido variada y está determinada por las necesidades de la misma sociedad. En su análisis sobre las burocracias, Mann plantea que se desarrollan racionalmente de acuerdo con sus prioridades dentro de la administración, sin embargo dependiendo del tipo de cristalización que tenga el Estado, priman unas lealtades. De esta manera: 
Los estados no establecen sus prioridades últimas entre funciones tales como la regulación de las clases, la centralización del gobierno o de la diplomacia. Los actores políticamente poderosos realizan la mayoría de las numerosas funciones estatales con el sentido pragmático, según la tradición y las precisiones del momento, y reaccionan con igual pragmatismo y precipitación a las crisis que los afectan a todos (Mann, 2006, 116).

Este acercamiento al Estado y sus burocracias no solo cuestiona el tipo ideal weberiano -lo que no quiere decir que se esté en desacuerdo con él-, sino que permite abrir dos puertas al debate; la primera tiene que ver con la cristalización del Estado y la segunda con el sentido pragmático, según la tradición y precisiones del momento que usen las burocracias. ¿Cuál es este sentido pragmático y cuáles son las tradiciones del momento?

El sentido pragmático podría ser rastreado en la pregunta de las necesidades, pues es claro que las burocracias del Quindío durante la colonización, resolvían los conflictos a través del pragmatismo oficial (legal) o no oficial (ilegal) y de igual forma, la sociedad colonizadora recurría a esas mismas prácticas. Las necesidades tenían dos caras, las relacionadas con las funciones u oficio de la burocracia, es decir: identificar un baldío, poblarlo, abrir procesos por ocupación a propiedades privadas, establecer linderos a los lotes, asignar lotes, elevar peticiones al gobierno departamental o nacional por algún inconveniente en el litigio, pedir ampliación de los ejidos, etc., y las personales: recibir un ingreso salarial, adquirir propiedades, sostenerse en el poder, ganar legitimidad, instrumentalizar sus cargos para obtener beneficios, escalar en el gobierno, vincularse a los negocios que surgían en la colonización, etc. Veamos los casos:

\subsubsection{De juntas pobladoras a concejos municipales: las disputas por la instrumentalización de las instituciones entre colonos, empresarios y comerciantes.}

Antes de elevarse a municipio, la ocupación de las tierras de Calarcá fue una de las primeras hazañas de la colonización del Quindío no solo porque llegar a la 
zona implicó un desgaste físico y empresarial, sino porque finalmente los primeros colonos tuvieron que sortear desde la lucha contra la naturaleza indomable, hasta los avatares en los estrados judiciales y los caminos que comunicaban a Salento con Ibagué.

Muchas son las versiones sobre la colonización del Quindío y Calarcá ${ }^{109}$; algunas que deambulan entre la búsqueda del dorado y la guaquería que perseguía las huellas del Cacique Calarcá (Friede, 1978), hasta la ocupación de tierras baldías ofrecidas por el gobierno para resolver el tapón natural que impedía una comunicación efectiva entre el sur y Bogotá; pero sobre estos debates emerge uno real, medible, tangible, $\mathrm{y}$ es que las tierras estaban beneficiadas por maderas, minas de sal y yacimientos arqueológicos, con un importante número de obras de orfebrería y cerámica Quimbaya y Pijao, que no fueron despreciables para los tres actores que enuncian este ítem: Estado, colonos y empresarios comerciantes.

Para el Estado ocupar las tierras del posterior Municipio de Calarcá, implicaba explotar las riquezas ofrecidas por los baldíos y fortalecer el proyecto poblacional que ocuparía los brazos disponibles de Antioquia, Cauca y Boyacá; de igual manera era un ingreso para Salento, pues finalmente Calarcá le pertenecía como corregimiento. En el caso de los colonos, poblar estas tierras permitía establecer un punto para pernoctar; también era un lugar que servía como avanzada en la búsqueda del Dorado y finalmente, el sitio garantizaba acceso a un lote de cultivo.

En el caso de los empresarios, fueran grandes como Burila o pequeños como aquellos mineros de los que se hablará más adelante, las tierras de Calarcá permitirían la explotación de recursos naturales claves para el incremento de las economías personales: se trataba principalmente de explotar minas de sal, maderas y oro.

Según Joaquín Lopera, Calarcá comenzó a poblarse:

109 Al respecto, la Alcaldía de Calarcá y varios académicos de la ciudad tienen distintas páginas web que permiten no solo la interacción con ellos, sino la discusión sobre la historia de la ciudad; al respecto pueden visitarse las siguientes páginas: http://www.calarca.net/libro/index.html y http://www.calarca.net/enlamano. $\underline{\text { html. }}$. 
En el año de 1.882, que fundadas ya las poblaciones de Pereira, Filandia, Circasia y Salento, se les ocurrió a algunos de los vecinos de esta última población hacer algunas exploraciones por el hermoso valle selvático rodeado por los ríos «Barragán» o «La Vieja», el «Quindío» y la «Cordillera Central de los Andes», en busca de minas de oro, fuentes saladas y guacas, descubriendo algunas de estas riquezas naturales, como la fuente salada de «Los Chorros», «Uritá», «Playarrica», «Rioverde» «La Paloma», y «Burila» del otro lado del Barragán, río éste que después de recibir las aguas del río Quindío, sigue llamándose De la Vieja, hasta su desembocadura en el río Cauca ${ }^{110}$.

Además del interés en colonizar, debemos tener presente que la guerra de 1885 dejó varios contingentes diseminados por el país; en el caso del Quindío, el contingente de Cartago puso muchos guerrilleros que huyendo de la persecución del Gobierno, se ocultaron en esta región para luego ser parte de los fundadores de poblaciones como la mencionada y otras como Armenia (Valencia Zapata, s.f., 37).

Así surgió Calarcá que de la mano de Segundo Henao, Cruz Peña, Pedro Ma. Flórez, Pedro Osorio, Francisco Antonio, y Bibiado Ospina, Ramón Ma. Franco y Santiago Parra, desmontaron un punto que se consideró como plaza central y construyeron los primeros ranchos.

El 8 de octubre de 1887 se consideró que este asentamiento podría tener el reconocimiento del Distrito de Salento y el Estado del Cauca, lo que permitía no solo participar en política municipal sino ser visitado por el cura y crear una escuela. El memorial elevado a la Cámara les permitió solicitar al gobierno departamental, poner atención sobre el asentamiento y:

La Gobernación, a su vez, comisionó al Sr. Prefecto de la Provincia del Quindío quien el 23 de Junio de 1.890, en asocio del Sr. Personero Municipal de Salento, y Dn. Heliodoro Peña, D. Primitivo Buenaventura, Dn. Manuel V. Estrada y otros, practicaron una Inspección ocular a estas regiones, y de las

110 Recuperado en: http://www.calarca.net/enlamano.html 
observaciones que hicieron y datos que tomaron dejaron constancia en una acta [...] en la que hicieron constar su opinión favorable, fundada entre otras cosas en las siguientes razones:

Que la población ya estaba trazada, con sus calles de 10 varas; sus cuadras de 80 varas; demarcada su área de población; con una capilla destinada al culto católico; con un local para oficinas públicas y otro para Cárcel; con una escuela funcionando en buen local y con 32 alumnos; que la población la constituían ya 148 habitaciones, con otras tantas familias en el centro de tales terrenos, y 130 familias diseminadas en los campos, ocupando estas una extensión de unas mil hectáreas de terrenos cultivados, constituyendo un total de 2.228 almas. Que la topografía del terreno donde se pretendía establecer la población, se prestaba para ello; fuera de que el lugar era de un clima agradable y sano; con fáciles y abundantes aguas, y maderas de construcción; con más de cinco fuentes saladas y cuatro minas en explotación, y sin que ningún camino nacional, ni departamental cruzara el territorio ${ }^{111}$.

Aceptada la fundación se le dio el nombre de Nueva Salento y la comisión agraria tenía la tarea de:

Dar 32 hectáreas a cada varón casado y sin familia, y los casados y viudos con familia tendrán derecho a otras cinco hectáreas por cada hijo menor de veintiún años que tengan a cargo. [Esta misma comisión les advertirá a los pobladores que quedan sujetos a las siguientes obligaciones:] (a) fijar su residencia en el territorio de la población, (b) no enajenar la porción de terreno que se les adjudica, sin haber puesto antes en ella casa y una labranza que no baje de cuatro hectáreas; (c) a no enajenarla a persona que posea en la misma población más de cincuenta hectáreas de terreno; (d) a no darla dentro del término de cuatro años en pago de deuda alguna (Lopera, 1986, 107).

111 Recuperado en: http://www.calarca.net/enlamano.html 
Pero si bien en apariencia el proceso de poblamiento estaba a favor de los colonos, mientras la población comenzaba a erigirse, la Empresa Burila también se fundaba en Manizales y sus escrituras abarcaban las tierras de los Caicedo y un amplio baldío donde estaban Sevilla, Caicedonia, Armenia y Calarcá; poblaciones de los actuales Valle del Cauca y Quindío respectivamente.

Después de fundada, la empresa pretendió estropear las colonizaciones en la región, por lo que el Concejo de Salento y la Personería Municipal se dirigieron al Ministro de Hacienda con el fin de denunciar los excesos de Lisandro Caicedo, argumentando que este quería apropiarse ilegalmente de varias hectáreas baldías. Al respecto, decía el personero, que Caicedo se estaba aprovechando de la confusión con los nombres de los linderos que:

Llamamos cordillera de los Andes en nombre de sierra de los Pijaos [lo que le permitía] apropiarse de una superficie de terreno baldío que excede de cien mil hectáreas; se privan así de un derecho de la nación y se privan a los colonos de lo que les concede las leyes 61 y 48 sobre tierras baldías ${ }^{112}$.

El memorial fue enviado con copia a la Procuraduría General de la Nación y la Gobernación del Departamento del Cauca, instancia administrativa a la cual pertenecía el Quindío como Distrito.

Como se analizó en el capítulo anterior, la emisión de normativa sobre los baldíos después de 1870 fue prolija, pero en el caso en mención, los colonos fundadores se valieron de dos leyes: la 61 de 1874 y 48 de 1882; ¿Por qué? ¿Qué capital cultural tenían dichos colonos? ¿Hacían parte del campo político en el sentido de Bourdieu, o estaban agenciando su movilidad de los márgenes al centro de dicho campo? ¿Eran conscientes de que su acción tendría una repercusión sobre el Estado y contribuirían a la cristalización de una política pública de tierras para el corregimiento, luego municipio de Calarcá?

112 AGN, Min Industrias, Baldíos, tomo 11, Salento, noviembre 10 de 1889, ff. 112-116 
Si hacemos un seguimiento a la biografía de los fundadores, podemos encontrar un grupo de personas que si bien no hacen parte de las familias tradicionales que dirigen la política local, son personas con capital cultural y muchos de ellos tenían experiencia en el asunto de la colonización. Este es el caso de Segundo Henao ${ }^{113}$, por ejemplo, quien relató en sus memorias las experiencias previas a la colonización de Calarcá y los constantes avatares que dejaba la política en el sentido institucional.

De igual manera, debemos recordar que la apertura liberal de 1853 permitió una movilidad social y con ella, la emergencia de nuevos grupos de presión en el campo político; el asunto es que estos grupos de presión, en algunos casos como el ejemplo estudiado, podían medir el alcance de sus acciones. También hubo ejemplos donde sus acciones no tenían la planificación que se detallará a continuación, aunque el efecto alcanzado contribuyó a sumar situaciones que finalmente, el Estado tuvo que asumir y regular.

¿De qué trataba la mencionada Ley 61 de 1874? Era específicamente una adición al título X del Código Fiscal sobre cultivos y colonización de tierras baldías (Edición Oficial, 1884, 98) en el que el Estado, por primera vez reconocía públicamente al colono, aunque como se vio en el tercer capítulo, dicha ley por su naturaleza, terminó exacerbando los conflictos al trasladar las disputas entre el colono (considerado propietario de buena fe) y el demandante o demandado, a juicio civil u ordinario.

Era claro que ninguno de los implicados, sea demandante o demandado, iba a sostenerse fácilmente en un proceso de larga duración y que requería esfuerzos económicos y políticos; más aún cuando se trataba de una ley que privilegiaba al colono sobre cualquier otro interesado, aunque en casos como el presente, el demandante fuera una empresa con injerencia en el campo de político. Recuérdese que Burila fue fundada por las élites caucanas y antioqueñas y sus primeros gerentes

113 De Segundo Henao (1986) existe en la Biblioteca Municipal de Armenia una copia de sus memorias, las cuales fueron compiladas por la Universidad del Quindío en homenaje a los fundadores de Calarcá. De igual manera se vienen organizando las memorias de otros fundadores a través de medios virtuales como blogs y páginas web. Una de dichas páginas fue consultada y se ha venido utilizando en este apartado (http:// www.calarca.net/enlamano.html). 
fueron posteriormente Gobernadores de Caldas y representantes del Gobierno central.

¿Por qué entonces recurrir a esta Ley? ¿Acaso no habría otras estrategias? El recurso a la ley es claro, cuando se comprende que esta pone en condiciones de privilegio al colono; revisemos el artículo primero:

Todo individuo que ocupe terrenos incultos de la Nación, a los cuales no se les haya dado aplicación especial por la Ley, y establezca en ellos habitación y labranza, adquiere derechos de propiedad sobre el terreno que cultive, cualquiera que sea su extensión (Memorias del Ministerio De Industrias, 1931, p. 122).

Ahora bien, los colonos de Calarcá, así como el Concejo de Salento y la Personería Municipal eran conscientes de que el recurso a dicha ley y éxito durante el litigio, estaban determinados por la capacidad de agenciar y moverse en el campo político. Sabían que la ley privilegiaba al colono sobre cualquier otro interesado en la titulación de un determinado baldío y que los artículos siguientes legalizaban la ampliación de terrenos adjudicados haciendo cercas con un premio de 30 hectáreas siempre y cuando se tuvieran cultivos, casa y se llevara más de cinco años habitando allí. Quizá por ello el afán que se lee en las memorias de levantar ranchos.

Además de la estrategia legal, el Concejo de Salento era favorable a los colonos y por ello su acompañamiento durante el pleito inicial, así como el apoyo para que Nueva Salento se lograra transformar en municipio y pudiera llevar con mayor facilidad los costos políticos y materiales del pleito con Burila.

La mencionada Ley 61, en su artículo 13, obligaba a las autoridades locales a publicitar su contenido y proteger a los colonos por medio de la vigilancia al cumplimiento de la normativa. Por ello, el 13 de noviembre se emitió el Decreto 518, que daba vigencia a la ley y especificaban los procedimientos en referencia a linderos, adjudicación y control de las adjudicaciones en beneficio del cultivador primario, "incluyendo las 
funciones del agrimensor quien, al hacer la mensura, deberá determinar la posición astronómica del terreno" (Lopera, 1984, 109).

En su en su artículo quinto también dejaba claro que de haber conflicto de intereses:

La autoridad política encargada de la administración del Distrito o Corregimiento a que corresponda la localidad, a solicitud verbal o escrita de cualquiera de los pobladores, hará comparecer ante ella a los individuos entre quienes se haya suscitado la disputa, y si no pudiere lograr que estos avengan amigablemente, procederá, previa inspección ocular del terreno, a demarcar provisionalmente los límites dentro de los cuales cada uno de los colonos puede continuar sus trabajos. El funcionario encargado de hacer la demarcación dejará constancia, de todos los incidentes de ella en un expediente, que remitirá al Presidente o Gobernador del Estado o Prefecto del Territorio para su apropiación ${ }^{114}$.

Fue por ello que en 1890 se hizo la respectiva inspección ocular y se legalizó la Junta Pobladora, dándole a esta, poderes para disponer de la distribución territorial, la demarcación de vías y hasta la explotación de recursos. Posteriormente, fue esta misma Junta que gestionó la elevación de corregimiento a municipio.

¿Qué poderes tenía esta primera Junta Pobladora? Además de los ya mencionados, la Junta podía adjudicar o quitar lo adjudicado, por ejemplo, el 8 de diciembre de 1886 dictaron el siguiente acuerdo:

Art. $1^{\circ}$ Todos los individuos que hayan recibido solares en este caserío y que hayan pagado derechos, quedan obligados, dentro del plazo de 15 días, para limpiar lo que les toca de calle, desarraizándola, que quede a satisfacción de la autoridad; El que no lo haga así, cumplido este tiempo, perderá el derecho y se le entregará a otro. Esto en los solares que estén sin edificar, cumpliendo con lo mandado en otro acuerdo. Los que tienen solares encargados y que no

114 Memorias del Ministerio de Industrias, 1931, p. 121. 
han pagado derechos, en este plazo, los pagarán y cumplirán con lo dicho, y si no, quedarán los solares vacantes.

$2^{\circ}$ Todos los individuos dueños de solares, quedarán prevenidos de los trabajos de la echada de el agua a esta plaza, para el día primero del año que viene, para trabajar de cada semana un día, cada individuo, hasta concluir esta obra. Publíquese y ejecútese [sic] ${ }^{115}$.

En el caso de la Ley 48 de 1882, fue reglamentada en el Decreto Oficial número 640 de 1882 y publicada en el Diario Oficial número $5.541^{116}$ de 1884 . El uso de Salento y los colonos del corregimiento de esta otra ley tenía que ver con lo que Lopera (1984) expone, y es que esta consideraba que:

El principio de que la propiedad de las tierras baldías se adquiría por el cultivo, aunque limitaba la adjudicación a varios individuos o compañías a "una extensión de terreno no mayor de cinco mil hectáreas", reservándose la Nación franjas alternadas del mismo tamaño para otros cultivadores, y las tierras limítrofes que servían a dos o más Estados para el fomento de nuevas poblaciones o de las vías de comunicación. (Años más tarde el General Reyes, mediante el decreto 23 de 1906, propició el fomento de la agricultura de cacao y caucho en terrenos baldíos de la Nación concediendo "una prima consistente en una adjudicación definitiva hecha por el Ministerio de Obras públicas y de Fomento de mil hectáreas de terrenos baldíos donde tengan los cultivos, salvo derechos de terceros, por cada veinticinco mil matas de caucho o de cacao sembradas o cultivadas por ellos (p. 110).

Pero si esta ley fue considerada como la prueba maldita, ¿por qué los colonos de Nueva Salento y el Concejo de Salento se apoyaron en ella? La respuesta puede estar en la misma consideración o título.

115 Recuperado en: http://www.calarca.net/enlamano.html

116 Diario Oficial número 5.541, Edición Oficial, 1884, 100. 
Como se vio en el tercer capítulo, esta fue diseñada con el fin de terminar con los alegatos entre colonos y supuestos dueños de latifundios. Con una estructura de 14 artículos y varios parágrafos, la Ley 48 de 1882 sostenía desde el artículo $1^{\circ}$, la legitimidad de la ya mencionada Ley 61 de 1874, pero precisando que los lotes tenían que estar cercados y cultivados; el artículo $3^{\circ}$ consideraba que los lotes baldíos no prescribían contra la nación y en el artículo $4^{\circ}$ ponía de presente la razón para que fuese considerada como prueba maldita:

En el juicio plenario de propiedad del terreno único admisible contra cultivadores de terrenos baldíos, establecidos en ellos con casa y labranza, el actor deberá exhibir los títulos legales de la propiedad de la tierra que reclama, que tengan una antigüedad de diez años, por lo menos, y en los cuales se expresen, con toda claridad, los linderos del terreno que reclama como suyo ${ }^{117}$.

En el tercer capítulo mencionábamos que las estrategias de los reclamantes con títulos eran de diversa índole y en algunos casos los cultivadores no conocían las leyes que les amparaba; en otros, los conflictos se daban entre los mismos cultivadores y también es evidente que las cercanías políticas y familiares de los actores crearon una especie de grieta entre la norma y la realidad, en la que se filtraban los efectos esperados de la ley.

En cuanto a Calarcá, se contaba con las pruebas y el desenvolvimiento en el ámbito jurídico, por lo que las estrategias que estaban a disposición de estos actores, fueron la pronta elevación de corregimiento a municipio y la constante invasión a las tierras en litigio con Burila.

117 Memorias del Ministro de Industrias, 1931, p. 149. 
Tabla 10: Nombre de los integrantes de la primera Junta Pobladora

\begin{tabular}{|c|c|}
\hline Segundo Henao & Román Ma. Valencia \\
\hline Ramón Franco & Cruz Peña \\
\hline Jesús Ma. Buitrago & Pedro Flórez \\
\hline Baltazar Gonzalez & Manuel Ocampo \\
\hline Esteban Morales & Ezequiel Peña \\
\hline Claudio Valencia & Juán J. Herrera \\
\hline Gabriel González & Francisco Velásquez \\
\hline Jacobo Bermudez & Pedro Herrera \\
\hline Leobigildo Ospina & Emilio Patiño \\
\hline Joaquín Pérez & Ciprian Flórez \\
\hline José Ma. González & Tomás Moná \\
\hline Andrés Robayo & Aniceto Arango \\
\hline Félix Londoño & Francisco Ospina \\
\hline Pedro Ma. Osorio & Santiago Parra \\
\hline Fuente: recuperada en http://www.calarca.net/enlamano.html. \\
\hline
\end{tabular}

Tabla 11: Nombre de los integrantes de la Junta Pobladora del Corregimiento Nueva Salento

\begin{tabular}{|c|c|}
\hline Andrés Arango & José D. Chica \\
\hline Tomás Cardona & Antonio Buitrago \\
\hline Rafael Correa Toro & Jacinto Correa T. \\
\hline Isaac Londoño & Marcelino Cardona \\
\hline Belisario Ospina & Jesús Ma. Londoño \\
\hline Santiago Giraldo G. & Benicio Herrera \\
\hline Antonio Herrera & Rogerio Gómez (P.) \\
\hline Juan J. Valencia & Erasmo Herrera \\
\hline Rudesindo Herrera & Juán J. Giraldo \\
\hline Aristóbulo Ibáñez & Diego Bermúdez \\
\hline Juán Bta. Angel & Bibiano Ospina \\
\hline Silverio Bermúdez & Jesús Arango Ch. \\
\hline Juán Silva & Marco Correa \\
\hline Fuente: recuperada en http://www.calarca.net/enlamano.html \\
\hline
\end{tabular}


Entre 1890 y 1905, Nueva Salento se transformó de corregimiento a municipio y por ello mismo el conflicto adquirió otro matiz. Con una junta pobladora avalada por el Concejo de Salento y unas disposiciones legales que les permiten justificar la ocupación de las tierras, Burila tendría que comprobar en estrados judiciales que los terrenos que reclamaba eran de su propiedad, que el primer deslinde hecho no estaba viciado y posteriormente, pagar las mejoras hechas en sus supuestos terrenos; ¿Qué era más fácil para Burila?: ¿Apartarse del pleito? ¿Acaso sabotear la junta pobladora infiltrando agentes? ¿Pretender la ocupación de las tierras con colonos a su favor?

Podría decirse que la empresa se apartó finalmente del pleito porque perdió, sin embargo, durante la duración de este las estrategias legales e ilegales fueron la constante. Durante todo el litigio estuvo el interés de apoderarse de los baldíos del Quindío y por ello mantuvo sus programas de invasión y venta de lotes; asunto que dejó finalmente un saldo negativo entre los colonos que reclamaban tierras y los que habían comprado sin saber que se trataba de una estafa.

Calarcá había asegurado inicialmente unos terrenos desde 1870 con la Ley 14 de 21 de abril, la cual le cedía unas tierras baldías al caserío ${ }^{118}$, pero finalmente los terrenos que habían ocupado seguían en pleito con Burila y sin resolución alguna.

Debido a la alta migración, los colonos elevaron un memorial al Gobierno pidiendo que se les adjudicara tierras con el fin de resolver la situación de aquellos habitantes que no contaban con títulos, pero tenían casas y cultivos ${ }^{119}$. El referido Memorial nos permite identificar varios elementos: como primero, la estructura es similar a los memoriales enviados desde otras poblaciones reclamando derechos sobre baldíos (¿habitus?); este punto es importante porque da un respaldo a nuestra hipótesis, que pretende identificar unas prácticas políticas y justificar en estas, las estrategias para alcanzar los fines. De igual manera, se trata de un documento argumentado con solidez, que reconoce la normativa y los funcionarios encargados de estos menesteres, convirtiéndose en la voz legal de los actores, asunto que facilita el diagnóstico sobre quiénes eran los colonos fundadores.

118 Archivo del Congreso, 1931, p. 73.

119 Ver el memorial en el anexo 1. 
Entre 1890 y 1905, la población creció lo suficiente para ser elevada a Municipio y desprenderse de la tutela administrativa de Salento, por lo que el memorial presentado se convirtió en el medio para adquirir las tierras que necesitaban, sin embargo durante este tiempo, las disputas con Burila fueron constantes y se caracterizaron por la invasión a las tierras en litigio, así como también, el apoyo del concejo y la personería municipal de Salento a través de misivas y denuncias, solicitando "al gobierno nacional una resolución por medio de la cual se prohíban las enajenaciones de baldíos en la olla del Río la Vieja por el inconveniente que pudiere presentar para los colonos que hayan de establecerse en ellos" ${ }^{20}$.

Por su parte, Nemecio Peña, presidente del Concejo Municipal de Calarcá, denunciaba ante el Ministerio de Obras Públicas la importancia y urgencia de intervenir en el litigio con Burila; sin embargo, en la delación se denota claramente una estrategia de doble vía: por un lado se imputa y se pide auxilio de la administración central, pero por el otro el concejo asume una postura favorable a dichos invasores haciendo adjudicaciones provisionales amparados en la Ley $56^{121}$ y mencionando que "no es conocido el título de propiedad de dicha sociedad la cual abarca una extensión considerable. Urge una resolución a fin de poder obrar con acierto"122.

Pero si Salento y Calarcá se movilizaban través de memoriales, los colonos no escatimaban en acciones que iban desde la invasión hasta el envío de misivas al Gobierno. Ejemplo de ello es la carta enviada al Ministro de Obras Públicas para que se apersone del problema con Burila, la cual producto del ambiguo deslinde perjudica a varios colonos. La denuncia plantea que la empresa usaba unos títulos que eran falsos y para ello justifican la acusación como se expone a continuación:

120 AGN; Baldíos, tomo 11, Ministerio de Industria y Fomento, septiembre 26 de 1889, f. 42.

121 La mencionada Ley 56 de 1905 era favorable a los colonos desde su primer artículo que consideraba que "Todo individuo que ocupe tierras baldías y establezca en ellas casa de habitación y cultivos artificiales, adquiere derechos de propiedad sobre el terreno cultivado y otro tanto" (A.C., Memorias Del Ministerio De Industrias, 1931, p. 216).

122 AGN; Baldíos, tomo 24, Calarcá, Administración Municipal de Hacienda, julio 31 de 1905, f. 76. 
Bien conocida es la intención del actual gobierno de proteger las industrias y principalmente la colonización pobre que es la que penetra á los bosques en busqueda de sus riquezas y el porvenir de sus familias. Con las pretenciones previamente citadas se le causa gravísimos perjuicios a este vecindario porque se abarca una extensión no despreciable de territorios que sirve para su engrandecimiento y en el cual ya hay muchos colonos establecidos pero con los temores que más adelante ellos, o sus sucesores se expongan a controversias que dan por resultado la pérdida del fruto de sus trabajos en litigios de distintas clases que quizá no tendrían razón de $\operatorname{ser}^{123}$.

Igualmente, en la referida correspondencia se denunciaba que las autoridades del Cauca no colaboraron haciendo un deslinde previo (1893) pedido por el ciudadano Rafael Cancino y tanto el extinguido tribunal del Cauca, a través del auto 107 de 8 de diciembre de 1893, como el Procurador General de la Nación, negaron tal petición; ¿Cuál sería el motivo? ¿Habría intereses personales al desconocer el derecho de los peticionarios? ¿Tendrían algún vínculo familiar o empresarial los políticos caucanos de finales de siglo en Burila?

Lo cierto es que los terrenos de Calarcá se debatían en la ambigüedad jurídica de las adjudicaciones y solo una intervención directa del Estado central, podría dar solución al litigio con Burila. De los predios donde se hizo la fundación, no había duda en la titulación, pues pertenecían al Sr Don Ramón Franco, quien:

En el año de 1886, cuando los fundadores empezaron la edificación; [...] don Ramón [los] cedió a la ciudad, por escritura pública de 8 de septiembre de 1887, otorgada ante el Notario Público del distrito de Salento, Sr. Cesar Mata, y marcada con el No 118; a favor de Jesús Ma. Buitrago, en carácter de Presidente que era, de la Junta Pobladora, en tal fecha ${ }^{124}$.

123 AGN; Baldíos, tomo 24, Calarcá, Administración Municipal de Hacienda, Agosto 12 de 1905 f. 351.

124 Recuperado en: http://www.calarca.net/enlamano.html 
En cuanto a los terrenos nuevos, adquiridos por los colonos bajo el amparo transitorio del concejo municipal y la fe puesta en la Ley 56 de 1905, solo la capacidad de agencia del concejo y estos migrantes determinaría los giros que diera el litigio.

Como se trataba de presionar para llamar la atención, el concejo y la alcaldía mantuvieron una epistolar constante con los ministerios encargados del ramo; por ejemplo, Benjamín Palacios, alcalde del municipio, envió un telegrama al Ministro de Obras Públicas mencionando con insistencia la necesidad de intervenir en lo relacionado con los planos de la municipalidad, y para ello decía que, "para cumplir ley (56) este año y hoy obligación de revisar planos por toda demarcación, o se excluyen las pruebas pasen cien (100) hectáreas conforme a disposiciones anteriores, pero observando prescripciones científicas, Alcalde Benjamín Palacios"125.

También enviaban misivas a la Gobernación del Cauca pidiendo que los colonos no tuvieran que pasar por las distintas instancias y rituales de las adjudicaciones, pues estos eran muy pobres. Decía la notificación:

A) Que en atención al número de vecinos y a la inmigración de ciudadanos con sus familias, dignese acatar nuestra solicitud y dispongais concesión o reglamento para distribuir la riqueza mas sin las ritualidades actuales por que es imposible cumplirlas por la desastrosa situación económica y otras causas

B) como lo deseamos cesarán los disturbios, dejará la policía de resolver cuestiones que no hacen tránsito a cuestión juzgada, se acabarán los deslindes provicionales que no constituyen propiedades y cada uno sabrá en firme lo que tiene [sic]126.

De todas formas, la mencionada Ley 56 sería transitoria por su ambigüedad, especialmente para resolver casos como el de Burila y Calarcá. En dicha normativa se permitía que los concejos municipales adquirieran jurisdicción administrativa

125 AGN, Baldíos, tomo 24, Calarcá, Administración Municipal de Hacienda, Agosto 12 de 1905, f., 22

126 AGN, Baldíos, tomo 26, Gobernación del Cauca, febrero de 1905 
sobre las adjudicaciones, de esta manera se reservaría la discrecionalidad a ellos, pero no se lograba resolver si aplicaba para adjudicaciones de menor cuantía o para todo tipo de adjudicación; de allí que el Gobernador del Cauca le preguntara al Ministro de Obras Públicas, si los expedientes previos a la ley debían pasar ahora a los concejos, y si quienes cultivaban más de 1000 hectáreas debían perder las ya cultivadas. En dicha carta, más de preguntas que respuestas, interpelaba el gobernador con asuntos tales como:

¿El procedimiento que debe adoptarse para la adjudicación de tierras baldías tratándose de pobladores, puede ser análogo al que determina el artículo 4 de la ley 56 de 1905 para los compradores de dichas tierras y para los colonos o cultivadores?; bajo esta consulta a ese ministerio en atención a que citada ley guarda silencio respecto de los pobladores, y á qué la nación tiene hoy dominio absoluto sobre dichas tierras, para su aplicación, algunas de las disposiciones del código fiscal, expedido bajo otro régimen y también a que dpto, número 553 de 31 de mayo de este mes nada dispone sobre el particular $[\text { sic }]^{127}$.

Pero así como el concejo de Calarcá usaba la Ley a su favor y se ayudaba del gobernador para pedir que se respondieran prontamente las peticiones de los colonos que estaban en litigio con la empresa ${ }^{128}$, también se presentaron casos de concejos que no daban trámite a las peticiones, por lo que el gobernador Valencia tuvo que enviar otra misiva alegando que "algunos particulares se quejan de que concejos municipales no dan curso a las oposiciones hechas a las denuncias de baldíos, por no estar facultados conforme ley 56. Decidme qué autoridad conoce de las oposiciones y resuelve qué"129.

De todas maneras, durante esta transición Calarcá mantuvo su crecimiento: en 1890 ya era corregimiento y fue Belisario Ospina su primer Corregidor y Benito González su primer Juez Municipal por Decreto 15 de 1890. El 23 de octubre de 1890 Calarcá comenzó su vida como Viceparroquia y en el mismo año tuvo cementerio y escuela.

127 AGN, Baldíos, tomo 26, Gobernación del Cauca, agosto 10 de 1905, f., 76

128 AGN, Baldíos, tomo 24, , Gobernación del Cauca, 6 de noviembre de 1905, f., 76.

129 AGN; Baldíos, tomo 26, Gobernación del Cauca, 21 de septiembre de 1905, f., 76. 
En 1903, se instaló la oficina de telégrafos, correos y giros postales; en 1912 se creó la Oficina de Inspectoría Municipal y por la Ley 18 de 1917 se creó el Juzgado $1^{\circ}$ del Circuito, compuesto de los municipios de Calarcá y Salento, y posteriormente Colón (hoy Pijao). Este proceso de cristalización del Estado en la zona se fortaleció más aún con la oficina de Recaudación Municipal de Hacienda Nacional en 1905 y la Oficina de Registro de Instrumentos Públicos que empezó a funcionar el 13 de mayo de 1915.

Al mes siguiente (15 de junio de 1907), el Gobierno nacional dio la primera estocada contra Burila emitiendo la Ley 36, en la que el Estado establecía su dominio sobre los baldíos y por ello la autonomía para ceder un importante globo de tierra a Calarcá ${ }^{130}$. Posteriormente, a través de Resolución emanada del Ministerio de Obras Públicas y Fomento, publicaba en el Diario Oficial número 13168, de 14 de enero de 1908, se entregó la reglamentación que debía seguirse para adjudicar los terrenos a los colonos.

Dicha resolución, compuesta por 18 artículos y algunos parágrafos, resolvía una cara de la conflictividad, pues finalmente la citada Ley 36 terminó por convertirse en zanahoria para quienes venían disputando con Burila y eran afectos al Concejo Municipal de Calarcá; sin embargo, también era garrote para quienes no estaban en la lista de adjudicatarios, dado que los que no alcanzaron a movilizarse adecuadamente, se vieron envueltos en las dilaciones y evasiones administrativas impulsadas desde el mismo concejo y ratificadas en despojos de tierras y lanzamientos. Es importante aclarar que tales hechos no solo fueron denunciados por los colonos afectados, sino por el Personero y los clérigos del municipio. Este caso se retomará posteriormente. En este escenario, vale la pena preguntarnos por qué el concejo de Calarcá, asumió un comportamiento ambiguo e incoherente con su lucha por la adquisición de tierras. Para respondernos esto debemos tener presentes tres aspectos: el primero está relacionado con el tipo de conflicto, el segundo, con los intereses municipales de las burocracias, asunto mencionado inicialmente y propuesto desde la perspectiva de Mann, y el tercero, se relaciona con la característica de la Ley 36.

130 A.C., Memorias del Ministerio De Industrias, 1931, p. 240. 
Si revisamos el primer aspecto, es claro que no puede compararse el enfrentamiento entre los colonos fundadores con la empresa Burila, y los nuevos cultivadores con el Consejo de Calarcá. Recuérdese que los primeros colonos de Calarcá habían contado con el apoyo de otro concejo municipal y la maquinaria administrativa y financiera obtenida después de elevarse a municipio; situación contraria a los cultivadores demandantes quienes tenían que sortear los pleitos con sus propios recursos.

En cuanto al segundo punto, como se verá más adelante, el concejo peleaba por sus intereses pues finalmente eran los fundadores y se estaban viendo afectados por Burila; de igual manera veían en la discusión sobre las adjudicaciones, la posibilidad de ganar o perder las tierras adjudicadas, pues el artículo 13 decía que:

Si terminada la adjudicación hubiere lotes sobrantes, éstos se determinarán y alinderarán como de propiedad del común y se harán figurar en el libro de adjudicaciones. Tales lotes como de propiedad del Municipio, podrán se enajenados de conformidad con las disposiciones del Código Político y Municipal ${ }^{131}$.

El tercer aspecto en mención relacionado con la característica de la Ley 36 pone en evidencia un interés por el Estado de resolver la ocupación ilegal, por ello en el artículo primero se dedicaban 60.400 hectáreas al área de la población que serían medidas y levantadas en plano, con doble ejemplar para que reposara uno en el archivo municipal y otro en el Ministerio de Obras Públicas. De igual manera, la Ley 36 permitía al concejo de Calarcá ser el máximo garante de justicia sobre las adjudicaciones; por ello delegaba en la primera autoridad política del municipio, formar:

Una lista de los pobladores allí establecidos que tengan derecho a adjudicación de baldíos, en que se exprese de cada uno su edad y estado civil, clasificándolos en casados, viudos y viudas con o sin familia, solteros, mayores de edad,

131 Memorias del Ministerio de Industrias, 1931, p. 257. 
huérfanos, menores de veintiún años y mayores de quince, y los menores que están bajo la guarda de una persona ${ }^{132}$.

De esta manera se cerraba un capítulo en el conflicto entre Calarcá y Burila, sin embargo, la intromisión de la empresa promoviendo juntas pobladoras y fundaciones dentro de la adjudicación municipal fue la otra cara de la moneda que tuvieron que sortear el concejo municipal y las autoridades judiciales.

En cuanto a los efectos generados por la Ley 36 de 1907, en relación con las reclamaciones de baldíos y ajena al asunto que vinculaba a Calarcá y a la empresa Burila, estos serán retomados en el ítem 4.2.3. Volvamos entonces a la transformación del conflicto entre concejo y empresa y analicemos las estrategias adoptadas por ambos actores.

\subsubsection{El control de territorio: Burila, la Junta Pobladora de Colón (Pijao) y el Concejo Municipal de Calarcá}

Como se vio en el apartado anterior, para fundar una población era requisito crear una junta pobladora y garantizar que fuera avalada por la municipalidad a la que perteneciera el sitio de asentamiento. Si se trataba de tierras baldías, era necesario crear la junta, hacer los planos, pagar el agrimensor y los testigos oculares (2 testigos), estar seguros que el lote no estaba en tierras privadas y finalmente, elevar la petición al Ministerio que en su momento, administrara el respectivo ramo ${ }^{133}$.

De igual manera se pretendió exponer la importancia de este procedimiento, poniendo como caso el devenir histórico del municipio de Calarcá que empezó siendo un caserío, se elevó a corregimiento con el nombre de Nueva Salento y finalmente fue la gestión de su junta pobladora la que le permitió ser municipio.

132 Memorias del Ministerio de Industrias, 1931, p. 255

133 Durante toda la discusión presentada desde el segundo capítulo, se pueden identificar las distintas leyes y procesos para la respectiva adjudicación. De todas formas, no está de más recordar las siguientes: Ley 48 de 1882, la Ley 14 de 1870, la Ley 61 de 1874, la Ley 56 de 1905, el Decreto 533 de 1905 y el 1113 de 1905 , que por cierto es muy detallado sobre cómo se adjudica. Podrían citarse más pero se mencionan estas por ser las más referidas en los documentos primarios consultados. 
Durante esta presentación vimos cómo funcionaba la junta, qué disposiciones legales tenía, sobre qué aspectos se desenvolvía y cuál era su importancia para determinar el futuro del poblamiento; pero claro está, si la junta era importante, alcanzar la condición de municipio lo era mucho más pues finalmente los concejos municipales durante la Regeneración fueron el único espacio de poder popular garantizando parte de la autonomía administrativa del pueblo.

En vista de que los alcaldes y gobernadores eran nombrados por el Gobierno central, ¿Quién garantizaba que las disposiciones legales fueran a favor del interés local y no nacional? El concejo municipal.

El concejo tenía la facultad de crear impuestos y fabricar decretos que si bien tenían que pasar por la mirada de la Alcaldía y el Ministerio de Gobierno, de ser aprobados, les garantizaba la autoridad suficiente para ser vistos por la población como un apéndice del abstracto Estado central.

Vimos igualmente que fueron las estrategias políticas de los fundadores de Calarcá, las que permitieron superar los primeros litigios con Burila, sin embargo: ¿La empresa siguió insistiendo a pesar de la intervención del Estado con la adjudicación de las hectáreas bajo el amparo de la Ley 36 de 1907 ?

En el anterior punto analizamos cómo el concejo municipal, sin saber sobre la suerte que podrían correr los colonos que llegaban a Calarcá, incentivaron la ocupación de las tierras en litigio con Burila, y con prácticas políticas como el envío de memoriales pidiendo auxilio al Gobierno y la instrumentalización de la ambigua Ley 56 de 1905, se aventuraron a la adjudicación de lotes: ¿Qué pasaría si hubieran perdido el pleito con Burila? ¿Qué tal si el Gobierno departamental y nacional desconociera ese poder del concejo y declarara que la actuación era anticonstitucional? Por fortuna para dichos colonos la resolución final les favoreció. Pero volvamos a nuestro punto en discusión: qué pasó con Burila y cómo asumió la empresa esta pérdida inicial.

Si de algo sirve la reflexión sobre las estrategias, es que pueden convertirse en prácticas y ello fue lo que finalmente hizo Burila. 
$\mathrm{Al}$ ver que las tierras en litigio terminaron siendo reclamadas como baldíos del Estado y estos no prescribían contra la Nación, Burila tuvo que asumir la pérdida y pensar una estrategia para no solo cobrárselas a Calarcá, sino ganar legitimidad en el Quindío. Fue por ello que recurrió a la misma vía de los primeros pobladores de Nueva Salento, es decir, a fomentar con sus agentes y colonos desposeídos la creación de juntas pobladoras y el reclamo de tierras baldías para erigir nuevas poblaciones.

La empresa ya tenía una amplia experiencia al respecto, pues en el Valle del Cauca habían logrado infiltrar a sus agentes en la junta pobladora de Sevilla y hasta creado una población: Caicedonia. En el caso de Calarcá, la estrategia funcionó a medias a favor de Burila, pues como lo relata Joaquín Lopera en sus memorias:

Hasta el año de 1926, CALARCA contaba con una extensión territorial, aproximada, de 1.200 kilómetros cuadrados, y dentro de ese territorio había 4 corregimientos, de los cuales sólo le quedaron los de Barcelona y Córdoba, pues la Ordenanza No 11, de 27 de Marzo de 1.926 erigió en municipio los corregimientos de Colón y Génova, segregando el territorio que ocupan, y con cabecera en Colón ${ }^{134}$.

A partir de 1923 la empresa fomentó el poblamiento de las tierras deshabitadas del sur de Calarcá y formó una junta pobladora en Colón (hoy Pijao) con el fin de hacer pasar como baldíos algunos predios y vender los otros. A la cabeza de tal proyecto estaba Daniel Gutiérrez Arango, gerente de la empresa para ese momento y posterior gobernador (diciembre 2 de 1926 - agosto 22 de 1930) del recién nacido departamento de Caldas.

Gutiérrez Arango tenía conocimiento de la normativa sobre juntas agrarias, sabía que:

El artículo 25 de la Ley 56 de 1905 autorizó al Gobierno para crear juntas ó comisiones agrarias con facultades determinadas por decretos ejecutivos,

134 Recuperado en: http://www.calarca.net/enlamano.html 
y el artículo 38 del Decreto Ejecutivo número 1113 de 1905 dispuso que la adjudicación de baldíos destinados á fundación de nuevas poblaciones y nuevos pobladores se llevaría á cabo previa la cesión que del terreno necesario hiciera el Gobierno Nacional a los respectivos Municipios de acuerdo con los artículos siguientes entre los cuales está el 41 que impone a los Concejos Municipales respectivos hacer la distribución adaptando las disposiciones de la Ley 14 de 1870 y del Decreto número 520 de 1878 [sic] ${ }^{135}$.

Además de este desempeño en el ámbito jurídico, podría decirse que hizo uso de una puerta giratoria, pues de Gerente de empresa territorial pasó a ser Gobernador del departamento de Caldas, del cual dependía Calarcá y la nueva municipalidad. De igual manera, al revisar los nombres de los gobernadores de Caldas, encontramos que el General Alejandro Gutiérrez Arango, hermano de Daniel Gutiérrez, fue el primer Gobernador del departamento (mayo 15 de 1905 - Junio 22 de 1909) por lo que no es de extrañar que el litigio entre Calarcá y Burila tuviera una larga duración y poca disposición por resolverse; esto sin contar con que el General Marcelino Arango (junio 24 de 1909 - agosto 22 de 1909) y el General Pompilio Gutiérrez Arango (septiembre 25 de 1918 - julio 5 de 1923) también compartieron la silla de la gerencia de la empresa y del departamento.

$\mathrm{Al}$ percatarse el concejo de Calarcá que se estaba haciendo un poblamiento sin su autorización, elevaron inmediatamente un largo y detallado memorial ante la gobernación y el Ministerio de Industrias, diciendo que:

A los suscritos [previamente se dijo quiénes estaban a cargo del proceso] se ha encomendado el estudio del acta de instalación de la junta denominada “junta pobladora” creada por el Dr., Daniel Gutiérrez Arango Gerente de la Empresa Burila, según escritura 1265 otorgada en Bogotá el 24 de julio de 1923, y registrada el 11 de Agosto del mismo año en la Oficina respectiva de esa población. 
El Dr., Gutiérrez Arango [...] adjudica al corregimiento de Colón de este municipio, el terreno que constituye el área de la población, crea una junta pobladora encargada de dictar los reglamentos del caso para la entrega de lotes e incremento de la población, y determina el perímetro para las manzanas, anchura de calles y dimensión de los lotes ${ }^{136}$.

¿Pero acaso eran terrenos baldíos? ¿Qué ganaba Burila haciendo estos procedimientos? ¿Por qué Calarcá se oponía al poblamiento? ¿Tenía la empresa infiltrados en la junta pobladora? Evidentemente se trataba de tierras entregadas por la Nación al municipio y era este quien tenía la pretensión de controlar las adjudicaciones, por ello habían creado una junta pobladora dispuesta a intervenir en cualquier poblamiento. Esto se hace manifiesto en el memorial mencionado, cuando dicen que:

En la escritura de adjudicación no se hace mención del título por el cual la Empresa Burila hubo los terrenos materia de la adjudicación que hace al corregimiento.

El señor Pastor Garavito es el secretario de la junta, en referencia fue quien hizo el plano de la población de acuerdo con la Empresa Burila, y es el actual Corregidor de Colón.

Por otra parte por la Ley 36 de 1907 se le sedió al municipio de Calarcá los terrenos baldíos situados dentro del territorio de su jurisdicción para que fueran distribuidos entre sus pobladores; y haciendo uso que le confiere esta ley, el concejo expidió el acuerdo número 3 de ocho de febrero de 1908, por el cual se creó la comisión agraria para la entrega de lotes y expedición de títulos.

Posteriormente el Concejo expidió el acuerdo número 19 de 10 de noviembre de 1914. Por este acuerdo se creó la Junta Pobladora conformada por el Corregidor -como Presidente- y de cuatro vecinos padres de familia, y del Secretario del Corregidor que debe actual como Secretario de la Junta, dependiente de un todo del Concejo, a la cual corresponde dictar los 
reglamentos sobre demarcación del área del Corregimiento; condiciones de las manzanas; perímetros de los solares que daban entrega a los particulares; títulos de adjudicación \& \& reglamentos sujetos a aprobación del Concejo $[\text { sic }]^{137}$.

Sin embargo, como se puede evidenciar en el documento citado, el corregidor del caserío, Pastor Garavito, al parecer estaba aliado con la empresa y promover el poblamiento era un negocio con muchas aristas. Por un lado ganaban si vendían lotes, de no ser así, ganaban controlando las adjudicaciones, pues finalmente se podían entregar a sus más cercanos allegados. También se ganaba porque las disposiciones de la junta eran de tipo financiero, de orden público, etc., y en el caso de Calarcá, perdía no solo unas tierras que por ley podría explotar, sino que su legitimidad se veía entredicha.

Este asunto llevó a que el Gobierno creara una comisión para evaluar el problema y entre las sorpresivas pesquisas, estuvo que la empresa había donado unos supuestos terrenos dentro del globo que no le pertenecían. Por ello el informe consideró que:

El Corregimiento de Colón, como todos los corregimientos, carece de Personería Jurídica y por lo mismo no puede aceptar legalmente sesión de esta suerte, la mencionada adjudicación, en apariencia un acto de generosidad, no parece tener otro objeto que el de buscar los medios de obtener una aceptación tácita por parte del Gobierno Municipal de Calarcá, de los derechos que la Empresa Burila pretende en la región del Quindío ${ }^{138}$.

A renglón seguido, la comisión fue enfática no solo en la falsedad de los documentos presentados por Burila y el dicho regalo de tierras, sino que se estaba cometiendo un delito, no solo por parte de Gutiérrez Arango sino del corregidor Garavito, quien se prestaba para el cohecho. Fue por ello que la comisión considero que,

137 AGN, Baldíos, tomo 59, 1924; Bogotá, marzo 27 de 1924; ff. 452, 454.

138 AGN, Baldíos, tomo 59, 1924, Bogotá, marzo 27 de 1924; ff. 453-454 
El Dr. Gutiérrez Arango, gerente de la Empresa Burila, ha adjudicado al Corregimiento de Colón, un lote de terreno del cual no ha exhibido ningún título de propiedad; el terreno materia de cesión, pertenece al Municipio por disposición de la Ley 30 de 1907; el Corregimiento es una mera dependencia del Municipio de Calarcá y no puede aceptar ninguna clase de adjudicaciones que se le haga, de donde se deduce la nulidad de la escritura de que se ha hablado; el señor Pastor Garavito en su carácter de Secretario de la Junta nombrada por el Dr. Gutiérrez Arango, está autorizando un atropello contra los intereses del municipio y de los trabajadores, y como Corregidor, encargado de velar por el fiel cumplimiento de las leyes, se hace cómplice de la violación de ellas, a sabiendas de los derechos que asisten al Municipio y de la nulidad de los documentos en que se funda la actuación de la Junta Pobladora nombrada por el Dr., Gutiérrez Arango y por último considera la comisión, que si el Municipio consintiera de este atentado contra sus propios intereses y contra los muy sagrados de los trabajadores que han hecho, a fuerza de sudor y de sacrificios, la rápida prosperidad de este pueblo, faltaría a su conveniencia, al decoro y al cumplimiento de sus deberes ${ }^{139}$.

Cerrado este evento, al parecer Calarcá seguía con la vigencia legal sobre los terrenos, había logrado desmentir nuevamente a Burila y movilizar todo el peso de su concejo a favor de los intereses locales. Mientras tanto, la comisión recomendaba que el concejo resolviera qué debería hacer en tan delicado asunto; por su parte proponían:

1) Hagase saber inmediatamente al Señor Alcalde Municipal la conducta observada por el Corregidor, señor Pastor Garavito, a fin de que dicte inmediatamente las medidas que hagan cesar la irregularidad anotada; 2) Dese aviso al Señor Gobernador del Departamento para que intervenga en este grave asunto; 3) Dígase a la Junta de donde emana el acta que se estudia, que el concejo desconoce la legalidad de su existencia, y que niega los derechos que pretenden sobre el área del Corregimiento, 4) Dese cuenta al 
Señor Procurador de la Nación por referirse este hecho a terrenos baldíos que han pertenecido a la Nación, y publiquese el presente informe en hojas sueltas para que sean distribuidas en los Corregimientos del Municipio e incertarse en el Organo Oficial. Señor Gabriel Cubides, Daniel Betancour, Juan Pablo Osorio, Atento servidor, Eduardo Norris [sic]140.

Por su parte, otros concejos municipales de la región seguían enviando memoriales en los que denunciaban abusos similares por parte de Burila; por ejemplo, el Concejo Municipal de Armenia escribió un telegrama al Ministerio de Industrias pidiendo auxilio a favor de los colonos para que:

Resuelva la petición de los colonos "de el Quindío" contra la Empresa Burila, fundado en que el apoderado de los colonos se estuvo allá ocho meses unicamente esperando esa resolución, y que el ministro saliente, Dr. Bravo, se retiró sin solucionar tan importante asunto, por el cual están vinculados grandes intereses de la nación y de millares de labriegos que no saben si tienen algo, o si han perdido sus esfuerzos de largos años, halagados por las promesas de la nación. Firma: J. M. Gonzáles [sic ${ }^{141}$.

A su llegada a la Gobernación de Caldas, el Dr. Gutiérrez Arango pretendió instrumentalizar un poder mayor, tanto fue así que veremos disposiciones de su parte, acusando de comunismo a las invasiones de terrenos hechas en sitios de litigio y enviando memoriales al Gobierno central donde pide mapas para corroborar la legalidad de la propiedad de Burila; sin embargo respuestas tales como "Tratándose de obtener copia de un documento que figura en asunto litigioso entre particulares, la petición que se hace en este oficio debe venir en forma de memorial y papel competente" ${ }^{142}$, fueron la constante, hasta que finalmente el Ministerio de Industrias, a cargo de Juan Montalvo considero que:

Los colonos cultivadores de la región del Quindío pueden solicitar, de acuerdo con el Código Fiscal, las adjudicaciones de baldíos a que crean tener derecho,

140 AGN, baldíos, tomo 59, 1924; Bogotá, marzo 27 de 1924; f. 454.

141 AGN, Baldíos, tomo 64, 1926; Armenia, 8 de septiembre, f. 83.

142 AGN, Baldíos, tomo 58, 1927, Bogotá, septiembre 29 de 1927, f. 273. 
y las oposiciones respectivas deben resolverse según lo previene ese mismo Código y el procedimiento judicial. A su vez los propietarios de Burila pueden ejercitar los derechos que crean tener, de acuerdo con esos mismos códigos y con la legislación del país en general (Lopera, 1986, p. 84-85).

Hemos visto en los dos casos presentados cuáles fueron las estrategias políticas usadas por el Concejo Municipal de Calarcá, el Concejo Municipal de Salento, las personerías de ambas municipalidades, la empresa Burila y los colonos de Nueva Salento, Calarcá y Colón. En términos generales, se trata de mecanismos símiles, que se valen de la ley o las vías de hecho cuando es propicio. Es claro que el control del campo político es un factor clave, pues permite movilizar con mayor éxito la atención del Estado central; sin embargo, no es la única estrategia, pues los recursos ilegales como las invasiones y los legales como los memoriales, denuncias, etc., también alcanzaron efectos positivos.

Estas estrategias se convierten en prácticas políticas cuando no solo son constantes y usadas por distintos actores, sin importar su ubicación en la escala de poder político, sino que se interiorizan y dándose por naturales; por ejemplo: si se pretende alcanzar una adjudicación, es necesario hacer una junta pobladora y seguir los parámetros ofrecidos por la ley; si se quiere obtener una propiedad, se aprovechan zonas en litigio y se invaden esperando un espaldarazo de la normativa; etc.

Ahora bien ¿Qué desempeño tuvo el Estado y sus diferentes instrumentos (leyes, normas, burocracia) durante los conflictos? Como hemos venido analizando, el Estado colombiano de comienzos del siglo XX, en lo que respecta al problema de la tierra, no tenía la capacidad de regular y establecer una política clara y coherente con las necesidades del territorio nacional. El problema se agudizó cuando finalmente, debido a la tramitología que caracterizaba la entrega de tierras, dejó en manos de alcaldías y gobernaciones dichas adjudicaciones.

Este tipo de estrategias, que por un lado tendrían una cara amable con las autonomías y la responsabilidad de los servidores públicos, también se prestaba para el cohecho, la dilación, el robo, etc. Veremos por ejemplo, cómo en el caso de los colonos que no 
alcanzaron a estar en la lista inicial de fundadores de Calarcá, tuvieron que vérselas con un concejo adverso a sus intereses legales.

De todas maneras, recurrir al Gobierno central por medio de memoriales y denuncias deja entrever que hay una aceptación y reconocimiento de un sistema jurídico, que se considera necesario seguir unos procedimientos y que, por más autónomos y venales que puedan ser las burocracias locales, se acata -aunque no se cumplan- las disposiciones del Estado. Seguiremos más adelante con esta discusión; para ello veamos cómo funciona el Estado central cuando se trata de colonos sin afectos al concejo municipal.

\subsubsection{Ley 36 de 1907 y distribución de tierras en Calarcá. El concejo municipal y la disputa con los colonos}

A partir de la emisión de la Ley 36 de 1907 y la posterior Resolución del Ministerio de Industrias de 1908, Calarcá obtuvo un globo de tierra de 60.400 hectáreas con las cuales se esperaba resolver la situación de los cultivadores sin título; sin embargo, quienes estaban inscritos en la lista inicial de fundadores tenían asegurada su respectiva parcela, pero aquellos colonos que no eran afín al concejo tuvieron que entrar en una pelea jurídica desgastante y poco provechosa.

Desde 1906 ya se reportaban adjudicaciones ${ }^{143}$, pero estas no eran legales por estar en litigio y por lo tanto quedaban de forma provisional esperando el aval del Ministerio de Obras Públicas y Fomento. Ejemplos de estos casos están en el tomo 26 del AGN, fondo Baldíos, año 1906, donde se pueden numerar casi 500 folios entre denuncias, adjudicaciones provisionales y disposiciones legales para poblar.

Entre los denunciantes se pueden identificar colonos pobres y ricos, con capital suficiente para sostener pleitos largos. Un caso interesante fue el de Cristóbal Jaramillo, quien prestó dinero al concejo de Calarcá para sostener el litigio con

143 AGN, Baldíos, tomo 26, agosto 15 de 1906, f. 83. 
Burila pretendiendo finalmente alcanzar beneficios en la adjudicación de tierras, pero al final tuvo que emprenderla contra el concejo y se hizo representante de otros colonos con su misma suerte.

Gráfico 6: Adjudicaciones en Calarcá: 1897-1921

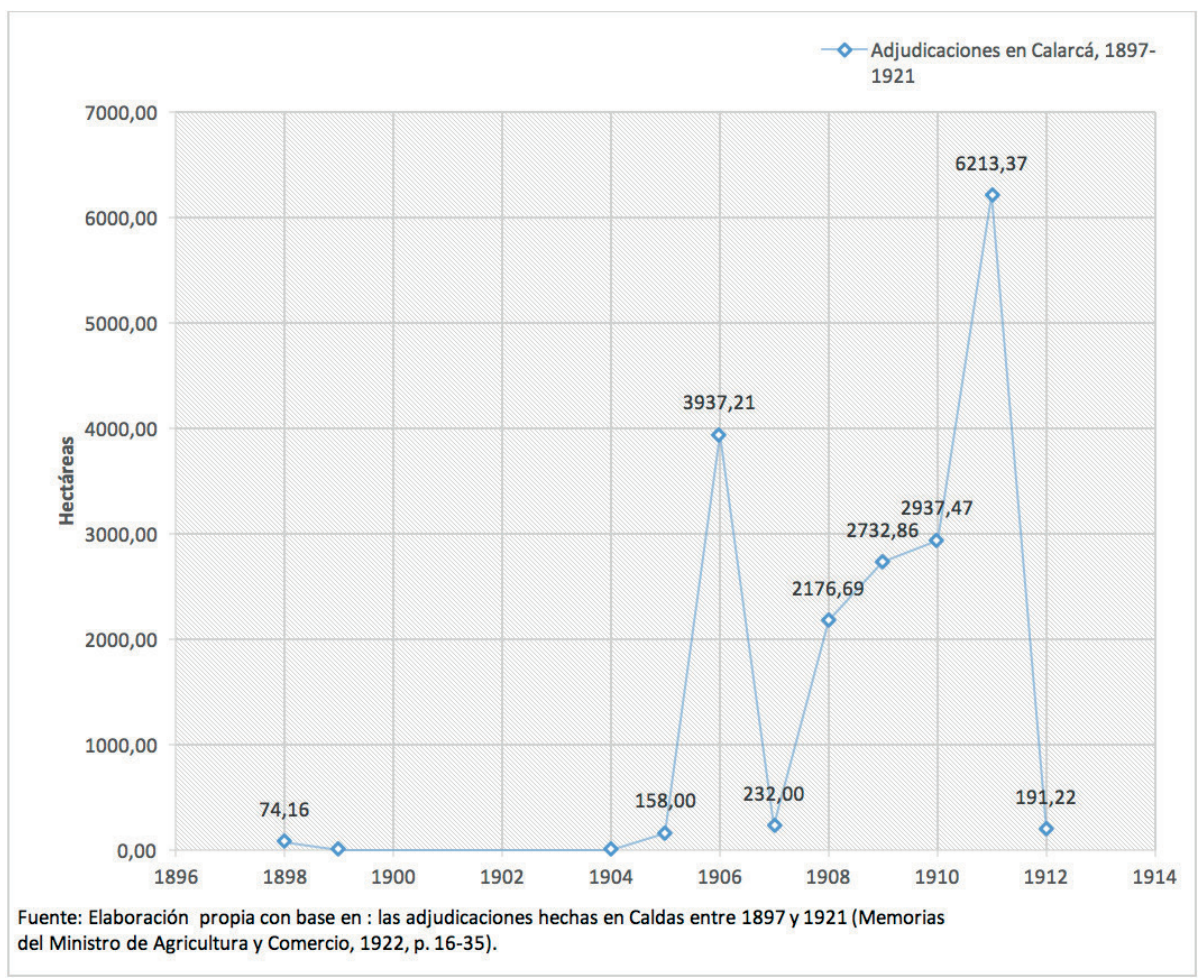

Como se expresaba anteriormente, la junta pobladora se había remitido de manera constante al gobierno central para obtener beneficios en tierras; al elevarse a municipio, el Concejo Municipal de Calarcá continuó con la misma estrategia, especialmente porque se habían hecho acuerdos previos de adjudicación con varios colonos como el caso de Lázaro Jaramillo, quien recibió un título provisional en virtud de venta y no se había finalizado el proceso esperando directrices del Gobierno $^{144}$.

144 AGN, baldíos, tomo 26, septiembre 15 de 1906, f. 109 
Amparados en la vigencia de la Ley 56 de $1905^{145}$, el decreto 520 de 1878 que explicaba cómo debía hacerse una comisión agraria y la Ley 14 de 1870 que les daba las facultades, el concejo y varios vecinos se dirigieron al Gobierno para obtener 60.400 has., de tierra "tanto para el ensanche del área de población, como para distribuir a los trabajadores que afluyen constantemente a ese lugar y que calculan hoy en más de diez mil habitantes"146, dando garantía de que las tierras presentadas por la comisión agraria eran baldías y contaban con la aprobación del gobernador departamental.

Posteriormente, del consejo de ministros envió la notificación respectiva al Ministerio de Obras Públicas con el fin de dar a conocer su aprobación para adjudicar las respectivas tierras a Calarcá, disponiendo que a cada colono "se le entregaría su respectiva propiedad conforme a los decretos y leyes vigentes en la materia"147. Sin embargo, si bien la disposición del Gobierno central pretendía resolver el problema de la tierra y comenzaba a aclarar el caso de Burila y Calarcá, la ejecución acertada de la posterior Ley 36 de 1907 estuvo filtrada por el interés personalista del concejo municipal.

De acuerdo con Olga Cadena (1988), esta adjudicación benefició únicamente a 103 familias, y si se tiene presente la anterior petición elevada al Gobierno central, se hablaba de más de diez mil habitantes; cifra algo grande pero que no necesariamente estaba alejada del número de personas que afluían al lugar.

145 la cual "autorizó al Gobierno para crear juntas o comisiones agrarias con facultades determinadas por decretos ejecutivos, y el artículo 38 del Decreto Ejecutivo número 1113 de 1905 [que] dispuso que la adjudicación de baldíos destinados a fundación de nuevas poblaciones y nuevos pobladores se llevaría á cabo previa la cesión que del terreno necesario hiciera el Gobierno Nacional a los respectivos Municipios de acuerdo con los artículos siguientes entre los cuales está el 41 que impone a los Concejos Municipales respectivos hacer la distribución adaptando las disposiciones de la Ley 14 de 1870 y del Decreto número 520 de 1878 ".

146 AGN, Baldíos, tomo 26, diciembre 6 de 1906, f. 406.

147 AGN, Baldíos, tomo 26, diciembre 6 de 1906, f. 406. 


\begin{tabular}{|c|c|c|c|c|}
\hline $\begin{array}{c}\text { Número } \\
\text { hectáreas }\end{array}$ & $\begin{array}{c}\text { Número } \\
\text { Adjudicadas }\end{array}$ & $\%$ & $\begin{array}{c}\text { Hectáreas } \\
\text { Adjudicadas }\end{array}$ & $\%$ \\
$\mathbf{0 - 9}$ & 26 & 25,24 & 96 & 1,97 \\
$\mathbf{1 0 - 4 9}$ & 40 & 38,83 & 798 & 16,44 \\
$\mathbf{5 0 - 9 9}$ & 20 & 19,41 & 1416 & 29,17 \\
$\mathbf{1 0 0 - 2 0 0}$ & 17 & 16,51 & 2543 & 52,44 \\
\hline TOTALES & 103 & 100 & 4853 & 100 \\
\hline \multicolumn{4}{|c|}{ Fuente: Cadena, (1988, p. 62). } \\
\hline
\end{tabular}

Tabla 12: Distribución de baldío, Concejo de Calarcá, 1908

Como era de esperarse, muchos colonos molestos con la demora en la adjudicación tomaron la iniciativa y comenzaron a invadir predios, enviar memoriales al Gobierno e iniciar nuevos pleitos; lo que el concejo municipal leyó como una amenaza a su legitimidad y por ello respondió legalmente enviando también misivas aclaratorias $^{148}$, ante los ministros encargados del ramo o en su defecto, haciendo uso de la fuerza cuando la ley lo permitiese.

Con lo que no contaba el concejo municipal era con desavenencia de otras figuras públicas como el párroco, el personero municipal y terratenientes reconocidos en la zona como Cristóbal Jaramillo, quien se apersonó del proceso representando a otros colonos no solo por ver afectados sus intereses, sino por ganar afectos y peso en su movilización.

Otro caso que se presentó en contra del concejo tuvo relación con el desconocimiento de los colonos que estaban habitando la zona antes de la adjudicación hecha por la Ley 36, pues al parecer el concejo facilitó, por medio de la falsificación de linderos, la apropiación a terceros de tierras desmontadas y cultivadas en detrimento de los verdaderos dueños. También se presentaron denuncias en relación con la legitimidad de la propiedad, pues colonos pobres habían descuajado el monte considerando baldías las tierras, pero después aparecieron supuestos dueños y, con el aval del concejo, les arrebataban sus tierras. Al respecto decía el Personero Municipal que:

148 AGN, Baldíos, tomo 25, 10 de diciembre de 1906, f. 33. 
Hace ya muchos años que se hicieron adjudicaciones de baldíos a algunos colonos que solicitaron al Gobierno las adjudicaciones de lotes a título de cultivadores o á cambio de bonos territoriales. Cuando se entregó la medida de esos lotes y se hicieron los títulos respectivos, estaba inculto todo este territorio y no había quién se opusiera a que tales mensuras y adjudicaciones se hicieran como sucedió, sin adjuntarse á procedimiento y condiciones que la Ley exige. Ni la nación tenía entonces quienes la representaran aquí en debida forma, pues como digo, todo esto estaba inculto por cuya razón la adjudicación eran estimaciones mucho mayores de las que habían sido solicitadas y decretadas.

$\mathrm{Al}$ paso que la inmigración fue creciendo y estableciéndose algunos colonos en bosques que encontraban y que consideraban baldíos nacionales, de estos hay multitud que con el trabajo de muchos años y sufriendo toda clase de calamidades y luchando casi contra imposibles, han conseguido tener hoy sus labranzas productivas que les proporciona la manutención de sus familias y quieren algún pequeño porvenir. De estos, la mayor parte llevan más de 10 años que comenzaron a descuajar los bosques de lo que hoy constituye una única labor.

Hoy se presentan los adjudicatarios de que hablé y presentando los títulos, piden que los colonos sean despojados violentamente, en contienda y sin misericordia de sus labranzas y viviendas. Hay título de que fue expedido por 300 hectáreas y sin embargo abarca una extensión de territorio en el cual se han colocado más de cuarenta colonos, cada uno con su finquita buena sin que por eso deje de existir las que resa el título.

Algunos vecinos de este distrito, pero que no poseen mejoras, han denunciado ante el gobierno los excedentes que pueden haber, deduciendo las trescientas hectáreas que resa el título; esta denuncia fue hecha después de la expedición de la Ley 36 que cedió los baldíos a este municipio por los límites que lo constituyen luego mordieron el derecho que pueda tener, o mejor dicho, que tienen los denunciantes de los escedentes, al dueño del título que el Gobierno aduciría, fuera medido nuevamente. De este modo han dejado a los colonos 
privados del Derecho que la Ley les concede. Casos iguales a este creo que se presentan varios $[\mathrm{sic}]^{149}$.

Pero el concejo no solo actuaba a favor de sus intereses sino que, de acuerdo con las otras denuncias encontradas, establecía un cobro para los procesos de adjudicación que superaba en muchas ocasiones la capacidad de pago para algunos colonos, pues se exigía de “\$200 a $\$ 500$ pesos por una estampilla que según el número de hectáreas se cobra en el Ministerio de Obras Públicas, a lo que se debe agregar, gasto de comisión, postes de correo, papel sellado, abogado"150.

También se puede evidenciar, por las denuncias elevadas desde la parroquia y la personería ${ }^{151}$, que el concejo dejó de adjudicar lotes, al parecer esperando la resolución de la Ley 26 de 1907 que les permitía administrar los baldíos entregados al municipio. Otro aspecto que se resalta es que los agrimensores que trabajaban para el municipio estaban haciendo mal su trabajo y generando resultados a pérdida de los verdaderos propietarios ${ }^{152}$. Es muy posible que estas acciones tuvieran que ver con el interés del concejo por controlar las tierras restantes, las cuales por la mencionada Ley 26 podrían administrar al beneficio del fisco local y de los intereses personalistas de sus integrantes.

En vista de la presión por las constantes prácticas políticas, el alcalde de Calarcá, don Pedro Henao, escribió al Ministerio de Obras públicas para aclarar si la autoridad del concejo le permitía hacer las adjudicaciones ${ }^{153}$, aunque no está de más recordar que ya el Ministerio se había pronunciado enviando una guía para las respectivas adjudicaciones $^{154}$.

149 AGN, Baldíos, tomo 28, noviembre 5 de 1907, f. 119.

150 AGN, Baldíos, tomo 28, diciembre 21 de 1907, f. 50.

151 AGN, Baldíos, tomo 32, 1909, Calarcá, 9 de enero de 1909, f. 593.

152 AGN. Baldíos, tomo 32, 1909, Calarcá, 16 de febrero de 1909, ff. 205, 206.

153 AGN, Baldíos, tomo 31, 1909, Calarcá, enero 22 de 1909, f. 470.

154 AGN, Baldíos, tomo 28 diciembre 21 de 1907, f. 50. 
De acuerdo con los documentos encontrados en el AGN, el año de mayor conflictividad por las adjudicaciones amparadas en la Ley 36, fue 1910. No solo el concejo tuvo que sortear el problema con colonos que reclamaban su respectivo lote, sino que tuvieron la personería y la parroquia en su contra, esto sin contar con acciones políticas anticonstitucionales como pretender crear leyes, cuando es únicamente el Congreso de la República quien tiene esa potestad.

Por ejemplo, en abril de 1910 el personero municipal se dirige al alcalde de Calarcá pidiendo que se explique qué ley estaban usando en las adjudicaciones, si la 56 o la $36^{155}$ "puesto que se han generado confusiones sobre el funcionamiento de las mismas"156.

En vista de las constantes denuncias y desmanes presentados durante las adjudicaciones, el concejo consideró conveniente que se modificara la mencionada Ley 36, por lo que envió un telegrama al Ministerio de Obras Públicas y este fue enfático en su respuesta: "ni el presidente ni el ministerio pueden hacerlo, eso es tarea del poder legislativo"157.

¿Por qué el concejo municipal actuaba de esta manera? ¿Qué intereses veía afectados? ¿Por qué inicialmente veíamos a un concejo apoyando a los colonos y ahora era adverso a los intereses de estos? Al parecer, el interés del concejo por modificar la Ley 36 tenía que ver con los sucesivos problemas que presentaban las adjudicaciones, especialmente por las denuncias elevadas al Ministerio de Obras Públicas quejándose de las trabas y la corrupción durante las entregas de lotes. Un ejemplo es el de Benicio Herrera, quien se quejaba por la demora y contratiempos en la entrega de su propiedad ${ }^{158}$.

Como respuesta gubernamental, se asignó un perito agrimensor para revisar las respectivas adjudicaciones y dar cuenta de los procesos que se estaban llevando en

155 La Ley 56 de 1905 era favorable a los colonos porque reconocía su propiedad por tener cultivos y casa, con esta ley los primeros colonos de Calarcá disputaron el litigio con Burila; la Ley 36 de 1907 se refiere a los baldíos adjudicados por el Estado al municipio para que fueran entregados a los colonos que no tenían tierras.

156 AGN, baldíos, tomo 34, Calarcá, Abril 1 de 1910, ff. 323-324.

157 AGN. Baldíos, tomo 33, Calarcá, octubre 2 de 1910, f. 251.

158 AGN, Baldíos, tomo 33, octubre 22 de 1910, Sevilla, ff. 548, 550. 
la municipalidad. Lo primero que hizo el perito fue comunicarse con el personero de Calarcá para que diera cuenta de cuántos terrenos se habían adjudicado hasta ese momento y lo que contestó el personero se convirtió en un asunto contraproducente para el concejo, pues decía que "consta en el libro respectivo del Concejo Municipal, que se han inscrito ciento cuarenta y nueve (149) adjudicaciones, libro que creo no está arreglado a lo dispuesto en la Reglamentación de la Ley 36, pues éste es un simple cuaderno"159.

Además de esto, argumentaba el personero que las adjudicaciones fueron hechas sin su presencia como lo establecía la ley, y aprovechando la ocasión, expresaba que no debía realizarse ninguna variación a la ley 36 porque con esta se derogaba la 56 de 29 de abril de 1905.

No siendo suficiente, Lucio Suárez, al parecer otro afectado con las adjudicaciones arbitrarias del concejo, denunció ante el Gobierno nacional no solo la falta a las disposiciones establecidas por la ley, caso mencionado previamente por varios vecinos, sino que el concejo había tomado la iniciativa ilegal de administrar justicia e inventar leyes. Decía el mencionado Suárez que:

El Concejo Municipal de este Municipio ha puesto en vigencia la Ley, número 56, y su Decreto reglamentario 113 como lo verá su S.S. por documento que en copia acompaña lo cual además de ser demasiado ilegal, no tiene más objeto que hacer negatividad los derechos de estos montañeros pobladores de esta región. Esto sin darle cuenta á Su S. de los gravamenes que pasan sobre cada uno de estos individuos como son veinticinco (\$25) con que está gravado cada boleta que debe expedir la Junta Agraria, y la de cinco pesos (\$5) que debe pagar cada colono poblador, por la adjudicación de cada hectárea de terreno.

Las disposiciones sobre la materia, expedidas por las que han llegado á ocupar ese Ministerio, son sabidas y en todas ellas le reconocen perfecto derecho á los ocupantes anteriores con posterioridad á nuevas leyes, expedidas y en

159 AGN, Baldíos, tomo 34, Calarcá, septiembre 9 de 1910, f. 321. 
este caso, lo manifiesto ingenuamente que se encuentran los señores Luis Jaramillo E., Cristobal Jaramillo, José A, Giraldo y otros, que desde hace más de quince años y basados en disposiciones anteriores entraron a despojar o descuajar, hace más de quince años estas montañas y se encuentran como vastas regiones cultivadas de pastos artificiales y dehesas de ganado.

En más de tres corporaciones Municipales señor ministro no han podido legislar o por mejor decir, no han podido dar cumplimiento á disposiciones tan claras y terminantes como las que establecen la Ley N 36 y su reglamentación y tanto que han perdido hasta la esperanza los pobres colonos de ver algún día titulados legalmente sus tierras [sic ${ }^{160}$.

Pero si las adjudicaciones se hacían lentas y dificultosas, los honorarios que cobraba el agrimensor y que estaban establecidos por ley eran minúsculos, por lo que estos se negaban a realizar los trabajos. Al respecto el personero municipal, en carta dirigida al Ministerio de Obras Públicas planteaba que "cuánto cobran los agrimensores y cómo debe hacerse el procedimiento de adjudicación de tierras en Calarcá, no es coherente con las necesidades reales de movilizarse a las zonas donde se harán las entregas, pues finalmente el agrimensor sale perdiendo por los costos que implica movilizarse en el territorio" ${ }^{161}$.

Con el transcurrir del tiempo, los procesos se mantuvieron y algunos colonos lograron llamar la atención del Gobierno pero otros con menos capital para sostener los pleitos, tuvieron que hacerse a un lado y movilizarse hacia nuevas tierras. También se presentaron casos donde el concejo y la alcaldía, con el aval de la Gobernación de Caldas, actuaron con violencia arrojando y quemando los ranchos levantados por los colonos. Estos casos se presentarán más adelante, al referirnos a los colonos que invadieron las tierras de Playa Rica y que no estaban entre quienes disputaron litigios con Burila o que se debían beneficiar de la Ley 36.

160 AGN, Baldíos, tomo 34, 1910, Calarcá, septiembre 9 de 1910, f. 319.

161 AGN, Baldíos, tomo 35, Calarcá, febrero 3 de 1911, ff. 312-314. 
Hemos visto hasta ahora, cómo el concejo municipal actuó de manera distinta a la presentada inicialmente, es decir, cómo cuando el conflicto era con Burila, la solidaridad entre junta pobladora o concejo, con los colonos era manifiesta. Con la publicación de la Ley 36, el concejo obtuvo su premio y quienes participaban de dicha disputa, en su mayoría, se vieron beneficiados; sin embargo otros cultivadores tuvieron que emprender una nueva disputa, esta vez se trataba de enfrentar al mismo concejo y en otros casos seguir disputando con Burila, pues finalmente la empresa había vendido lotes y los había escriturado, generando una disputa entre los mismos colonos y con un desinterés manifiesto por parte del Concejo de Calarcá.

¿Cómo se siguió transformando el problema de la tierra en el Quindío? ¿Qué tipo de litigios se mantuvieron? ¿Qué prácticas políticas se siguieron presentando? ¿Qué normativa tuvo que diseñarse para regular dichos conflictos?

Si bien, no se citaron los demás casos consultados, la problemática de la propiedad de la tierra es abundante; sin embargo, después de 1919 se identifican una serie de cambios sustanciales entre los que podríamos mencionar:

- La cartera de baldíos pasó al Ministerio de Agricultura, aunque en algunas ocasiones se reporta el Ministerio de Industrias.

- En 1905 se creó el departamento de Caldas, lo que conllevó un cambio de jurisdicción para los procesos, y

- Los nuevos pleitos ya no se relacionan con la mencionada Ley 36, sino que se dan entre cultivadores y los concejos por invasiones a predios municipales, $o$ cultivadores y la Secretaría de Hacienda Departamental.

Un caso particular es el que obligó a la mencionada secretaría a dirigirse hasta el Ministerio de Agricultura con el fin de tener una directriz para aquellos procesos donde apareciera el supuesto dueño del terreno adjudicado invocando leyes como la 71 de $1917^{162}$. La respuesta dada por el ministerio deja nuevamente en entre dicho el

162 La Ley 71 del 24 de noviembre de 1917 se emitió con el fin de defender los derechos de los cultivadores y los colonos, sin embargo como se expresaba en el segundo capítulo, la cantidad de normativa generó más trabas en las adjudicaciones, pues finalmente, como podemos ver en este caso mencionado, todos los 
conocimiento que tenían las burocracias locales de la ley, pues decía el ministro que "el artículo es claro en lo que debe hacerse y que esto pasa al dominio judicial quien debe atender el caso"163.

Pero si la normativa era confusa, el manejo de jurisdicciones y competencias hacía que los pleitos por adjudicaciones fueran más difíciles de comprender, pues la naturaleza del asunto, la cuantía, las instancias, el factor territorial, el factor de conexión, etc., determinaban cómo debía instaurarse las demandas, así como dónde debían llevarse los procesos.

¿Qué sabía un colono al respecto o un cultivador sobre jurisdicciones? ¿A dónde debían dirigirse ahora? ¿Dónde continuarían los procesos abiertos en el departamento del Cauca? Al respecto, el abogado José Villegas se remitía al Ministro de Agricultura con el fin de aclarar las partes confusas de la ley sobre adjudicación de Baldíos, especialmente porque al escribirse desde una nueva jurisdicción (Manizales), habría modificaciones sustanciales ${ }^{164}$.

Un caso relacionado con este asunto se presentó entre el señor José Ortega, vecino de Calarcá y la Secretaría de Hacienda de Caldas, desde donde se dirigió una misiva al Ministerio de Industrias con el fin de recibir instrucciones sobre el procedimiento que debía llevarse en una adjudicación. El supuesto procedimiento era el siguiente:

Venido el expediente del Ministerio con la aprobación de la resolución, se toma copia de la resolución autenticada por el señor Gobernador, y el Secretario de Hacienda, y se envía al Registrador de Instrumentos Públicos respectivo, y una vez registrada, se le envía al interesado por conducto del

\footnotetext{
interesados en los pleitos, pareciera que leyeran a su antojo qué artículo convenía más; por ejemplo, el demandante de este caso, se escudó en el artículo 10 de la Ley 71, que reza: "cuando al hacer una adjudicación de terrenos baldíos a cualquier título, se hallaren establecidos previamente colonos o cultivadores en la extensión respectiva, se les deberá reconocer las extensiones cultivadas, para lo cual no se les exigirá a los cultivadores el que tengan adquirido título de propiedad. Podrán ellos solicitarlo posteriormente ciñéndose a las disposiciones de esta Ley" (A.C., Memorias Del Ministerio De Industrias, 1931, p. 337-338).

163 AGN, Baldíos, tomo 57, Manizales, 20 de abril de 1917, f. 271

164 AGN, Baldíos, tomo 44, Manizales, 18 de junio de 1919, f. 387.
} 
Alcalde del Municipio donde está ubicado el baldío. Dicha resolución se le notifica personalmente al Fiscal del Tribunal Superior, al Personero Municipal y al interesado. La copia de la Resolución se toma además en un libro especial que en esta Secretaría se abrió para tal fin, y el expediente, se devuelve a ese Ministerio, tal como lo dispone la Resolución ${ }^{165}$.

Sin embargo, a renglón seguido de esta especificación, decía el Secretario que necesitaba que se corroborara si estos pasos eran los adecuados pues al parecer cada instancia estaba usando un procedimiento distinto llevando a confusiones y situaciones donde la información terminaba perdida.

Por su parte, la oficina de Caldas encargada de estos asuntos tampoco colaboraba, pues argumentaban que ellos llevaban los procesos adecuadamente, pero era en Bogotá donde estaban las confusiones, aunque se reconocía que en tiempos anteriores hubo confusiones que generaron malas prácticas.

De todas formas, la respuesta dada al Ministerio de Industrias respecto a la situación de los baldíos y las respectivas adjudicaciones, fue contundente. Decían desde la oficina de la Gobernación que:

La mayoría de los cultivadores son individuos de precaria situación, y por lo tanto, este despacho no menoscaba el derecho de ellos, y su mayor deseo es develar porque éstos reciban, en el menor término posible, el título de propiedad de los terrenos que solicitan en adjudicación. Cursan por esta oficina un crecido número de negocios de baldíos, la mayor parte de ellos son pequeñas parcelas que no exceden de veinte hectáreas. No obstante la corta tramitación que estos negocios demanda, sí sufren demoras de bastante consideración no por parte de esta oficina -no huelga decirlo- porque los negocios son despachados en la debida oportunidad. Muchos son los interesados que preguntan sin cesar, a esta Secretaría por el paradero de sus expedientes, y se ha sacado en conclusión que es el departamento de baldíos

165 AGN, Baldíos, tomo 69, Manizales, 11 de julio de 1929, f. 132. 
del Ministerio de Industrias donde reposan estos, esperando la resolución definitiva. Hay muchos negocios en el Ministerio enviados desde los primeros meses el año pasado, y aún no han sido devueltos ${ }^{166}$.

A partir de 1919, las denuncias elevadas al Gobierno nacional tienen también el matiz de la radicalización a través de vías de hecho, pues los cultivadores optaron por invadir predios y asentarse en ellos con cultivos, valiéndose de las distintas normas mencionadas a lo largo de este apartado; algunas de ellas derogadas, otras vigentes pero con modificaciones y otras aún más confusas que las anteriores, pero que para el cultivador y el colono, se convirtieron en la tabla de salvación que por muchos momentos, llegó a justificar su práctica política. Este punto se desarrollará en el siguiente ítem.

Ejemplos para estos casos fueron muchos, tanto que Abigail Aguado, encargado de la oficina de Estadística y Agricultura del Municipio de Calarcá se remitió al Ministro de Agricultura con el fin de dar cuenta de la situación que se tenía en el departamento de Caldas, en relación con los baldíos existentes. Al respecto, Aguado denunciaba que había cien mil ochocientas hectáreas sin adjudicar y que las mismas eran ricas en recursos con un valor aproximado de $\$ 20.000$ pesos, pero dentro de ellas existían personas con cultivos ${ }^{167}$. ¿Qué hacer al respecto? ¿Debían lanzarlos de las tierras? ¿Deberían adjudicárseles dichas tierras?

Sin contar con estos pormenores, las nuevas leyes sobre baldíos no dejaban claro cómo adjudicar cuando se tratara de grandes o pequeñas parcelas, o si ya se poseía un lote o en su defecto, la propiedad a entregar quedaba entre otras propiedades, es decir: no solo se tenía que resolver el cambio de jurisdicción, sino la característica de la adjudicación. Al respecto preguntaban desde la administración departamental de Caldas si:

166 AGN, Baldíos, tomo 71, Manizales, 10 de mayo de 1930, f. 34.

167 AGN, Baldíos, tomo 44, noviembre 28 de 1919, f. 314. 
En caso que un cultivador en pequeña escala solicite la adjudicación de dos o más globos de terrenos baldíos, todos menores de veinte (20) hectáreas, pero que sumados sobrepasen ese número, y separados uno de otro por terrenos distintos dueños, debe dársele curso a una solicitud solamente y negar de plano la otra u otras conforme a la Resolución 221 de 31 de julio de 1918? o pueden aceptarse todas? y en este caso, qué procedimiento se adoptaría?

Se hace esta consulta porque ya se ha presentado el caso y por opinar este Despacho que deben atenderse ambas o todas las solicitudes, pues no parece justo que a un cultivador que no es culpable de no haber podido labrar un campo de mayor extensión sin solución de continuidad, y capaz para hacerlo, y sin querer tampoco aprovecharse del favor de la ley 71 de 1917, se le prive del derecho de adquirir un lote que ha labrado con la esperanza de recibir un día, tan sólo porque ese terreno no tiene determinada extensión, viéndose obligado a desprenderse de lo que ha favorecido con sus esfuerzos.

Parece que el caso a que se refiere la Resolución N 221 citada es para cuando los terrenos son contiguos y pretende dividirlos por gozar de los beneficios de la Ley dicha. Si así fuere, el hecho consultado es distinto y necesita solucionarse. Si el asunto se resolviere conforme a la tal Resolución desea este Despacho que se resuelva también cómo ha de procederse para desechar una de las solicitudes cuando se presente en una misma fecha; si para ello se ha de consultar o no el consentimiento del peticionario [sic ${ }^{168}$.

Además de estas mencionadas ambigüedades y dificultades, los abogados locales poco colaboraban con el buen funcionamiento de las instancias estatales. Fue común que falsificaran documentación, dilataran procesos aferrándose a leyes derogadas o confundieran a los funcionarios locales con falacias jurídicas. Al respecto denunciaba la Secretaría de Hacienda de Caldas que:

Ocurre con frecuencia que un mismo cultivador de pequeños baldíos en una misma documentación intenta titular dos o más lotes de terreno, que sumando la cabida de los dos o tres, no alcanzan a 20 hectáreas. Esta

168 AGN, Baldíos, tomo 40, Manizales, 20 de febrero de 1920, ff. 349-351. 
Secretaría de Hacienda, ha rechazado esas solicitudes, exigiendo que para cada lote de terreno se levante un expediente aparte, pero sucede, que abogados encargados de la gestación de esos negocios alegan que se puede en un mismo expediente, mediante una sola diligencia de entrega, o con una sola resolución, titular dos o más lotes de terreno que han cultivado e distintos parajes de un mismo municipio ${ }^{169}$.

Con la llegada del ferrocarril, nuevas aristas para el conflicto asomaron, pues las poblaciones que compartían línea férrea se volvieron atractivas para el empleo de mano de obra, pero también para hacer uso de los suelos de manera distinta a la establecida por las leyes de tierras, es decir que cuando se asignaba un baldío, su uso era de cultivo, pero los colonos transformaban sus casas en bodegas, asunto no considerado por la normativa y que finalmente reñía con el objetivo de las leyes de adjudicación, como lo reportaban la Secretaría de la Gobernación de Armenia, al revocar la adjudicación de lotes a los señores Rosendo Gonzáles y Gabriel Villa Álvarez:

Porque no se había dado cumplimiento en su integridad a lo que dispone el artículo 1 de la Ley 47 de 1926, es decir, que los adjudicatarios comprobarán que esos lotes de terreno los tenían cultivados con cultivos artificiales y permanentes, pues con el solo hecho de tenerlos ocupados con casas de habitación no era suficiente para el caso.

En los municipios de Armenia y Calarcá ocurre con frecuencia que se denuncian lotes de terrenos como baldíos, en los cuales los peticionarios tienen construidas casas de habitación cuya edificación ocupa toda la extensión del lote, no quedándoles campo alguno para establecer cultivos artificiales, pues el incremento que en los últimos tiempos ha tomado esas dos poblaciones debido al ferrocarril Zarzal Armenia y Nacederos Armenia, y a la carretera Ibagué Armenia, la mayor parte de los poseedores de solares

169 AGN, Baldíos, tomo 68, 1928; Manizales, 12 de diciembre, ff. 213-214. 
sin titular han construido en ellos grandes edificios para habitaciones o almacenes y depósitos ${ }^{170}$.

Al parecer, las leyes ya no solo eran ambiguas sino también inconsecuentes con las nuevas necesidades del capital y los intereses individuales. Por otra parte, las constantes misivas y memoriales enviados a los varios ministerios seguían insistiendo en lo mismo: la necesidad de tener una política pública clara frente a la tenencia, ocupación y propiedad de la tierra, como por ejemplo, la comunicación enviada por Neftalí Agudelo a Francico J. Chaux.

El señor Agudelo exponía el caso de Calarcá, donde a pesar de que se había diseñado una normativa para resolver el asunto, aún se mantenían conflictos en el municipio, por lo tanto le proponía a Chaux que se hiciera un cobro de impuestos sobre el terreno si no se estaba trabajando, dado que no había claro interés por parte de la administración central por regular el asunto de los baldíos. Le decía el señor Agudelo al Ministro Chaux:

Sabe usted, señor doctor Chaux, que entre nosotros ha existido la mala costumbre de entrarnos a un terreno baldío y señalar nuestro lote por donde nos alcanza la vista; ponemos una pocas mejoras y ya nos creemos dueños de todo el lote que nos hemos señalado. Con este motivo, podría decirse que en todo el país, existen grandes cantidades de montañas que ni las cultiva el presunto dueño ni las deja cultivar. Así tenemos infinidad de territorios donde hace más de cincuenta u ochenta años que se abrió una parte y el resto, manu-militare, es tenido como cosa propia por esos ciudadanos sin habersela hecho adjudicar, sin haber tenido la titulación como cosa peligrosa porque no tienen la cantidad cultivada para que se les adjudique el resto de monte que conservan. [...] En este municipio por ejemplo, hay más del sesenta por ciento de fincas sin titular y que no las titulan por el motivo anotado, es decir, por temor de que tengan que ampliar sus cultivos o dejar montaña para que otros la tomen $[\mathrm{sic}]^{171}$.

170 AGN, Baldíos, tomo 68, Manizales, diciembre 2 de 1928, f. 216.

171 AGN, Baldíos, tomo 76, Calarcá, marzo 7 de 1932, f.111. 
La respuesta del Ministro Chaux fue inmediata, planteándole a Agudelo lo importante que era resolver este asunto, por lo que se volvió a mencionar una circular de septiembre de 1930, considerando que:

Teniendo en cuenta en este Ministerio de que en varias regiones del país, individuos aspirantes a grandes adjudicaciones de terrenos baldíos, impiden la ocupación de ellos a cultivadores de pequeñas extensiones, sin que previamente exista por parte de los aspirantes solicitud alguna de conformidad con las leyes de adjudicación de baldíos, ni tengan cultivo alguno, ruego a usted se sirva tomar las medidas del caso a fin de evitar tales atropellos, garantizando hasta donde lo permita la ley la libertad de ocupación sobre los baldíos no solicitados en adjudicación ${ }^{172}$.

El asunto clave de la discusión es que, por una parte, se presentara una circular favorable a los colonos, pero por la otra, la Gobernación de Caldas como veremos más adelante, avalara la represión en las ocupaciones no legalizadas por los jueces. ¿Cómo se pretende entonces que fallar a favor de los colonos, cuando las burocracias locales están inmersas en la corruptela?

Hemos visto hasta aquí tres facetas del problema de la tierra en la región del Quindío y el municipio de Calarcá. La primera tiene que ver con las disputas entre colonos que alegaban tener derechos a tierras de acuerdo con la Ley 36 de 1907 y el concejo municipal, quien dilataba las adjudicaciones; vimos cómo la personería municipal y el cura del pueblo, de la mano con algunos terratenientes afectados, se movilizaron a través de misivas, memoriales y demandas contra el municipio.

La segunda faceta tiene que ver con la radicalización de las prácticas; vimos cómo algunos cultivadores optaron por invadir los predios que consideraban baldíos y con el apoyo de la personería, se movilizaron con una combinación de estrategias: por un lado, las legales a través de la denuncia pública, el memorial, etc., y las ilegales, es decir, la invasión y el apoyo a quienes tomaran dicha iniciativa.

La tercera faceta ya no menciona la Ley 36 , sino que se trata de cultivadores que llegan

172 El asunto es cómo garantizar que las disposiciones del centro se cumplan en la periferia. Ver. AGN, Baldíos, tomo 76, Bogotá, 4 de mayo de 1932, f. 112. 
a la población o a la región y ocupan tierras en litigio o consideradas como baldías. En esta faceta el problema adquiere varias características, entre las que se cuentan los cambios en la política departamental, pues el nacimiento del departamento de Caldas determinaba nuevas jurisdicciones, esto sin contar con las burocracias encargadas de su administración. Recuérdese que el primer Gobernador de Caldas fue gerente de la Empresa Burila y tenía ya un historial de pleitos por predios.

Se identifica en esta faceta una radicalización de los conflictos, pero también una transformación en el uso de la propiedad, aspecto que riñe con el sentido de la ley que se había elaborado para resolver el problema. También es claro que el Gobierno central tiene el interés de actuar sobre la conflictividad, por ello la prolija producción de leyes, pero las grietas de las normas se materializan en la acción autónoma de las burocracias locales, así como también, en la capacidad de agencia de los actores.

En el siguiente ítem se pretende profundizar en las prácticas políticas ilegales y analizar la reacción de las burocracias locales, regionales y nacionales, asunto que nos permite identificar los precedentes que sirvieron como guía para el diseño de las políticas sobre tierras a comienzos del siglo XX.

\subsection{Repertorios de protestas: las prácticas políticas de los colonos no vinculados a los concejos municipales}

El uso de la categoría práctica política estuvo determinado por el interés de analizar los repertorios de protesta iniciados por cultivadores y colonos que estaban al margen del campo político, es decir, que no pertenecían o eran reconocidos por los grupos de injerencia directa en el Estado tales como los concejos, las asociaciones de partido, los gremios, etc.

Pero ¿Por qué considerar los repertorios de protesta de quienes están en los márgenes del campo político como prácticas políticas? la recurrencia, objetivación 
y institucionalización de una estrategia nos da la pista para llamarle práctica; por ejemplo: el envío de misivas y de memoriales, como también la invasión de predios y la violación a las propiedades se volvió estratégico para obtener la titularidad de un predio, especialmente después de 1919 cuando no solo hay un crecimiento poblacional, sino que se amplía el abanico de labores y oficios: en el ámbito agrícola, la producción de café; y en ámbito industrial y comercial, la llegada del ferrocarril.

Quizá los cultivadores o colonos no eran conscientes de que sus acciones contribuían a la configuración de una legislación agraria; al parecer muchos de ellos se movilizaban por sus intereses personales, pero lo cierto es que el seguimiento de los documentos públicos nos permite identificar una preocupación en los representantes del campo político: ¿Qué hacer cuando la presión social es superior a la capacidad del Estado para regular? ¿Cómo asumir las transformaciones sociales y económicas en un marco jurídico y administrativo? ¿Cómo debe tratarse a quien irrumpe en la propiedad privada sin autorización? ¿Cómo garantizar que las burocracias locales ejecuten adecuadamente las leyes? ¿Qué le pertenece al Estado y qué no?

Son muchas preguntas que podríamos formularnos, pero para dar respuesta a esta, debemos analizar la transformación de los conflictos; por ello este apartado se centra principalmente en la presentación de algunos casos donde los colonos y cultivadores, estando en los márgenes del campo político, terminaron por movilizar no solo la parte represiva del Estado, sino la necesidad de diseñar una política pública más coherente con las lógicas del siglo XX.

\subsubsection{Las transformaciones del conflicto: los casos Grisales, Jaramillo y Playa Rica}

Los tres casos mencionados se presentaron entre 1884 y 1932, pero a diferencia de la disputa entre los colonos de Calarcá y la Empresa Burila, los cultivadores y colonos que mencionaremos no hacían parte de las juntas pobladoras o los concejos municipales. Para los casos que a continuación se presentan, la transformación del conflicto estuvo determinada por la capacidad de agencia; es decir que de acuerdo con las estrategias usadas, los resultados fueron o no favorables para sus intereses. 
El primer caso es de los colonos de Risaralda ${ }^{173}$ contra Manuel María Grisales; la disputa se inició a partir de 1884 cuando el mencionado Grisales, junto con Antonio Cardona, e Isidoro Flórez, cambiaron unos bonos territoriales por predios en la región.

De acuerdo con la denuncia interpuesta por los señores Ramón Ramos, Calidonio Molina, Julián Mina y Francisco Ospina, ante el Secretario de Hacienda de la Unión ${ }^{174}$, se pretendía que el gobierno rectificara la adjudicación de baldíos hecha en el Quindío, pues la asignación de tierras estaba perjudicando a varios cultivadores que estaban asentados antes del deslinde presentado por la compañía del señor Grisales.

La denuncia se da después de conocer el interés de Grisales, Cardona y Flórez por apoderarse de las tierras comprendidas entre los municipios de Salento, Circacia y Filandia, lo que nos permite identificar a un grupo de colonos con conocimientos, no solo de los pormenores de las ventas y adjudicaciones en la región, sino del sistema administrativo y judicial del país.

En la notificación enviada decían los demandantes que se había:

Denunciado estos terrenos como baldíos y van a pagarlo al gobierno con bonos territoriales, lo que implica un mal gravísimo a la multitud de colonos cultivadores que diariamente [...] afluyen aquí a convertirse en arrendatarios y propietarios.[La oposición a la adjudicación de tierras se sustenta porque] no satisface las necesidades de los cultivadores y de la sociedad en general, porque esas tierras divididas en lotes, paraliza la industria y estanca la riqueza que pronto desarrollarían millares de brazos trabajadores ${ }^{175}$.

173 No se hace mención precisa del departamento de Risaralda, se trata más bien de una adjudicación que recibió dicho nombre.

174 Recuérdese que antes de la Constitución de 1886 la República de Colombia era aún federal, llamándose Estados Unidos de Colombia.

175 AGN, Baldíos, Tomo 5, Salento, 5 de marzo de 1884, f. 237. 
En vista de la gravedad de la denuncia y quizá la importancia de quienes la interpusieron, Julián Mora, al parecer el Secretario de Gobierno de Salento, se dirigió al juez del Distrito del Quindío para que se le entregara una copia del proceso iniciado por el señor Ospina contra Grisales y compañía, y considerando que, "de acuerdo a lo que dispone el artículo 5to de la Ley 61 del 24 de junio de 1864 haga comparecer al despacho a los individuos entre quienes se ha suscitado la disputa" ${ }^{176}$, y llegado al caso que no comparecieran o no se llegara a un acuerdo, el alcalde estaría autorizado a tomar la decisión sobre los límites de la nueva propiedad provisionalmente y posteriormente enviar copia a la Secretaría de Hacienda del Estado para su aprobación.

El problema se agudizó cuando el perito agrimensor encargado del levantar nuevamente los planos llegó al punto en disputa y fue recibido con desdén por parte del señor Cardona, quien:

Manifestaba que él acataba las disposiciones de la Ley y las Autoridades, pero que se oponía a la demarcación provisional por cuanto tiene en su poder y presenta ante esta autoridad, la orden del señor secretario del Estado en que le ordena al señor jefe municipal nombre a los respectivos que deben demarcar y entregar el lote denunciado" [posteriormente dijo que] "con este procedimiento se verá defraudado de su propiedad, tanto más cuando esta alcaldía tienen conocimiento de los documentos que le acreditan su propiedad; y como esta alcaldía se atiene solo a lo que dispone la ley, se procedió al auto a lo que el señor Cardona desapareció no pudiendo demarcarse el terreno, a lo que se procedió a demarcar el del señor Ospina [sic $]^{177}$.

Pero las denuncias en contra de Grisales, Cardona y Flórez no solo llegaron por parte de los mencionados colonos; de acuerdo con la documentación obtenida en el AGN, fondo baldíos, varios cultivadores de la región demandaron las intenciones de Grisales y compañía por considerarlas no solo ilegales, sino en detrimento de

176 AGN, Baldíos, tomo 5, Salento, 5 de marzo de 1884, f. 238.

177 AGN; Baldíos, Tomo 5, Salento, 5 de marzo de 1884, ff. 239-240. 
sus intereses, al punto de que la Secretaría de la Unión se pronunció a favor de estos considerando necesario protegerlos de cualquier abuso que pudiera manifestarse durante la colonización, especialmente porque no debería haberse hecho disposición de los baldíos sin el debido proceso ${ }^{178}$.

¿Por qué en este caso el Estado se inclinó hacia los colonos y no los empresarios territoriales? Este ejemplo nos obliga a indagar no solo el procedimiento usado por los afectados, sino también la biografía de los demandantes, puesto que la disposición gubernamental no solo fue efectiva sino que se desarrolló con premura ${ }^{179}$. Ahora bien, este no fue el único factor clave, pues los firmantes de la demanda contra Grisales eran personas públicas en la región, y algunos alcanzaron escaños políticos. El segundo caso se presentó a partir de 1909 entre algunos colonos de Calarcá contra la empresa minera (de sal) Playa Rica del señor Cristóbal Jaramillo, quien había prestado dinero al Concejo Municipal de Calarcá durante la disputa con Burila.

El mencionado Jaramillo era dueño de varias hectáreas de tierra adquiridas con bonos territoriales, sin embargo pretendía que el concejo le favoreciera entregándole más de las legalmente adquiridas. Con lo que no contaba Jaramillo era que la normativa sobre adjudicaciones había tenido algunas variaciones entre las que se cuenta el criterio de asignación y su número; asunto determinado por la ubicación del predio de acuerdo a su altura sobre el nivel del mar.

178 AGN, Baldíos, tomo 5, Despacho de Hacienda, Bogotá, 1884, f. 241.

179 Al parecer, la producción y configuración de la normativa de la tierra tuvo la característica de beneficiar a los cultivadores y colonos contra los abusos durante los procesos de colonización, tanto así que una lectura detallada de la misma permite evidenciar una protección al pequeño propietario frente al terrateniente; ¿Entonces por qué la conflictividad histórica y despojo de un significativo número de personas? Pareciera que se juntan varios elementos entre los que podríamos mencionar: El conocimiento sobre las leyes de parte de los colonos; la capacidad de agenciar sus procesos, la organización política campesina; el respaldo estatal que garantice la expresión y seguridad de los reclamantes, la desarticulación entre el ser y el deber ser del Estado en relación con las acciones autónomas de las burocracias locales -caso estudiado con el Concejo de Calarcá y los colonos que hacen parte de dicho grupo-, consolidación del concepto de riqueza en la infraestructura, entre otros. 
Por esta condición el problema adquirió tres caras: por un lado, se tenía que pagar la deuda con Jaramillo, por otra parte, se tenía que justificar legalmente el pago y como último, se tenía que resolver la invasión creciente de colonos sobre las tierras que reclamaba Jaramillo y que el concejo no había asignado en el reparto amparado con la Ley 36 de 1907.

En vista de esto, el concejo optó por tres alternativas: usar la Ley 56 de 1905, la Ley 36 de 1907 o entregar a Jaramillo más tierras de las reportadas en los libros de adjudicación. El asunto era que la primera ley solo permitía adjudicarle a Jaramillo 500 has $^{180}$., y este pedía 5032 has., la segunda ley había sido diseñada únicamente para los pobladores, y no precisamente para pagar deudas como aclaraba el Ministerio de Obras Públicas ${ }^{181}$, y la tercera opción sería polémica por tener los ojos no solo de la personería municipal, sino de los colonos interesados en los predios.

Debido a que la zona reclamada por Jaramillo seguía siendo en la vox populi baldía, muchos cultivadores y colonos de Calarcá y la región optaron por asentarse en el terreno y, de la mano del personero municipal, comenzaron un pleito por vías legales e ilegales contra Jaramillo y las autoridades municipales, quienes prefirieron el desalojo como el mecanismo más práctico.

En vista de esto, la personería municipal dirigió al Ministro de Obras Públicas una misiva haciendo mención al memorial enviado desde el 28 de octubre de 1906, con el que se pretendía cuestionar la agrimensura y adjudicación de terrenos que habían dejado fuera a varios cultivadores y que a la fecha de la nueva notificación, perderían sus propiedades. Decía el personero que:

180 La Ley 56 de 1905 y el Decreto 1113 del mismo año, contenían varios elementos que no les eran favorables ni al concejo ni a Jaramillo, por ejemplo: el artículo 13 de la Ley 56 especificaba que no se podían adjudicar más de 1.000 hectáreas a ningún individuo; de igual manera, el tamaño de las adjudicaciones por individuo estaban determinadas por la altura sobre el nivel del mar, por lo que a Jaramillo solo se le podrían adjudicar 500 hectáreas como máximo. Por su parte, el Decreto 1113 del mismo año, en su artículo 16, establecía que los personeros municipales emitían conceptos en todos los casos donde el concejo hubiese dictado resolución alguna sobre adjudicaciones (Memorias del Ministro de Industrias, 1931, ff. 218 y 225).

181 AGN, Baldíos, tomo 32, 1909 Calarcá, octubre 27 de 1909, f. 69. 
El motivo de esta solicitud implorando la resolución a que se alude en el memorial dicho por motivo a que los colonos que ocupan los excedentes del globo de terreno de Playarica, de los cuales algunos están establecidos hace ya por lo menos diez y seis años y que tienen plantíos de pastos artificiales y cafetales de alguna significación han sido notificados para que desocupen inmediatamente sin reconocerles nada por las labores.

Esto señor Ministro llega al colmo de la insensatez y de marcada injusticia, y por esto me atrevo államar de nuevo y á explicar al señor Ministro que se digne resolver el punto que se le consulta, si los excedentes en las adjudicaciones afectadas hace algún tiempo son baldíos unicamente cuando se efectuen la remedida, y eran de hecho desde que se incluyeron por malicia o por equivocación al tiempo de efectuar las equivocaciones... el lote de terreno que encierra título de Playarica no es mayor de dos mil hectáreas y la adjudicación se efectúo por solo $300[\mathrm{sic}]^{182}$.

También varios pobladores enviaron misivas al ministerio preguntando por la legalidad en la adjudicación ${ }^{183}$, por lo que el Ministro se dirigió al Concejo Municipal de Calarcá preguntándole por los hechos denunciados. La respuesta fue técnica y sin mayores pormenores al respecto:

Ultramar: Luis Jaramillo la labora a título de descubridor y cultivador de baldíos. Rio Verde, José Giraldo elabora como descubridor, comprador y cultivador de baldíos, Playa Rica, Daniel Gómez E y C., elabora como propietario a cambio de bonosterritoriales como compradoresy descubridores; la Romelia, Rafael Correa y C. elabora como descubridores y adjudicatario de baldíos como cultivadores. Quebradanegra, Jesús A Jaramillo elabora como propietario territorial y descubridor, La Palestina, Valentino Giraldo elabora como propietario territorial, descubridor y comprador, Remolinos mortuoria de Bernardino López, elabora como cultivador y descubridor, Los Chorros y Oritá, Camilo A Jaramillo, elabora como propietario y comprador

182 AGN, Baldíos, tomo 28, diciembre 8 de 1907, f 119.

183 AGN, Baldíos, tomo 29, Calarcá, 15 de octubre de 1908, f. 628 
y comprador de tierras al Gobierno, San Rafael, Mortuoria de Daniel de la Pava, elabora por derecho de compra y cultivadora de baldíos [sic $]^{184}$.

¿Qué pretendía el concejo con esta respuesta? ¿Acaso desviaría la atención del gobierno central? ¿Cómo actuarían los colonos y cultivadores inmersos en el problema? ¿Qué recursos seguirían usando las autoridades locales?

Como era de esperarse, las invasiones a los predios de Playa Rica no se hicieron esperar y quienes llevaban varios años dentro del predio, radicalizaron sus acciones apoyando a quienes llegaban a cultivar; por su parte, el concejo municipal optó por el desalojo forzado y el 6 de noviembre de 1911 realizaron las respectivas acciones. Por otra parte, Antonio Luis Peláez, abogado de los empresarios, inició una querella en contra de los colonos alegando que el título de dominio sobre las tierras fue hecho por el Ministerio de Hacienda el 29 de abril de 1889 y que la escritura 1066 del 23 de noviembre de 1908 había sido otorgada en la notaría de Armenia. De igual manera demandaba a los señores Pedro Giraldo, Rafael Osorio, Pablo Beltrán, Alejandro García, Eleazar Ramírez, Jesús Tamayo y Ramón Osorio, porque habían hecho ensanchamientos, tumbas de bosques, construido casas y tenían sementeras, generando menoscabo en la propiedad de Playa Rica:

Notandose en ellos maldad y mala fé con que proceden. Al cortar los bosques han perjudicado porque de allí se obtienen las sales y los dueños han sembrado para su explotación" en concepto de la Alcaldía á llegado el caso de cumplir lo estatuido por el art. 15 de la Ley 57 de 1905 [sic ${ }^{185}$.

Con apoyo en esta demanda, se procedió a realizar el respectivo lanzamiento de los colonos, y el 7 de noviembre de 1911, en asocio con el secretario, el alcalde se trasladó a los terrenos de Playa Rica con el fin de que se practicaran todas las diligencias pertinentes y fueran:

Intimados los señores Pedro Giraldo, Rafael Osorio, Pablo Beltrán, Alejandro

184 AGN, Baldíos, tomo 29, Concejo Municipal, Calarcá Mayo 2 de 1908, ff. 86-87.

185 AGN, Baldíos, tomo 35, Calarcá, noviembre 6 de 1911, f. 528. 
Gaviria, Elezar Ramírez, Jesús Arango, Ramón García, i Ismael Soto para que presentaran si los tienen, contratos [cosa que] no hicieron o se ocultaron. [Por tal motivo se procedió] a realizar el lanzamiento sin dar lugar a recurso alguno, ni a diligencia que pueda demorar la desocupación de la finca.... Notifíquese resolución al señor Luis Peláez ${ }^{186}$.

En vista que la acción tenía que incluir los respectivos testigos, se pidió a Miguel María Ángel y Benito González para que sirvieran en tal labor, por lo que:

Declaró al respecto el señor Miguel María Ángel reconocer los terrenos, también que los ocupantes estaban sobre tierras privadas hacía tres meses, que las tumbas hechas por los mencionados invasores menoscaba los intereses privados por estar dentro de los linderos de la finca, [y Benito González declaró en] Calarcá a 27 de octubre de $1911^{187}$.

Como era de esperarse, la reacción de los cultivadores a través del uso de repertorios de protesta como la invasión de predios, quemas de cultivos, etc., llevó a que el concejo pidiera apoyo del cuerpo de policía a través de telegramas enviados al Ministro de Obras Públicas ${ }^{188}$.

¿Pero cómo se efectuó el procedimiento? ¿Qué caracterizó la reacción de los afectados? De acuerdo con el informe entregado por la alcaldía al personero municipal, el alcalde se movilizaba acompañado del abogado a cargo de la demanda contra los colonos, dos policías y un agrimensor. Al llegar a cada casa, los demandados asumieron diferentes reacciones, por ejemplo: según Apolinar Palacio, cuando llegaron a la casa de Jesús Arango, y el alcalde comenzó a preguntar por los predios y la justificación de su propiedad:

186 AGN, Baldíos, tomo 35, Calarcá, noviembre 6 de 1911, f. 528.

187 Benito González dio respuestas similares a las del primero, por tal motivo no se transcribieron. Ver, AGN, Baldíos, tomo 35, Calarcá, noviembre 6 de 1911, f. 528.

188 AGN, Baldíos, tomo 35, 1911; Belalcázar, 30 de noviembre, f. 179. 
Al ver [Arango] que le habían tumbado los tabacos que tenía y un caney y otro tabaco en la casa se enojó y dijo que qué iban a hacer con su tabaco, que ya había pagado los derechos legales; el alcalde le hablaba y este no atendía y se entró a la casa con la escopeta que traía y con machete al cinto, con actitud desafiante. Visto lo cual el alcalde dio orden a los policías para que lo cogieran y amarraran para evitar alguna desgracia, lo cual fue hecho y en la batajola resultó Hernández herido, pero no por voluntad de los policías que la casa de este la tumbaron por consentimiento de él al ofrecerle Peláez dinero por valor de ella y luego se fue con su esposa a una casa vecina ${ }^{189}$.

Por otra parte, Duque declaró que al mencionado Arango lo amarraron los policías:

Y ordenó dicho alcalde á sus policías que sacaran los muebles y enceres de la casa para afuera, que los policías los sacaran y los mandaran para otra casa vecina, y al hombre que estaba enfermo en dicha casa lo sacaron de a caballo en la bestia en que andaba el alcalde. Y también mandó el alcalde subir á una señora que estaba allí próxima a dar a luz cuyo parto se efectúo al día siguiente según se dijo al exponente Nuncio Aguirre $[\mathrm{sic}]^{190}$.

Otro de los testigos que usó la Alcaldía como respuesta al personero, fue Narciso Aguirre, quien aseguró que:

La primera que visitamos fue la de Elezar Ramírez pero antes de llegar a ella el alcalde cojió preso a Ramírez y lo llevó á la dicha casa inmediatamente para no irse en el caso de sacarle al callejón los muebles y enseres que tuviera allí para entregarsela á Antonio Luis Peláez allí presente"...” Pero que si daba fianza le otorgaban plazo al día siguiente para no tumbarle la casa y yo otorgué la fianza e intervine para que Peláez pagara a Ramírez 2500 pesos que este ya atemorizado pidió demás como se trataba en lo que creía de su propiedad de más de diez años de constante trabajo para perderlo en un momento a

189 AGN, Baldíos, tomo 35, Calarcá, diciembre 4 de 1911, f. 534.

190 AGN, Baldíos, tomo 35, Calarcá, diciembre 4 de 1911, f. 536. 
razón de un lanzamiento extemporáneo" Luego se fueron para la casa de Jesús Arango y como este no estaba "El alcalde lo hizo llamar mientras tanto intervino a la familia Arango y a otra señora que había en la casa para que desocuparan inmediatamente y ordenó a los policías que fueran sacando afuera un montón de trabajo que tenía dentro de la casa, lo que efectuaron y en estas llegó Arango y preguntó que qué hacían con sus tabaco, que sí era que le iban a quemar su casa y el alcalde contestó no. Lo llamo para que desocupe esta casa para entregársela al apoderado de Playa Rica aquí presente; Arango se enojó y fue a entrarse para la casa llevando en su mano una escopeta, el alcalde mandó a unos policías que lo cogieran y desarmaran, lo que se efectuó quitándole a la vez un machete que llevaba al cinto, ya encadenado; luego procedieron los policías a desocupar la casa pasando lo que había en ella a la de Antonio Hernández. Manco Romero que estaba en ella enfermo lo sacaron a caballo donde el mismo Hernández y la señora de este que estaba en cinta también salió y dio a luz a los tres días después [sic] ${ }^{191}$.

En los casos mencionados, llama la atención que se despojaran a algunos colonos, pero a otros se les permitiera el pago de fianzas por los terrenos donde se encontraban. De igual manera, la acción de las autoridades locales fue usar la fuerza y las vías legales como estrategia para mantener el control sobre unos predios que siguieron en litigio.

En cuanto a la suerte de los colonos y cultivadores que estaban dentro de los predios y fueron lanzados por la autoridad local, de acuerdo con los documentos del proceso, estos fueron puestos a disposición de las autoridades judiciales ${ }^{192}$, y leído el memorial a los señores invasores, se procedió a sacar a la vía pública los objetos que contenían en las casas.

Por su parte, los colonos mantuvieron también una constante respuesta que consistía en volver a invadir y enviar memoriales ante las autoridades competentes expresando que:

191 AGC, Baldíos, tomo 35, Calarcá, diciembre 4 de 1911, ff. 536-538.

192 AGN, Baldíos, tomo 35, Calarcá, diciembre 8, f. 525. 
Apoyados escrituras otorgadas Concejo Municipal ésta registrada solo mil novecientos ocho (1908) sin fallo definitivo juicio plenario sin lugar defensa; fuimos lanzados mejoras posesiones hace doce (12) años cultivos que fueron tumbados a machete por alcalde y policías esta interesados ${ }^{193}$.

Pero no todos los casos vinculados con la invasión tenían la misma característica. Hubo casos de colonos que tenían títulos, lo que hacía más difícil resolver la titularidad de Playa Rica y la situación de los demás.

Al visitar la casa de Pablo Beltrán, este mostró que tenía cómo comprobar que no había hecho tumbas ni casa, solo que había comprado mejoras. Decía el respectivo informe que:

El señor Pablo Beltrán no hecho tumbas de maderas ni ejecutado ensanchez a las mejoras que compró y además que cuando compró esas mejoras se encontraban en duda los linderos de las tierras de Playa Rica y se consideraba fuera de estos linderos aquellas mejoras. En este estado el Sr., Peláez como apoderado de los propietarios pidio que se aclararan los testigos la declaración en el sentido de lo que estos consideraban por ensanchez y aquellos manifestaron que se han referido á que Pablo Beltrán no ha abrogado mayor terreno que el comprado por las mejoras que compró, aunque sí han variado estos en su calidad pues las compradas primeramente fueron transitorias y las de hoy son estables. En vista de esto la alcaldía vio que no había razón de lanzamiento a Beltrán y así lo aplicó. El mismo caso tuvo Pedro Giraldo. A Alejandro García se le impuso una multa de $\$ 50$ pesos y se le prohibió hacer en lo sucesivo ensanchez; esto se hizo en vez del lanzamiento [sic] ${ }^{194}$.

¿Por qué se habían vendido los predios? ¿Quiénes los habían vendido? Nuevamente se puede corroborar la dificultad para regular estas adjudicaciones, ventas y especulación sobre los predios, asunto característico del periodo de estudio.

193 AGN, Baldíos, tomo 36, Calarcá, 23 de noviembre de 1911, f. 148.

194 AGN, Baldíos, tomo 35, Calarcá, diciembre 8 de 1911, f. 531. 
El tercer caso vincula a Julio Vélez, Pedro Mejía y Juan Jaramillo, quienes se vieron envueltos en una serie de denuncias que iban desde apropiación ilegal, hasta vínculos con funcionarios públicos y testaferrato.

El proceso se inició en 1921, presentando acciones violentas de parte de los colonos, como también de las autoridades municipales y departamentales que vieron en los repertorios de protesta, elementos de alto riesgo para el orden público pues al parecer, varios cultivadores se habían asentado en unas tierras de dudosa propiedad generando un choque con los presuntos dueños.

Aunque podría decirse que este pleito no tiene mayor diferencia con el sinnúmero de casos que se presentaron en la región, el asunto se vuelve relevante cuando al revisar los pormenores, se logra identificar que las denuncias interpuestas por los colonos van más allá de la apropiación ilegal, pues acusan a Vélez de ser testaferro y a Mejía y Jaramillo de tener vínculos familiares con autoridades administrativas y judiciales de la región, permitiéndoles dilatar los procesos y adueñarse de los predios con mayor facilidad.

El pleito se abrió en el Circuito de Anserma, pero con lo que no se contaba, era con que el juez encargado y los abogados del juzgado tenían vínculos familiares con Jaramillo, por lo que los denunciantes alegaban ante el Gobernador de Caldas que:

Tenemos conocimiento de que el mencionado despacho del juzgado del Circuito de Anserma reposan varios expedientes relacionados a los terrenos de Risaralda introducidos allí hace por más o menos diez años sin darseles resolución ninguna, cosa que huelga la presunción de injuria o malidisencia de ese despacho en contra de los cultivadores. Y no es que huelga la presunción y nada más, Señor Gobernador, es que varios exempleados de ese despacho, que les dije ponerme al corriente de los expedientes que le relato y que hasta el presente llevan el profundo sueño de los archivos, son los abogados de los que se titulan dueños de las tierra, por lo que se puede deducir sin equivocación ninguna, que allí a habido mala fe para nuestros asuntos. 
Ahí está Tiberio Ospina, que fue juez de ese Circuito abogando en contra del gremio agricola de este municipio [...] ahí está Rodrigo Baena quien fue juez de ese Circuito de abogado contra los cultivadores fraguando despojos que les permite llevar a efectos el mecanismo incurrente y malicioso de su maleante pasada administración en el Circuito de Anserma [sic] ${ }^{195}$.

Como puede verse en esta denuncia, los procesos judiciales relacionados con las adjudicaciones no necesariamente garantizaban transparencia y éxito para los demandantes, menos cuando se trataba de personas con poco capital para sostenerlos y estaban en el bando contrario a los afectos de algunos jueces, concejales, abogados y demás representantes de las burocracias locales.

En vista de esto, los colonos recurrieron a Jesús Jaramillo como su apoderado, y este se dirigió al Ministro de Obras Públicas con copia del memorial, manifestando el interés de que tomara nota "minuciosa de las dificultades administrativas que en este departamento se presenta para el esclarecimiento de baldíos y defensa de este débil gremio a quien por muchos años me he convertido en su defensor" ${ }^{196}$.

Como los sucesos que se estaban presentando ponían en riesgo el orden público, el alcalde de Calarcá, Ruperto Isaza, también envió una misiva al Ministerio de Obras Públicas para preguntar,

¿[podían] ser ocupados de hecho terrenos adjudicados sin previa provanza existencia exceso?" más aún cuando el demandado era una figura pública y por otra parte, el "personero [estaba] fomentando la [invasión] iniciando así atropellos, violaciones, [que] causa desconcierto en la región [sic] ${ }^{197}$.

La respuesta del ministerio fue enfática al respecto: "Los terrenos baldíos adjudicados, en que se presume exceso en la adjudicación, no pueden ser ocupados de hecho por terceros, sin previa provanza de tal exceso" (Decreto $N^{\circ} 582$ de 1916).

195 AGN, baldíos, tomo 48, Belalcázar Caldas, 5 de octubre de 1921, f. 258.

196 AGN, baldíos, tomo 48, Belalcázar 14 de octubre de 1921, f. 238.

197 AGN, Baldíos, tomo 48, 19 de enero de 1921, f. 250. 
Pero ¿por qué el personero municipal actúa a favor de los colonos y fomenta desmanes en la región?, ¿ cuál es la acción legítima que debería impartir el gobierno municipal?, ¿qué respuestas darían los colonos? Por ley, el personero municipal debía estar al tanto de las adjudicaciones y era quien daba el aval a las mismas. Al parecer, la ambigüedad de estas llevó a que se fragmentara la representación estatal en la región, siendo una parte afín a los cultivadores y colonos, y la otra, manteniendo las alianzas y legitimando la corruptela.

En un siguiente memorial firmado por 64 colonos, la denuncia sigue sosteniendo que el dicho Juzgado de Anserma dilataba el proceso. En la misma se hacía referencia a la vulneración de los derechos de los cultivadores y vuelve y menciona la relación directa entre los jueces y abogados del circuito, quienes son los verdaderos tenedores de la tierra y que si bien, había pronunciamientos previos del Gobierno sobre el caso, no se había cumplido la disposición legal.

La primera repuesta llegó con copia a Juan María Roche, diciendo:

Me permito poner en conocimiento de usted que su memorial de fecha 6 de los corrientes se remitió junto con los documentos que acompañan al señor Gobernador del Departamento de Caldas para que este funcionario se sirva ordenar la práctica de una investigación y dictar las medidas que juzgue convenientes, para evitar los atropellos que usted se queja ${ }^{198}$.

¿Pero existían garantías para que dicho funcionario tomara cartas en el asunto? Según las siguientes comunicaciones, al parecer no hubo tal pronunciamiento, tanto que se elevó otro memorial al gobernador pidiéndole que renovara:

La orden de investigación, se haga la declaratoria legal sobre si las escrituras son títulos legales o no lo son, pues sin estar resuelto este punto le fue interrumpida la posesión a Ramón María con unas escrituras que según las leyes son otras ${ }^{199}$.

198 AGN, Baldíos, tomo 48, Belalcázar Caldas, 5 de octubre de 1921, f. 260.

199 AGN, Baldíos, tomo 48, Belalcázar Caldas, 5 de octubre de 1921, f. 261. 
$\mathrm{Al}$ año siguiente el Ministerio de Agricultura retomó el proceso enviando una misiva donde preguntaba sobre la suerte de los demandantes y en la respuesta dada por la Alcaldía de Calarcá se especificaba que "cumpliendo comisión del Juez Circuito Calarcá, procedí practicar diligencia lanzamiento de Colonos cultivadores". Inmediatamente recibida la notificación, el Ministro ordenó suspender dicha providencia hasta no tener mayor claridad sobre los hechos ${ }^{200}$.

Por su parte, los colonos siguieron presionando a través de memoriales, pero en esta ocasión fue directamente al Presidente de la república mencionando que recurrían a él, porque en los otros despachos se había negado la atención y que por no haber ocupación por más de diez años, se pidió al ministerio que se hiciera una inspección ocular como lo ordena la Ley 83 de 1920 para garantizar el abandono del predio y ocupar, asunto que no se había realizado.

Además de estos pormenores, el memorial denunciaba no solo los atropellos llevados contra los colonos y cultivadores, sino la corruptela que se presentaba en el circuito de Anserma y cómo esta beneficiaba a los demandados. Decía el memorial que:

El 18 de junio de 1906, se adjudicó por el Ministerio de Obras Públicas y Fomento, al Sr. Julio Vélez A., y a título de cultivador, un lote denominado "FLORESTA". Ese terreno fue entregado por el señor Alcalde de Salento al señor BENJAMIN PALACIO, tal vez como recomendado del adjudicatario, el 24 de octubre de 1906. El titulado adjudicatario que desde la entrega no se volvió a saber de el, y que desde entonces recibio por medio de un comisionado, ningún interés tomó en cumplir la obligación que le imponía la ley, de tener mejorado o trabajado, sino todo, la mitad según artículo 7 de la Ley 56 de 1905, y al contrario, vendió o simuló vender pues parece que no era más que un personaje decorativo, para favorecer personales e interesadas aspiraciones , a los señores FRANCISCO MEJÍA Y PEDRO JUAN JARAMILLO, acaso a IGNACIO LONDOÑO, pero en todo caso, el terreno vino a quedar de MEJIA Y JARAMILO muy pronto después de su adjudicación [sic $]^{201}$. 
De igual forma, explicaban cómo se había dado el testaferro acusando a Vélez de haber enajenado:

Los terrenos de que venimos hablando, [y] sus adquirientes Francisco Mejía y Pedro Jaramillo, sin preocuparse nada de su mejora, lo tomaron como medio de seguridad para afianzar sus deudas particulares y al efecto, garantizaron a Carlos Pinzon y Jesús Arcila en lo principal y los remanentes, respectivamente, sendas deudas que con ellos contrajeron.

Los acreedores, una vez cumplido y pasado el plazo de las deudas establecieron, o estableció primeramente Arcila demanda ejecutiva con acción real hipotecaria, contra los deudores o mejor dicho, contra el terreno viniendo así a tener que hacer tercería el señor Pinzón.

En el juicio ejecutivo que se siguio, como es natural, el terreno fue puesto en depósito: en ese depósito, que por conveniencia del señor Jaramillo, fue cambiado repetidas veces el depositario (cosa que hacía el deudor en conveniencia con los depositarios) los colonos nos presentamos en la audiencia reclamando el derecho de oposición para que se nos dejara la tenencia provisional, pero fuimos desoidos, pretextando y diciéndonos que como solo se trataba de un simple cambio, no era el caso de oírsenos y admitírsenos oposición alguna" (AGN, baldíos, tomo 54, Calarcá, Junio 20 de 1923, f. 599), [y que el mencionado Jaramillo se había visto interesado en los terrenos cuando] “...el ejecutado al ver que las empresas que habíamos establecido a su vista y contemplación, que habían dado inmeso valor a los terrenos, pretendió quedarse con ellas, obrando de acuerdo con el depositario último pidió por conducto de ésta lanzamiento, alegando una perturbación posterior al depósito, y consiguió con el Señor Juez del Circuito -entonces prometido yerno y luego su hijo político- que decretara el lanzamiento, que como ya dijimos se llevó a cabo desconociendo todo derecho, y aun privandonos del de sacar los víveres que existían para sustento de nuestras familias [sic] ${ }^{202}$. 
Agregaban que el señor Jaramillo había agredido al apoderado de los colonos y que las autoridades se habían puesto a favor de Jaramillo, pues:

Cuando menos lo esperamos, fuimos arrojados sin misericordia, sin que se nos oyera los reclamos, ni se nos atendieran las peticiones que en vía de protección elevamos, tanto a las autoridades de aquí, como al Ministerio y la Procuraduría General, suplicando al menos, una protección y posesión provisional a que teníamos y tenemos derecho, salvo caso que para nosotros no hayan hecho las leyes 45 y 71 de 1917 y 85 de $1920^{203}$.

Después de revisar con detenimiento el caso, el Ministerio de Hacienda se pronunció al respecto por medio del oficio 908 y 911 devolviendo las copias de adjudicación y entrega de terrenos baldíos decretadas en favor de los señores Luis Alfonso Mejía, Luis Ángel Castañeda y Feliciano García para que se corrigieran las irregularidades anotadas por ese ministerio. Lo llamativo del proceso fue la respuesta dada por la Secretaría de Hacienda del Departamento de Caldas, pues esta terminó cuestionando la decisión y argumentando que hacer una revisión de la adjudicación era imposible dado que ya era un hecho cumplido.

¿Por qué la Secretaría de Hacienda respondía al ministerio de esta manera? ¿Tendrían acaso vínculos con los demandados? En la respuesta decía Arturo Salazar, encargado de la respectiva secretaría que:

Ha sido costumbre en esta secretaría sancionada por ese despacho, admitir la prueba de número de hectáreas por aproximación, porque consistiendo esa prueba en testimonio de testigos, éstos en su generalidad no son agrimensores y de aquí que en su concepto no puedan determinar de una manera fija el número de hectáreas de un terreno sino a cálculo que sea poco más o menos. Y como la resolución de adjudicación debe estar de acuerdo con la prueba traida al expediente, la adjudicación se ha hecho siempre por aproximación como consta en esa prueba y no fijó el número de hectáreas. 
Ese ministerio aprobó sin objeción alguna las resoluciones de baldíos número 262, 263 y 266 dictadas por este Despacho idénticas a las que se han devuelto y con anterioridad a éstas aprobó muchas otras de ésta índole; y, desde luego, esa aprobación sentó una doctrina legal que ha seguido esta Secretaría

Hacer la corrección anotada, sería hoy imposible porque los expedientes respectivos se encuentran ya protocolizados. Se tendrá en cuenta que para lo sucesivo la observación que se hace; pero hoy por hoy creo debe aceptarse los hechos cumplidos ya que ellos han sido autorizados por ese ministerio $[\text { sic }]^{204}$.

Esta respuesta permite varias interpretaciones: por una parte, vemos cómo la Secretaría de Hacienda de Caldas libra su responsabilidad sobre el Ministerio que aprobaba sin cerciorarse de cómo se estaban llevando los procedimientos de adjudicación; sin embargo, como pudo leerse en el segundo capítulo y parte de este, el haberle dado autonomía a los concejos y gobernaciones para adjudicar ponía de presente que el Estado central no podría controlar todos los pormenores administrativos por lo que tenía que entregar en las manos de las autoridades locales la responsabilidad de administrar lo público. Este es un ejemplo del debate sobre qué tanto debe, y qué debe controlar el Estado central, pues evidentemente habrán posturas a favor y en contra de estas disposiciones.

Otro elemento interesante es que finalmente las autonomías no necesariamente afectaban la construcción del Estado, más bien enriquecían tal proceso, pues como se ha evidenciado, la coacción ejercida por instituciones de vigilancia como la personería y la presión social a través de vías legales e ilegales, permitió poner en cuestionamiento la corrupción del ramo. Ahora bien, ¿Qué se necesitaría para reducir los índices de corrupción presentados por estas burocracias? Como hemos visto, los mecanismos de participación popular y de coacción interna eran débiles; la Constitución de 1886 solo reconocía los memoriales y el voto como un mecanismo de participación ciudadana, dejando gran parte del peso administrativo y de

204 AGN, Baldíos, tomo 57, Manizales, 15 de enero de 1924, f. 176. 
vigilancia estatal sobre sus propias burocracias; de igual manera, la construcción del Estado es producto de una ida y vuelta, donde la normativa es una vía para legitimar la legalidad, pero esta a su vez debe ser acogida por quienes participan activamente en la vida cotidiana del Estado.

Aceptar o no una ley, decreto o resolución, no es únicamente una muestra de legitimidad que tiene el Estado entre la población, más bien se trata de un juego donde los actores sociales asumen con interés o desdén, y por ello se movilizan con el fin de alcanzar un objetivo. Pero volvamos al caso en discusión; ¿Qué pasó con los colonos? ¿Cuál fue la suerte del proceso llevado en el juzgado de Ansema?

El 25 de enero de 1924 llegó un telegrama firmado por Jesús Jaramillo y Luis Rocha a la oficina del Ministerio de Agricultura, denunciando los pormenores acaecidos en el Quindío por cuenta de la autorización del Juez del circuito, quien había ordenado despojar e incendiar las habitaciones y cultivos de los colonos que estaban en las tierras de disputa ${ }^{205}$.

Por su parte, el mencionado juez envió una misiva al ministerio acusando al Procurador Municipal de apoyar a los invasores que él había decidido expulsar de los terrenos de Risaralda. Esta información fue remitida al Procurador General de la Nación para tomar cartas en el asunto ${ }^{206}$.

El caso se había comenzado a salir de las manos del juzgado y las autoridades municipales, pues ya no solo se tenía la presión de los colonos, sino que estos contaban con el apoyo del personero de Calarcá y el procurador municipal.

En vista de esto, el proceso pasó al Tribunal Superior de Manizales desde donde se escribió al Ministro de Industrias con el fin de que se enviran las pruebas aportadas por el señor Manuel F. Ospina en oposición a la adjudicación de los terrenos de Luis $\mathrm{M}$. Roche a fin de que se digne proceder a pronto auxilio y devolución ${ }^{207}$.

205 AGN, Baldíos, tomo 57, Belalcázar Caldas, 25 de enero de 1924, f. 439.

206 AGN, baldíos, tomo 57, Belalcázar Caldas, 25 de enero de 1924, f. 440.

207 AGN, Baldíos, tomo 57, 1924; Manizales julio 4 de 1924, f. 497. 
De igual forma, se pronunció el Juez del Circuito de Calarcá, pidiendo al Ministro de Agricultura y Comercio que exhortara sobre el caso de los colonos contra el señor Jaramillo y el abogado de los colonos envió una misiva pretendiendo que se realizaran los siguientes puntos:

1) Que para prueba en la articulación a que el poder se refiere, se practiquen las siguientes previa citación con presencia y del señor personero municipal, 2) Que se libre exhorto al Señor Ministro de Agricultura y Comercio de Bogotá [...] para que su Secretario eleve diligencia extrajudicial: 1. La copia original del título expedido a favor de Tulio Vélez que debe llevar fecha 18 de junio de $1906^{208}$.

Evidentemente, este proceso tenía muchas aristas e intereses de por medio. Como podemos ver, los colonos eran personas con conocimientos del tema, pero estaban enfrentando representantes de la autoridad estatal, asunto que hacía dispendioso y desgastante el pleito.

No siendo suficiente, la llegada de nuevos pobladores a la región incrementaba la presión social sobre las tierras en litigio, así que las acciones se incrementaron, principalmente las violentas e ilegales.

Para los años treinta del siglo XX, la situación era tan tensa que el gobernador del departamento de Caldas tuvo que recurrir a las vías represivas, enviando al Ministerio de Gobierno un oficio (\# 4423 de 16 de diciembre de 1931) donde pedía el concepto del Señor Ministro para dictar algunas medidas de orden público. El telegrama decía lo siguiente:

Orden Público Gobernación de Manizales. Ante grave situación hase presentado región Quindío por ocupación de hecho de numerosas haciendas, en grupos de cincuenta, cien y más personas, lo que hace imposible el ejercicio 
de propietarios de las acciones establecidas en derechos vigentes del gobierno nacional y en ordenanzas de policía, gobernación dictó decreto que necesita para regir aprobación Gobierno Nacional y al efecto estudiarlo Señores ministros Gobierno e Industria. Tratándose asunto inaplazable, urgentísimo, ruego a su excelencia interesarse pronto despacho. Servidor Jorge Gartner, $[\text { sic }]^{209}$.

Dado que dicha disposición debía resolverse con el aval del Ministerio de Gobierno y el visto bueno del de Industrias, en el informe numerado 4423 se le escribía al ministro:

Como seguramente debe estar enterado el Ministerio, en algunas regiones del Departamento de Caldas se han creado unas situaciones verdaderamente alarmantes, por la ocupación que han hecho algunos individuos sin título alguno de propiedades de particulares para cuyo lanzamiento se ha tropezado con dificultades de cierta índole. En tal emergencia el señor Gobernador del Departamento ha dictado un decreto por el cual se expiden algunas medidas que dicho funcionario titula de orden público en relación con la efectividad de la acción de lanzamiento de que trata el artículo 15 de la Ley 57 de 1905. Como el despacho a su digno cargo hizo el año pasado algún estudio en relación con la aplicación que debe darse al artículo citado, estudio que dio origen al decreto 992 de 21 de junio de 1930 que trata de estos asuntos, me permito enviar a usted una copia del referido Decreto del Gobernador de Caldas para que usted se sirva darme su opinión sobre dicha providencia y decirme si es el caso aprobarla o si sería más conveniente adicionar el decreto 992 citado reglamentando los casos no previstos en el decreto del Ejecutivo Nacional y que si se contemplan en el expedido reciente por el Gobernador de Caldas y que este á enviado a la aprobación del Gobierno ${ }^{210}$.

El problema era que el respectivo Gartner había propuesto un decreto que le 
permitía resolver prontamente los sucesos que se estaban presentado antes y durante su administración, sin embargo, la aprobación y ejecución del mismo debían tener la aprobación del Gobierno en representación del Ministerio de Gobierno. Como los casos mencionados vinculaban al Ministerio de Industrias, se le participó de los hechos, especialmente porque la ejecución del decreto propuesto por la Gobernación de Caldas, podría violar leyes que establecían procedimientos y pretendían aclarar bajo qué circunstancias podrían llevarse a cabo despojos y lanzamientos.

Teniendo presente la gravedad de los hechos acaecidos en el departamento, el Decreto fue aceptado con algunas modificaciones, pretendiendo ajustarse a la generalidad de los casos presentados en todo el país ${ }^{211}$.

Después de haberse considerado viable el acuerdo propuesto, el Ministerio de Gobierno se dirigió al Ministerio de Industrias dando el aval para su ejecución siempre y cuando se hicieran los respectivos ajustes; de igual manera el ministerio consideraba importante hacer la respectiva reforma a la Ley 993 de 1930, reconociendo que contenía vacíos e irregularidades. El dicho decreto terminó socializándose entre distintos gobernadores con el fin de que estos actuaran de acuerdo con las necesidades pertinentes ${ }^{212}$.

Al socializarse el acuerdo en el despacho de Caldas, se le enviaron al Ministerio de Gobierno los respectivos agradecimientos por las indicaciones propuestas y se propuso que se modificara "el aludido decreto 326 en el sentido propuesto por usted, antes de impartirle la aprobación ejecutiva”213.

Con este espaldarazo a la administración departamental, el Gobernador de Caldas se dirigió a todos los alcaldes del departamento con el fin de especificar qué tipo de acciones debían tomarse en situaciones donde se dieran ocupaciones de hecho. En la circular informativa, decía que:

211 Ver anexo 2.

212 AGN, Baldíos, tomo 75, Manizales, 18 de diciembre de 1931, f. 30.

213 AGN, Baldíos, tomo 75, Bogotá, diciembre 18 de 1931, f. 26. 
La magnitud trascendental de estos acontecimientos ha llevado al Gobierno a pensar que si bien es cierto que tantos preceptos constitucionales, oro la legislación civil sustantiva y las normas policivas adoptadas por el Ejecutivo General y la Asamblea Departamental, consagran los derechos de los funcionarios de la República están en el deber de salvaguardar, existen para determinados casos en los estatutos procedimentales serios vacíos que los hacen ineficaces para garantizar con plenitud los expresados derechos, debido a la forma inusitada en que pueden actuar los detentadores, dejando burlado o por lo menos indefinidamente aplazado el cumplimiento de las leyes, [y con una justificación político administrativa, explicaba el por qué necesitó diseñar el decreto 326$]^{214}$.

De igual manera, haciendo una presentación del sentido de las leyes en la sociedad occidental, explicaba que por error interpretativo se había fomentado la invasión sobre predios privados, por lo que era necesario hacer una presentación detallada del sentido que tenía el artículo 56 de la Ley 110 de 1912, (Código Fiscal).

Según Gartner, habían tres leyes complejas: La ley 85 de 1920, la ley 71 de 1917 y la ley 52 de 1931. El diseño de cada una tuvo referentes de conflictos distintos a los del Quindío, por lo que su interpretación generaba confusiones entre los vinculados a un pleito y fueron comunes los casos en los que colonos invadieran predios justificando una agrimensura errada, o en su defecto, se apropiaran de varias hectáreas desconociendo a los ocupantes de hecho.

Finalmente el Gobernador se dirigió a la población de Caldas diciendo que:

Todas aquellas personas que pretendan establecer trabajos dentro de los terrenos titulados so pretesto de que la Concesión excede los límites legales o de que el concesionario no ha cumplido con las disposiciones impuestas por la ley, deben establecerlo previamente así ante el gobierno, y mientras tanto las autoridades están en el deber de proteger al poseedor del título con

214 AGN, Baldíos, tomo 75, Bogotá, diciembre 18 de 1931, f. 31. 
observancia de los trámites legales” Jorge Gartner, Secretario de Gobierno, José Jaramillo Montoya ${ }^{215}$.

De esta manera, la gobernación y el Estado central pretendieron dar soluciones prácticas a las distintas manifestaciones ilegales que se veían promoviendo y manifestando en la región, sin embargo, la algidez del conflicto y los constantes vacíos jurídicos siguieron presentes, generando nuevos choques entre colonos y supuestos propietarios.

Ahora bien, en el caso del Quindío, la producción cafetera sirvió como amortiguador para los conflictos, pues finalmente se ocupaba muchos brazos y podría decirse que, en términos generales, la concentración de la propiedad no era tan marcada como en otras regiones del país; caso Tolima, la Costa Atlántica o los Santanderes y Boyacá, donde los choques entre campesinos y terratenientes aliados con las autoridades locales y nacionales, fueron el pan de cada día (Palacios, 2011).

\subsection{A manera de Conclusiones}

El presente capítulo tuvo como objetivo principal, articular las tres categorías de la investigación: Estado, colonización y práctica política con el fin de analizar la relación entre el proceso formativo del Estado y la transformación de los conflictos.

Para lograr esta articulación, se tuvo presente que la formación del Estado es producto de la imbricación de necesidades y acciones de las élites, gobernantes y la presión social. Como sería muy dispendioso abarcar todos los ámbitos del Estado, nos concentramos en la transformación de lo jurídico, específicamente lo relacionado con los baldíos entre 1870 y 1930, pues no solo es un periodo y tema poco estudiado, sino que puede considerarse como un antecedente del intervencionismo liberal de los años treinta y la justificación para las acciones armadas de la segunda mitad de siglo XX.

215 AGN, Baldíos, tomo 75, 1931; Bogotá, diciembre 18, f. 35. 
La colonización como categoría y fenómeno social nos permitió identificar hechos que daban cuenta, por su transformación, de las prácticas políticas y del mismo proceso formativo del Estado, solo que si no se discutían con una perspectiva relacional, podría considerarse que la colonización era un fenómeno y el proceso formativo del Estado otro.

Fue por ello que el capítulo se dividió en tres partes, pretendiendo en la primera, dar cuenta de la posición que asumían las burocracias centrales frente a los problemas de la sociedad colombiana, especialmente lo relacionado con los baldíos y la colonización. En este punto, se presentó la postura de los conservadores del siglo XIX, como también de los liberales del siglo XX.

En este aparte, se pudo evidenciar el interés del gobierno central por regular la tenencia, ocupación y propiedad de la tierra, sin embargo fueron los últimos gobiernos conservadores y los liberales, quienes consideraron que los repertorios de protesta debían ser vistos como producto de la insuficiencia administrativa del Estado, por lo cual era necesario establecer una coherencia jurídica con tales necesidades.

En el segundo ítem, se analizaron las prácticas políticas de los actores de la colonización; por lo que fue necesario recurrir a varios casos, donde se pudieron evidenciar no solo los ambigüedades de las normas, sino la capacidad de agencia que tenían las élites locales y algunos colonos; asunto que fue fundamental en el desarrollo de los muchos litigios. Por otra parte, se analizaron los casos donde las burocracias locales se enfrentaron a empresarios y colonos, por la administración y explotación de los baldíos.

Este punto fue importante porque permitió hacer un recorrido por las prácticas políticas que llevaron a cabo los actores de la colonización y que finalmente sirvieron como excusa para el diseño de políticas públicas sobre la tierra.

El último punto de este capítulo abordó varios casos donde los colonos y cultivadores recurrieron a estrategias legales e ilegales para alcanzar fines. Es importante recordar 
que se consideraron como prácticas, aquellas acciones que estaban amparadas en el marco de la legalidad jurídica, pero también las ilegales, porque finalmente estas acciones también sirvieron para que el gobierno movilizara no solo las instituciones de la represión (policías y juzgados) sino que pensara y diseñara políticas públicas coherentes con las necesidades de los contextos.

Finalmente podemos concluir que la construcción de la legislación sobre los baldíos entre 1870 y 1930 , fue producto de la presión social y del afán de las administraciones locales y centrales de regular la tenencia, ocupación y propiedad de la tierra. De todas maneras, el Estado estaba en un proceso formativo reciente, lo que implicaba una desarticulación entre las burocracias del centro y de la periferia, entorpeciendo de esta manera no solo el diseño de una legislación agraria coherente con los contextos, sino una estructura gubernamental sólida y sin grietas.

Por otra parte, la presión social contribuyó a la exposición de las grietas de las normas, asunto que fue hábilmente identificado por los gobiernos liberales y que sirvió no solo para denunciar los abusos en las localidades, sino para movilizar al Estado resolviendo los principales problemas de la cuestión agraria. También es importante resaltar que las estrategias usadas por los actores de la colonización tuvieron la particularidad de transformarse en prácticas políticas que se diseminaron por la región, sirviendo como mecanismos de presión y acción para alcanzar fines.

Queda en el tintero la comparación con otras regiones, con el fin de identificar si los hechos vividos en el Quindío tuvieron las mismas características, así como también analizar los años posteriores a 1930 y evaluar la capacidad del Estado para regular los problemas que reconoció, habían comenzado desde 1870 y no habían tenido la atención necesaria. 



\section{Conclusiones}



"El Estado no es una cuestión suprahistórica, o supracultural, ni una entidad separada o independiente de la sociedad, sino que esta imbuido en la cultura y en una densa gama de relaciones locales" (González, F., 2014, 75).

¿Cómo se construye el Estado? ¿Qué relación hay entre el poder estructural e infraestructural? ¿Qué factores endógenos y exógenos determinan el tipo de cristalización? ¿Qué tipo de mecanismos usan los Estados para centralizar el poder? ¿En qué momentos de la historia social, el Estado interviene para centralizar? ¿Qué relación hay entre el Estado, las burocracias y la sociedad civil? ¿Qué deberíamos entender por centralización?

Para el lector puede ser paradójico que se concluya esta investigación con nuevas preguntas, especialmente, porque parecen girar sobre la misma rueda que anduvo durante el trabajo: es decir, la relación entre el proceso formativo del Estado, la colonización y las prácticas políticas.

Sin embargo, teniendo presente que se trata de una problemática no tan reciente en abordaje pero sí en alternativas interpretativas, la lectura de los hechos más allá de la vivencia, podría ponernos al filo de un abismo del que no sabemos cuál es el fondo; pero si somos coherentes con la crítica a las teleologías sobre el Estado, tendremos presente que no se trata de saber a dónde se llega, sino de analizar cómo y por qué se ha llegado de X o Y manera. 
Evidentemente, hoy por hoy gran parte de la producción académica sobre el Estado -que por cierto vuelve a tomar importancia en las investigaciones-, utiliza la interdisciplinariedad como estrategia para dilucidar su proceso formativo; por lo que pensar el Estado obliga a ubicarnos lejos de las fronteras disciplinarias y más bien acogernos a la que ofrezca los caminos adecuados. Reservar el estudio del Estado a los sociólogos o politólogos, o a las instituciones estatales y los burócratas retirados ya no es precisamente la ley que rige el cuerpo académico que asiste a las discusiones sobre su existencia, sentido y formación.

Es por ello que durante la elaboración de esta investigación nunca faltaron las preguntas y mientras resolvíamos una, surgían dos o tres; en especial, cuando se trataba de hilvanar -como me lo enseñaron mis profesores- las fuentes, con una teoría que inicialmente poco comprendía.

Ahora bien -y en esto ofreceré disculpas al sociólogo lector por la atrevida incursión en su campo-, quizá la mayor dificultad para elaborar respuestas ha estado en la separación de la excusa de algunos colegas Historiadores, quienes argumentando la visita al archivo y la lectura de muchos documentos:

Abandonan toda pretensión de hacer del trabajo en historia algo más que una crónica, un relato curioso del pasado, por lo menos si es cierto que la ciencia consiste "en la posibilidad de establecer un conjunto de reglas que permitan 'controlar' operaciones proporcionadas a la producción de objetos determinados" (Silva, 2007, p. 45).

De esta manera, reconocemos que el ejercicio es un atisbo a las grietas que ha dejado la formación del Estado en Colombia, y por eso de que "las sociedades no pueden librarse de su pasado que irremediablemente ya fue" (Silva, 2007, p. 48), podemos revisar uno de los múltiples campos en los que la relación entre burocracias y sociedad civil, construye Estado.

A esta altura del documento, ¿qué podríamos decir entonces? 
Básicamente este ejercicio consistía en resolver tres asuntos. El primero se relacionaba directamente con el Estado y su interpretación, que como puede revisarse en el primer capítulo; leer sobre el Estado más allá de los sucesos, no solo fue propicio para acercarnos a un debate histórico, sino que permitió identificar la variedad interpretativa que ha tenido.

Evidentemente, la revisión de los clásicos permitió no solo fortalecer las discusiones para justificar la elección de una teoría, sino que facilitó el reconocimiento de una diversidad interpretativa sin descalificar necesariamente la teoría previa y más bien haciendo dúctil ${ }^{216}$ las tesis del Estado.

En el transcurso de dicho capítulo se logró justificar por qué la propuesta de Mann, con la teoría del embrollo, se ajustaba claramente a nuestro interés dado que pudimos articular lo local con lo nacional, evidenciando esos aspectos que el autor considera fundamentales: es decir, las lógicas con que funcionan las burocracias con relación a los procesos de centralización y cómo el Estado se fortalece en la infraestructura. Ahora bien, en este análisis fue clave el reconocimiento de las acciones de quienes no hacen parte de la burocracia, por lo que no solo justificamos teóricamente la importancia de analizar al Estado desde una perspectiva teórica flexible, sino también en relación con las dinámicas sociales producto de una política pública.

La propuesta teórica de Mann también nos permitió identificar no solo la acción del Estado sobre los territorios, que en muchos casos fue jurídica, militar o económica; sino también, la participación de las burocracias y las reacciones de la población a dichas disposiciones.

Por otra parte, considerar al Estado como productor de discurso materializado en el orden jurídico nos permitió analizar cómo se relacionaba la producción de normativa con la modernización estatal y el proyecto de sociedad pensado por las élites del centro; pues al revisar con lupa la producción de derecho a nivel central,

216 Además de su significado original, según la RAE, dúctil nos sirve para indicar que algo es acomodadizo, de blanda condición, condescendiente. 
identificamos cómo el país fue ajustando paulatinamente su estructura jurídica y administrativa a las discusiones internacionales sobre el deber ser del Estado y cuál fue la participación de las burocracias centrales y locales en dichos ajustes. En este sentido la interpretación sobre la participación burocrática, el diseño de jurisprudencia, la capacidad de cohesión y la legitimidad en las periferias, son asuntos claves que deben tenerse presentes para estudiar el proceso formativo del Estado.

En esta lectura que se hizo del Estado y su relación con las periferias durante los procesos de colonización, evidenciamos igualmente que hubo un interés por centralizar el poder a través de la regulación de los conflictos; sin embargo, como diría Zagrevelsky (2011) hay una evidente desarticulación de las lógicas sociales de construcción de realidad con las supuestas lógicas verdaderas amparadas en el derecho, es decir, mientras se emite la norma para resolver el cuestionamiento ¿De quién es la tierra?, la cotidianidad del campesino era hacerse propietario de un terreno a través de la palabra; esto quiere decir que si bien en las fronteras de colonización es común encontrar conflictos con la tierra, el asunto va más allá pues no necesariamente por ser frontera es que se materializan este tipo de conflictos, más bien se trata de un asunto relacionado con la cultura de propietario donde quizá comienza a gestarse la transformación del conflicto.

La siguiente tarea consistió en identificar un hecho social susceptible de estudio, y que diera pistas para analizar el proceso formativo del Estado. Fue por ello que el tercer capítulo se enfocó en la colonización del Quindío, como estrategia analítica del proceso formativo del Estado, por lo que nos preguntamos: ¿Cómo se relaciona la colonización con el Estado?

Siguiendo a González (2014), la presencia diferenciada del Estado en el espacio y en el tiempo, es directamente proporcional a la manera:

Diversa comolas instituciones estatales se relacionan con las diferentes regiones y las redes de poder realmente existentes en ellas, según sus particularidades, 
su tipo de poblamiento y el grado de cohesión y jerarquización social que hayan alcanzado (p. 60).

De acuerdo con esto, estudiar los procesos de colonización nos permitió identificar cómo se articularon las necesidades de los actores con las del Estado; de allí que la colonización fuera no solo una política pública, sino una vía alternativa para enriquecerse o construir poderes locales a través del acceso al campo político o al capital económico ${ }^{217}$.

Para nuestro caso, vimos cómo colonizar el Quindío resolvía momentáneamente la presión sobre las tierras del sur de Antioquia, Cauca, Boyacá y Cundinamarca; de igual manera fue claro que colonizar era la vía para garantizar la cohesión, especialmente para limitar los intentos autonomistas del Cauca frente a Bogotá. También vimos que la colonización fue un negocio lucrativo para muchas personas, y una estrategia política que garantizaba el acceso al poder para los colonos fundadores. Podría decirse que democratizaba el acceso al campo político, abriendo nuevas oficinas burocráticas en espacios que no se habían contemplado.

De acuerdo con esto, la colonización es una estrategia del Estado para garantizar avanzadas en el territorio, pero también es una vía que las personas usan para ascender en la movilidad social, crear trayectorias que les permita un enclasamiento (Bourdieu, 1979) y finalmente, entrar a participar del poder en el campo político.

Durante este análisis llama la atención la manera como se relacionaba el Estado central con sus burocracias y sus gentes de las periferias, puesto que evidencian dos aspectos a saber: El primero ya mencionado, es decir, que el Estado está en un proceso de centralización y que la normativa se orienta hacia la protección del colono en detrimento del terrateniente, y dos; que si bien, ese interés ideológico

217 Pretendiendo una lectura más allá de la interpretación popularizada de lo político, es evidente que durante la colonización, el poder no solo se reservó para el campo político; una nutrida bibliografía en Colombia (Ocampo, U. 1980; Ciro, R., A. 2013; Prado, L., 2007, 2013; Ramírez, M., 2001) y otros países ponen en evidencia el gamonalismo el cual se ha ido transformando hasta abandonar, en algunos casos el campo político, aunque conserve el control de la política (Román, R., Jiménez, R., “y” Romero, O., 2007; Tateiwa (s.f.); Ternavacio, M., 1991 ${ }^{\text {a }}$ 1191 ; Caetano, 2003; Wrigth, C., 2005). 
de protección al verdadero propietario es un tipo ideal, el pactismo, amiguismo y demás estrategias de centralización usadas en la historia colombiana y reveladas por autores como González y Prado, permitieron filtrar el deber ser favoreciendo a los detentores del poder político organizados en lo que llamamos campo político.

¿Cómo ocurrió esto? Con una mirada más socio-histórica, en el tercer capítulo se expuso, además de las transformaciones jurídicas de la tierra, cómo el Estado delegó en las burocracias locales la fiscalización de las adjudicaciones, pasando a manos de los gobernadores departamentales y prefectos municipales durante el siglo XIX y en el XX a los concejos municipales.

Podría pensarse que esta descentralización administrativa es positiva en cuanto empodera a las localidades para hacer uso de sus bienes; sin embargo, ¿estaba la sociedad civil colombiana lo suficientemente empoderada de la política como para disputar el control del campo político? Ubicados al margen del campo, la suerte de los pleitos estuvo determinada por los capitales que acompañaron a los demandantes; pues cuando se trató de casos como los revisados en Playa Rica, o los relacionados con las propiedades de Grisales y Jaramillo, la transformación del pleito estuvo en detrimento de los colonos.

Por otra parte, vimos también cómo los concejos municipales eran un espacio que permitía, de acuerdo a quien lo controlase, el éxito o fracaso en la reclamación de unos derechos sobre la propiedad. Evidenciamos este proceso en la disputa entre Calarcá con su consejo municipal, y la empresa Burila; pero también cómo se cambiaron los papeles cuando se trató de colonos no afín al concejo que reclamaban sus derechos de propietarios justificándose en la Ley 36 de 1907. Ahora bien, aunque se produjera una significativa legislación no quiere decir que esta fuera acertada o peor aún, pareciera que el Estado fuera tímido a la hora de intervenir y regular las relaciones entre poseedores de facto y de título.

El tercer asunto que nuestra investigación pretendió abordar fueron las prácticas políticas, pues finalmente podemos aceptar que existe una presencia diferenciada del Estado en el espacio y el tiempo (González, 2014) y que no cristaliza de una 
sola manera (Mann, 1997), sin embargo, ¿qué determina el tipo de cristalización?, ¿qué desempeño tienen las poblaciones al margen del campo político en esta cristalización?, ¿cómo leer la centralización sin caer en el reduccionismo militar o jurídico?

En el desarrollo del cuarto capítulo se reconoció que estudiar el proceso formativo nos obligaba a dirigir la atención a las relaciones entre el Gobierno central y local y la reacción popular a esta centralización. Llama la atención entonces que las poblaciones, de acuerdo con el número de casos revisados, prefieran el recurso legal que el ilegal, y que sus denuncias no sean contra-estatales sino más bien, contra las burocracias locales o personas que aprovechan su favoritismo o participación activa del campo político; ¿por qué después de 1930 la protesta comienza a tener un manto contra-estatal?, ¿por qué la protesta campesina e indígena en Colombia se radicaliza y termina orientándose hacia la organización de grupos de guerrillas locales? Quizá la respuesta puede estar en la manera como cristalizó el Estado, por lo menos, en este ámbito, dado que el éxito o fracaso de un proceso estaba mediado más que por las leyes, por la disposición de las burocracias locales en la atención correcta de los procesos, así como también, la capacidad de agencia del colono.

Volviendo a la discusión inicial del párrafo anterior, cuando miramos la relación entre las burocracias centrales y locales lo hicimos siguiendo a Mann (1997), especialmente porque el Estado necesita relacionarse con las burocracias locales para garantizar su poder centralizador y poco a poco, ir reduciendo el poder despótico por el infraestructural. Quizá con esta interpretación podamos analizar cómo durante la Regeneración, a pesar de tratarse de un proceso de centralización, por lo menos en los primeros años, el Estado reservó los concejos municipales como los lugares para la administración local autónoma.

Consideramos entonces que el proceso formativo del Estado es producto de las relaciones entre el poder estructural e infraestructural, pues allí se construyen los mecanismos legítimos de cohesión, usando estrategias articuladoras que pueden ser: los partidos políticos, las fuerzas militares, los pactos con burocracias locales, 
etc., sin embargo ¿dónde queda la presión social? Evidentemente, la relación entre estructura e infraestructura está cruzada por la aceptación y el reconocimiento, como también el desdén y la oposición.

Vimos cómo por ejemplo, al presentarse presuntas irregularidades en las adjudicaciones o en su defecto, una actuación ilegal por parte de un representante local del Estado, la movilización social a través de repertorios de protesta, era una manifestación de oposición local, pero también de reconocimiento a una centralización.

Si se tienen presentes los análisis de la antropología del Estado recomendados por González (2014), el pago de impuestos, el envío de una misiva o un memorial, el interponer una demanda, el seguir un conducto regular, el recurso a una doctrina, el reconocimiento de códigos civiles y la identificación con categorías definidas por la legislación tales como: cultivador, propietario, colono, etc., es una muestra fundamental para comprender hasta dónde el Estado ha logrado una centralización de su poder, es decir, hasta dónde ha logrado despojarse del poder absoluto para abrirle paso al poder infraestructural. Hablamos entonces de una población que no se opone al Estado, más bien que lo acata, lo recibe, lo significa y se identifica con él en la simbología jurídica; tanto así que es capaz de movilizarse cuando ve vulnerada la legalidad y más aún, si siente amenazado un derecho adquirido (¿inventado?) en el Estado.

Para el caso estudiado, el Estado cristalizó con el apoyo de las burocracias locales, pero también como producto de las prácticas políticas que usaron los colonos excluidos de la representación oficial. Esta lectura permite evidenciar que las poblaciones se reconocían a sí mismas en el marco de unos derechos civiles dados por un abstracto orden jurídico; de igual manera, los repertorios de protesta fueron denuncias ante el Estado central, de los desmanes de las autoridades locales; entonces, ¿no se trata de un reconocimiento del Estado, de un orden, de unos rangos de autoridad?, ¿podría pensarse que el Estado logró cristalizar en la infraestructura, aunque no controlara del todo a sus burocracias locales? 
Antes de finalizar resaltemos dos asuntos más: el primero tiene que ver con las prácticas de las autoridades locales durante los conflictos y el segundo, se relaciona con los repertorios de protesta inscritos en el marco de la ilegalidad jurídica.

Dentro de la cristalización del Estado, es necesario reconocer la agencia de los actores aunque estén al margen del campo político. En los casos estudiados, vimos cómo las burocracias del Quindío y el departamento de Caldas no solo instrumentalizaron las instituciones para traer a su beneficio los derechos dados por la ley, sino que fueron capaces de relacionar conflictos de nivel internacional con los hechos locales. De allí que el gobernador Arango, por ejemplo, denunciara la alteración del orden público como producto de una ola revolucionaria comunista que se tomaba a Colombia.

No miremos este suceso como falso o verdadero, analicemos el hecho desde la relación entre lo endógeno y lo exógeno. Evidentemente, se trató de un recurso político para movilizar la atención represiva del Gobierno central, al tiempo que desviaba la atención defensora del Estado sobre unos cultivadores que reclamaban derechos sobre los predios. Como vimos, la jugada política fue positiva para el gobernador y sus allegados.

El otro factor en mención tiene que ver con los repertorios de protesta enmarcados en la ilegalidad. Por tratarse de invasiones, quemas, asonadas, levantamientos, etc., fueron acciones que violaban las leyes de la república, pues iban contra la propiedad, la integridad de los servidores públicos o demás actores de la colonización; se cometían daños en bienes ajenos, etc. Pero si hacemos un recorrido más extenso y no nos limitamos a la visión de las burocracias locales, o no nos quedamos en el tiempo del suceso, podemos evidenciar cómo el Estado en su proceso formativo, reconoció que el ramo de los baldíos había sido creado con grietas que finalmente, como se corroboró en la disertación ministerial de 1935, generaban este tipo de desmanes $^{218}$.

218 Este punto queda en evidencia cuando el ministro Echandía planteó que "El orden público es una resultante de la acción de determinado estatuto jurídico en determinado medio social. Cuando juricidad y realidad se acoplen naturalmente, habrá orden, y éste se verá perturbado cuandoquiera que se sobrevenga un desequilibrio o disparidad entre tales factores" (Memorias del Ministro de Agricultura y Comercio, 1935, p. 
Podríamos decir finalmente que el Estado se forma en la interacción entre el poder central y el poder local, donde la presión social cuenta como factor clave, dado que acoge o desacata las disposiciones de dicha centralización. El reconocimiento de los repertorios de protestas permite identificar la concepción del Estado que se tiene, como también el tipo de Estado que se quiere.

Ahora bien, como se trataba de la transición del siglo XIX al XX, la estructura rígida y cuasi despótica del Estado colombiano después de la Constitución de 1886, hizo que el ingreso al campo político fuera más restringido; esta situación legalizada en la norma facilitó a las burocracias locales, empresarios y demás individuos la exclusión de otros competidores, relegándolos a los márgenes o en otros casos, cargándoles con delitos para garantizar así su exclusión y retiro de la competencia ${ }^{219}$.

La importancia de estos conflictos radica en el seguimiento a su transformación, pues pone en evidencia las prácticas de las burocracias locales como también, las estrategias de los colonos, cultivadores, abogados, agrimensores y demás actores de la colonización quienes a través de repertorios de protesta, se movilizaron para alcanzar fines. Como resultado de esta interacción entre burocracias y actores sociales, tenemos la construcción de unas prácticas políticas que contribuyeron al diseño de la estructura jurídica para regular la tenencia, ocupación y propiedad de la tierra.

La transformación de los conflictos estudiados nos permitió identificar la reacción de las autoridades locales y nacionales para resolver los problemas de orden público generados por las protestas. Posteriormente, se analizó el tipo de representación que construyó el receptor de las normas; pues así como muchos acogían el debido proceso, la algidez de los conflictos, combinada con la dilación y presión social sobre las tierras, creó un coctel de desmanes y violencia que impulsó a muchos cultivadores hacia las vías de hecho, desestimando la legalidad y forzando al gobierno a emitir fallos al respecto.

\section{IV-V).}

219 Recuérdese que Marx expuso cómo el delito es producto de una construcción social, la cual la clase dominante puede aprovechar para la garantía de sus intereses en detrimento de otros competidores; ver Marx (s.f.). 
Ahora bien, aunque el control del campo político es clave porque nos permite movilizar con mayor facilidad la atención del Estado o instrumentalizar su poder, esto no quiere decir que la exclusión o marginalización sea el fin de lo político puesto que existieron otros recursos que permitieron competir con estas burocracias; por ejemplo los repertorios de protesta enmarcados en la ilegalidad jurídica tales como: las invasiones, las asonadas, las quemas de cosechas; o los que aprovecharon las pocas ventajas del derecho como los memoriales, las denuncias, las peticiones, etc.

Para finalizar nos quedan en el tintero muchas preguntas a resolver, entre estas, si los conflictos que estudiamos podrían ser comparados con otras experiencias a nivel nacional e internacional y si los resultados darían pistas similares. En este sentido, será clave para futuros ejercicios, continuar articulando las disciplinas, que hoy por hoy, contribuyen a la interpretación de ese proceso formativo, revisar nuevas fuentes que por asuntos logísticos, fueron imposibles de consultar y finalmente, será necesario seguir la lectura detallada y lejana del hecho por el hecho, para comenzar a comprender el tipo de configuración histórica de nuestros Estados. 



\section{Anexo 1: Memorial enviado por los colonos de Calarcá al Gobierno central}



Los suscritos, naturales indistintamente de los diversos distritos del departamento de Antioquia, residentes hoy en las montañas vírgenes del «Quindío», territorio baldío de la nación, perteneciente a la provincia de «El Quindío», en el departamento de «El Cauca», por conducto, de ese ministerio, al Gobierno Nacional, exponemos muy respetuosamente:

Que agobiados por la inesperanza de adquirir propiedades en territorio antioqueño, y pensando en el porvenir de nuestros hijos, abandonamos resueltamente, a pesar del sentimiento natural que produce la separación del suelo donde se nace, aquellos lugares, para, venir a poblar estas regiones incultas.

Sin mas elementos que la salud y la fuerza, sin mas capital que el hacha, y sin más apoyo que el de Dios, hace ya para veinte años que hemos ido entrando diseminadamente a formar hogar en estos bosques con risueña esperanza de fundar propiedad para nuestros decendientes.

Hoy formamos ya un grupo de mas de 500 habitantes que componen mas de 150 familias, y hemos formado en el valle del rio «La Vieja», al pie de la cordillera Central una hermosa población denominada Calarcá, nombre del ilustre avorigen que, esquivó la conquista, hasta obtener su muerte natural en estos lugares. Aqui, señor 
Ministro, tenemos cementerios agrestes sobre-agrestes, bellas y bajas colinas y a la sombra de árboles seculares, donde se destacan multitud de cruces de madera, que cada una de ellas señala el sepulcro de un compañero, de un deudo, o de un amigo: Aquí hay hombres que cubren con una faja negra la copa del sombrero, insignia de luto y de dolor porque han perdido sus esposas, dulces y resignadas compañeras de nuestra inmigración: Aquí hay viudas y hay huérfanos que se consuelan en su dolor, con la herencia que han recibido de amor al trabajo y la pequeña apertura de montes que sus antecesores les dejaron, con casa y sementeras que sostienen contentos con su trabajo, porque estas facilmente los sustentan, y alimentan su esperanza de que la propiedad adquirida será trasmisible: Aquí hay una agrupación de mas de cuarenta casas, que forman la base de nuestra población, bien ordenadas, formando calles y plaza, la cual se denominará «Plaza de Ricaurte», en conmemoración del héroe que sacrificó su vida por la independencia Nacional.

[...] Aquí hay locales destinados para casa Municipal, escuelas primarias e iglesia, donde tenemos una capilla en construcción, pues siendo el pueblo antioqueño esencialmente cristiano y católico, el primer edificio de su pueblo, es la iglesia parroquial.

Como el señor Ministro ve, estamos animados de buenos propósitos, pero hay algo que contrista nuestras almas, y nos llena de angustia: $y$ es el ver que nuestros hijos se crecen sin educación. Estamos en el corazón de estas montañas, lejos de los centros de civilización, y fuera de los límites de nuestro suelo natal, donde el gobierno tanto propende por la educación, y aunque pertenecemos a este departamento, su territorio es muy inmenso y el Tesoro no alcanza.

Solicitamos del Gobierno Nacional, que es nuestro padre común, una subvención o auxilio para la educación de nuestros hijos, mientras la sostenemos a nuestras expensas, pues hoy sólo contamos con recursos para alimentarnos.

Conocemos en oidas algunas disposiciones de la Ley, o leyes sobre baldíos, y si bien vemos con gusto que éllas en parte fomentan la inmigración; también vemos con temor que la propiedad de éllos puede pasar a empresarios y a negociantes, y, es por 
esto que elevamos este memorial a nuestro gobierno, para que hoy que el Congreso, augusto y soberano cuerpo de la Nación, se halla reunido dicte un acto legislativo especial, que nos favorezca en la propiedad de una faja de los inmensos baldíos que aquí tiene.

Una conceción, como a nuevos pobladores, según las reglas del Código de Fomento, tal vez será mas difícil que dictada por ley especial, y en este caso, emplazando medida, pero designando cantidad, ésta podría hacérsenos dentro de los que demarcan estos linderos:»

«Nacimiento del raudal Nabarco o Cumbarco»; siguiendo el curso de sus aguas, hasta la dirección «Alto del Castillo» (límites con el distrito de Salento); siguiendo esta línea, que fija el plano de este distrito, hasta el raudal «EI Roble»; siguiendo el curso de sus aguas, hasta el desemboque de éste en el río de «La vieja»; éste arriba, hasta la afluencia del «Quindío»; éste arriba, hasta la confluencia del «Rioverde»; por éste a sus nacimientos en la cordillera, (límites con el departamento de «El Tolima») por la línea con este departamento, a buscar la dirección del punto de partida.»

Esta demarcación comprende, poco mas o menos, un territorio de doce a 14.000 hectáreas, que es el número que por la presente solicitamos, como conceción en favor de esta nueva población y para los nuevos pobladores que vengan en lo sucesivo.

Estamos seguros y ciertos de que una disposición favorable, atraerá millares de familias, y pronto, esta agrupación será erigida en entidad de las que reconoce la Constitución y de tanta consideración, como es hoy la de Pereira, la mas pujante de todas las que ha formado la inmigración pacifica de Antioquia en esta provincia del "Quindío".

Esperamos de su Señoría, que acogerá y protegerá favorablemente esta solicitud, dándole el curso legal, la cual firmamos en Calarcá, el domingo nueve de septiembre de 1888 Es copia Por Román Ma Valencia." Va con doscientas treinta y una firmas" $[\mathrm{sic}]^{220}$.

220 Recuperado en: http://www.calarca.net/enlamano.html 



\section{Anexo 2: \\ Decreto 326 de 1930}



Art. 1: toda ocupación de hecho que se verificare por más de 10 personas dentro de los linderos de un mismo fundo serán suspendidas por el alcalde respectivo del municipio, siempre que a la solicitud el propietario acompañe la siguiente prueba: a) que el poseedor regular del lote de cuya ocupación se trata, acreditando los linderos de este y acompañando el título respectivo, y que esa posesión data de más de un año. [...] c) que los ocupantes son en número mayor de 10 y que los actos atentatorios no hacen más de 60 días que se están verificando

Art. 2: el alcalde después de corroborar la verdad de esta invasión procederá en un plazo no superior a 48 horas y los gastos de diligencia corren por cuenta del interesado,

Art. 3: el alcalde se movilizará si considera necesario con dos testigos y su secretario para dirigir la expulsión y usará la fuerza si considere necesario,

Art. 4: se hace público el auto en la finca y lugares de concurrencia,

Art. 5: en esta clase de diligencias no se admitirán títulos escritos de ninguna clase presentados por los ocupantes, a menos que procedan de contratos celebrados entre los supuestos ocupantes y el propietario; cualquier otra prueba escrita se remitirá al Poder Judicial,

Art. 6: [el alcalde se dirijirá directamente a los ocupantes mencionando el abandono que deben hacer, de lo contrario] "se les considerará como opositores francos a las providencias de la autoridad y serán considerados responsables frente a las sanciones que establece el Código Penal,

Art. 7: Si continuare la oposición material por parte de los ocupantes, el alcalde iniciará inmediatamente el sumario correspondiente para averiguar la 
responsabilidad en que puedan incurrir los opositores por alguno o algunos de los delitos de que tratan los artículos 210, 217 y 238 y sus relaciones con el Código Penal, investigación que se dirigirá también contra los promotores dictando auto de prisión si fuere necesario",

Art. 8: el funcionario que esté al frente debe levantar un acta si fuese necesario el uso de la fuerza, la cual se la enviará al juez para que levante proceso si es el caso,

Art. 9: Si para llevar a efecto la acción de lanzamiento el funcionario encontrare que carece de policía suficiente para practicar la diligencia, pedirá el número de agentes que considere necesario a la Gobernación. Parágrafo 1: Cuando a juicio de la Gobernación se considere preciso que intervenga la fuerza armada en el lugar de los acontecimientos, se hará la solicitud correspondiente al Ministerio de Guerra a fin de que por medio del ejército sea debidamente garantizado el cumplimiento de la sentencia

Art. 10: Si después de lanzados los invasores estos vuelven al terreno se considera necesario abrir proceso correspondiente,

Art. 11: Cuando a virtud de la investigación hecha por el funcionario que conoce de la acción de lanzamiento resultare que funcionario público o entidad oficial de cualquier categoría estuviera patrocinando, incitando o apoyando de cualquier forma a los ocupante de hecho, se procederá a dar aviso inmediato al juez del Circuito respectivo a fin de que se inicie la información sumaria en la averiguación del delito de responsabilidad que se haya cometido y del responsable o responsables ${ }^{221}$.

221 AGN, Baldíos, tomo 75, Manizales, diciembre 14 de 1931; ff. 22-24. En la respuesta del Ministro de Gobierno se estimaba que: "El artículo primero debe adicionarse con un parágrafo que diga: antes de darse curso a la solicitud que habla este artículo, el propietario prestará juramento de que la ocupación de que trata se ha efectuado sin su consentimiento [...] igualmente insinuó la conveniencia de cambiar el final del artículo $7^{\circ}$ que dice "Si fuere necesario" por "si hubiere mérito legal para ello". Creo que no es prudente dejar el solo arbitrio de los alcaldes la libertad de los individuos. Considero que la situación que se trata de corregir, no solo se presenta en Caldas sino en otros Departamentos en que algunos individuos invaden las propiedades particulares pretendiéndose colonos u ocupantes de Baldíos. Para corregir esta anomalía peligrosa, este despacho está listo a estudiar con el Ministerio las reformas que deban hacérsele al Decreto 992 de 1930" (AGN, Baldíos, tomo 75, Bogotá, diciembre 16 de 1931; ff. 25-26). 


\section{REFERENCIAS}





\section{Documentos de archivos históricos y notarías.}

Archivo Central del Cauca, fondo judicial, serie demandas, 1878.

Archivo Central del Cauca, sección República, año 1878, caja 145, legajos 65-68.

Archivo General de la Nación, fondo baldíos, tomos 1- 77, 1878-1932.

Archivo Histórico de Cartago, fondo judicial, serie demandas, folio: 92.

Escritura Pública, Empresa Burila, Manizales, notaría primera, 1884.

\section{Periódicos.}

Diario Oficial \# 5541, Edición Oficial, 1884.

Diario Oficial \# 13168, de 14 de enero de 1908.

Periódico El Ferrocarril (1884), Cali, No 263, Octubre 3 p. 1049.

\section{Informes oficiales}

Anales de la Cámara de Representantes, 20 de diciembre de 1935. Informe del Procurador de Hacienda al Congreso de 1916, Bogotá, Imprenta Nacional, 1916. 
Memorias del Ministerio de Agricultura y Comercio al Congreso de 1922, Bogotá, Imprenta Nacional, 1922.

Memorias del Ministerio de Agricultura y Comercio al Congreso de 1923, Bogotá, Imprenta Nacional, 1923.

Memorias del Ministerio de Agricultura y Comercio al Congreso de 1935, Bogotá, Imprenta Nacional, 1935.

Memorias del Ministro de Agricultura y Comercio al Congreso de 1918, Bogotá, Imprenta Nacional, 1918.

Memorias del Ministro de Agricultura y Comercio al Congreso de 1917, Bogotá, Imprenta Nacional, 1917.

Memorias del Ministro de Gobierno al Congreso de 1919, Bogotá, Imprenta Nacional, 1919.

Memorias del Ministro de Gobierno al Congreso de 1935, Bogotá, Imprenta Nacional, 1935.

Memorias del Ministro de Hacienda al Congreso de 1914, Bogotá, Imprenta Nacional, 1914.

Memorias del Ministro de Industrias al Congreso de 1931, Bogotá, Imprenta Nacional.

Memorias del Secretario de Hacienda del Departamento de Antioquia al Señor Gobernador en 1921, Bogotá, Imprenta Nacional, 1921.

\section{Memorias de pobladores.}

Henao, S. (1986). La Miscelánea, Armenia, Universidad del Quindío.

Valencia Zapata, A. (s.f.). Quindío Histórico, monografía de Armenia, (sin editorial).

\section{Artículos de revistas en línea:}

Borja, M. (2009). Los caminos de la guerra durante el siglo XIX. Análisis político, 22 (67). Recuperado de: http://www.scielo.org.co/scielo.php?pid=S012147052009000300009\&script=sci_arttext

Demsetz, H. (1967). Toward a Theory of Property Rights. The American Economic 
Review, 57 (2), 347-359. Recuperado de: http://links.jstor.org/sici?sici=00028282\%28196705\%2957\%3A2\%3C347\%3ATATOPR\%3E2.0.CO\%3B2-X

García, N. (2013). Aproximación teórica al estudio de la acción colectiva de protesta y los movimientos sociales, recuperado de: http://www.redcimas.org/ wordpress/wpcontent/uploads/2013/03/t_aproximacion_teorica_mmss_ garcia.pdf

Garretón, M (2002). La transformación de la acción colectiva en América Latina. Revista CEPAL, (76), 1-18.

LeGrand, C. (1984) Labor Acquisition and Social Conflict on the Colombian Frontier, 1850-1936. Journal of Latin American Studies, 16 (1), 27 49. Recuperado de http://links.jstor.org/sici?sici=0022-216X\%28198 405\%2916\%3A1\%3C27\%3ALAASCO\%3E2.0.CO\%3B2-

Mann, M. (2006). El poder autónomo del Estado, sus orígenes, mecanismos y resultados. Revista académica de relaciones internacionales, (5), 1-43. Recuperado de http://www.relacionesinternacionales.info/ojs/issue/view/5. html

Velasco, D. (2002). ¿Mandar obedeciendo? Pierre Bourdieu y el campo político. Revista de Guadalajara, Dossier Pierre Bourdieu en ocho perspectivas, un homenaje, (24), 1-7. Recuperado de http://www.cge.udg.mx/revistaudg/ rug24/contenido.html

\section{Blogs:}

Vélez, L. (2012) (16 de septiembre de 2014). Política y legislación de tierras, siglos XIX y XX. [Mensaje en un blog]. Recuperado de: http:// luisguillermovelezalvarez.blogspot.com/2012/03/politca-y-legislacion-detierras-en.html, recuperado el 16/09/2014

\section{Libros en línea}

Foreing Policy and the fund for peace. (2005). The failed state index. Recuperado de: http://foreignpolicy.com/2009/10/22/the-failed-states-index-2005 
Pizarro, E. Et. Al. (2015). Contribución a al entendimiento del conflicto armado en Colombia. Comisión histórica del conflicto y sus víctimas. Recuperado de: http://static.elespectador.com/ archivos/2015/02/1952328280f79f83ccb8b9929c8d8fa5.pdf

Mill, J. S. (1943). De los fundamentos y límites del principio de "Laisser - Faire" o no intervención. En Principios de Economía política. Recuperado en: http://www.antorcha.net/biblioteca_virtual/politica/mill/indice.html

Tateiwa, R. (SF). El caudillismo y sus interpretaciones: un análisis sobre un fenómeno común de la Historia de América Latina en el siglo XIX. Recuperado en: http://www.canela.org.es/cuadernoscanela/canelapdf/cc7tateiwa.pdf

Weber, Max. (1919). La política como vocación. Recuperado en: http://www.hacer. org/pdf/WEBER.pdf

\section{Páginas institucionales:}

IGAC. (2014). Mapas de Colombia y el eje cafetero. Recuperados de: www.igac.gov. co:10040/wps/portal/igac/raiz/iniciohome/Mapas\%20de\%20Colombia/ Mapas/Nacionales

RAE, 2014. Recuperado http://lema.rae.es/drae/

Buenavista Quindío, mapas del Quindío. Recuperado en: http://buenavista-quindio. gov.co/mapas_municipio.shtml?apc=bcEl\%20municipio $\% 20 \mathrm{en} \% 20 \mathrm{el} \% 20$ pa\%EDs-1-\&x=1498744

Historia de Calarcá. Recuperado en: http://www.calarca.net/enlamano.html Historia de Calarcá. Recuperado en: http://www.calarca.net/libro/index.html

\section{Trabajos de grado:}

Burbano, M. (2014). Aproximaciones sociológicas a la identidad colectiva de la corporación Ecofuturo y la cooperativa Camino Verde, organizaciones sociales del norte del Valle del Cauca (tesis de Maestría en Sociología), Universidad del Valle, Cali, Colombia.

Cadena, O. (1988). Procesos de colonización en el Quindío: el caso de Burila (tesis de Maestría en Historia), Universidad Nacional, Bogotá, Colombia. 
Carrero, A. (2007). Conflictos y colonización en el norte del Valle, el caso de Sevilla y la empresa Burila (1903-1930) (tesis de pregrado), Universidad del Valle, Cali, Colombia.

Prado, L. (2005). Rebeliones en la provincia: la Guerra de los Supremos en las provincias surorientales y nororientales granadinas, 1839-1842 (Tesis de Maestría), Universidad Industrial de Santander, Bucaramanga, Colombia.

Ternavacio, M. (1991). Municipio y política, un vínculo histórico conflictivo (Tesis de Maestría), FLACSO, Buenos Aires, Argentina.

\section{Libros}

Arango, M. (1977). Café e industria 1850-1930. Bogotá, Colombia: Carlos Valencia Editores.

Arendt, H. (1997). ¿Qué es la política? Barcelona, España: Paidós.

Arroyo, J. (2006). Historia de las prácticas empresariales del Valle del Cauca. Cali 1900-1940. Cali, Colombia: Universidad del Valle.

Bauman, Z. (2015). ¿Para qué sirve realmente...? un sociólogo. Barcelona: Paidós.

Betancourt, A. (2007). Historia y nación. Medellín, Colombia: La Carreta Editores.

Bobbio, N. (2000). Estado, gobierno y sociedad. México: Fondo de Cultura Económica.

Bolívar, I. (Ed.) (2006). Identidades culturales y formación de Estado en Colombia: Colonización, naturaleza y cultura. Bogotá, Colombia: Universidad de los Andes.

Bourdieu, P. (1979). La distinción. Criterios y bases sociales del gusto. Bogotá, Colombia: Editorial Taurus.

Bourdieu, P. (2000). Sobre el campo político. Lyon, Francia: Presses Universitaires de Lyon.

Bourdieu, P. (1997). Razones prácticas, sobre las teorías de la acción. Barcelona: Editorial Anagrama.

Bourdieu, P. (1995). Respuestas por una antropología reflexiva. México: Grijalbo.

Bushnell, D. (2002). Colombia una nación a pesar de sí misma. Bogotá, Colombia: Planeta Editores. 
Christie, K. (1986). Oligarcas, campesinos y política en Colombia. Bogotá, Colombia: Universidad Nacional.

De Sousa Santos, B. (2009). Sociología Jurídica Crítica, para un nuevo sentido común del derecho. Bogotá, Colombia: ILSA.

Elías, N. (1989). El proceso de la civilización, investigaciones sociogenéticas y psicogenéticas, México: Fondo de Cultura Económica.

Escobar, A.; Álvarez, S. y Dagnino, E. (2001). Política cultural y cultura política. Una nueva mirada sobre los movimientos latinoamericanos, Bogotá, Colombia: Taurus/ICANH.

Flores, L. (1997). Modernidad política en Colombia, el republicanismo en el Valle del Cauca 1880-1920. Cali, Colombia: Editorial Universidad del Valle.

Flórez, L. (1985). La Regeneración y la formación de la nación colombiana: El caso del Cauca. Cali, Colombia: Universidad del Valle.

Franco, V. (s.f.). Guerras civiles. Introducción al problema de su justificación. Medellín, Colombia: Universidad de Antioquia.

Friede, J. (1878). Los Quimbayas bajo la dominación española, Bogotá, Colombia. Editorial Carlos Valencia Editores.

Gaitán. J (SF). Las masacres en las bananeras, documentos 1928. Bogotá, Colombia. Sin Editorial.

García, A. (1978). Geografía económica de Caldas. Bogotá, Colombia: Banco de la República.

García, M. (2014). La eficacia simbólica del derecho; sociología política del campo jurídico en América Latina. Bogotá, Colombia: IEPRI/Universidad Nacional.

Garrido de Payán, M. (1983). La Regeneración y la cuestión estatal nacional en Colombia. Bogotá, Colombia: Banco de la República.

Gärtner, A. (2005). Los místeres de las minas: crónica de la colonia europea más grande de Colombia en el siglo XIX, surgida alrededor de las minas de Marmato, Supía y Riosucio. Manizales, Colombia: Universidad de Caldas.

Gómez, L. (1988). Obras Selectas, Primera parte. Bogotá, Colombia: Cámara de Representantes.

Gonzales, F. (1997). Para leer la política, ensayos de historia política colombiana. Bogotá, Colombia: CINEP. 
González, F. (2014). Poder y violencia en Colombia. Bogotá, Colombia: Odecofi. González, F., Bolívar, I., Vázquez, T. (2003). Violencia política en Colombia: de la nación fragmentada a la construcción del Estado. Bogotá, Colombia: CINEP.

Gouldner, A. (1979). La crisis de la sociología occidental. Buenos Aires, Argentina: Amorroutu editores.

Halperin, T. (1981). Historia contemporánea de América Latina. Bogotá, Colombia: Alianza Editorial.

Helmsing, B. (1981). Colonización agrícola y asentamientos en zonas fronterizas. Bogotá, Colombia: Universidad de los Andes-Centro Interdisciplinarios de Estudios Regionales CINDER.

Hoffman, P. (2015). ¿Por qué Europa conquistó el mundo? Barcelona: Crítica editorial.

Jaramillo, J. (1964). El pensamiento colombiano en el siglo XIX. Bogotá, Colombia: Editorial Temis.

Kalmanovitz, S. (1978). Desarrollo de la Agricultura en Colombia. Bogotá, Colombia: La Carreta Editores.

Kalmanovitz, S. (2010). Nueva historia económica de Colombia. Bogotá, Colombia: Universidad Jorge Tadeo Lozano y Editorial Taurus.

Karl, M. (2004). El Manifiesto comunista. España: Editorial Akal.

LeGrand, C. (1988). Colonización y protesta campesina en Colombia 1850 - 1950. Bogotá, Colombia: Universidad Nacional.

Lopera, J. (1986). La colonización del Quindío, apuntes para una monografía del Quindío y Calarcá. Bogotá, Colombia: Banco de la República.

López de Mesa, L. (1934). De cómo se ha formado la nación colombiana. Bogotá, Colombia: Librería colombiana.

López, A. (1979). Migración y cambio social en Antioquia durante el siglo XIX. Bogotá, Colombia: Ediciones Uniandes.

López, E. (2004). Teoría impura del Derecho, las transformación de la cultura jurídica latinoamericana. Bogotá, Colombia: Legis-UniAndes-UNAL.

Machado, A. (1977). EI Café: de la aparcería al Capitalismo. Bogotá, Colombia: Editorial Punta de Lanza. 
Machado, A. (1981). La Política Cafetera: 1920-1967. Bogotá, Colombia: Universidad Nacional.

Marx, K. (2005). El 18 Brumario de Luis Bonaparte. Buenos Aires, Argentina: Longseller.

Mann. M. (1997). Las fuentes del poder social, II. El desarrollo de las clases y los Estados nacionales, 1760-1914. Madrid, España: Alianza Editorial.

Martínez, G. (1996). El Poder Político en Colombia. Bogotá, Colombia: Planeta Editores.

Morales, O.; Eastman, C. (Comp.), (2014). Conflictos: su incidencia en el devenir rural y agrario colombiano. Pereira, Colombia: Fundación Universitaria del Área Andina.

Murgueitio, C. (2007). La diplomacia del café: estrategias político-económicas del Brasil y Colombia en los años treinta (1886-1929). Cali, Colombia: Universidad Javeriana.

Nieto, L. (1941). Economía y Cultura en la Historia de Colombia. Bogotá, Colombia: Editorial Tiempo Presente.

Ocampo, U. (1980). Urbanización y violencia en el Valle del Cauca. Bogotá, Colombia: Editorial Armadillo.

Offe, C. (1984). Los nuevos movimientos sociales. Barcelona, España: Ariel.

Olson, M (1965). The logic of collective action. Cambridge: Harvard University Press.

Orjuela, L. (Ed.). (2010). El Estado en Colombia. Bogotá, Colombia: Uniandes.

Palacios M. (2011). ¿De quién es la tierra? Propiedad, politización y protesta campesina en la década de 1930. Bogotá, Colombia: Fondo de Cultura Económica/Universidad de los Andes.

Palacios, M. (2002). El Café en Colombia, 1850-1970. Bogotá, Colombia: Editorial Planeta.

Palacios, M; Safford, F. (2002). Colombia: país fragmentado, sociedad dividida. Su historia. Bogotá, Colombia: Grupo Editorial Norma.

Parsons, J. (1961). La colonización antioqueña en el occidente de Colombia. Bogotá, Colombia: Banco de la República.

Parsons, J. (1996). Urabá, salida de Antioquia al mar. Geografía e historia de su colonización. Santafé de Bogotá, Colombia: Banco de la República/El Áncora. 
Pècaut, D. (1985). Orden y Violencia, Colombia 1930-1952, Bogotá, Colombia: TM Editores.

Pérez, H. (2007). El tránsito hacia el Estado nacional en América Latina en el siglo XIX: Argentina, México y Colombia. Bogotá, Colombia: Unal/Tercer Mundo Editores.

Pinzón, M. A. (2009). Florentino González; jurisconsulto y hacendista. Bogotá, Colombia: Ediciones Academia Colombiana de Jurisprudencia, colección portable.

Prado, L. (2007). Rebeliones en la provincia. La Guerra de los Supremos en las provincias suroccidentales y nororientales granadinas, 1839 - 1842. Cali, Colombia: Editorial Facultad de Humanidades, Universidad Del Valle.

Ramírez, M. (2001). Entre el Estado y la Guerrilla: identidad y ciudadanía en el movimiento de los campesinos cocaleros del Putumayo. Bogotá, Colombia: ICANH.

Ramírez, M. C. (2001) Entre el Estado y la Guerrilla: identidad y ciudadanía en el movimiento de los campesinos cocaleros del Putumayo. Bogotá, Colombia: ICANH-Colciencias.

Raush, J. (1999). La frontera de los Llanos en la Historia de Colombia (1830-1930). Bogotá, Colombia: El Áncora Editores.

Roll, E. (2009). Historia de las doctrinas económicas. México: Fondo de Cultura Económica.

Roman, R., Jiménez, R., Romero O. (2007) Cacicazgo y oligarquía en el oriente de Tlaxcala. México: Colegio de Tlaxcala.

Sáenz E. (1993). La ofensiva empresarial. Industriales, políticos y violencia en los años 40 en Colombia. Bogotá, Colombia: Tercer Mundo Editores Uniandes.

Sáenz, E. (1990). De ciertos caballeros: La ANDI y los políticos en Colombia. Bogotá, Colombia: Tercer Mundo Editores.

Sáenz, E. (2002). Colombia años 50: industriales, política y diplomacia. Bogotá, Colombia: Universidad Nacional.

Sánchez, G. (1987). Colombia: Violencia y Democracia. Informe presentado al Ministerio de Gobierno, Bogotá, Colombia: Universidad Nacional de Colombia. 
Sánchez, G. (1976). Los Bolcheviques del Líbano (Tolima). Bogotá, Colombia: Editorial el Mohan.

Santa, E. (1993). La colonización antioqueña, una empresa de caminos. Bogotá, Colombia: Tercer Mundo Editores.

Serje, M. (2005). El revés de la nación, territorios salvajes, fronteras y tierras de nadie. Bogotá, Colombia: Uniandes/CESO.

Silva, R. (2007). A la sombra de Clio. Medellín, Colombia: La Carreta Editores.

Smith, A. (1997). Investigación sobre la naturaleza y causas de la riqueza de las naciones, México: Fondo de Cultura Económica.

Suescún, A. (2008). Derecho y Sociedad en la Historia de Colombia, Tomo III, el Derecho Republicano, Siglo XIX. Bogotá, Colombia: UPN.

Tarrow, S. (1994). Power in movement. Social movements, collective action and politics. Cambridge, Cambidge University Press.

Tilly, C. (1978). From mobilization to revolution. Addison-Wesley Publishing Co., Reading, Mass.

Tilly, C. (1990). Coerción, capital y Estados europeos: 990-1900. Madrid, España: Alianza Editorial.

Torres, A. (2007). Identidad Política de la acción Colectiva: Organizaciones populares y luchas urbanas en Bogotá 1980 - 2000. Bogotá, Colombia: UPN.

Touraine, A. (1997). ¿Podremos vivir juntos? México: Fondo de Cultura Económica. Tovar, H. (1995). Que nos tengan en cuenta. Bogotá, Colombia: Tercer Mundo Editores.

Tovar, H. (1975). EI Movimiento Campesino en Colombia durante los Siglos XIX y XX. Bogotá, Colombia: Editorial Libre.

Tovar, H. (1980) Grandes empresas agrícolas y ganaderas: su desarrollo en el siglo XVIII. Bogotá, Colombia: Editorial CIEC/Universidad Nacional de Colombia.

Valencia, A. (1988). Estado Soberano del Cauca, Federalismo y Regeneración. Bogotá, Colombia: Banco de la República.

Valencia, A. (1990). Manizales en la dinámica colonizadora (1846 - 1930). Manizales, Colombia: Universidad de Caldas.

Valencia, A. (1993). Empresarios y políticos en el Estado Soberano del Cauca. Cali, Colombia: Universidad del Valle. 
Valencia, A. (2000). Colonización, fundaciones y conflictos agrarios. Manizales, Colombia: Artes Gráficas Tizán.

Velásquez, L. (s.f.). Bienes. Bogotá, Colombia: Temis.

Vélez, J. (2002). Los pueblos allende el Río Cauca, la formación del suroeste y la cohesión del espacio en Antioquia, 1830-1875. Medellín, Colombia: Universidad de Antioquia.

Villegas, J., Yunis, J. (1979). La Guerra de los Mil Días. Bogotá, Colombia: Carlos Valencia Editores.

Weber, M. (1974). Economía y sociedad, vol. II. México: Fondo de Cultura Económica.

Weber, M. (1979). El político y el científico. Madrid: Alianza Editorial.

Zagrevelsky, G. (2011). El derecho dúctil; Ley, derechos, justicia. Madrid, España: Editorial Trotta.

\section{Artículos de revistas:}

Bejarano, J. (1997). Guía de Perplejos: una mirada a la historiografía colombiana. Anuario Colombiano de Historia Social y de la Cultura, (24), 283-329.

Bolívar, I. (2004). Comprender la nación: identidad, interdependencia y violencia política. Estudios Políticos, (25), 73-86.

Bolívar, I. (2010). Formación del Estado y biografía de las categorías. Revista Nómadas, (33), 93-107.

Cadena, O. (1997). Impacto de la compañía Burila en el Quindío. Voces, Revista de estudios sociales, (3), 57-70.

Carrero, A. (2010). Ocupación de fronteras: los proyectos poblacionales entre el Cauca y Antioquia después de la era federal. Revista Historia y Espacio, (35), 11-34.

Christie, K. (1978). Antioqueño Colonization in Western Colombia: A Reappraisal. The Hispanic American Historical Review, 58 (2) pp. 260-283.

Christie, K. (1984). Labor Acquisition and Social Conflict on the Colombian Frontier, 1850-1936. Journal of Latin American Studies, 16 (1), pp. 2749. 
Estrada, M. (2003). ¿Acción o práctica política? Notas en torno a un programa de investigación sobre la distinción conceptual entre lo social y lo político. Estudios Sociológicos, XXI (1), 191-200.

González, F. (2006). Guerras civiles y construcción del Estado en el siglo XIX colombiano: una propuesta de interpretación sobre su sentido político. Boletín de Historia y antigüedades, 93 (832), 31-80.

González, F. (2010). Espacio, conflicto y poder las dimensiones territoriales: de la violencia y la construcción del Estado en Colombia. Sociedad y Economía, (17), 159-183.

Hincapié, S. (2015). Acciones colectivas de innovación democrática local en contextos de violencia. Revista Mexicana de Sociología, 77 (1), 129-156.

Lenis, C. (2009). Las otras colonizaciones en Antioquia. El caso del nordeste antioqueño: 1824-1886. Revista Historia y Sociedad, (16), 16-48.

Londoño, J. (2002). El modelo de colonización antioqueña de James Parsons. Un balance historiográfico. Fronteras de la historia, revista de historia colonial latinoamericana, 7, 187-228.

Martins, J. (1996). O tempo da fronteira. Retorno à controvérsia sobre o tempo histórico da frente de expansão e da frente pioneira. Tempo Social. Rev. Sociol, 8 (1), 25-70.

Medina, M. (1998). Los terceros partidos en Colombia 1900-1960. En A. Tirado. (Ed.). Nueva Historia de Colombia, vol II, cap.2 (263-294). Bogotá, Colombia: Planeta Editorial.

Oro, L. (2008). La idea de la política en Hannah Arendt. Revista Enfoques, VI (9), pp. 235-246

Prado, L. (2013). Redes, movilización y bases de autoridad en el valle del Patía, 1820 - 1851. Revista Historia Caribe, VIII, (22), 75-103.

Prado, L. (2014). El jefe natural, poder y autoridad en el valle del Patía, 1810-1850. Revista Historia y Sociedad, 23, pp. 243-265.

Wills, M. (2002). Inclusión partidista y exclusión cultural en Colombia: pistas para comprender su relación. Revista Análisis Político, 46, pp. 44-57. 


\section{Capítulo de libro}

Archila. M. (2005). El fortalecimiento del Estado y la sociedad civil. Idas y venidas, vueltas y revueltas, protestas sociales en Colombia. Bogotá, Colombia: Cinep-ICANH.

Bejarano, J. (1985). Campesinado, luchas agrarias e Historia Social: Notas para un Balance Historiográfico. En P. Casanova (Ed.), Historia Política de los Campesinos Latinoamericanos, (9-72). México, Siglo XXI Editores.

Bergquist, C. (2007). Los trabajadores del sector cafetero y la suerte del movimiento obrero en Colombia 1920 - 1940. En G. Sánchez “y” R. Peñaranda (Comp.), Pasado y presente de la violencia en Colombia (139-174). Medellín, Colombia La Carreta Editores.

Cadena, O (2008). Importancia de la colonización empresarial en el Quindío. En A. Betancourt Mendieta. (Ed.), Policromías de una región, procesos históricos y construcción del pasado local en el eje cafetero (135-156), Pereira, Colombia: Red de Universidades públicas del Eje Cafetero/Alma Mater.

Caetano, G. (2003). Ciudadanía política e integración social en el Uruguay (19001933). En H. Sábato. (Coord.), Ciudadanía política y formación de las naciones, perspectivas históricas de América Latina. México, Fondo de Cultura Económica.

Cortés, R. (1979). El crecimiento de la economía Argentina1870-1914. En L. Bethell. (Ed.), Historia de América Latina, vol. 10, América del Sur, c. 1870-1930 (13-40), Barcelona, España: Crítica Editorial.

Flórez, C.; Romero, O. (2010). La demografía de Colombia en el siglo XIX. En A. Meisel "y” M. T. Ramírez. (Ed.). Economía colombiana del siglo XIX (375-418). Bogotá, Colombia: Banco de la República/Fondo de Cultura Económica.

Gilhodes, P. (1989). La cuestión agraria en Colombia. 1900-1946. En A. Tirado. (Ed.). Nueva Historia de Colombia. III Relaciones Internacionales- Movimientos Sociales. Bogotá, Colombia: Planeta Editorial.

González, F. (1994). Poblamiento y conflicto social en la Historia colombiana. En R. Silva (Ed.), Territorios, Regiones y Sociedades (pp. 13-33), Bogotá, Colombia: Cerec. 
Habermas, J. (1998). Sobre el papel de la sociedad civil y de la opinión pública política. Facticidad y Validez (407-468), Valladolid, España: Editorial Trotta. Jaramillo, C. (2007). La Guerra de los Mil Días: aspectos estructurales de la organización guerrillera. En G. Sánchez "y" R. Peñaranda (Comp.), Pasado y presente de la violencia en Colombia (87-118). Medellín, Colombia La Carreta Editores.

Leal, F. (2010). La crisis del régimen bipartidista. En L. Orjuela (Comp.) el Estado en Colombia (67-102). Bogotá, Colombia: Uniandes.

LeGrand, C. (1989). El conflicto de las bananeras. En A. Tirado. (Ed.). Nueva Historia de Colombia, vol III, cap. 8 (183-217). Bogotá, Colombia: Planeta Editorial.

LeGrand, C. (2007). Los antecedentes agrarios de la violencia: el conflicto social en la frontera colombiana, 1850-1936. En G. Sánchez “y” R. Peñaranda. (Comp.). Pasado y presente de la violencia en Colombia (119-138). Medellín, Colombia: La Carreta Editores.

Londoño, J. (1996). La colonización de vertiente en el valle del Cauca. En A. Valencia (Ed.) Historia del Gran Cauca, historia del suroccidente colombiano. Cali, Colombia: Instituto de Estudios del Pacífico-Universidad del Valle.

Londoño, J. (2003). Lisandro Caicedo: Un empresario territorial caucano. En C. Dávila (Comp.). Empresas y empresarios en la historia de Colombia. Siglos XIX - XX (407-441). Bogotá, Colombia: Norma-Cepal.

Londoño, J. (2008). Frontera y colonización en el norte del suroccidente colombiano. Hacia una "nueva agenda" de investigaciones. En A. Betancourt. (Ed.). Policromías de una región, procesos históricos y construcción del pasado local en el Eje Cafetero (181-206). Pereira, Colombia: Red de Universidades Públicas del Eje Cafetero-Alma Mater.

Marx, C. (s.f.). El Estado y el Derecho. En T. Bottmore (Ed.), sociología y filosofía social, selección de textos por Tom Bottomore (pp. 237-263), España: Ediciones Península.

Medina, M. (1994). La historiografía política del siglo XX en Colombia. En B. Tovar (Ed.), La Historia al final del milenio: ensayos de historiografía colombiana y latinoamericana (433-532), Bogotá, Colombia: Universidad Nacional. 
Melo, J. (1987). Las vicisitudes del modelo liberal (1850-1899). En J. A. Ocampo. (Ed.). Historia económica de Colombia (119-172). Bogotá, Colombia: Siglo XXI Editores.

Múnera L. (2009). Génesis del Estado en Colombia: 1810-1831. El proceso de unificación. En L. Múnera “y” R. Nathaly (Ed.), Fragmentos de lo públicopolítico; Colombia siglo XIX (pp. 11-81). Bogotá, Colombia: La Carreta Editores.

Múnera, L. (2011). El Estado en la Regeneración (¿la modernidad política paradójica o las paradojas de la modernidad política?). En L. Múnera “y” E. Cruz (Ed.), La Regeneración revisitada, pluriverso y hegemonía en la construcción del Estado-Nación en Colombia (13-76), Bogotá, Colombia: La Carreta Editores.

Murgueitio, C. (2009). Estrategias comerciales de los principales productores de café. Brasil y Colombia, antes y después de la crisis económica mundial de 1929. Ensayos sobre economía cafetera (51-67). Colombia: Federación Nacional de Cafeteros de Colombia.

Oquist, P. (2010). El derrumbe parcial del Estado. En L. Orjuela (Comp.), el Estado en Colombia (103-216). Bogotá, Colombia: Uniandes.

Ortiz C. (2007). “La Violencia” y los negocios, Quindío años 50 y 60. En G. Sánchez "y" R. Peñaranda (Comp.), Pasado y presente de la violencia en Colombia (239-268). Medellín, Colombia La Carreta Editores.

Restrepo, L. (2006). Los arduos dilemas de la democracia en Colombia. F. Gutiérrez "y" G. Sánchez. (Ed.), Nuestra guerra sin nombre (313-346). Bogotá, Colombia: Editorial Norma.

Rock, D. (1979). Las Pampas, el interior. Buenos Aires Argentina en 1914. En L. Bethell. (Ed.). Historia de América Latina, vol. 10, América del Sur, c. 18701930 (67-88). Barcelona, España: Crítica Editorial.

Rodríguez, N. (2009). De fronteras, Bárbaros y civilizados. Construyendo nación en Colombia. Unión nacional, ciudadanía y diferenciación 1810-1850. En L. Múnera “y” R. Nathaly (Ed.), Fragmentos de lo público-político; Colombia siglo XIX (pp. 82-130). Bogotá, Colombia: La Carreta Editores. 
Rodríguez, N. (2011). Un siglo construyendo la Regeneración. Identidades mínimas, subjetivas e íntimas para la construcción de lo comunitario, nacional y público en Colombia. En L. Múnera “y” E. Cruz (Ed.), La Regeneración revisitada, pluriverso y hegemonía en la construcción del Estado-Nación en Colombia (155-192), Bogotá, Colombia: La Carreta Editores.

Sánchez, Fabio; Fazio, A. “y” López-Uribe, M. P. (2010). Conflictos de Tierra, Derechos de Propiedad y Surgimiento de la Economía Exportadora en Colombia, 1850-1925. En A. Meisel. (Ed.). Economía colombiana del siglo XIX (245-282). Bogotá, Colombia: Banco de la República-Fondo de Cultura Económica.

Wolf, E. (1975). Fases de la Protesta Rural en América Latina. En E: Feder (Ed.), La lucha de clases en el campo. Análisis estructural de la economía latinoamericana (260-271). México, Universidad Nacional Autónoma de México/Fondo de Cultura Económica.

\section{Simposios y conferencias.}

Carrero, W.; Naranjo, D. (Mayo de 2014). Acciones colectivas y sociedad rural; la experiencia educativa en la Vereda La Hondura del Municipio de El Dovio Valle del Cauca. En IV Seminario de Trabajo Social Comunitario "Acciones desde lo Rural", Bogotá, Colombia.

Elías, N. (septiembre de 1970). Los procesos de formación de Estado y de construcción de la nación. Séptimo Congreso Mundial de Sociología, Varma, Bulgaria.

López, C.; Cano, M. \& Mora, L. (Agosto de 2007). Procesos de poblamiento y colonización del actual territorio de Pereira: aportes desde la arqueología regional. En II simposio de Historia Local y Regional, Academias y Universidades, Pereira, Colombia.

Quiceno, A. (Agosto de 2007). El territorio y la territorialidad en la construcción de un espacio social regional. En II simposio de Historia Local y Regional, Academias y Universidades, Pereira, Colombia.

Tobasuña, I. (Agosto de 2007). Del altiplano cundiboyacense al páramo de letras (caldas). Algunos aspectos socioculturales del proceso. En II simposio de Historia Local y Regional, Academias y Universidades, Pereira, Colombia. 


\section{Bibliografía}



Crozier, M. (1974). El fenómeno Burocrático II. Buenos Aires, Argentina: Amorrortu.

De la Peña, G. (2001). Los desafíos de la clase incómoda. En M. León. (Coord.), Motivos de la antropología americanista; indagaciones en la diferencia (134-198). México: Fondo de Cultura Económica.

Joseph, G., Nugent, D. (Comp.) (1994). Aspectos cotidianos de la formación del Estado. México: Ediciones Era.

Martínez, S. (2013). Política y espacio, historia de la conformación territorial de Pereira, 1857-1884. Pereira, Colombia: Gobernación de Risaralda.

Melo J. O. (1977). ¿Cuánta tierra necesita un indio? Recuperado en: http://www. jorgeorlandomelo.com/cuantatierra.htm.

Morales, O; Eastman, C. (2014) Identidades, construcción del mestizo espiritual, tomo IV, Colección Cátedra Otto Morales Benítez, Pereira, Fundación Universitaria del Área Andina.

Palti, E. (2007). El tiempo de la política reconsiderado, Argentina, Siglo XXI Editores.

Perla, Zusman, (1999). Representaciones, imaginarios y conceptos en torno a la producción material de las fronteras. Reflexiones a partir del debate Hevilla-Escamilla. Revista Bibliográfica de Geografía y Ciencias Sociales, 
(149). Recuperado en: http://www.ub.es/geocrit/b3w-149.htm

Reveiz, E. (Comp.). (1980). La Cuestión Cafetera: su impacto económico, social, político. Bogotá, Colombia: Editorial Tercer Mundo

Sánchez G., Meertens D. (1993). Bandoleros, Gamonales y Campesinos, el caso de la Violencia en Colombia. Bogotá, Colombia: El Áncora Editores.

Sánchez, G. (1976). Los Bolcheviques del Líbano (Tolima). Bogotá, Colombia: Ed. Mohan.

Sánchez, G. (1977). Las Ligas Campesinas en Colombia. Bogotá, Colombia: Editorial Tiempo Presente.

Sennett, R. (1982). Temor a la autoridad. En Sennett, R. La autoridad (23-53). Madrid, España: Alianza Editorial.

Tovar, H. (1975). EI Movimiento Campesino en Colombia durante los Siglos XIX y XX. Bogotá, Colombia: Editorial Libre.

Tovar, H. (1980). Grandes Empresas Agrícolas y Ganaderas: su desarrollo en el siglo XVIII. Bogotá, Colombia: Universidad Nacional. 

Este libro terminó de imprimirse en Junio del 2018, en los talleres gráficos de Publiprint S.A.S., bajo el cuidado del autor.

Pereira, Risaralda, Colombia. 
La Editorial de la Universidad Tecnológica de Pereira tiene como política la divulgación del saber científico, técnico y humanístico para fomentar la cultura escrita a través de libros y revistas científicas especializadas.

Las colecciones de este proyecto son: Trabajos de investigación, Ensayos, Textos Académicos, Tesis Laureadas y Maestría en Historia.

Este libro pertenece a la Colección Maestría en Historia. 
Entre 1980 y 1930, los procesos de colonización en Colombia se fomentaron a través de las empresas privadas -colonización empresarial-, apertura de baldíos -colonización espontánea- y acciones dirigidas por el Estado -colonización dirigida-; sin embargo, por la ambigüedad normativa para regular la propiedad, tenencia y ocupación de la tierra, los conflictos entre colonos, empresarios y agentes del Estado se recrudecieron durante estos años.

En muchos casos, los empresarios que fomentaron la colonización aprovecharon esta situación para ampliar los linderos de sus territorios. En otros casos, con el apoyo de agentes del Estado impusieron sus intereses; o en su defecto, fueron representantes de la institucionalidad trabajando para los intereses personales y no precisamente para los fines del colectivo. Igualmente, colonizadores sin tierra, pero con un capital cultural y social previo -que se fue cualificando en los mismos procesos de lucha-, ocuparon baldíos y alegaron su derecho a ser propietarios por medio de memoriales, demandas, denuncias y demás estrategias políticas legales; aunque también recurrieron en algunos casos a la violencia como un recurso político ilegal, pero legítimo socialmente.

En este contexto se desarrolló la dinámica colonizadora del actual Eje Cafetero, de allí que el presente libro exponga la experiencia de cientos de campesinos colonizadores, agentes de Estado y empresarios que, en medio de las disputas por la propiedad de la tierra, recurrieron a distintas estrategias y prácticas políticas para alcanzar sus intereses. La revisión de la normativa agraria, las estrategias de acción política, y los usos que se les dio permiten proponer hipótesis sobre el proceso formativo del Estado, en el que la capacidad de agencia de los actores sociales de la colonización se convirtió en referente para la construcción de nuevas leyes, la justificación para cambiar la definición de la propiedad con la Ley 200 de 1936 y darle una función social, y la institucionalización de lo agrario en Colombia.

Para desarrollar la obra, el libro hace un acercamiento teórico a distintas perspectivas que podrían servir como herramienta explicativa de los conflictos agrarios y la formación del Estado, posteriormente se dedica a confrontar las ambigüedades normativas de la colonización, con las acciones políticas adelantadas por los actores objeto de la investigación; luego expone casos de estudio que sirven para corroborar el modelo analítico y finalmente cierra con unas conclusiones en las que se invita a seguir discutiendo el proceso formativo del Estado colombiano, utilizando el modelo de análisis desarrollado en la investigación pero proponiendo otras unidades y población de estudio.

elSBN: 978-958-722-541-9

ISBN: $978-958-722-310-1$

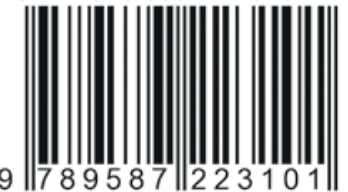

